\title{
7. SITES 419-423 AND 426-429: OCEAN CRUST DRILLING ON THE EAST PACIFIC RISE AND IN THE SIQUEIROS FRACTURE ZONE
}

\author{
The Shipboard Scientific Party ${ }^{1}$
}

\section{SITE 419 (HOLE 419)}

Data occupied: 8 May 1977

Date departed: 9 May 1977

Time on hole: 23 hours

Position (latitude; longitude): $08^{\circ} 55.96^{\prime} \mathrm{N} ; 105^{\circ} 41.17^{\prime} \mathrm{W}$

Water depth (sea level; corrected m, echo-sounding): 3274

Water depth (rig floor; corrected m, echo-sounding): 3290

Bottom felt (m, drill pipe): 3294

Penetration (m): 35.0

Number of holes: 1

Number of cores: 5

Total length of cored section (m): 35.0

Total core recovered $(\mathrm{m}): 21.6$

Core recovery (\%): 62

Oldest sediment cored:

Depth sub-bottom (m): 35.0

Nature: foraminifer-nannofossil ooze

Age: upper Pliocene
Measured velocity $(\mathrm{km} / \mathrm{s}): 1.462-1.510$

\section{SITE 419 (HOLE 419A)}

Date occupied: 9 May 1977

Date occupied: 9 May 1977

Time on hole: 8.9 hours

Position (latitude; longitude): $08^{\circ} 55.47^{\prime} \mathrm{N} ; 105^{\circ} 41.22^{\prime} \mathrm{W}$

Water depth (sea level; corrected m, echo-sounding): 3274

Water depth (rig floor; corrected m, echo-sounding): 3267

Bottom felt (m, drill pipe): 3277

Penetration (m): 46.0

Number of holes: 1

Number of cores: 1

Total length of cored section (m): 8.0

Total core recovered $(\mathrm{m}): 4.74$

Core recovery $(\%): 59$

Oldest sediment cored:

Depth sub-bottom (m): 8.0

Nature: foraminifer-nannofossil ooze

Age: Pleistocene

Measured velocity $(\mathrm{km} / \mathrm{s}): 1.5$

\section{SITE 420 (HOLE 420)}

Bruce R. Rosendahl (Co-Chief Scientist), Department of Geology, Duke University, Durham, North Carolina; Roger Hekinian (Co-Chief Scientist), Centre Océanologique de Bretagne, Brest, France; John Barron, U.S. Geological Survey, Menlo Park, California; J. David Bukry, U.S. Geological Service, Scripps Institution of Oceanography, La Jolla, California; Yuri Dmitriev, Institute of Geology of Ore Deposits, Petrography, Mineralogy, and Geochemistry, Moscow, USSR; Ronald V. Fodor, Department of Geology and Institute of Meteoritics, University of New Mexico, Albuquerque, New Mexico (now at: Department of Geosciences, North Carolina State University, Raleigh, North Carolina); Robert M. Goll, Duke University Marine Laboratory, Beaufort, North Carolina; Michel Hoffert, Institute de Géologie, Strasbourg, France; Susan E. Humphris, Imperial College, London, United Kingdon (now at: Sea Education Association, Woods Hole, Massachusetts); George Lynts, Department of Geology, Duke University, Durham, North Carolina; David P. Mattey, Department of Geology, Bedford College, London, United Kingdom; James H. Natland, Scripps Institution of Oceanography, Deep Sea Drilling Project, La Jolla, California; Nikolai Petersen, Institut für Allgemeine und Angewandte Geophysik, Ludwig-Maximilians-Universităt, Munich, Federal Republic of Germany; William Roggenthen, Princeton University, Princeton, New Jersey (now at: South Dakota School of Mines and Technology, Department of Geology, Rapid City, South Dakota); Edward L. Schrader, Department of Geology, Duke University, Durham, North Carolina (now at: Department of Geology and Geography, University of Alabama, University, Alabama); Ramesh K. Srivastava, Institut für Petrographic und Geochemic der Universităt Karlsruhe, Karlsruhe, Federal Republic of Germany (now at: Department of Geology, Rajasthan University, Udaipur, India); and Nick Warren, Department of Geology, University of California, Los Angeles, California.
Date occupied: 10 May 1977

Date departed: 11 May 1977

Time on hole: 42.5 hours

Position (latitude; longitude): $09^{\circ} 00.10^{\prime} \mathrm{N} ; 106^{\circ} 06.77^{\prime} \mathrm{W}$

Water depth (sea level; corrected $\mathrm{m}$, echo-sounding): 3381

Water depth (rig floor; corrected m, echo-sounding): 3397

Bottom felt (m, drill pipe): 3404

Penetration (m): 147.0

Number of holes: 1

Number of cores: 17

Total length of cored section (m): 147.0

Total core recovered $(\mathrm{m}): 95.07$

Core recovery $(\%): 65$

Oldest sediment cored:

Depth sub-bottom (m): 118.5

Nature: foraminifer-nannofossil ooze

Age: Pliocene

Measured velocity $(\mathrm{km} / \mathrm{s}): 1.5$

Basement:

Depth sub-bottom (m): 118.5

Nature: basalt

Velocity range $(\mathrm{km} / \mathrm{s}): 5.2$ 


\section{SITE 420 (HOLE 420A)}

Date occupied: 11 May 1977

Date departed: 12 May 1977

Time on hole: 12.7 hours

Position (latitude; longitude): $09^{\circ} 00.50^{\prime} \mathrm{N} ; 106^{\circ} 06.32^{\prime} \mathrm{W}$

Water depth (sea level; corrected $\mathbf{m}$, echo-sounding): 3382

Water depth (rig floor; corrected m, echo-sounding): 3398

Bottom felt (m, drill pipe): 3412

Penetration (m): 63.0

Number of holes: 1

Number of cores: 1

Total length of cored section (m): 6.0

Total core recovered $(\mathrm{m}): 6.05$

Core recovery $(\%): 100$

Oldest sediment cored:

Depth sub-bottom $(\mathrm{m}): 6.0$

Nature: foraminifer-nannofossil ooze

Age: Pleistocene

Measured velocity $(\mathrm{km} / \mathrm{s}): 1.5$

SITE 421 (HOLE 421)

Date occupied: 12 May 1977

Date departed: 13 May 1977

Time on hole: 32.1 hours

Position (latitude; longitude): $09^{\circ} 01.41^{\prime} \mathrm{N}$; $106^{\circ} 03.68^{\prime} \mathrm{W}$

Water depth (sea level; corrected m, echo-sounding): 3339

Water depth (rig floor; corrected $\mathbf{m}$, echo-sounding): 3355

Bottom felt (m, drill pipe): 3342

Penetration (m): 114.0

Number of holes: 1

Number of cores: 4

Total length of cored section (m): 38.0

Total core recovered $(\mathrm{m}): 11.22$

Core recovery $(\%): 30$

Oldest sediment cored:

Depth sub-bottom (m): 86.5

Nature: foraminifer-nannofossil ooze

Age: Pleistocene

Measured velocity $(\mathrm{km} / \mathrm{s}): 1.5$

Basement

Depth sub-bottom (m): 86.5

Nature: basalt

Velocity range $(\mathrm{km} / \mathrm{s}): 5.18-5.97$

\section{SITE 422 (HOLE 422)}

Date occupied: 14 May 1977

Date departed: 15 May 1977

Time on hole: 23.9 hours

Position (latitude; longitude): $9^{\circ} 10.59^{\prime} \mathrm{N} ; 105^{\circ} 16.27^{\prime} \mathrm{W}$

Water depth (sea level; corrected m, echo-sounding): 3247

Water depth (rig floor; corrected $\mathrm{m}$, echo-sounding): 3250

Bottom felt (m, drill pipe): 3254
Penetration (m): 73.0

Number of holes: 1

Number of cores: 10

Total length of cored section $(\mathrm{m}): 73.0$

Total core recovered $(\mathrm{m}): 46.97$

Core recovery $(\%): 64$

Oldest sediment cored:

Depth sub-bottom $(\mathrm{m}): 52.0$

Nature: foraminifer-nannofossil ooze

Age: Pleistocene

Measured velocity $(\mathrm{km} / \mathrm{s}): 1.5$

Basement:

Depth sub-bottom (m): 52.0

Nature: basaltic rock

Velocity range $(\mathrm{km} / \mathrm{s}): 5.8-6.2$

SITE 423 (HOLE 423)

Date occupied: 15 May 1977

Date departed: 16 May 1977

Time on hole: 17 hours

Position (latitude; longitude): $9^{\circ} 08.81^{\prime} \mathrm{N} ; 105^{\circ} 06.57^{\prime} \mathrm{W}$

Water depth (sea level; corrected m, echo-sounding): 3161

Water depth (rig floor; corrected m, echo-sounding): 3167

Bottom felt (m, drill pipe): 3177.5

Penetration (m): 53.5

Number of holes: 1

Number of cores: 8

Total length of cored section (m): 53.5

Total core recovered $(\mathrm{m}): 27.98$

Core recovery $(\%): 52$

Oldest sediment cored:

Depth sub-bottom (m): 42.0

Nature: nannofossil ooze

Age: Pleistocene

Measured velocity $(\mathrm{km} / \mathrm{s}): 1.5$

Basement:

Depth sub-bottom (m): 11.5

Nature: basalt

Velocity range $(\mathrm{km} / \mathrm{s}): 5.7$

SITE 426 (HOLE 426)

Date occupied: 3 June 1977

Date departed: 3 June 1977

Time on hole: 16 hours

Position (latitude; longitude): $08^{\circ} 47.28^{\prime} \mathrm{N} ; 104^{\circ} 15.27^{\prime} \mathrm{W}$

Water depth (sea level; corrected m, echo-sounding): 2617, 2621,2632

Bottom felt (m, drill pipe): 2624, 2628, 2666

Penetration (m): 0

Number of holes: 0

Number of cores: 0

Total length of cored section (m): 0

Total core recovered $(\mathrm{m}): 0$

Core recovery $(\%): 0$ 


\section{SITE 427 (HOLE 427)}

Date occupied: 4 June 1977

Date departed: 5 June 1977

Time on hole: 33.4 hours

Position (latitude; longitude): $08^{\circ} 06.79^{\prime} \mathrm{N} ; 104^{\circ} 36.35^{\prime} \mathrm{W}$

Water depth (sea level; corrected m, echo-sounding): 3834

Water depth (rig floor; corrected m, echo-sounding): 3850

Bottom felt (m, drill pipe): 3848

Penetration (m): 174.5

Number of holes: 1

Number of cores: 11

Total length of cored section (m): 98.5

Total core recovered $(\mathrm{m}): 57.26$

Core recovery $(\%): 58$

Oldest sediment cored:

Depth sub-bottom (m): 146.0

Nature: foraminifer-nannofossil ooze

Age: Pleistocene

Measured velocity $(\mathrm{km} / \mathrm{s}): 1.5-2.0$

Basement:

Depth sub-bottom (m): 146.0

Nature: basaltic rock

Velocity range $(\mathrm{km} / \mathrm{s}): 5.7$

\section{SITE 428 (HOLE 428)}

Date occupied: 6 June 1977

Date departed: 7 June 1977

Time on hole: 33 hours

Position (latitude; longitude): $09^{\circ} 02.77^{\prime} \mathrm{N} ; 105^{\circ} 26.14^{\prime} \mathrm{W}$

Water depth (sea level; corrected m, echo-sounding): 3295

Water depth (rig floor; corrected m, echo-sounding): 3299

Bottom felt (m, drill pipe): 3301

Penetration (m): 76.5

Number of holes: 1

Number of cores: 6

Total length of cored section (m): 54.5

Total core recovered $(\mathrm{m}): 36.34$

Core recovery $(\%): 67$

Oldest sediment cored:

Depth sub-bottom (m): 61.0

Nature: foraminifer-nannofossil ooze

Age: $1.2-1.8 \mathrm{~m} . \mathrm{y}$.

Basement:

Depth sub-bottom $(\mathrm{m}): 61.0$

Nature: basaltic rock

\section{SITE 428 (HOLE 428A)}

Date occupied: 7 June 1977

Date departed: 8 June 1977

Time on hole: 34.1 hours

Position (latitude; longitude): $09^{\circ} 02.77^{\prime} \mathrm{N} ; 105^{\circ} 26.14^{\prime} \mathrm{W}$

Bottom felt (m, drill pipe): 3358.5
Penetration (m): 115.0

Number of holes: 1

Number of cores: 7

Total length of cored section (m): 52.5

Total core recovered $(\mathrm{m}): 16.37$

Core recovery $(\%): 31$

Basement:

Depth sub-bottom (m): 62.5

Nature: basaltic rock

\section{SITE 429 (HOLE 429)}

Date occupied: 9 June 1977

Date departed: 9 June 1977

Time on hole: 2.3 hours

Position (latitude; longitude): $09^{\circ} 02.01^{\prime} \mathrm{N}$; $106^{\circ} 46.35^{\prime} \mathrm{W}$

Water depth (sea level; corrected m, echo-sounding): 3406

Water depth (rig floor; corrected m, echo-sounding): 3422

Bottom felt (m, drill pipe): 3426

Penetration (m): 31.0

Number of holes: 1

Number of cores: 1

Total length of cored section (m): 5.0

Total core recovered $(m): 4.67$

Core recovery $(\%)$ : 93

Oldest sediment cored:

Depth sub-bottom (m): 31.0

Nature: nannofossil-foraminifer ooze

Age: 0.4-1.2 m.y. (mud-line core)

\section{SITE 429 (HOLE 429A)}

Date occupied: 9 June 1977

Date departed: 10 June 1977

Time on hole: 13.25 hours

Position (latitude; longitude): $09^{\circ} 02.01^{\prime} \mathrm{N}$; $106^{\circ} 45.87^{\prime} \mathrm{W}$

Water depth (sea level; corrected m, echo-sounding): 3426

Bottom felt (m, drill pipe): 3426 PDR

Penetration (m): 52.5

Number of holes: 1

Number of cores: 3

Total length of cored section $(\mathrm{m}): 21.5$

Total core recovered $(\mathrm{m}): 2.95$

Core recovery $(\%): 14$

Oldest sediment cored:

Depth sub-bottom $(\mathrm{m}): 31.0$

Nature: foraminifer-nannofossil ooze

Basement:

Depth sub-bottom $(\mathrm{m}): 31.0$

Nature: basaltic rock

Principal results of drilling at Sites $\mathbf{4 1 9}$ through $\mathbf{4 2 3}$ and $\mathbf{4 2 6}$ through 429: The principal objective of Leg 54, to drill a deep-penetration, multiple re-entry site into representative fast-spreading crust on the flank of the East Pacific Rise near the Siqueiros fracture zone, was not achieved. Instead, 
13 short-penetration, single-bit holes at nine sites were attempted or drilled. All primary and secondary re-entry targets were attempted, plus several additional targets, including one each on the rise crest itself and in the Siqueiros fracture zone. In all cases, basement drilling was thwarted by insufficient sediment cover or extremely hard and fresh, but highly fractured basalt which typically bound up the bit after only a few tens of meters' penetration.

Altogether, 433 meters of sediment and 210 meters of basalt were cored. Recovery in the sediments was over 80 per cent, and five holes were cored continuously. Recovery in basalt ranged from good $(>75 \%)$ in massive flows to poor $(<10 \%)$ in pillows or apparent thin-sheet flows. The longest, single continuously cored sediment section, 115 meters, was in Hole 420, in a small sediment pond on crust about 3.4 million years old. The deepest penetration into basalt was 52.5 meters into massive flows in Hole 428A.

Sediments at all the sites consist of Pliocene to Quaternary foraminifer-nannofossil oozes, nannofossil oozes, siliceous nannofossil oozes, and brown calcareous clays. The latter are prevalent as interbeds at the top of most holes. Foraminifers show the effects of strong selective dissolution. The carbonate-free fraction is rich in potassic iron montmorillonite which appears in part to form from diagenetic transformation of slumped or winnowed-in basaltic volcanic glass, and probably more importantly, diagenetic reaction between hydrothermally produced amorphous iron hydroxides and siliceous microfossil tests. The sediment sections at all sites show several of the effects of local accumulation in sediment ponds, mainly redeposition from surrounding basement highs. At most locations, for example, the oldest recovered sediments are between 0.3 and 2.2 m.y. younger than basement ages estimated from magnetic anomalies. Sedimentation rates range from a low of 17 meters/m.y. at Site 419 to 130 meters/m.y. at Site 428 , where it was apparently accelerated by addition of slump deposits from a nearby ridge. Sediments were also slumped into the deepest part of the Siqueiros fracture zone in the survey area, where Site 427 was drilled. The sediments there also are more pyritiferous than elsewhere and smelled of hydrogen sulfide, possibly reflecting limited oxygen availability in this deep trough.

Together with the site survey and other dredge data, the distribution of basalts in the Siqueiros region can be considered in terms of three major tectonic associations: 1) The flanks and crest of the East Pacific Rise, where the predominant (but not exclusive) rock type is quartz-normative, tholeiitic ferrobasalt (cored at Sites 420,421 , and 423, and dredged near Site 426); 2) the Siqueiros fracture zone, where olivine-plagioclase and olivine-chrome spinel basalts have been dredged, but also where ferrobasalt lavas which probably erupted at the rise crest were ponded in deep troughs (Site 427); and 3) off-rise seamounts and ridges, where basalts have distinctly less depleted $\mathrm{K}_{2} \mathrm{O}, \mathrm{TiO}_{2}, \mathrm{P}_{2} \mathrm{O}_{5}$, light rare earth elements, and ${ }^{87} \mathrm{Sr} /{ }^{86} \mathrm{Sr}$ abundances and near one of which two different types of olivine-plagioclase tholeiitic basalt were drilled (Site 428).

A distinctive petrographic feature of virtually all the basalts we cored is that they are either aphyric or very sparsely phyric. A streaked, apparently hybrid ferrobasalt lava was cored at Site 423 .

The rise crest ferrobasalt association is remarkably uniform in composition wherever it was sampled, and implies both strikingly uniform parental compositions and fractionation processes in the rise crest axial magma chamber inferred from geophysical evidences. Less fractionated olivine-plagioclase basalts from a rise-flank loca- tion at Site 429, however, imply that ferrobasalt is not the steady-state product of such a magma chamber.

Structurally, apart from the massive ponded flows, basement at all sites is highly fractured, and typically has joint patterns and alteration rinds indicative of sheet flows. Alteration is minor, confined mainly to distinctive oxidative rinds on near-glassy pieces. This alteration has slightly enriched the rocks in $\mathrm{K}_{2} \mathrm{O}$ and $\mathrm{Fe}_{2} \mathrm{O}_{3}$ contents by formation of $\mathrm{K}-\mathrm{Fe}$ smectites. A possible 3-meter sill was cored at Site 422 , bounded above and below by sediments. All the basalts have systematically higher sonic velocities and densities than integrated upper crustal velocities inferred from seismic evidence, implying that the upper crust in the area is extensively fractured and full of voids. Ferrobasalts have particularly high sonic velocities given their densities, probably a consequence of their high iron and low magnesium contents.

The direction of stable natural remanent magnetization in basalts agrees with inclinations expected from magnetic anomalies for all holes drilled on the flanks of the rise, namely Holes 420 and 421 (Gilbert reversed), 423 (Matuyama reversed), and 429A (reversal just older than Nunivak), although the uppermost basalts from Hole 429A have positive inclinations, implying that they are younger. Ponded basalts that may have had an off-axis origin have negative inclinations at Sites 422 and $\mathbf{4 2 8}$, but inclinations at Site 428 also agree with the magnetic anomalies of adjacent crust, making the off-axis interpretation ambiguous there. The several cooling units recovered in Hole 428A suggest an average secular variation of about $15^{\circ}$. Ponded lavas at Site 427 in the Siqueiros fracture zone have inclinations agreeing with the inferred (Gilbert reversed) magnetization of the crustal block south of the fracture zone. Intensities of stable remanent magnetization in all the basalts vary primarily because of grain size between 0.2 and 8 $\mathrm{emu} / \mathrm{cm}^{3}$, values typical of pillows and flows from the MidAtlantic Ridge. There is ne particular correlation with the degree of iron enrichment in the basalts. Fine-grained to glassy basalts have higher median demagnetizing fields $(200-1100$ Oe) than coarser grained doleritic basalts (20-70 Oe).

\section{BACKGROUND AND OBJECTIVES}

The original strategy for drilling the East Pacific Rise on Leg 54, and the circumstances of the drilling eventually done, can only be understood in the context of the overall plans for crustal drilling devised by the JOIDES Ocean Crust Panel and Planning Committee, and of events which conspired to change that strategy radically.

The core of the crustal drilling program consisted of three transects - two in the North Atlantic and one in the Pacific. The North Atlantic transects were designed to investigate slow-spreading oceanic crust produced at a spreading center with a pronounced axial rift. The $\mathrm{Pa}$ cific transect was to investigate fast-spreading crust produced at the non-rifted East Pacific Rise. One of the North Atlantic transects was a series of holes on Miocene or younger crust in a roughly north-south array, to evaluate crustal chemical heterogeneities perhaps related to postlated Iceland and Azores mantle plumes. In somewhat modified form, this transect was accomplished during Leg 49 (Luyendyk, Cann et al., 1979). The other North Atlantic transect was a series of more or less east-west holes along a supposed "mantle flow 
line" between $22^{\circ} \mathrm{N}$ and $26^{\circ} \mathrm{N}$, where the problems of secular variation in magmatic processes and crustal aging could be addressed. Not all the sites along this transect have been drilled, but a major part of the program was accomplished by the drilling of two deep holes at Sites 417 and 418 into Cretaceous crust during Legs 51 through 53 (Donnelly, Francheteau, Bryan, Robinson, Flower, Salisbury, et al., 1980). These holes into old oceanic crust, plus the holes drilled on the north-south transect during Legs 37 (Aumento, Melson, et al., 1977) and 49 were all designed to be compared with the two deep-penetration attempts, Holes 395A and 396B, drilled respectively during Legs 45 (Melson, Rabinowitz, et al., 1978) and 46 (Dmitriev, Heirtzler, et al., 1978 ) into Miocene-age crust at the intersection of the two transects near $23^{\circ} \mathrm{N}$. These two holes were conceived of as being central to the fundamental problems of both transects. On the one hand, they were drilled into crust of manifestly normal (i.e., depleted) geochemical characteristics, yet nevertheless along a typical segment of the Mid-Atlantic Ridge. On the other hand, their basalts also represented in effect a little-altered base line with which to compare older basalts drilled progressively further away from the ridge crest. Extensive logging and geophysical programs were planned to monitor the physical state of the oceanic crust, and possible modifications to it as a function of age and distance from the median rift.

The Pacific transect was planned as essentially a parallel to the North Atlantic east-west transect, again to monitor the effects of possible secular variation in source compositions, magmatic processes, and crustal aging. A series of holes was to be drilled between the crest of the East Pacific Rise near $9^{\circ} \mathrm{N}$ and Japan. Extensive site surveys were completed at survey areas PT-4, PT-5, PT-6, and PT-7 along this transect (Figure 1). Two legs of drilling were originally scheduled for the bulk of this transect out to Hawaii, with the primary objective of establishing a deep-penetration, multiple reentry hole in the PT-4 survey area analogous to Holes 395A and 396B in the North Atlantic. As in the North Atlantic transect, the survey areas on older crust, PT-5 and PT-6, were also back-up re-entry targets should a deep-penetration attempt prove impossible in the PT-4 area.

Three factors effectively destroyed this Pacific transect. The first was a decision on the part of the JOIDES Planning Committee to take one Leg out of the Pacific program (Leg 53) and use it for extending a second reentry hole attempted into North Atlantic Cretaceous crust, at the request of the Leg 52 scientific party following loss of a bottom-hole assembly in the first reentry hole, Hole 417D. Here the possibility of reaching Layer 3 was the overriding concern. Leg 53 was therefore re-organized around this Atlantic objective, staffed in a very few weeks, and the Pacific drilling deferred and limited to Leg 54 .

The second factor was that the Glomar Challenger required dry-docking before proceeding to the northwest Pacific, and the only logistically feasible place and time for this to occur was Long Beach, California, following
Leg 54. This port was eight days steam from the PT-4 area, and an even longer steam from PT-5 or PT-6. Leg 54 was originally scheduled to terminate in Mexico, not Long Beach. We consequently left our port of embarkation in Panama with the sudden news that up to a full week's operations time would now have to be devoted to steaming to Long Beach. Survey areas PT-5, and especially PT-6, were no longer realistic back-up targets for Leg 54.

The third and most telling factor was that it was, indeed, impossible to establish the deep-penetration hole so hoped for in the PT- 4 area. Within a very few days of drilling, it became clear that basaltic crust in the area was so intensely fractured, and so little healed by alteration, that frictional binding of the bit everywhere prevented penetration into basement of more than even a few tens of meters. It also seemed likely that sheet flows, apparently abundant on this segment of the East Pacific Rise (Lonsdale and Spiess, this volume) were particularly impossible to drill, and that our recovery on any truly representative piece of crust would mainly be that of sheet flows. Comparison with drilling results in the East Pacific on Leg 34 (Yeats, Hart, et al., 1976b) indicated to us that a successful deep-penetration attempt to drill fast-spread crust might not even succeed on crust as old as 30 m.y. Moreover, the Leg 34 basalts had recently been split at DSDP allowing one of us (J.H.N.) to observe the same types of alteration rinds, joint patterns, and flat upper chilled margins in those basalts. Therefore, they were probably also primarily sheet flows rather than the pillow basalts cored so successfully at several North Atlantic sites. We consequently requested the Chief Scientist of the Deep Sea Drilling Project and the JOIDES Ocean Crust Panel to let us move to PT-5, even though that would mean loss of still more operations time. We were motivated to make this request after having been in the PT- 4 area for only five days by the following considerations:

1) In that period, we had cored, or attempted to core, at five sites, exhausting the primary and most secondary sediment pond targets selected by the Ocean Crust Panel, plus one additional target of our own choosing;

2) as an example of the kind of difficulties we were encountering, in our initial basement target, Site 420, the bit was worn in a dramatic fashion to a complete polished bare nub, sheared of all four cones, the core guides, and even the stabilizer pads in less than 9 hours of rotation in basement, during which only 32 meters was penetrated, with less than 1.5 meters recovered;

3) identification of additional sediment ponds in the PT-4 area using the Glomar Challenger was severely hampered by lack of a $3.5-\mathrm{kHz}$ depth recorder on the vessel (such a system was installed subsequent to Leg 54 during dry-docking at Long Beach);

4) we estimated that by leaving at that time, but no later, we would have sufficient operations time at PT-5 (approximately three weeks) to drill a pilot hole, set a reentry cone, and drill 200-300 meters into basement;

5) we had all the site survey data on board for PT-5 and PT-6; 


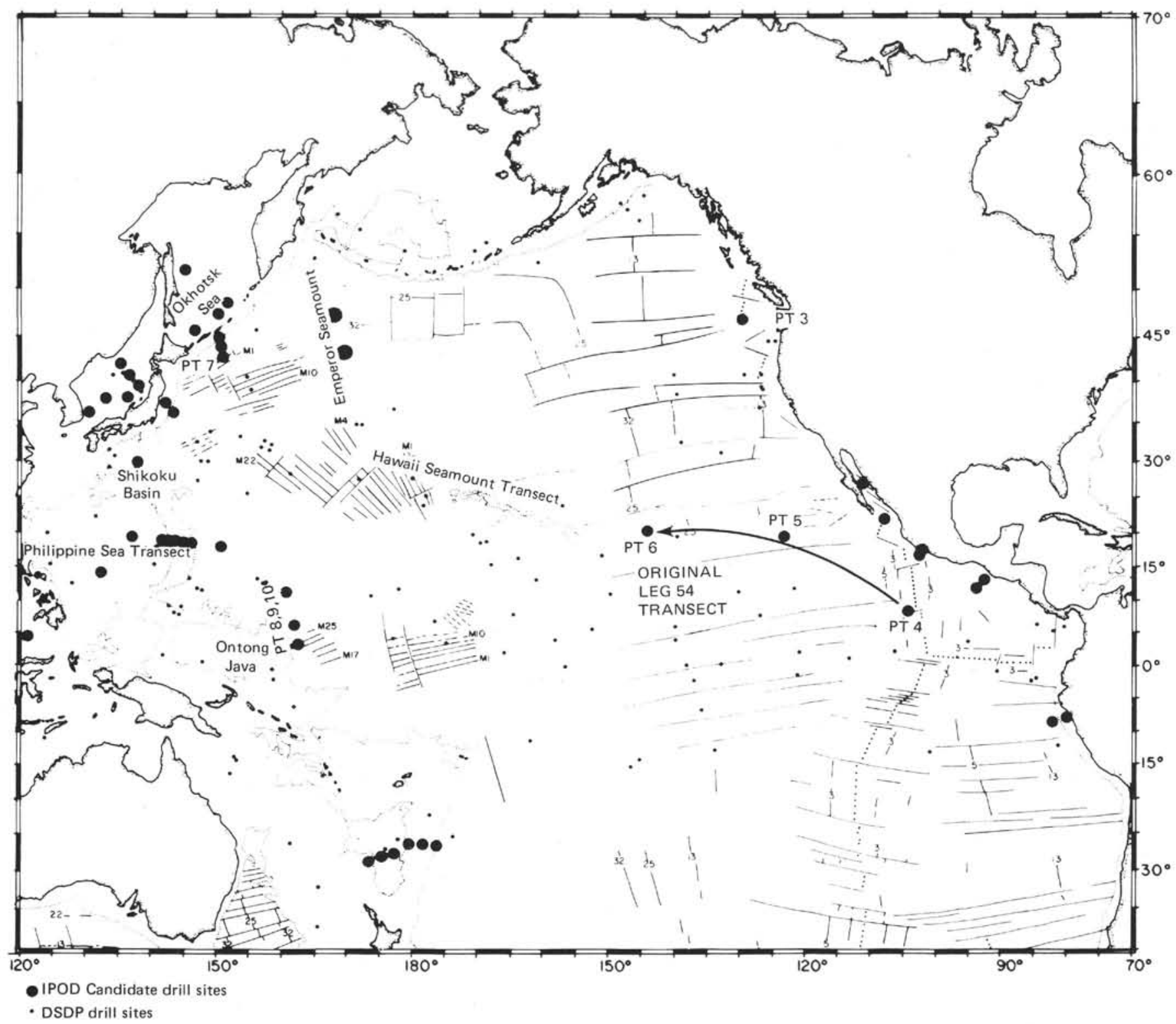

Figure 1. Location of Pacific IPOD candidate drilling sites. Discontinuous dotted lines denote East Pacific Rise and Galapagos Spreading Center. Magnetic anomalies 3, 5, 13, 25, 32, M1, M4, M10, M17, M22, and M25 are indicated, offset by fracture zones. Small dots are pre-IPOD DSDP sites. Filled circles are candidate sites in January 1976. Survey areas PT-5 and PT-6 were originally back-up targets to PT-4 for Leg 54 drilling.

6) even if re-entry also proved impossible at PT-5, there was a sufficiently widespread sediment blanket to allow us to spud in at many more places than the PT-4 area, allowing us wider discretion in locating drilling targets.

Instead of letting us move to PT-5, however, we were directed to the Galapagos Rift, there to conduct drilling trials for the sake of overall Deep Sea Drilling Project and IPOD-JOIDES plans. There were no site survey data for this venture. The drilling there, at Sites 424 and 425 , is the subject of the next chapter in this volume. It necessitated a full 13-day round trip transit between PT-4 and the Galapagos Rift in addition to six days of drilling. At the end of the Galapagos drilling, we were granted a seven-day cruise extension which we used for additional drilling in the Siqueiros (PT-4) region; from there we proceeded to Long Beach.

In all, then, we devoted just under 14 days (including on-site surveying, trip time, beacon dropping, etc.) to operations in our primary target region. During that period we drilled 13 holes at nine sites. This is all that has ever been done out of the original two-leg, 100-day Pacific transect with its projected 75 days of operations.

The PT-4 survey area was selected as the primary reentry target for the Pacific transect largely because, even before the site survey, it was probably the best known segment of an accreting plate margin in the Eastern Pacific. With the additional site survey data, and recent deep-tow studies (Lonsdale and Spiess, this volume), it should now be considered the bathymetric 
standard of all IPOD survey areas (Figure 2; chart in packet). Moreover, an imposing array of geophysical experiments conducted before and during the site survey (Rosendahl et al., 1976, Orcutt et al, 1975, 1976; Rosendahl et al., this volume) has been of fundamental importance in understanding the structure and origin of the greater part of the Earth's oceanic crust, most notably supplying firm geophysical evidence for a shallow axial magma reservoir beneath the rise crest. More than this, the ocean-bottom seismometer survey of Orcutt et al (1976) showed that the crust away from the rise crest consists not merely of three simple layers, but that the "layer" transitions are truly gradients (Figure 3). Still other evidence came from these studies for an extremely uniform structure to the crust at almost all locations removed from the Siqueiros fracture zone. It was this evidence which led Rosendahl (1976) to propose that consolidation of magmas emitted from the axial magma chamber, as well as of its sides and bottom during spreading, was the underlying cause of the worldwide oceanic layered crustal structure. Crustal structure in the Siqueiros region was also certainly simpler than on the Mid-Atlantic Ridge, a feature which made it easier to model geophysically and which offered great promise that a deep hole, properly logged and in which appropriate geophysical experiments had been conducted, would add physical substance to our understanding of oceanic crustal structure. Indeed, in the Siqueiros region, it seemed eminently possible that a hole 500-600 meters deep, no deeper than several already drilled in the North Atlantic, could reach at least the upper part of the firmly documented Layer 2-Layer 3 velocity gradient transition in the region (Figure 3). With this in mind, the site survey was commissioned to conduct an elaborate geophysical experiment, shooting to both sonobuoys and an array of ocean-bottom seismometers clustered over a primary target to be selected during the site survey. This experiment was to detail as completely as possible any variation in crustal velocity gradients sensed in different directions from the projected hole, with shot spacings designed especially to elucidate the structure of the upper 500-1000 meters of crust which we would (optimistically) drill.

Rarely has any drilling cruise set out with such wellfounded, elegantly conceived, and fundamentally important drilling objectives as Leg 54. And equally rarely have such high expectations been so totally dashed. The request of the Leg 54 scientific party to leave PT- 4 for PT-5 was not lightly made; the gravity of the drilling situation made it imperative. Thirteen holes at nine sites in 14 days are mute testimony to how completely everyone concerned underestimated the difficulties to be encountered in drilling young East Pacific Rise crust.

This chapter recounts what we learned with the drilling that we were able to do in those 14 days. It would not be fair to say that we were able to formulate successfully an alternative scientific program for the Siqueiros area that addressed our original objectives even remotely as well as the hoped-for re-entry hole. We also had a series of assigned targets to test before we could begin to reformulate a drilling program. And then, with the Ga- lapagos directive, over half of our operating time was taken away; only the seven-day extension allowed us any additional drilling in the Siqueiros (PT-4) region at all. In fact, a return to the Siqueiros region was not our first choice for use of this extension time. We much preferred to attempt one or more sites on older East Pacific Rise crust further south, closer to the Panama Basin, in the belief that drilling trials should also be applied to the East Pacific Rise, not just the Galapagos Rift, and that such drilling would be consistent with our original objectives and the spirit of the Pacific transect. However, we were instructed to use the extension only for either the Galapagos Rift or the PT-4 area. We elected the latter.

The Siqueiros (PT-4) drilling was consequently devoted initially to finding a target, any target, where we could drill into basement to bit destruction. Later, the additional holes drilled were designed to supplement the initial group of holes such that in effect a short east-west transect was drilled into what we considered "normal" East Pacific Rise crust. These were Sites 420, 421, 423, and 429. In addition, one location (Site 427) was drilled in the Siqueiros fracture zone, and two (Sites 422 and 428) where basement acoustic signature indicated ponding of lavas next to a prominent line of seamounts (OCP Ridge; Figure 2). Our experience throughout the Leg had been to convince us that it was feasible to spud into basement with as little as 20 meters of sediment, using a shortened bottom-hole assembly. Consequently, Site 426 was an attempt to drill on the prominent axial block at the rise crest (Figure 4), where geophysical evidence suggested the basalts might be relatively unfractured. We considered that we would attempt this drilling even if there were only a very few meters of sediments, just enough to implant the bit. Without a $3.5-\mathrm{kHz}$ system, however, we could not "see" sediments on the axial block; hence we tried to grope for sediments blindly using the drill string. Apparently the axial block is virtually free of sediments (Lonsdale and Spiess, this volume), and we were compelled to give up this attempt. At Site 419, our first on the Leg, basement drilling was also not attempted because of insufficient sediment cover. Little did we know then, however, that by the end of the Leg we would be repeatedly spudding into basement with as little as half the 45 -meter sediments cover encountered in Hole 419A.

In order to consider the results of this drilling properly, it is necessary to summarize briefly the principal physiographic and structural features of the East Pacific Rise and its flanks in our drilling region, and mention the leading ideas on how they originated.

The locus of plate accretion is the crest of the East Pacific Rise, manifested in the Siqueiros region by a prominent axial block having two general geomorphologies (Figure 5). To the north, near $9^{\circ} \mathrm{N}$, the summit has a smooth triangular cross section 200-300 meters high and about $10 \mathrm{~km}$ wide. Closer to the Siqueiros fracture zone $\left(8^{\circ} \mathrm{N}-8^{\circ} 30^{\prime} \mathrm{N}\right)$, however, it is a "lava plateau" $12-15 \mathrm{~km}$ wide (Lonsdale and Spiess, this volume). In both cases, the summit is flanked by fault-block "abyssal hills" 20-50 meters high. The triangular summit 


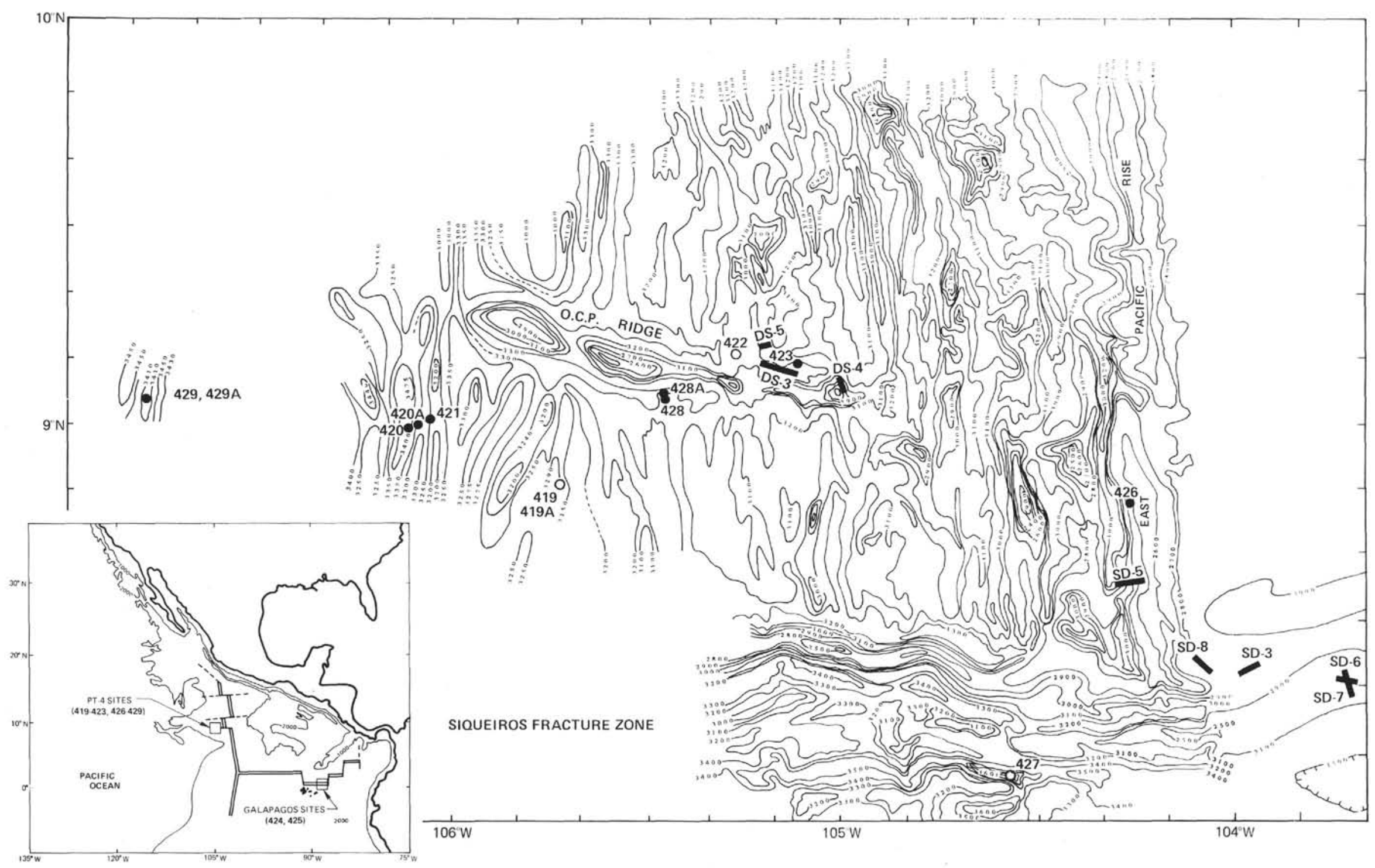

Figure 2. Bathymetry of the PT-4 survey area, showing location of dredge stations (SD, DS, CO, IMED) and drill sites (419 through 423, 426 through 429$)$. 


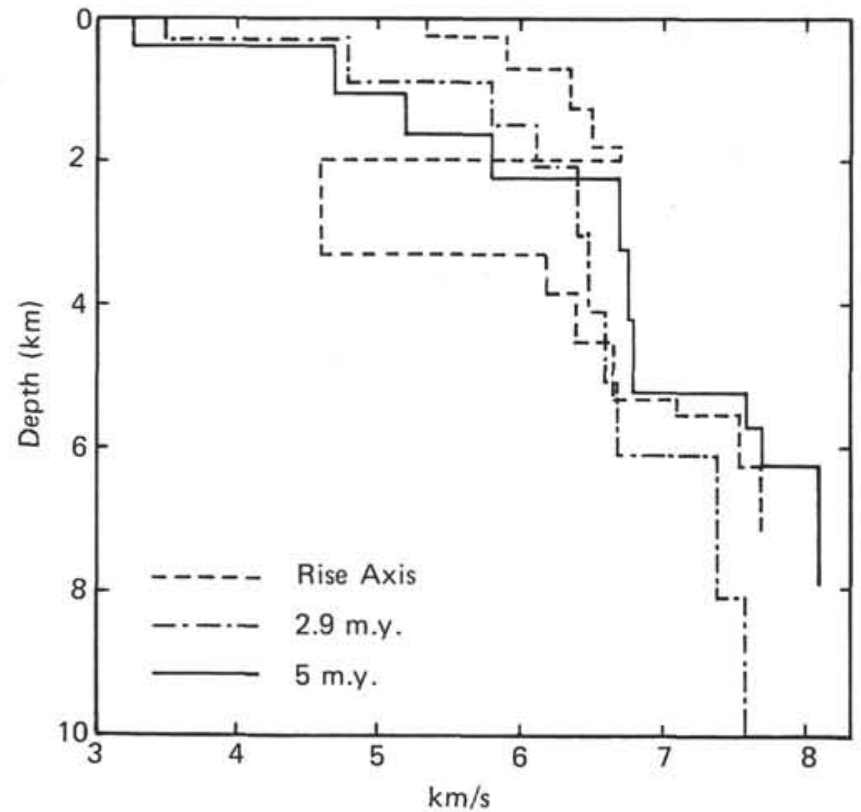

Figure 3. Velocity models based on ocean-bottom seismometer data for three north-south profiles along the crest and flanks of the East Pacific Rise near $9^{\circ} \mathrm{N}$ from Orcutt et al. (1976), with permission. The depth origin is taken at the sea floor. Note velocity inversion between 2 and $3.5 \mathrm{~km}$ below the sea floor on rise axis profile.

resembles the "axial shield volcano" described by Lonsdale (1977) on the basis of a deep-tow study of the rise crest at $3^{\circ} 25^{\prime} \mathrm{S}$. There, a 400 meter-wide crestal zone, with a summit graben $10-35$ meters deep, is the locus of dike injection and fissure eruption. In the Siqueiros region, the axial shield volcano, where it exists, is somewhat broader at its base than that at $3^{\circ} 25^{\prime} \mathrm{S}$. It varies between 500 and 2000 meters in width, and has some lava walls 90 meters high (Lonsdale and Spiess, this volume). Instead of breaking up into small fault blocks on its flanks, as does the axial shield volcano, the plateau is bounded by outward-facing normal faults with throws of over 100 meters. Lonsdale and Spiess (1979) have interpreted this somewhat anomalous axial plateau as, in effect, the surface expression of an unusually inflated axial magma reservoir. They linked the initial stages of eruption of two symmetrically disposed nearby seamounts - one on either side of the rise - to episodes of inflation and collapse of this plateau region. It was over this plateau region that the geophysical studies of Rosendahl et al. (1976) and Orcutt et al. (1976) detected the rise-crest magma chamber within the crust. Rosendahl (1976) interpreted the axial plateau, or "block" as he called it, as the "isostatic expression" of this "shallow sub-axial magma reservoir."

A dredge haul on the southern portion of the axial plateau (SD-5, Figure 2) had recovered tholeiitic ferrobasalt (Batiza et al., 1977) similar in composition to basalts recovered from the precise summit of the axial shield volcano at $3^{\circ} 25^{\prime} \mathrm{S}$ (Lonsdale, 1977). The place of ferrobasalts in the economy of rise-crest magmatic pro-
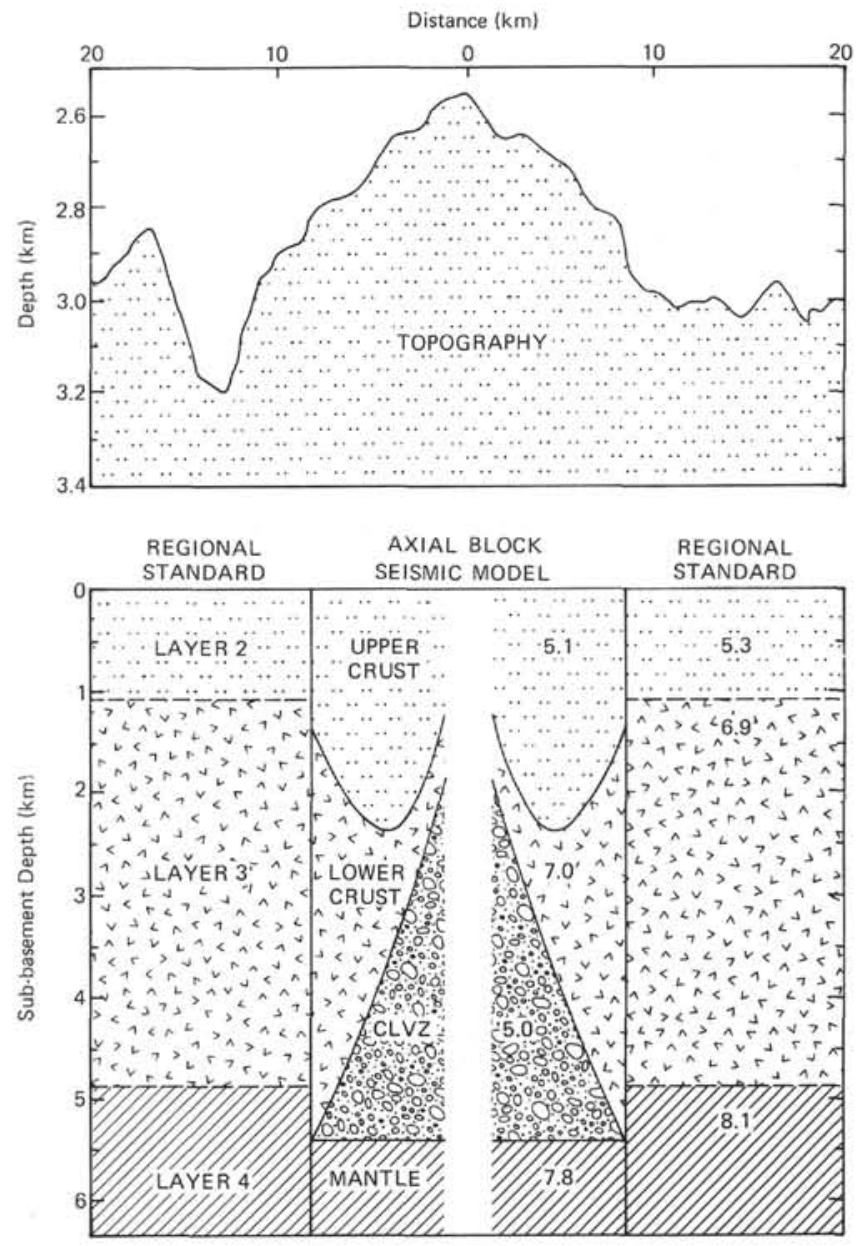

Figure 4. Topography and seismic model of the East Pacific Rise crest. The topographic profile represents the mean depth measurement of the axial block between $8^{\circ} 25^{\prime} \mathrm{N}$ and $9^{\circ} 35^{\prime} \mathrm{N}$. The numbers in the lower panel represent the mean compressional wave velocities in the individual seismic layers. The structure immediately beneath the ridge axis is unknown. The regional standard represents an average of seismic refractions CH8, 9, 10, 11AB, and 13 of Shor et al. (1970). CLVZ refers to the axial low-velocity zone (after Rosendahl, 1976).

ducts has been a subject of considerable discussion, with growing evidence that they are more abundant on the East Pacific Rise than the Mid-Atlantic Ridge (cf., Bass, 1971; Scheidegger, 1973; Rosendahl, 1976; Clague and Bunch, 1976; Natland, 1978). It was therefore of considerable interest to us to determine how, if at all, they might be related to the presence of an axial magmatic reservoir and to fractionation processes therein. The work of Lonsdale and Spiess (1979 and this volume) suggested that the dimensions of the axial magma chamber certainly vary along the rise axis, and probably also with time. In this respect, at least, the magma chamber is not strictly a "steady-state" phenomenon, although it certainly seems to be more readily detectable geophysically than on the Mid-Atlantic Ridge (e.g., Nisbet and Fowler, 1978). 


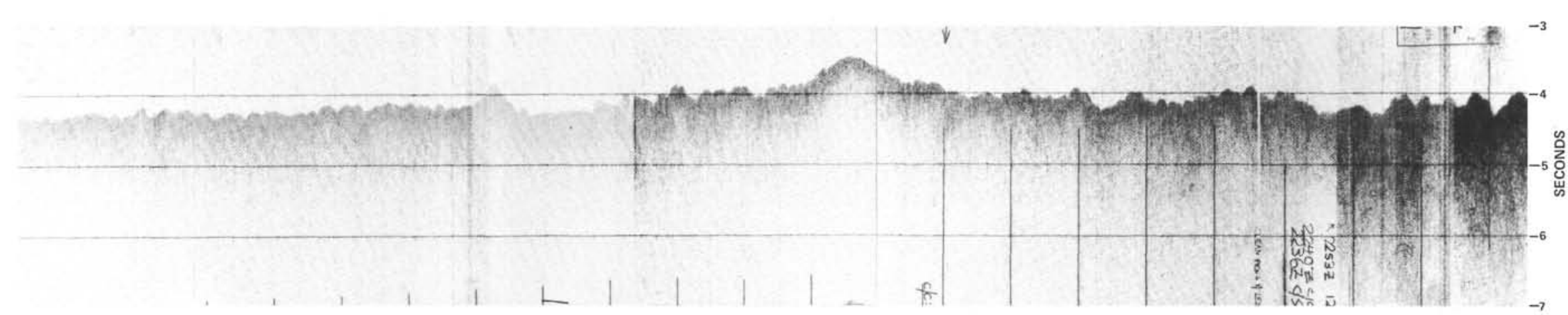

East-west Profile near $9^{\circ} \mathrm{N}$

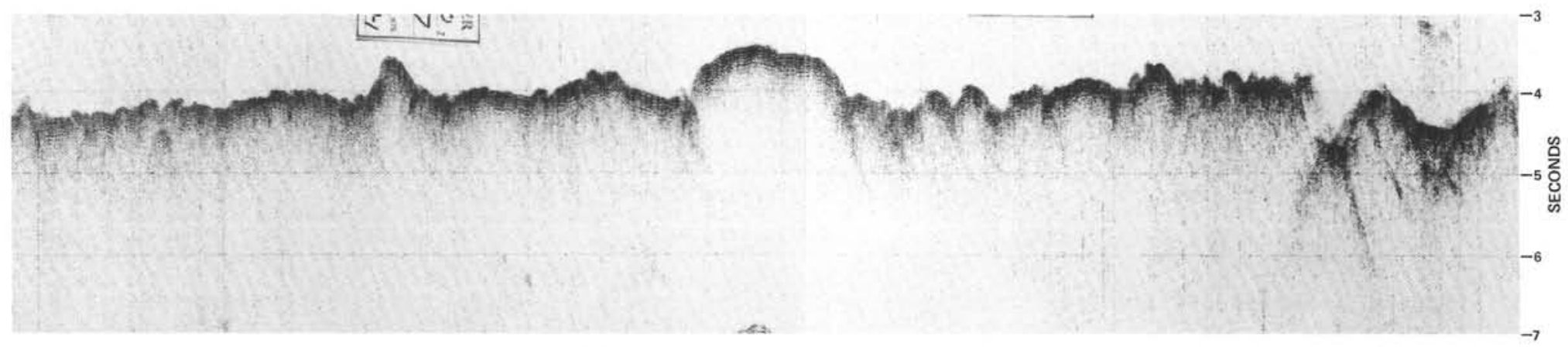

East-west Profile near $8^{\circ} 30^{\prime} \mathrm{N}$

Figure 5. East-west profiles of the East Pacific Rise near $9^{\circ} \mathrm{N}$ obtained by the Glomar Challenger on Leg 54. Note the two types of axial geometry-triangular and plateau-like-described in the text. Location of crossings are shown on Figure 2. Vertical exaggeration is $\sim 9 \times$. 
To return to the problem of ferrobasalts, leastsquares calculations and high concentrations of elements having very low partition coefficients (e.g., P, K, $\mathrm{Zr}$, and $\mathrm{Rb}$ ), suggested that they could be derived by upwards of 60 per cent fractionation of plagioclase, clinopyroxene, and olivine from plausible olivine tholeiite parents (e.g., Clague and Bunch, 1976; Batiza et al., 1977). An important question is whether ferrobasalts are the fundamental product of a steady-state East $\mathrm{Pa}$ cific Rise magma chamber within which the internal magma composition reaches a relatively fixed composition, buffered by the size and cooling rate of the chamber in a regime of balanced magma input and eruption (O'Hara, 1977; Usselman and Hodge, 1978). We could cast serious doubt on this possibility simply by finding interbedded olivine tholeiite and ferrobasalt at any particular location, or by showing that flank basalts have different compositions at different locations. Similarly, we should be able to detect changes in magma compositions supplied to the axial magma reservoir through time, either as a consequence of changes in the degree of melting or of fundamental differences in source composition, using well-established procedures of trace-element discrimination (e.g., Bougault et al., 1979; Tarney et al., 1979).

We would be drilling the products of axial magmatism in the flank regions of lineated north-south abyssal-hill fault blocks. Lonsdale (1977 argued that these fault blocks form as a consequence of repetitive inflation and draining of the axial magma reservoir. Steep ( $60^{\circ}$ ) master shears form, in this scenario, within a zone of intense fissuring (as for example, detected by the $3^{\circ} 25^{\prime} \mathrm{S}$ deep-tow survey) on the flanks of the axial shield volcano as magma injection uplifts the summit region. Draining attended by "caldera" (i.e., summit graben) collapse causes downwarping of this flank region, leading to formation of new "hanging-wall" faults, and thus of keystone fault blocks. The strongly lineated crustal fabric in the Siqueiros region (Figure 2) apparently formed by some such mechanism as this. However, the faulting process may have been much more severe than usual because of the large 100-meter throws on the faults bounding the axial plateau region. We cannot be certain if such a plateau existed at the time of extrusion of lavas at all the sites we drilled, but the similarity of crustal velocity structure from place to place (Rosendahl et al., 1976) makes this a distinct possibility.

An important consequence of such fault-block formation to our drilling may have been to fragment individual flows to a very high degree, making them, as we discovered, difficult to drill. These were already fractured by "dike injection at the spreading axis (and presumably by lesser off-axis intrusions), repeated collapse of the summit graben, (and) extensional fissuring and faulting on the plateau surface" prior to being "stepfaulted as the crust descends the sides of the axial ridge" (Lonsdale and Spiess, this volume). At least one consequence of all this faulting appears to have been a steepening of the velocity gradient in the upper crust as it drops off the axial plateau (Figure 3), primarily by decreasing velocities in the upper few hundred meters of crust, presumably by fracturing flows and stretching void spaces in the rocks. Avoiding the effects of this was the justification of our attempt to drill on the axial plateau at Site 426.

There are at least two types of seamounts in the Siqueiros region. The first type, already mentioned, appears to have originated (at least in part) as a result of axial magmatic activity which formed a pair of symmetrically disposed volcanoes on either side of the rise axis. Basalts from one of these seamounts have the depleted compositional characteristics of rise tholeiites (Lonsdale and Spiess, 1979).

The second type of seamount probably forms an older "flank" lithosphere, or in leaks along the Siqueiros fracture zone. Basalts from these have marked enrichments in $\mathrm{K}_{2} \mathrm{O}, \mathrm{P}_{2} \mathrm{O}_{5}, \mathrm{TiO}_{2},{ }^{87} \mathrm{Sr} /{ }^{86} \mathrm{Sr}$, and ${ }^{143} \mathrm{Nd} /{ }^{144} \mathrm{Nd}$ compared with depleted rise tholeiites (Batiza et al., 1977; Carlson et al., 1978; Johnson, 1979; Batiza and Johnson, this volume). With our drilling, we were able to examine the characteristics of basalts ponded at two locations (Sites 422 and 428 ) next to a major transverse line of seamounts in the PT- 4 area, the OCP (Ocean Crust Panel) Ridge, where so-called "transitional" basalts with undepleted chemistries had been dredged (Johnson, 1979).

One of the objectives of drilling these two sites was to find out how far flows from the OCP Ridge may have spread on the surrounding sea floor. There was some concern that they might have reached the vicinity of our prime target, also the location of the site survey geophysical array, drilled at Site 423. An elaborate suite of chemical tests was devised to discriminate rise tholeiites from "transitional" OCP Ridge basalt types. These were to be applied at the time of drilling Site 423, using the shipboard X-ray fluorescence unit. Failure to drill basement at Site 423 successfully, however, rendered academic the use of these discriminants.

The Siqueiros fracture zone was the third tectonic province in our survey area we investigated by drilling. It is a highly complex zone of rugged relief and active seismicity (Crane, 1976), having a major central fracture-zone ridge and a number of very deep troughs (Figure 2). Most of the basalts examined by Batiza et al. (1977) are from the Siqueiros fracture zone; they are predominantly olivine-spinel, olivine-plagioclase, and coarsely plagioclase-olivine phyric pillow fragments. Lonsdale (1978), again on the basis of deep-tow surveys, inferred that at the intersections of the East Pacific Rise with the Siqueiros $\left(8^{\circ} \mathrm{N}\right)$ and Quebrada $\left(4^{\circ} \mathrm{S}\right)$ fracture zones, the rise axis is twisted obliquely into the fracture zone, where extrusions locally flood the transform valleys and build fracture-zone ridges. At Site 427 , we drilled lavas ponded in the deepest part of the Siqueiros fracture zone within our survey area.

Combining the results of drilling and dredging, we have accomplished a thorough, if nonetheless modest, petrologic reconnaissance of a small segment of the East Pacific Rise, an adjacent fracture zone, and several seamounts in the region. The drilling redressed, to some extent, the imbalance of sample distribution toward the large steep scarps and slopes of seamounts and fracture- 
zone faults, to include rocks from the less easily dredged but more typical block-faulted ocean floor. With a deep hole, we had hoped to investigate the chemical and magnetic stratigraphy of the products of the axial magma reservoir at a single place. Instead, with our shortpenetration holes, we are able to discuss the products of this reservoir at several times over the past $4.6 \mathrm{~m}$.y. With a deep hole we had hoped to obtain important information about the depth and thickness of the magnetized source layer - the source of lineated magnetic anomalies - in the crust. With our short-penetration holes, we can discuss the general tendency of the uppermost basalts cored at several places on the East Pacific Rise to have magnetic inclinations in agreement with those inferred from magnetic anomalies. Our petrologic reconnaissance also allows us to compare the range of magmatic products of the East Pacific Rise with those recovered by drilling from the Mid-Atlantic Ridge, and to outline any differences in their structural, physical, and magnetic properties. Finally, although we had no East Pacific Rise targets devoted exclusively to such problems, our drilling allows us to comment on the general features of early alteration of crust, including the accumulation of "hydrothermal" components in the sediments.

\section{DRILLING STRATEGIES AND OPERATIONS NARRATIVE}

We left Cristobal, Panama, with an excellent site survey of the PT-4 area, an intimate knowledge of the region by several members of the scientific party, and a drilling prospectus that chronicled the placement, sequencing, and logic of the site selections. In brief, this document called for the establishment of a type-section for fast spreading crust via multiple re-entry drilling. The strategy consisted of drilling pilot holes at both targets PT4A and PT-4C or 4B (see Figure 6) and applying some geochemical tests to the recovered rocks to determine which site would be the prime target for reentry (see Natland and Melson, this volume). These tests were required because the preferred target (PT-4A) was located close to the OCP Ridge, which in part is composed of transitional to alkali basalts (Johnson, 1979). In spite of the site survey information, a nagging uncertainty remained regarding the petrologic and chemical normality of PT-4A. Postponement of the Pacific drilling to Leg 54 and the scheduling of dry-docking at Long Beach resulted in a reduction in the length of our Leg from 51 to 44 days ( 41 to 27 days on station) and the loss of a back-up Leg that could re-occupy any re-entry targets left intact on Leg 54. During our transit to the PT-4 area, we decided that these scheduling changes were incompatible with the goal and strategy outlined above. Rather than sacrifice the re-entry program, we devised a somewhat abbreviated and implicitly more risky strategy. This called for drilling first a single-bit hole at either PT-4B or PT-4C (dependent upon profiler results of the incoming ship track) and then a standard sediment hole at PT-4A, including several basement cores. Assuming that PT-4A basement could be drilled, we would set up for re-entry and drill a complete single-bit hole. If the cored material met our geochemical normality criteria, we would proceed with the re-entry program. If PT-4A was unsuitable in terms of either ability to drill or chemical normality, we would establish the reentry hole at PT-4C or 4B.

As already discussed, this revised drilling plan also was to be short lived. Site 419 at PT-4C lacked the required sediment cover for spud-in (likewise, we now calculated, did PT-4A), and we decided instead to drill a substitute pilot hole further west along the L-DGO multichannel line. However, at this location (Hole 420), the drill penetrated only a few tens of meters into basement before the core bit was demolished; another attempt at penetration in the same area (Hole 421) proved less successful. At this point in the cruise it became clear that a significant but unknown proportion of the normal East Pacific Rise fabric must be characterized by highly fractured basalts, in which penetration, recovery, and rockstratigraphic control were woefully inadequate. It was equally obvious that the re-entry objective was probably beyond the scope of Leg 54 and, at the very least, the revised drilling plan would have to be scrapped.

With this realization, our thoughts began to shift toward an alternative drilling program, which would have included single-bit holes in the Siqueiros fracture zone, on 5-m.y.-old crust south of the fracture zone, and in the 7-to 10-m.y. PT-5 survey area. However, before abandoning the PT- 4 area drilling we decided to attempt two more holes in the survey area proper. Both were meant to be tests of the likelihood of reasonable penetration in the PT- 4 survey area and the practicality of continued drilling operations in the area. Hole 422 was to be placed in a trough termed "OCP Moat" and constituted what we considered to be our best attempt to achieve reasonable basement penetration. This feature is a flat, depressed area about $5 \mathrm{~km}$ wide that more or less surrounds the OCP Ridge. Acoustically, the moat is characterized by a thin blanket of stratified sediments overlying a very flat and very strong basement reflector, unlike that observed elsewhere in the immediate area. We thought it likely that basement here could represent more recent and perhaps thicker flows (ponded?), possibly originating from the OCP Ridge. If so, then we reasoned that the underlying fragmented fabric basalts should be capped and to some extent cemented by OCP Ridge flows. In essence, we decided to place a hole in a locality that was clearly anomalous in the hope that the normal situation (i.e., fabric basalts) could be drilled. At the very least, this site would provide new insights into the formation of the OCP Ridge and its relationship to the surrounding sea-floor rocks. The next site, Site 423 , was to be placed on the original preferred prime site of Leg 54, the PT-4A sediment patch. Unlike Site 422 , we had little expectation of tolerable drilling conditions there, but we thought another fabric site was needed to confirm our growing suspicions - that the highly fractured nature of the basalts was the characteristic state of young East Pacific Rise seafloor prior to the time (unknown) at which it becomes cemented by secondary processes. It was important aiso at least to attempt drilling at our primary target and resolve questions 


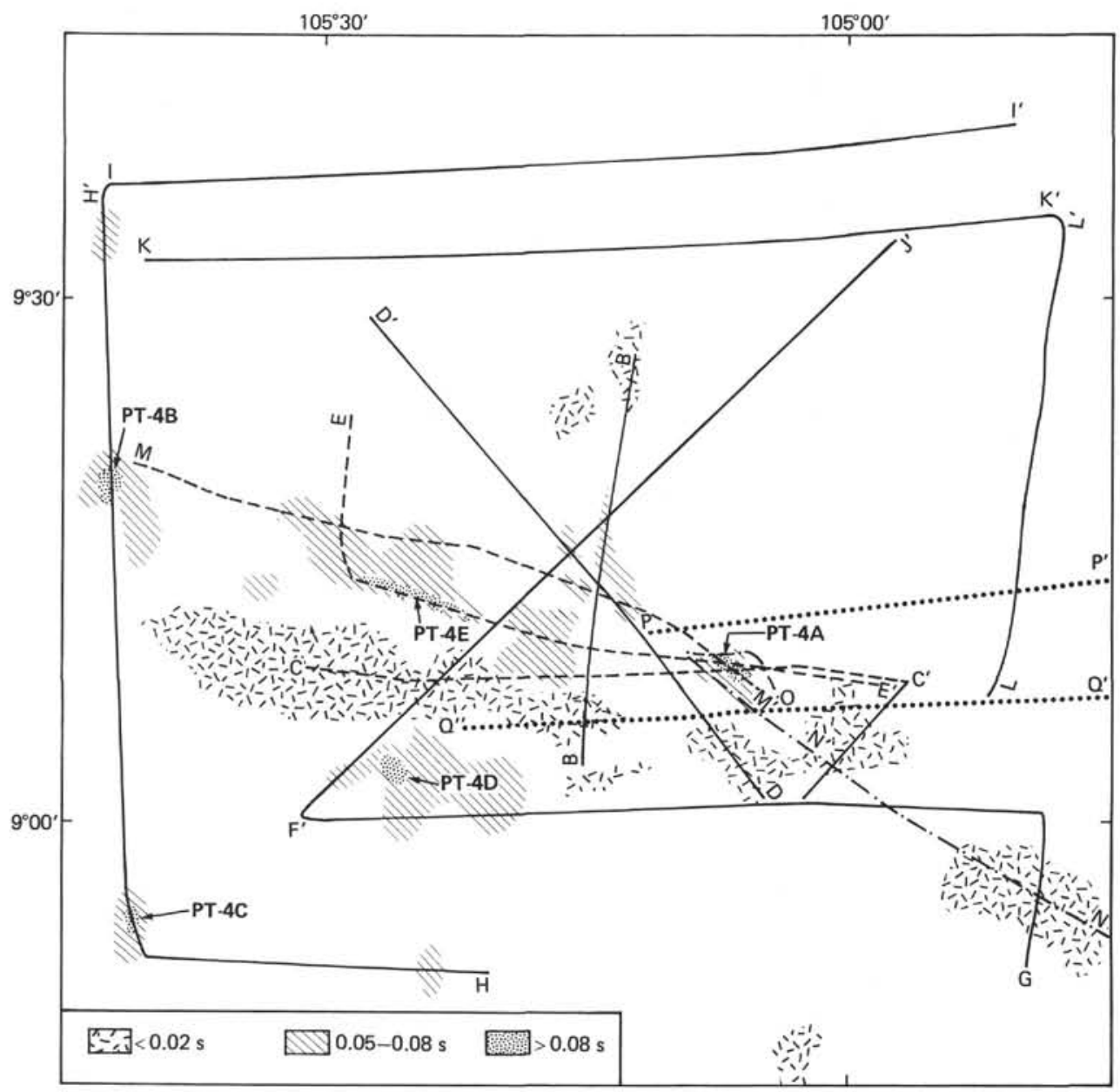

Figure 6. Sediment isopach chart of the PT-4 subarea and tracks of site survey reflection profiler records. The potential multiple re-entry sites are labeled PT-4A through $4 E$. Sediment thicknesses are given in two-way travel time. Site 419 was cored in PT-4C, Site 422 in PT-4D, Site 423 in PT-4A, and Site 428 near PT-4E.

about whether it was petrologically "normal" East Pacific Rise crust. Moreover, Site 423 would serve as the easternmost hole in a four-hole transect spanning 1.8 m.y. of plate chronology and crossing a transverse ridge structure. Even with minimal penetration and recovery, its results - combined with those from Sites 420 through 422 and the dredged rocks - would be useful in elucidating the magmatic history of the East Pacific Rise.

Since the OCP Moat was known to contain $0.08 \mathrm{sec}$ or less of sediment and Site 423 probably less than 80 meters of sediment, the occupation of Sites 422 and 423 required a change in the 80 -meter sediment minimum in force up to this time. After a radio patch with DSDP, the minimum was reduced to 40 meters and we proceeded to drill both sites. The results were neither encouraging nor acceptable, in our minds, and we decided to proceed with the alternative drilling plan, requesting DSDP to let us move to PT-5A. Then, while steaming toward a Siqueiros fracture zone site, we were instructed to suspend East Pacific Rise drilling operations and proceed to the Galapagos Spreading Center.

At this point in the cruise it appeared that the East Pacific Rise program was terminated and we spent much of the next six days analyzing and interpreting the results of Sites 419 through 423 . However, near the end of the Galapagos drilling, Leg 54 was given its seven-day extension which we chose to use for additional drilling in the PT- 4 area.

Upon returning to the PT- 4 area, as already mentioned, we were particularly interested in extending the transect to both older and younger portions of the sea floor and establishing a site in the Siqueiros fracture zone. Sites 427 (Siqueiros fracture zone), 428 (OCP Moat), and 429 (4.6-m.y.-old fabric) were drilled according to plan and without noteworthy incident. Site 426 , on the other hand, deserves special mention. Throughout the duration of Leg 54, we had spent considerable time and effort analyzing why penetration and drilling conditions were so bad and what we might do technically or geographically to circumvent the problem. By the time we returned to the PT- 4 area, we had decided that fracturing was the typical condition of the youthful fabric and that it was produced mainly by the spalling off of slivers of crust at the margins of the EPR axial block. Therefore, significant basement penetration was likely only at the top of the axial block, on sea floor not yet 
step-faulted down to a thermal equilibrium level, or on much older crust where diagenesis had led to cementation of the fragmented basement. Since we did not have the option to drill old crust, Site 426 was meant to be a test of the ridge axis portion of this prediction. If successful, the site would yield a near zero-age control point on the EPR transect. The main difficulty with such a site was, of course, that the extreme youthfulness of the area (up to 250,000 years old) precluded a sediment thickness greater than about 15 meters - and finding even this amount would be somewhat fortuitous, if not outrageously lucky. For one thing, the Glomar Challenger's only sediment profiler was the air-gun system and this was unable to detect sediments thinner than about 12 meters (the value for the minimum separation of the bubble pulse train). Still, we felt the attempt to be a worthwhile gamble, and permission of the Cruise Operations Manager was granted for the hole provided that at least 10 meters of sediment could be located using the drill string as a probe. This we were not able to do. Thus there were no cores taken at Site 426.

\section{Site-by-Site Operations Summary}

\section{Site 419}

We arrived in the PT-4 survey area at 15367 May, and conducted an east-to-west reflection profiling transect in the hope of finding a bathymetrically better-constrained alternative to Site PT-4C (Figure 6). However, no adequate sediment cover was detected during our east-west crossing. Upon intersecting a north-south profiling transect across PT- $4 \mathrm{C}$, obtained during the site survey, we turned south and began our final approach to the site, using the site survey reflection profile as our control (Figure 7). Due to a somewhat unpredictable cross current, combined with a less than satisfactory quality of satellite fixes and a reflection profiling system that struggled to "see" sediments where they were less than 0.1 thick, we either missed or were unable to locate PT$4 \mathrm{C}$ on our first approach. On our second pass we crossed the edge of the PT-4C sediment pond and dropped a $16-\mathrm{kHz}$ Benthos beacon at 0530 . All the gear was pulled in 30 minutes later in preparation for drilling. While nearing the sea floor, the beacon began pinging on a one-second repetition rate with a progressive loss in signal strength, and another beacon was dropped at 0646 . Although the sediment thickness was several hundredths of a second less at the original beacon position than along the thickest portion of the site survey profiled, the $0.08-0.09$ of reflection time was thought to merit a try and drilling commenced. After five sediment cores and 35 meters of penetration, Hole 419 encountered basement (Table 1). Since this value could not represent the sediment thickness beneath the original beacon, the second beacon must have dropped at some distance from the first - probably because the positioning computer could not give a correct location on the original malfunctioning beacon. After pulling the drill string about 91 meters above the mud line, we offset 3000 feet toward the thickest portion of the PT-4C sediment pond and attempted another hole. A mud-line core was taken and Hole 419A was then washed down to basement, which was encountered at a sub-bottom depth of 46 meters. Rather than continuing to compound this comedy of errors, we decided to pull the drill string and obtain a reflection profile across both Holes 419 and 419A before attempting another hole. This profile did, indeed, show only a thin sediment cover and also indicated that the mean velocity in the sediments could not be greater than about $1.54 \mathrm{~km} / \mathrm{s}$. Using this value, we recomputed the maximum thickness at PT-4C along the site survey profile. Arriving at a value of 77 meters, less than the nominal 80-100 meters required to support a bottomhole assembly, we decided it was best to abandon drilling at PT-4C. The same considerations precluded drilling at PT-4A (although it was later drilled), and at 1507 9 May we began steaming to a site farther west. It should be noted that the pore-water sampler was run successfully at Hole 419 at a sub-bottom depth of 29 meters.

\section{Site 420}

After leaving Hole 419, we proceeded west to a longitude of about $106^{\circ} 15^{\prime} \mathrm{W}$, turned north and intersected the Lamont-Doherty multichannel reflection profile (Figure 8). A beacon was dropped at 2344 on a 0.135 s-thick sediment blanket (Figure 9). Drilling at Site 420 began at 010010 May, and continuous sediment coring commenced seven hours later. A total of 13 sediment cores were recovered over an interval of 115 meters (Table 2). In addition, the pore-water sampler was successfully deployed at sub-bottom depths of 23.5, 71.0, and 99.5 meters. Basement drilling commenced at about 010011 May, and after about nine hours of actual rotation we had penetrated only 32 meters of highly fractured basalt (Table 2). During this period we encountered nearly continuous torquing and sticking of the drill stem, with pulls up to $400,000 \mathrm{lb}$. required to move the pipe. Spotting more than 200 barrels of mud helped little in this regard. Moreover, we found that the degree of drilling difficulty was increasing radically with depth. In view of these problems, combined with the loss of the blower shaft on the cement/gel pump and very low recovery rates $(<5 \%)$, we abandoned the hole at 1822 11 May.

Moving 3000 feet north-east toward the L-DGO multichannel line with the drill string pulled about 95 meters above the sea floor, we began another attempt to drill basement. However, after taking a mud-line core and washing down to basement, we discovered that the sediment thickness was only 63 meters. Because of the drilling regulations in force at this time $(80 \mathrm{~m}$ sediment minimum), spud-in was not attempted and Hole 420A was abandoned at 2355. The fact that the PDR depth at the beacon read 3382 meters (corrected) but the core bit did not encounter the mud line until a depth of 3412 meters was reached, suggested to us that Hole $420 \mathrm{~A}$ was located in a steep, narrow trough in the local sediment blanket. The reflection profile across Holes 420 and $420 \mathrm{~A}$, which we obtained upon leaving the site, revealed that we had, in fact, inadvertently drilled the latter hole in a vertically walled gouge in the sediment blanket.

Upon abandoning Hole $420 \mathrm{~A}$, we decided to again offset in a north-northwesterly direction, 1.5 miles from the Hole $420 \mathrm{~A}$ location. At the last minute these plans 


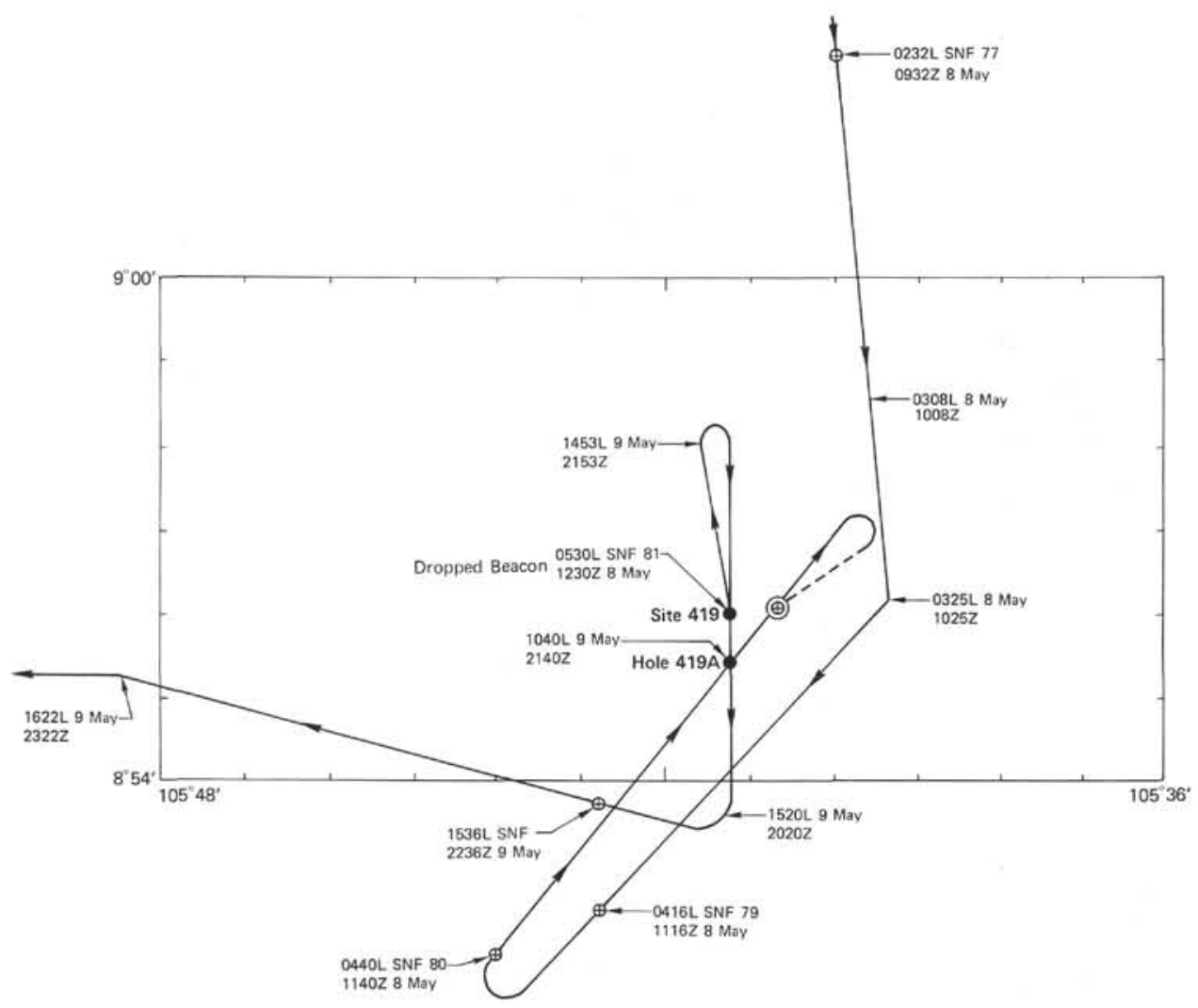

Figure 7. Glomar Challenger operations near Site 419. Satellite navigation fixes $(S N F)$ are circles with crosses. Times given are local $(L)$ and Greenwich $(Z)$ time.

TABLE 1

Coring Summary, Site 419

\begin{tabular}{|c|c|c|c|c|c|c|c|}
\hline Core & $\begin{array}{c}\text { Date } \\
\text { (May 1977) }\end{array}$ & Time & $\begin{array}{l}\text { Depth From } \\
\text { Drill Floor } \\
\text { (m) }\end{array}$ & $\begin{array}{l}\text { Depth Below } \\
\text { Sea Floor } \\
(\mathrm{m})\end{array}$ & $\begin{array}{l}\text { Length } \\
\text { Cored } \\
\text { (m) }\end{array}$ & $\begin{array}{l}\text { Length } \\
\text { Recovered } \\
\text { (m) }\end{array}$ & $\begin{array}{c}\text { Recovery } \\
(\%)\end{array}$ \\
\hline \multicolumn{8}{|l|}{ Hole 419} \\
\hline 1 & 8 & 2212 & $3294.0-3294.5$ & $0.0-0.5$ & 0.5 & 0.2 & 40 \\
\hline 2 & 8 & 2315 & $3294.5-3304.0$ & $0.5-10.0$ & 9.5 & 4.6 & 48 \\
\hline 3 & 9 & 0012 & $3304.0-3313.5$ & $10.0-19.5$ & 9.5 & 3.8 & 40 \\
\hline 4 & 9 & 0117 & $3313.5-3323.0$ & $19.5-29.0$ & 9.5 & 6.6 & 69 \\
\hline 5 & 9 & 0449 & $3323.0-3329.0$ & $29.0-35.0$ & 6.0 & 6.4 & 67 \\
\hline Total & & & & & 35.0 & 21.6 & 62 \\
\hline \multicolumn{8}{|l|}{ Hole 419A } \\
\hline 1 & 9 & 0805 & $3277.0-3285.0$ & $0.0-8.0$ & 8.0 & 4.74 & 59 \\
\hline Washed & & & $3285.0-3323.0$ & $8.0-46.0$ & - & - & - \\
\hline Total & & & & & 8.0 & 4.74 & 59 \\
\hline
\end{tabular}

were thwarted by a regulation limiting the offset distance (with the drill string down) to 3000 feet. In this instance, an arbitrary regulation actually proved useful because upon retrieving the drill string, we discovered that the F94 core bit was little more than a pock-marked hunk of steel casing. Every cone, core guide, and stabilizer pad had disappeared, and the bit was noticeably out of gauge.

The condition of the bit after a mere nine hours of drilling was a topic of conversation among the entire ship's party and a matter of chagrin to the few of us who were very familiar with the PT- 4 area. Hole 420 had been positioned (purposely) on typical East Pacific Rise fabric in a locality that should have been nearly as free of talus as any other potential site. Were our problems a fluke or an omen of things to come?

\section{Hole 421}

Upon leaving Hole 420A, we steamed north-east on a course of $45^{\circ}$ for 1.5 miles, turned east on the L-DGO multichannel line for a distance of about one mile (Figure 8), and dropped a beacon at 082212 May on a uni- 


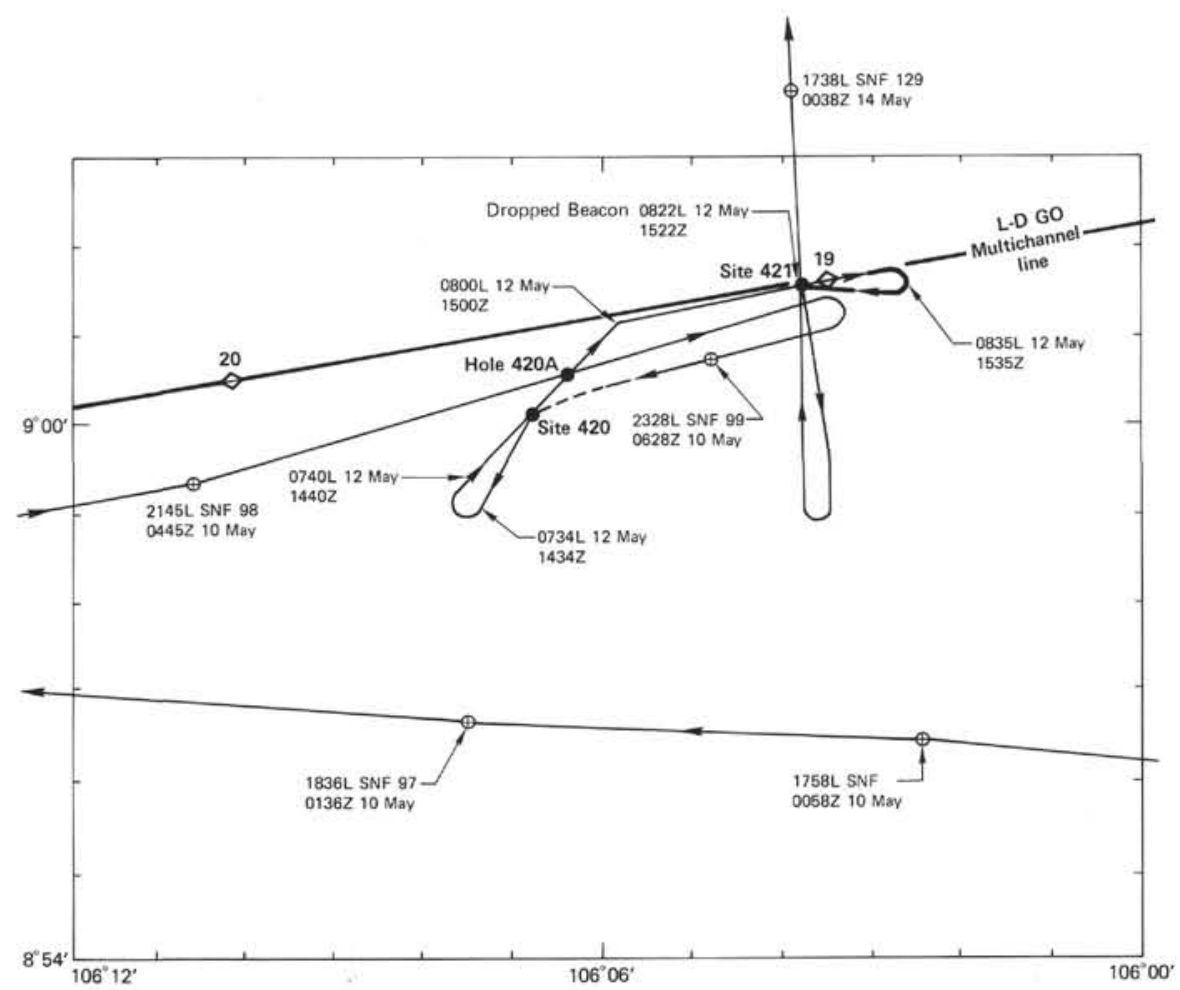

Figure 8. Glomar Challenger operations near Sites 420 and 421. Satellite navigation fixes $(S N F)$ are circles with crosses. Times given are local $(L)$ and Greenwich $(\mathrm{Z})$ time. Lamont-Doherty multichannel track (Ludwig and Rabinowitz, this volume) is shown.

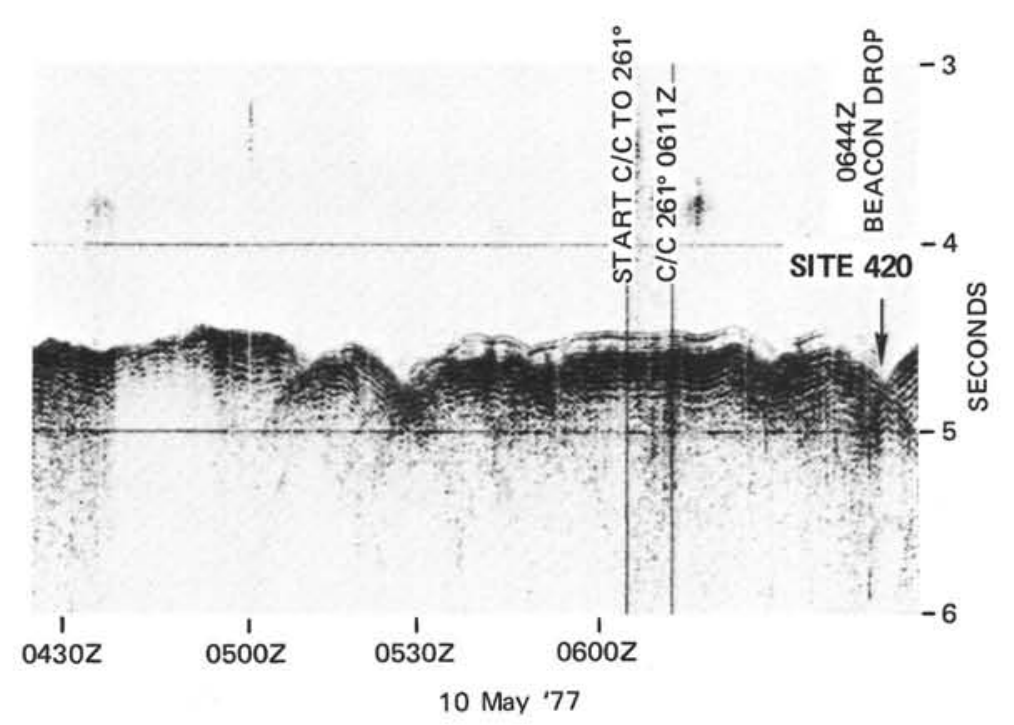

Figure 9. Glomar Challenger underway profile prior to beacon drop at Site 420.

form portion of the local sediment blanket (Figure 10). Drilling operations were delayed about 5 hours in order to repair the diaphragm and clutch lining in the makeup drum of the draw-works.

After taking a mud-line core, we washed down to basement, which was encountered at a sub-bottom depth of 85.5 meters, and commenced drilling at about 010013
May (Table 3). If anything, drilling conditions were even worse here than at Site 420 and the drill string began sticking with less than 5 meters of basalt penetrated. From there on, hole conditions deteriorated rapidly and it proved impossible to penetrate below a level of $30 \mathrm{me}-$ ters, where torque approached $425,000 \mathrm{lb}$. Spotting 300 barrels of mud had little noticeable effect on coring effi- 
TABLE 2

Coring Summary, Site 420

\begin{tabular}{|c|c|c|c|c|c|c|c|}
\hline Core & $\begin{array}{c}\text { Date } \\
\text { (May 1977) }\end{array}$ & Time & $\begin{array}{l}\text { Depth From } \\
\text { Drill Floor } \\
(\mathrm{m})\end{array}$ & $\begin{array}{l}\text { Depth Below } \\
\text { Sea Floor } \\
\text { (m) }\end{array}$ & $\begin{array}{l}\text { Length } \\
\text { Cored } \\
\text { (m) }\end{array}$ & $\begin{array}{l}\text { Length } \\
\text { Recovered } \\
\text { (m) }\end{array}$ & $\begin{array}{c}\text { Recovery } \\
(\%)\end{array}$ \\
\hline \multicolumn{8}{|l|}{ Hole 420} \\
\hline $\begin{array}{l}1 \\
2 \\
3 \\
4 \\
5\end{array}$ & $\begin{array}{l}10 \\
10 \\
10 \\
10 \\
10\end{array}$ & $\begin{array}{l}0843 \\
0943 \\
1043 \\
1304 \\
1401\end{array}$ & $\begin{array}{l}3404.0-3408.5 \\
3408.5-3418.0 \\
3418.0-3427.5 \\
3427.5-3437.0 \\
3437.0-3446.5\end{array}$ & $\begin{array}{r}0.0-4.5 \\
4.5-14.0 \\
14.0-23.5 \\
23.5-33.0 \\
33.0-42.5\end{array}$ & $\begin{array}{l}4.5 \\
9.5 \\
9.5 \\
9.5 \\
9.5\end{array}$ & $\begin{array}{l}4.50 \\
6.38 \\
6.62 \\
8.29 \\
6.48\end{array}$ & $\begin{array}{r}100 \\
66 \\
70 \\
87 \\
68\end{array}$ \\
\hline $\begin{array}{r}6 \\
7 \\
8 \\
9 \\
10\end{array}$ & $\begin{array}{l}10 \\
10 \\
10 \\
10 \\
10\end{array}$ & $\begin{array}{l}1459 \\
1558 \\
1657 \\
1923 \\
2024\end{array}$ & $\begin{array}{l}3446.5-3456.0 \\
3456.0-3465.5 \\
3465.5-3475.0 \\
3475.0-3484.5 \\
3484.5-3494.0\end{array}$ & $\begin{array}{l}42.5-52.0 \\
52.0-61.5 \\
61.5-71.0 \\
71.0-80.5 \\
80.5-90.0\end{array}$ & $\begin{array}{l}9.5 \\
9.5 \\
9.5 \\
9.5 \\
9.5\end{array}$ & $\begin{array}{l}5.60 \\
9.27 \\
7.96 \\
8.15 \\
9.00\end{array}$ & $\begin{array}{l}59 \\
98 \\
84 \\
86 \\
95\end{array}$ \\
\hline $\begin{array}{l}11 \\
12 \\
13 \\
14 \\
15\end{array}$ & $\begin{array}{l}10 \\
10 \\
11 \\
11 \\
11\end{array}$ & $\begin{array}{l}2123 \\
2350 \\
0120 \\
0315 \\
0615\end{array}$ & $\begin{array}{l}3494.0-3503.5 \\
3503.5-3513.0 \\
3513.0-3522.5 \\
3522.5-3532.0 \\
3532.0-3541.5\end{array}$ & $\begin{array}{r}90.0-99.5 \\
99.5-109.0 \\
109.0-118.5 \\
118.5-128.0 \\
128.0-137.5\end{array}$ & $\begin{array}{l}9.5 \\
9.5 \\
9.5 \\
9.5 \\
9.5\end{array}$ & $\begin{array}{l}3.90 \\
9.55 \\
8.15 \\
0.45 \\
0.50\end{array}$ & $\begin{array}{r}41 \\
100 \\
86 \\
5 \\
5\end{array}$ \\
\hline $\begin{array}{l}16 \\
17\end{array}$ & $\begin{array}{l}11 \\
11\end{array}$ & $\begin{array}{l}1000 \\
1718\end{array}$ & $\begin{array}{l}3541.5-3545.5 \\
3545.5-3551.0\end{array}$ & $\begin{array}{l}137.5-141.5 \\
141.5-147.0\end{array}$ & $\begin{array}{l}4.0 \\
5.5 \\
\end{array}$ & $\begin{array}{l}0.06 \\
0.21 \\
\end{array}$ & $\begin{array}{l}1 \\
2 \\
\end{array}$ \\
\hline Total & & & & & 147.0 & 95.07 & 65 \\
\hline \multicolumn{8}{|c|}{ Hole 420A } \\
\hline $\begin{array}{c}1 \\
\text { Washed }\end{array}$ & 11 & 2309 & $\begin{array}{l}3412.0-3418.0 \\
3418.0-3475.0\end{array}$ & $\begin{array}{l}0.0-6.0 \\
6.0-63.0\end{array}$ & $\begin{array}{l}6.0 \\
- \\
\end{array}$ & $\begin{array}{l}6.05 \\
- \\
\end{array}$ & $\begin{array}{c}100 \\
- \\
\end{array}$ \\
\hline Total & & & & & 6.0 & 6.05 & 100 \\
\hline
\end{tabular}

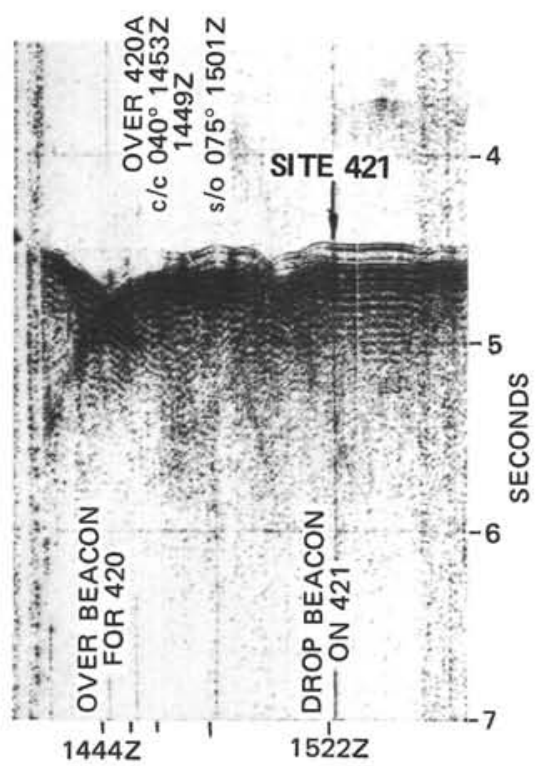

Figure 10. Glomar Challenger underway profile prior to beacon drop at Site 421 .

ciency. At 1045 the hole was abandoned after only 4 hours and 14 minutes of actual rotation. A total of 163 $\mathrm{cm}$ of basalt was recovered. Upon retrieving the drill string it was found that the rollers on the bit were still intact, but the stabilizer pads had been destroyed and the bit was about 0.125 in. out of gauge.

\section{Hole 422}

With a developing model of the mechanical state of basement, a revised drilling strategy, and a reduction in the sediment spud-in minimum from 80 to 40 meters, we proceeded north and then east-southeast along Site Survey Profile EE' (Figure 11) to a target in OCP Moat (Figures 12 and 13). At 014814 May, we dropped a beacon and began positioning the ship to maximize sediment thickness. Because the beacon was dropped relatively close the the eastern lip of the moat, a 3000 -foot offset in a westerly direction was used. Due to the predicted thinness of the sediments, the top bumper sub on the bottom-hole assembly was eliminated for this and most of the remaining holes.

We began running in pipe at 0500 and began continuous sediment coring at 1130 (Table 4). Basement was encountered at the top of Core 7 at a depth of 46 meters below the sea floor. Unlike our previous efforts at basalt drilling, basement drilling at Hole 422 began smoothly and remained that way for the next 15 meters of penetration. A total of 9.3 meters of massive basalt was recovered, of which 1.8 meters was found at the 46-meter level and separated from the remainder by a 3.5-4.0-meter-thick sediment unit. Near the base of the hole we encountered very difficult drilling conditions, including excessive binding, sticking, and torquing. These conditions were exactly like those encountered at Sites 420 and 421 and, again, could not be alleviated by spotting mud. At a sub-bottom depth of about $69.5 \mathrm{me}-$ ters, we lost water circulation and concluded that the bit 
TABLE 3

Coring Summary, Hole 421

\begin{tabular}{|c|c|c|c|c|c|c|c|}
\hline Core & $\begin{array}{c}\text { Date } \\
\text { (May 1977) }\end{array}$ & Time & $\begin{array}{l}\text { Depth From } \\
\text { Drill Floor } \\
(\mathrm{m})\end{array}$ & $\begin{array}{l}\text { Depth Below } \\
\text { Sea Floor } \\
\text { (m) }\end{array}$ & $\begin{array}{l}\text { Length } \\
\text { Cored } \\
\text { (m) }\end{array}$ & $\begin{array}{l}\text { Length } \\
\text { Recovered } \\
(\mathrm{m})\end{array}$ & $\begin{array}{c}\text { Recovery } \\
(\%)\end{array}$ \\
\hline 1 & 12 & 2316 & $3342.0-3351.5$ & $0.0-9.5$ & 9.5 & 9.48 & 100 \\
\hline Washed & & & $3351.5-3427.5$ & $9.5-85.5$ & - & - & - \\
\hline 2 & 13 & 0211 & $3427.5-3437.0$ & $85.5-95.0$ & 9.5 & 0.18 & 2 \\
\hline 3 & 13 & 0428 & $3437.0-3446.5$ & $95.0-104.5$ & 9.5 & 1.15 & 12 \\
\hline 4 & 13 & 0750 & $3446.5-3456.5$ & $104.5-114.0$ & 9.5 & 0.41 & 4 \\
\hline Total & & & & & 38.0 & 11.22 & 30 \\
\hline
\end{tabular}

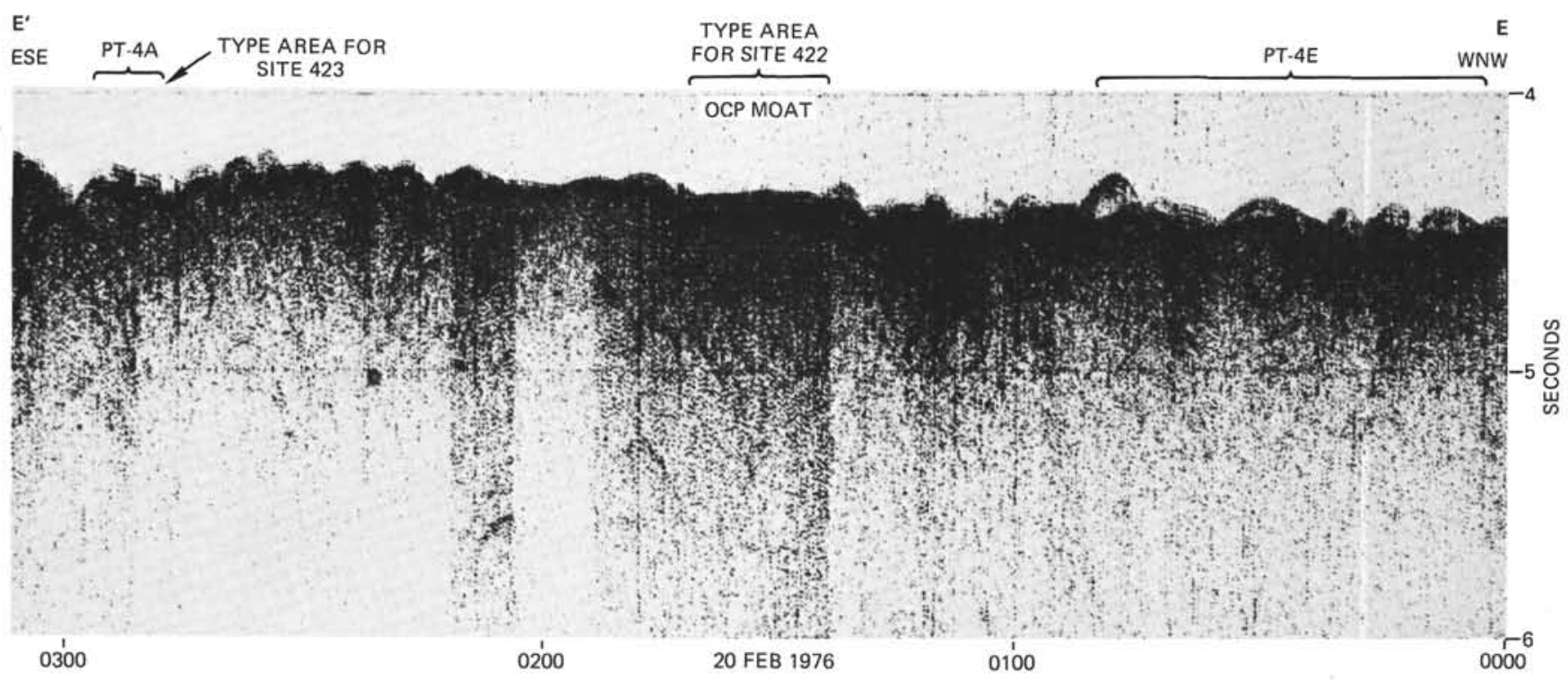

Figure 11. Site survey profile EE' over the vicinity of Sites 422 and 423.

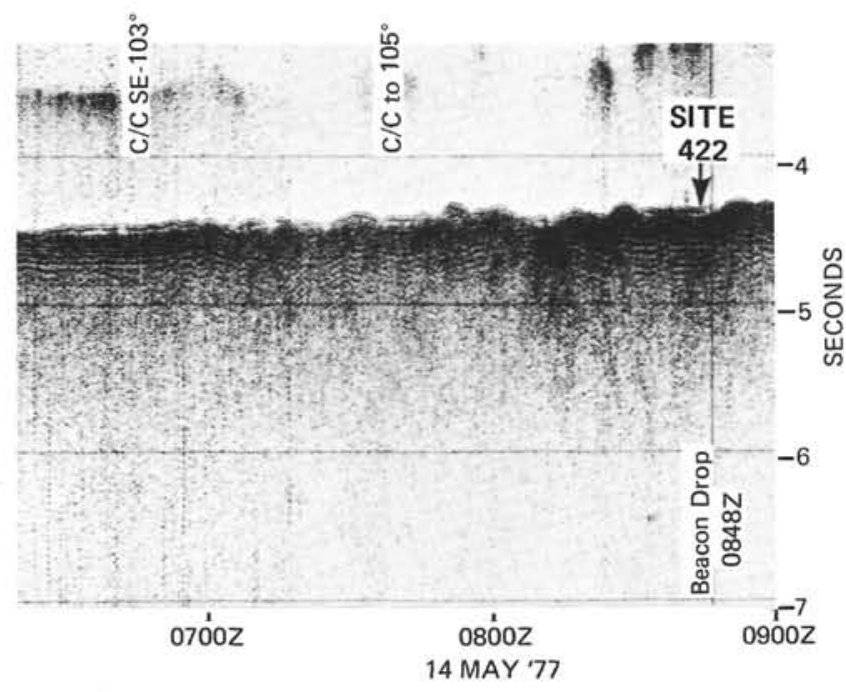

Figure 12. Glomar Challenger underway profile prior to beacon drop at Site 422. was plugged. Core 10 was retrieved and found to contain fractured, rubbly basalt in the core catcher. In order to clear the drill bit, a center bit was dropped, but upon retrieval it showed evidence of the bit being worn. We suspected that the bearings had failed and that the core guides were bent inward, not allowing a full gauge to be cut. In view of the above suspicion and circulation still not restored, the hole was abandoned at 080015 May.

Upon retrieval of the drill stem, we found that the bearings and core guides were, in fact, intact. However, three water jets were plugged with basalt chips and the cones apparently had been squeezed inward toward the center of the bit. The stabilizer pads also were about half worn away. In spite of these problems, the bit was in better shape than at any of the previous basement holes and there was some speculation that drilling could have continued for a few more hours.

It should be noted that the rationale for drilling Hole 422 was proven correct in every detail but one - the mechanical state of the fabric basalts. We had hoped to find that the fabric here was cemented by more recent flows, originating perhaps from the OCP Ridge. However, such proved not to be the case. 


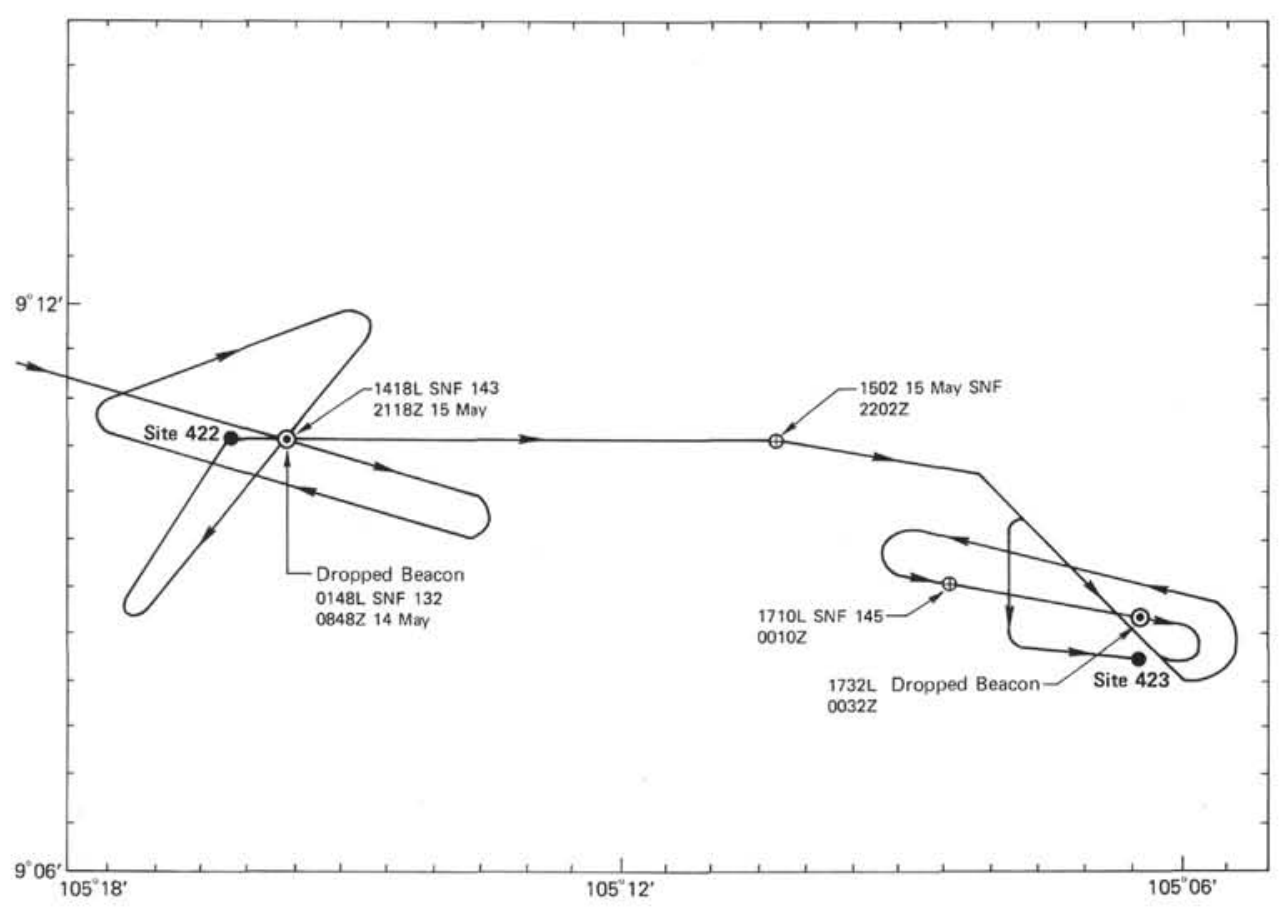

Figure 13. Glomar Challenger operations near Sites 422 and 423. Satellite navigation fixes (SNF) are circles with crosses. Times given are local $(L)$ and Greenwich (Z) time.

TABLE 4

Coring Summary, Hole 422

\begin{tabular}{|c|c|c|c|c|c|c|c|}
\hline Core & $\begin{array}{c}\text { Date } \\
\text { (May 1977) }\end{array}$ & Time & $\begin{array}{l}\text { Depth From } \\
\text { Drill Floor } \\
\text { (m) }\end{array}$ & $\begin{array}{l}\text { Depth Below } \\
\text { Sea Floor } \\
\text { (m) }\end{array}$ & $\begin{array}{l}\text { Length } \\
\text { Cored } \\
\text { (m) }\end{array}$ & $\begin{array}{l}\text { Length } \\
\text { Recovered } \\
\text { (m) }\end{array}$ & $\begin{array}{c}\text { Recovery } \\
(\%)\end{array}$ \\
\hline 1 & 14 & 1207 & $3254.5-3261.0$ & $0.0-6.5$ & 6.5 & 6.62 & 100 \\
\hline 2 & 14 & 1305 & $3261.0-3270.5$ & $6.5-16.0$ & 9.5 & 0.70 & 7 \\
\hline 3 & 14 & 1411 & $3270.5-3280.0$ & $16.0-25.5$ & 9.5 & 9.12 & 96 \\
\hline 4 & 14 & 1518 & $3280.0-3289.5$ & $25.5-35.0$ & 9.5 & 9.40 & 99 \\
\hline 5 & 14 & 1620 & $3289.5-3299.0$ & $35.0-44.5$ & 9.5 & 9.08 & 96 \\
\hline 6 & 14 & 1723 & $3299.0-3300.5$ & $44.5-46.0$ & 1.5 & 0.15 & 10 \\
\hline 7 & 14 & 2043 & $3300.5-3303.5$ & $46.0-49.0$ & 3.0 & 1.48 & 49 \\
\hline 8 & 14 & 2305 & $3303.5-3308.5$ & $49.0-54.0$ & 5.0 & 4.72 & 94 \\
\hline 9 & 15 & 0237 & $3308.5-3318.0$ & $54.0-63.5$ & 9.5 & 5.53 & 58 \\
\hline 10 & 15 & 0550 & $3318.0-3327.5$ & $63.5-73.0$ & 9.5 & 0.17 & 2 \\
\hline Total & & & & & 73.0 & 46.97 & 64 \\
\hline
\end{tabular}

\section{Hole 423}

Leaving Hole 422, we continued east-southwest along Site Survey Profile EE' in order to drill a hole at PT-4A (Figure 11). However, due to an error in navigation, we actually followed Profile MM' $^{\prime}$ (Figure 14) across the PT-4A site, and after another pass dropped a beacon at 173215 May (Figure 15). Because we no longer had to be concerned with the 80 -meter sediment-thickness limit, we decided not to expend ship time searching for a thicker part of the PT-4A sediment pond, but rather to offset 675 meters from the beacon along an azimuth of $279^{\circ}$ to a site where the predicted sediment thickness was about 40 meters.
The top two bumper subs were not placed in the bottom-hole assembly, and we began running in pipe at 1930. Continuous sediment coring began at 005516 May, and basement was encountered near the middle of Core 5 at a sub-bottom depth of about 38 meters (Table 5). Again, drilling conditions in the basalt were very bad and identical to those encountered at the previous sites. After penetrating only 15.5 meters into basement and recovering only $65 \mathrm{~cm}$ of basalt in about seven hours of rotation, Hole 423 was terminated at 141516 May. The reason for this decision was lack of progress during the last few hours of drilling, combined with very high torque levels. In our opinion, the hole did not merit further risk of losing the bottom-hole assembly, which the drillers 


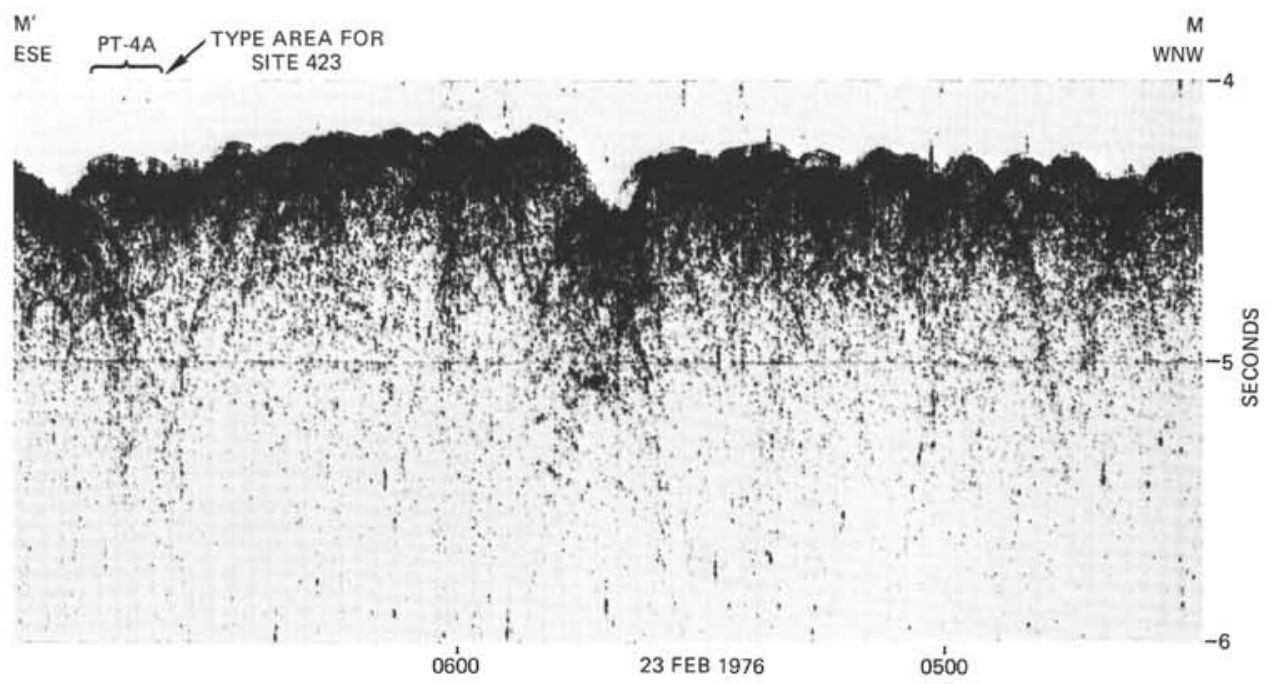

Figure 14. Site survey profile $M-M^{\prime}$ in the vicinity of Site 423.

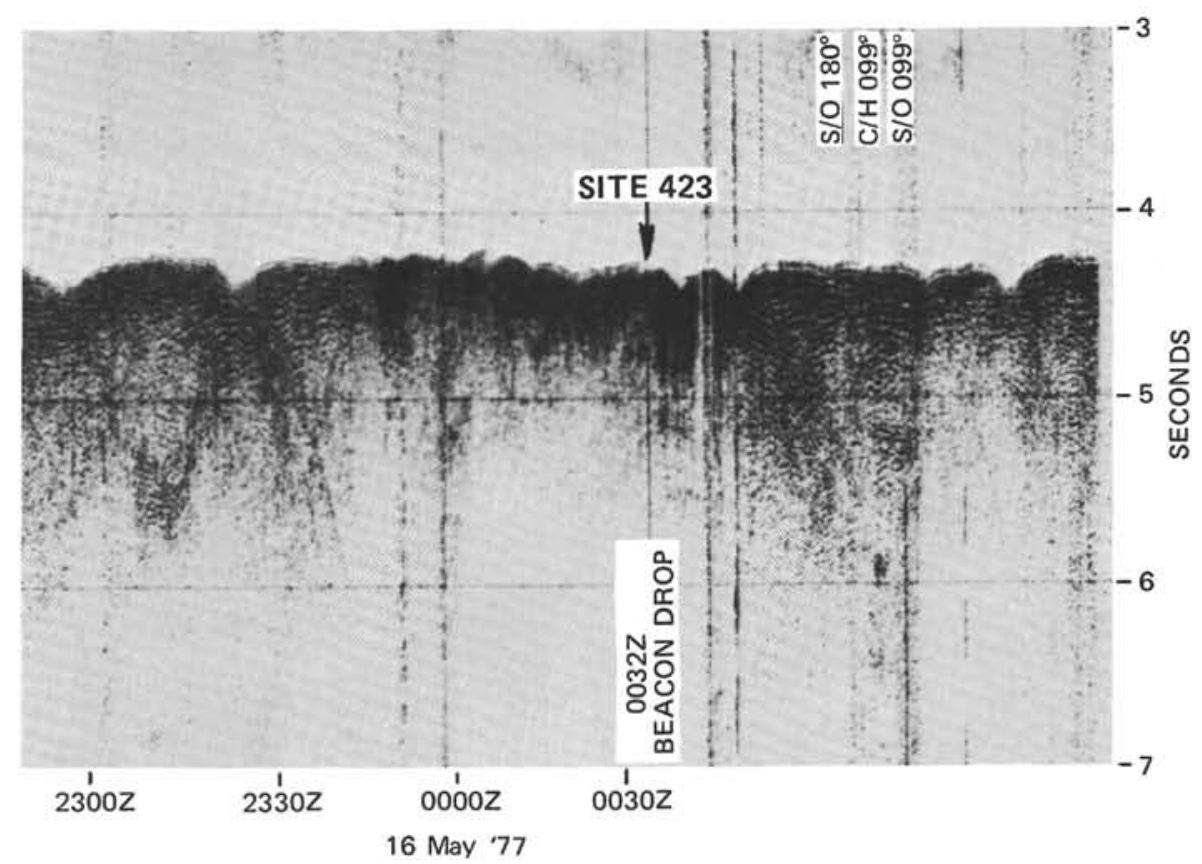

Figure 15. Glomar Challenger underway profile prior to beacon drop at Site 423.

TABLE 5

Coring Summary, Hole 423

\begin{tabular}{|c|c|c|c|c|c|c|c|}
\hline Core & $\begin{array}{c}\text { Date } \\
\text { (May 1977) }\end{array}$ & Time & $\begin{array}{l}\text { Depth From } \\
\text { Drill Floor } \\
\text { (m) }\end{array}$ & $\begin{array}{l}\text { Depth Below } \\
\text { Sea Floor } \\
(\mathrm{m})\end{array}$ & $\begin{array}{l}\text { Length } \\
\text { Cored } \\
(\mathrm{m})\end{array}$ & $\begin{array}{c}\text { Length } \\
\text { Recovered } \\
\text { (m) }\end{array}$ & $\begin{array}{c}\text { Recovery } \\
(\%)\end{array}$ \\
\hline 1 & 16 & 0128 & $3177.5-3181.5$ & $0.0-4.0$ & 4.0 & 3.78 & 95 \\
\hline 2 & 16 & 0225 & $3181.5-3191.0$ & $4.0-13.5$ & 9.5 & 4.93 & 52 \\
\hline 3 & 16 & 0324 & $3191.0-3200.5$ & $13.5-23.0$ & 9.5 & 7.18 & 76 \\
\hline 4 & 16 & 0416 & $3200.5-3210.0$ & $23.0-32.5$ & 9.5 & 5.19 & 55 \\
\hline 5 & 16 & 0528 & $3210.0-3219.5$ & $32.5-42.0$ & 9.5 & 6.03 & 63 \\
\hline 6 & 16 & 0905 & $3219.5-3224.0$ & $42.0-46.5$ & 4.5 & 0.22 & 5 \\
\hline 7 & 16 & 1205 & $3224.0-3229.0$ & $46.5-51.5$ & 5.0 & 0.38 & 8 \\
\hline 8 & 16 & 1455 & $3229.0-3231.0$ & $51.5-53.5$ & 2.0 & 0.27 & 14 \\
\hline Total & & & & & 53.5 & 27.98 & 52 \\
\hline
\end{tabular}


felt was likely if drilling continued. Upon retrieval of the drill stem, it was found that the juncture between the bit and the bit sub was completely obliterated and that instead of turning inward, which would be the normal situation for a worn bit, the rollers were turned outward.

\section{Site 426}

Upon returning to the PT-4 survey area from the Galapagos Spreading Center, we decided to attempt to drill a hole on the axial block of the East Pacific Rise, provided that 10 meters of sediment was available for spudin. We knew beforehand that successful spud-in was a long shot, and for this reason alloted only 24 hours to the attempt. However, we were fairly certain by this time that the axial block was the only place in the PT- 4 area where deep penetration was feasible. In our minds this goal justified the attempt, long shot or not.

After obtaining an east-to-west reflection profile across the axial block, we returned to a position on the western edge of the block where sediments were thought to be present. A $13.5-\mathrm{kHz}$ beacon was dropped at 19542 June. Due to its low signal strength, a $16.0-\mathrm{kHz}$ beacon was deployed 54 minutes later and used for subsequent positioning. The drill string was made up with the short bottom-hole assembly used at Sites 423 and 424 and lowered to within "stabbing" distance of the bottom. Lacking a $3.5-\mathrm{kHz}$ profiler aboard the Challenger, it was our intent to use the drill string and mud-line cores for locating an appropriate spud-in target. Three separate attempts (at the beacon, $700 \mathrm{ft}$. west, $2290 \mathrm{ft}$. west) failed to produce such a target and the site was abandoned at 07003 June.

\section{Site $\mathbf{4 2 7}$}

From previous work in the PT- 4 area, it was known that at least some of the troughs in the Siqueiros fracture zone are characterized by relatively flat-floored and reflective basement. We thought that these structures could represent intact downfaulted blocks into which flows had been ponded. We intended Site 427 to provide stratigraphic sampling in one of these troughs to determine if, in fact, ponding had occurred and whether the petrology and chemistry of the trough rocks were comparable with those of the fabric basalts erupted from the East Pacific Rise proper.

Our approach was planned to take us diagonally across a trough surveyed with the SIO deep-tow instrument (Crane, 1976), and then west along a semicontinuous trough near the southern edge of the Siqueiros fracture zone. The strategy was to deploy a beacon at the first trough locality showing at least 40 to 50 meters of sediments atop a flat and reflective basement (and away from the talus piles that border the adjacent fault scarps). Such a site was found in the deepest depression known to exist in the Siqueiros (Figure 16), and a beacon was dropped at 21483 June.

At 2242 , we began running in pipe, stopping at a depth about 150 meters above bottom, where we began "feeling" for the sea floor. This cautionary procedure was made necessary by the fact that the PDR was inop- erative prior to and during Site 427 operations, and we lacked complete faith in the depths provided by the EDO profiling recorders and the ship's fathometer. In fact, both instruments gave a depth that proved to be within 2 meters of spud-in depth. After alternately washing and coring through 146 meters of sediment (we cored those intervals in which prominent reflectors occurred), basement drilling commenced at about 1700 (Table 6). The first two basement cores were cut with only moderate difficulty in about $51 / 2$ hours of rotation, but while cutting the third basement core the pipe became stuck and required an hour of work to free it before drilling could continue. After spending almost three hours trying to get back to the base of the hole after retrieving the third basement core, we decided that the bit must be worn out and abandoned the hole at 08305 June. Upon retrieving the bit, we found that all the cones were gone and the stabilizer pads severely worn.

\section{Site $\mathbf{4 2 8}$}

This site was located just south of OCP Ridge (Figure 2 ) in a moat-like feature more or less equivalent to that in which Site 422 was placed. The purpose of this site was to provide additional petrologic, magnetic, and time control on the nature of the transition from normal East Pacific Rise fabric to the OCP Ridge. It was anticipated that Sites 422 and 428 , together, would provide new insight into the mechanism of volcanic overprinting at fast-spreading ridges.

The site approach was made from the north after completing a magnetic transect across the eastern end of the OCP Ridge. A beacon was dropped at 05186 June, on a 0.075 -s (two-way reflection time)-thick patch of sediments (Figure 17), and we began running in pipe at 0712. After taking a mud-line core, we washed down to 29 meters sub-bottom and then continuously cored down to basement, encountered at 61 meters below the sea floor (Table 7).

In trying to get back to the bottom of the hole (somewhere between a depth of 9 and 15 meters into basement - uncertainty is due to ship repositioning) after recovering the second core containing basalt, the pipe became stuck at 2202 . At 02057 June, we finally pulled loose after spotting 75 barrels of mud and 20 barrels of gel (a pumping system had been fabricated during transit to various sites) and pulling up to $525,000 \mathrm{lb}$. Hole 428 was abandoned at this time with only 2.5 hours of rotation recorded on the bit and 2.14 meters of basalt recovered. Moving 500 feet due north of the beacon, we again spudded into the bottom (at 0330) and washed 62.5 meters down to basement. Hole $428 \mathrm{~A}$ was drilled a total of 52.5 meters into basement and had to be abandoned at $06308 \mathrm{June}$, only because the bit was worn out. A total of 17.3 hours of rotation was recorded at Hole 428A, and 12.60 meters of basalt was recovered. Compared with all other holes in the Pt-4 area, the drilling here went relatively smoothly and most of the recovered material consisted of oriented cut pieces of core very similar to the doleritic material recovered at Site 422 . Unlike the latter site, we did not bottom out in 


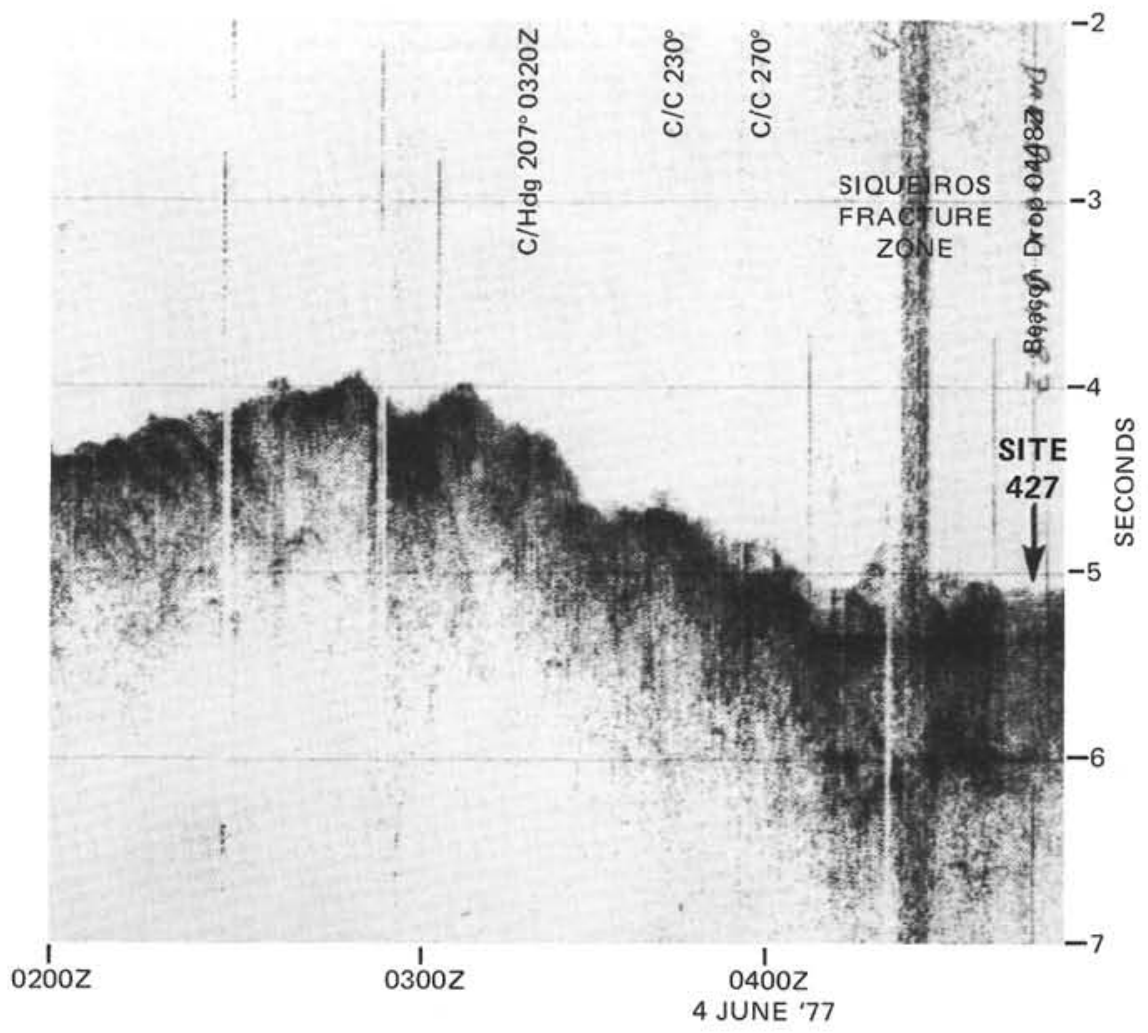

Figure 16. Glomar Challenger underway profile prior to beacon drop at Site 427.

TABLE 6

Coring Summary, Hole 427

\begin{tabular}{|c|c|c|c|c|c|c|c|}
\hline Core & $\begin{array}{c}\text { Date } \\
\text { (June 1977) }\end{array}$ & Time & $\begin{array}{l}\text { Depth From } \\
\text { Drill Floor } \\
(\mathrm{m})\end{array}$ & $\begin{array}{l}\text { Depth Below } \\
\text { Sea Floor } \\
\text { (m) }\end{array}$ & $\begin{array}{l}\text { Length } \\
\text { Cored } \\
\text { (m) }\end{array}$ & $\begin{array}{l}\text { Length } \\
\text { Recovered } \\
\text { (m) }\end{array}$ & $\begin{array}{c}\text { Recovery } \\
(\%)\end{array}$ \\
\hline 1 & 4 & 0655 & $3848.0-3851.5$ & $0.0-3.5$ & 3.5 & 3.30 & 94 \\
\hline 2 & 4 & 0758 & $3851.5-3861.0$ & $3.5-13.0$ & 9.5 & 8.70 & 92 \\
\hline 3 & 4 & 0915 & $3861.0-3870.5$ & $13.0-22.5$ & 9.5 & 4.91 & 52 \\
\hline Washed & & & & & & & \\
\hline $\begin{array}{c}4 \\
\text { Washed }\end{array}$ & 4 & 1015 & $3880.0-3889.5$ & $32.0-41.5$ & 9.5 & 5.97 & 63 \\
\hline 5 & 4 & 1118 & $3899.0-3808.5$ & $51.0-60.5$ & 9.5 & 0.04 & 0 \\
\hline $\begin{array}{c}6 \\
\text { Washed }\end{array}$ & 4 & 1230 & $3908.5-3918.0$ & $60.5-70.0$ & 9.5 & 7.26 & 76 \\
\hline Washed & & & & & & & \\
\hline $\begin{array}{c}7 \\
\text { Washed }\end{array}$ & 4 & 1345 & $3937.0-3946.5$ & $89.0-98.5$ & 9.5 & 5.62 & 59 \\
\hline Washed & & & & & & & \\
\hline $\begin{array}{c}8 \\
\text { Washed }\end{array}$ & 4 & 1514 & $3965.5-3975.0$ & $117.5-127.0$ & 9.5 & 8.95 & 94 \\
\hline 9 & 4 & 1948 & $3994.0-4003.5$ & $146.0-155.5$ & 9.5 & 5.91 & 62 \\
\hline 10 & 4 & 2310 & $4003.5-4013.0$ & $155.5-165.0$ & 9.5 & 6.15 & 65 \\
\hline 11 & 5 & 0830 & $4013.0-4022.5$ & $165.0-174.5$ & 9.5 & 0.45 & 5 \\
\hline Total & & & & & 98.5 & 57.26 & 58 \\
\hline
\end{tabular}

fabric basalts; however, there is every reason to believe that normal fabric rocks underlie the dolerite at some unknown depth.

\section{Site 429}

With something between 21 and 39 hours of operating time remaining to Leg 54 after completion of Site
428 , we opted to drill a hole further west (Figure 2) on a well-defined magnetic anomaly. Our strategy was to steam due west of Hole 428A and drop a beacon at the first site older than about $4.0 \mathrm{~m}$.y. that fulfilled both the magnetic and sediment requirements. The beacon was dropped at 00349 June, near the center of the unnamed negative anomaly immediately west of the Nunivak Pos- 


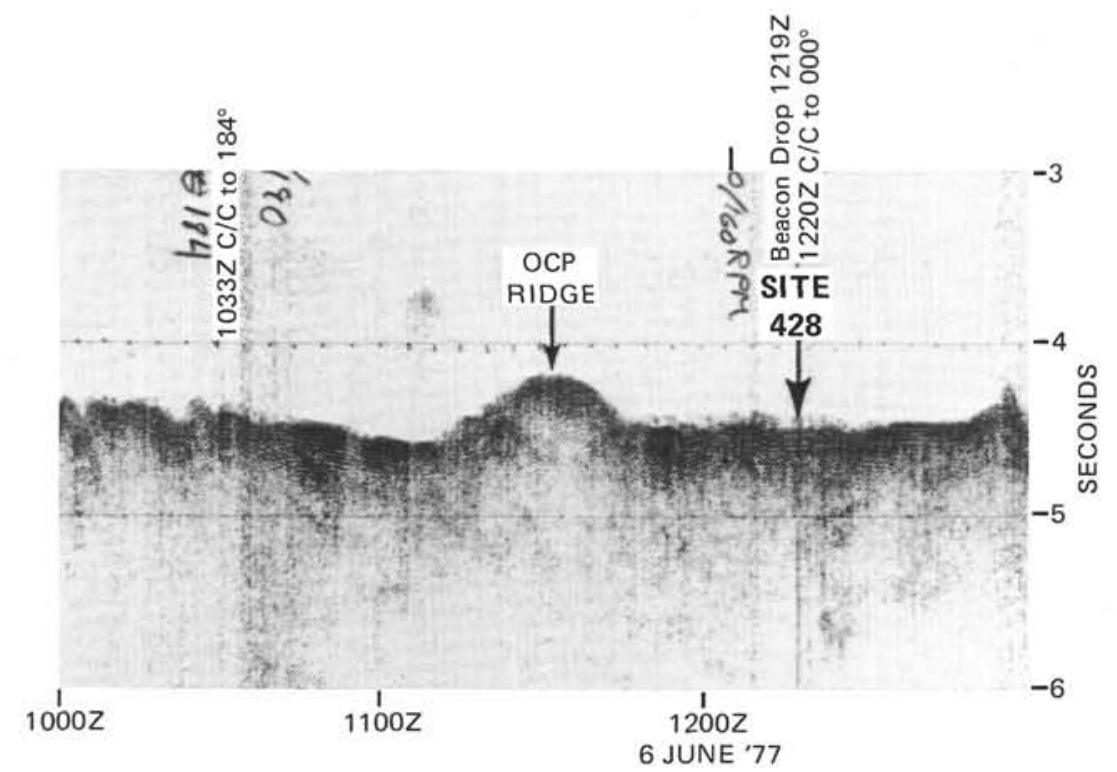

Figure 17. Glomar Challenger underway profile prior to beacon drop at Site 428 .

TABLE 7

Coring Summary, Site 428

\begin{tabular}{|c|c|c|c|c|c|c|c|}
\hline Core & $\begin{array}{c}\text { Date } \\
\text { (June 1977) }\end{array}$ & Time & $\begin{array}{l}\text { Depth From } \\
\text { Drill Floor } \\
\text { (m) }\end{array}$ & $\begin{array}{l}\text { Depth Below } \\
\text { Sea Floor } \\
\text { (m) }\end{array}$ & $\begin{array}{l}\text { Length } \\
\text { Cored } \\
\text { (m) }\end{array}$ & $\begin{array}{c}\text { Length } \\
\text { Recovered } \\
\text { (m) }\end{array}$ & $\begin{array}{c}\text { Recovery } \\
(\%)\end{array}$ \\
\hline \multicolumn{8}{|l|}{ Hole 428} \\
\hline $\begin{array}{c}1 \\
\text { Washed }\end{array}$ & 6 & 1252 & $\begin{array}{l}3301.0-3308.0 \\
3308.0-3330.0\end{array}$ & $\begin{array}{l}0.0-7.0 \\
7.0-29.0\end{array}$ & 7.0 & 6.80 & $\begin{array}{l}97 \\
-\end{array}$ \\
\hline 2 & 6 & 1420 & $3330.0-3339.5$ & $29.0-38.5$ & 9.5 & 5.50 & 58 \\
\hline 3 & 6 & 1525 & $3339.5-3349.0$ & $38.5-48.0$ & 9.5 & 7.26 & 76 \\
\hline 4 & 6 & 1625 & $3349.0-3358.5$ & $48.0-57.5$ & 9.5 & 9.38 & 99 \\
\hline 5 & 6 & 1902 & $3358.5-3368.0$ & $57.5-67.0$ & 9.5 & 5.26 & 55 \\
\hline 6 & 6 & 2142 & $3368.0-3377.5$ & $67.0-76.5$ & 9.5 & 2.14 & 23 \\
\hline Total & & & & & 54.5 & 36.34 & 67 \\
\hline \multicolumn{8}{|c|}{ Hole 428A } \\
\hline Washed & 7 & & $3246.0-3358.5$ & $0.0-62.5$ & - & - & - \\
\hline 1 & 7 & 0700 & $3358.5-3368.0$ & $62.5-72.0$ & 9.5 & 3.77 & 40 \\
\hline 2 & 7 & 1040 & $3368.0-3377.5$ & $72.0-81.5$ & 9.5 & 0.72 & 8 \\
\hline 3 & 7 & 1355 & $3377.5-3382.5$ & $81.5-86.5$ & 5.0 & 1.25 & 25 \\
\hline 4 & 7 & 1718 & $3382.5-3387.0$ & $86.5-91.0$ & 4.5 & 2.84 & 63 \\
\hline 5 & 7 & 2137 & $3387.0-3396.5$ & $91.0-100.5$ & 9.5 & 4.08 & 43 \\
\hline 6 & 8 & 0330 & $3396.5-3406.0$ & $100.5-110.0$ & 9.5 & 0.97 & 10 \\
\hline 7 & 8 & 0617 & $3406.0-3411.0$ & $110.0-115.0$ & 5.0 & 2.74 & 55 \\
\hline Total & & & & & 52.5 & 16.37 & 31 \\
\hline
\end{tabular}

itive Event in the Gilbert negative epoch in an area with about 0.05 to $0.06 \mathrm{~s}$ (two-way reflection time) of sediment.

After moving 2990 feet west of the beacon, which placed us virtually at the center of the negative anomaly, we began running in pipe at 0136 . A mud-line core then was taken and the hole was washed down to basement, encountered at 26 meters below the sea floor. Feeling somewhat uneasy about this thin sediment cover and not wishing to push our luck too far, we abandoned Hole 429 and moved back to the beacon position. We again washed down to basement, encountered at a subbottom depth of about 31 meters, and began basement drilling (Table 8). After penetrating 21.5 meters of basalt in three hours of rotation, Hole 429A was abandoned at 19169 June, due to moderately poor drilling 
TABLE 8

Coring Summary, Site 429

\begin{tabular}{|c|c|c|c|c|c|c|c|}
\hline Core & $\begin{array}{c}\text { Date } \\
\text { (June 1977) }\end{array}$ & Time & $\begin{array}{l}\text { Depth From } \\
\text { Drill Floor } \\
(\mathrm{m})\end{array}$ & $\begin{array}{l}\text { Depth Below } \\
\text { Sea Floor } \\
\text { (m) }\end{array}$ & $\begin{array}{l}\text { Length } \\
\text { Cored } \\
\text { (m) }\end{array}$ & $\begin{array}{c}\text { Length } \\
\text { Recovered } \\
\text { (m) }\end{array}$ & $\begin{array}{c}\text { Recovery } \\
(\%)\end{array}$ \\
\hline \multicolumn{8}{|c|}{ Hole 429} \\
\hline $\begin{array}{c}1 \\
\text { Washed }\end{array}$ & 9 & 0747 & $\begin{array}{l}3426.0-3431.0 \\
3431.0-3457.0\end{array}$ & $\begin{array}{l}0.0-5.0 \\
5.0-31.0\end{array}$ & $\begin{array}{l}5.0 \\
- \\
\end{array}$ & $\begin{array}{c}4.67 \\
- \\
\end{array}$ & $\begin{array}{c}93 \\
- \\
\end{array}$ \\
\hline Total & & & & & 5.0 & 4.67 & 93 \\
\hline \multicolumn{8}{|c|}{ Hole 429A } \\
\hline $\begin{array}{r}\text { Washed } \\
1 \\
2 \\
3\end{array}$ & $\begin{array}{l}9 \\
9 \\
9\end{array}$ & $\begin{array}{l}1235 \\
1515 \\
1916\end{array}$ & $\begin{array}{l}3426.0-3457.0 \\
3457.0-3462.5 \\
3462.5-3472.0 \\
3472.0-3478.5\end{array}$ & $\begin{array}{r}0.0-31.0 \\
31.0-36.5 \\
36.5-46.0 \\
46.0-52.5\end{array}$ & $\begin{array}{l}- \\
5.5 \\
9.5 \\
6.5 \\
\end{array}$ & $\begin{array}{l}- \\
0.59 \\
1.21 \\
1.15 \\
\end{array}$ & $\begin{array}{l}- \\
11 \\
13 \\
18 \\
\end{array}$ \\
\hline Total & & & & & 21.5 & 2.95 & 14 \\
\hline
\end{tabular}

conditions and lack of time. A total of 2.95 meters of basalt was recovered, containing a sufficient number of oriented pieces to meet the paleomagnetic objectives.

\section{SEDIMENT LITHOLOGY}

Sediments were cored continuously in Holes 419, $420,422,423$, and 428 . Mud-line cores were taken additionally in Holes 419A, 420A, 421, and 429. Hole 427 was spot-cored, 70 meters out of a possible 146 meters. Sites 419, 420, 421, 423, and 429 were in small sediment ponds on typical East Pacific Rise crust; Site 427 was deep in the Siqueiros fracture zone; and Sites 422 and 428 were in westerly trending elongate sediment ponds in moat-like depressions next to the OCP Ridge (Figure 6). Water depths for the "fabric" sites increase sequentially from east to west as follows: Site 423, 3167 meters; Site 419, 3274 meters; Site 421, 3339 meters; Site 420, 3382 meters; and Site 429, 3406 meters. Basement ages estimated from magnetic anomalies increase from 1.6 m.y. at Site 423 to 4.6 m.y. at Site 429 (see following sections). The sites span distances from about $99 \mathrm{~km}$ to $264 \mathrm{~km}$ west of the rise crest.

Water depths at the two OCP Ridge sites are 3247 meters (Site 422) and 3295 meters (Site 428). At Site 427 in the Siqueiros fracture zone, the depth of water is 3834 meters, some 600 meters deeper than the adjacent, unfaulted ocean crust.

Sediments at all these locations are primarily biogenic, but wherever they were cored, they must represent somewhat anomalous accumulations in topographic depressions. Sediments appear to have accumulated in lows especially near topographic highs such as the OCP Ridge (Figure 6), but even where small sediment ponds occur well away from ridges, seamounts, and fault scarps, sediments must have been swept by currents from adjacent, low-relief, virtually bare, rock outcrops into these ponds. The thickest accumulations cored were at Sites $420(119 \mathrm{~m})$ and $427(146 \mathrm{~m})$.

The sediments consist of calcareous and siliceous microfossils (nannofossils, foraminifers, radiolarians, diatoms, silicoflagellates, opal phytoliths, and others), a variable clay fraction, minor volcanic glass, traces of pyrite, and trace or minor Fe-Mn oxides. As will be dis- cussed shortly, the clay fraction appears to be partly eolian and partly diagenetic in origin.

There are four predominant sediment types present in at least five and as many as seven sites. Their general distribution is indicated on Figure 18 and on Table 9. There are also seven minor sediment types, present at only one or two sites apiece, most of them as thin beds. The sediment types can be considered to belong to three major groupings with only one type, basaltic volcanic sand, not assignable to any of these groupings. The groupings - dominantly calcareous, moderately to dominantly siliceous, and moderately to dominantly clayrich - are indicated on Table 9. Brief descriptions of the sediment types follow, based on lithologic observations and smear slides and in the order listed in the table. Detailed descriptions are given on the barrel sheets at the end of this chapter.

\section{Dominantly Calcareous}

A. Major type - foraminifer-nannofossil ooze

Colors are various shades of pale brown, gray, and green, depending primarily on the abundance of hydrous iron oxides or pyrite. They include olive-brown $(2.5 \mathrm{Y} 4 / 4)$, grayish olive-green (5GY $3 / 2)$, dark gray (5Y 4/1), dusky yellow-green ( $5 \mathrm{GY} 5 / 2)$, greenish gray $(5 \mathrm{GY} 6 / 1)$, olive $(5 \mathrm{Y} 4 / 3)$, grayish green $(5 \mathrm{G} 6 / 1)$, light olive-brown (2.5Y 5/4), moderate olive-brown (5Y 4/4), light olive-gray (5Y 5/2), grayish olive (10Y 4/2), and others. This type consists of nannofossils (40-70\%), foraminifers $(10-30 \%)$, radiolarians (trace-10\%), and clays $(5-25 \%)$ with minor spicules, glass, and $\mathrm{Fe}-\mathrm{Mn}$ oxides or pyrite.

B. Major type - nannofossil ooze

Colors are dusky yellow-green (10Y 4/4), olivebrown (2.5Y 4/4), moderate olive-brown (5Y 4/4), greenish gray $(5 \mathrm{G} 6 / 1)$, dark greenish gray $(5 \mathrm{GY} 4 / 2)$, and grayish olive-green (5GY $3 / 2)$. This type consists of 65-85 per cent nannofossils, 5-20 per cent foraminifers, up to 5 per cent diatoms, $10-20$ per cent clays, and traces of pyrite, spicules, glass, and Fe-Mn oxides.

C. Minor type - nannofossil-foraminifer ooze

This type is moderate olive-brown (5Y 4/4) and occurs only in thin layers in Hole 422 (Sections 1-3, 120 $\mathrm{cm}$, and $1-4,80 \mathrm{~cm})$. It has about 50 per cent foramini- 
fers, 35 per cent nannofossils, and 10 per cent Fe-Mn oxides, with minor or trace radiolarians, diatoms, spicules, and brown glass. Foraminifer tests show strong signs of dissolution.

II. Moderately to dominantly siliceous

A. Major type - siliceous nannofossil ooze

This type is fairly abundant at Sites 420,427 , and 428 , but only forms thin beds at Sites 422 and 423 . Colors are dark greenish gray (5G 4/1), greenish gray (5G $2 / 1$ ), olive-gray (5Y $3 / 2)$, grayish green $(10 G Y 5 / 2)$, and grayish olive-green $(5 \mathrm{G} 3 / 2)$. Sediment components are 55-70 per cent nannofossils, 5-20 per cent radiolarians, trace-20 per cent diatoms, $5-10$ per cent foraminifers, about 10 per cent clays, and traces of spicules, glass, pyrite, and $\mathrm{Fe}$ oxides.

B. Minor type - radiolarian nannofossil ooze

This type occurs only at Hole 419 as two beds, both 1-2 meters thick, in Core 4 . It is grayish olivegreen (5GY 3/2) and dark greenish gray (5GY 4/1), consisting of 50-60 per cent diatoms, $20-35$ per cent nannofossils, trace- 5 per cent foraminifers, trace- 5 per cent clays, and trace- 10 per cent radiolarians. Most of the diatom tests are pyritized, which suggests a reducing environment.

C. Minor type - calcareous siliceous ooze

This type is found in Core 3 of Hole 427, is grayish olive-green (5GY 3/2) and dusky yellow-green (5GY $5 / 2$ ), and consists of about 20 per cent nannofossils, 10-15 per cent foraminifers, $20-25$ per cent clay, $15-20$ per cent radiolarians, $15-30$ per cent diatoms, 5 per cent spicules, and traces of silicoflagellates, brown glass, and pyrite. In addition, lamellae of Fe-Mn oxides are scattered throughout the core.

D. Minor type - pyritic diatom nannofossil ooze

This type is found in the core catcher of Core 5, and in two small intervals in Cores 7 and 9 of Hole 427. It is not found at the other sites. It is olive gray ( $5 \mathrm{Y} 3 / 2)$, grayish olive-black (5Y 2/1), consisting of 70-90 per cent diatoms, $10-20$ per cent nannofossils, up to 5 per cent foraminifers, 5 per cent clays, and traces of radiolarians, brown glass, and spicules. Many of the diatom tests are partially replaced by pyrite.

III. Moderately to dominantly rich in clay

A. Major type - calcareous clay

This sediment type is found as distinct beds ranging from a few centimeters to a meter thick, interbedded with calcareous and siliceous sediments toward the tops of almost all holes (Figure 18). Contacts are both sharp (Figure 19) and gradational, but usually highly contorted by drilling disturbance. The sediments are dark reddish brown (5YR 3/2), dark brown (10YR $3 / 3$ and 7.5YR 4/4), olive-brown (2.5Y 4/4), dark yellowish brown (10Y 4/4), moderately olive-brown (5Y 4/4), light olive-brown (5Y 5/6), and grayish-brown (5YR $3 / 2$ ). Smear slides have $35-60$ per cent clay, $15-25$ per cent foraminifers, $20-55$ per cent nannofossils, trace- 10 per cent radiolarians, and variable amounts of $\mathrm{Fe}$ or Fe-Mn oxides (trace-10\% at Sites 420 and 427, and $15-25 \%$ at Sites $420,421,422$, and 423 ). There are also traces of glass, spicules, and diatoms.
B. Minor type - marly foraminifer-nannofossil ooze This sediment type, though present in only two holes, is most abundant in Hole 428 and a major type at Site 427. It is intermediate in clay abundance between more or less pure siliceous or calcareous oozes on the one hand, and calcareous clay on the other. It is dusky green $(5 \mathrm{G} 3 / 2)$, dark greenish gray (5GY $4 / 2)$, grayish olive-green ( $5 \mathrm{GY} 3 / 2)$, moderate olive-brown (5Y 4/4), grayish green (10GY $5 / 2$ ), dusky yellow green (5GY $5 / 2)$, and grayish olive (10Y $4 / 2)$ in color. Its components are $40-75$ per cent nannofossils, $15-30$ per cent foraminifers, $15-30$ per cent clay, trace-5 per cent radiolarians, trace-10 per cent diatoms, and traces of $\mathrm{Fe}-\mathrm{Mn}$ oxides, spicules, and glass.

In addition to all these sediment types, there is a 15 -cm-thick layer of dark olive gray (5Y $3 / 2)$ volcanic sand in Section 5-3, of Hole 428 at 56-71 cm. It consists of brown glass $(70 \%)$, plagioclase $(20 \%)$, opaques $(10 \%)$, and traces of radiolarians.

It is difficult to be certain of the interrelationships between these sediment types and of the causes of pigmentation in many of them, because sediment disturbance caused by coring is extreme. Evidence for bioturbation has been all but obliterated, and only the starkest of bedding features have been preserved, mainly in the lower sections of deeper cores. At the present time, the important sedimentological problems of this region can only be approached tentatively on lithological grounds, although somewhat more firmly on chemical and mineralogic grounds. The two principal areas of speculation concern (1) the role of the calcite compensation depth (CCD) in influencing the cyclic pattern of sediment types in the upper cores of the sites (calcareous clays alternating with biogenic sediments), and (2) the role of rise-crest hydrothermal processes in adding clays and/or $\mathrm{Fe}-\mathrm{Mn}$ hydroxides to the sediments.

The first problem, of course, is not one that is restricted to the Siqueiros region but is possibly of regional importance throughout much of the eastern equatorial Pacific. The cyclic pattern of sedimentation has been observed before, most notably at other DSDP sites to the south and west. The scientific staff of Leg 9 (Hays et al., 1972, Cook, 1972), in fact, described a "cyclic member" in Pliocene-Pleistocene sediments of what has been termed the Clipperton Formation (Tracey, Sutton, et al., 1971) at several sites drilled between the central Pacific and the coast of Central America. This cyclic member has features virtually identical to those described here, consisting of alternating biogenic siliceous calcareous oozes and reddish brown clays. The Leg 9 scientific party came to no firm conclusions on the origin of these alternations. The distribution of sites having Pliocene-Pleistocene sediments with alternating lithologies is shown on Figure 20.

The Leg 54 sites provide a different perspective on these sediments than the Leg 9 sites. Rather than being located hundreds of kilometers apart, the Leg 54 sites are at most a few tens of kilometers apart. Instead of capping a widespread sediment blanket, the Leg 54 sites record sedimentation in small topographic depressions 


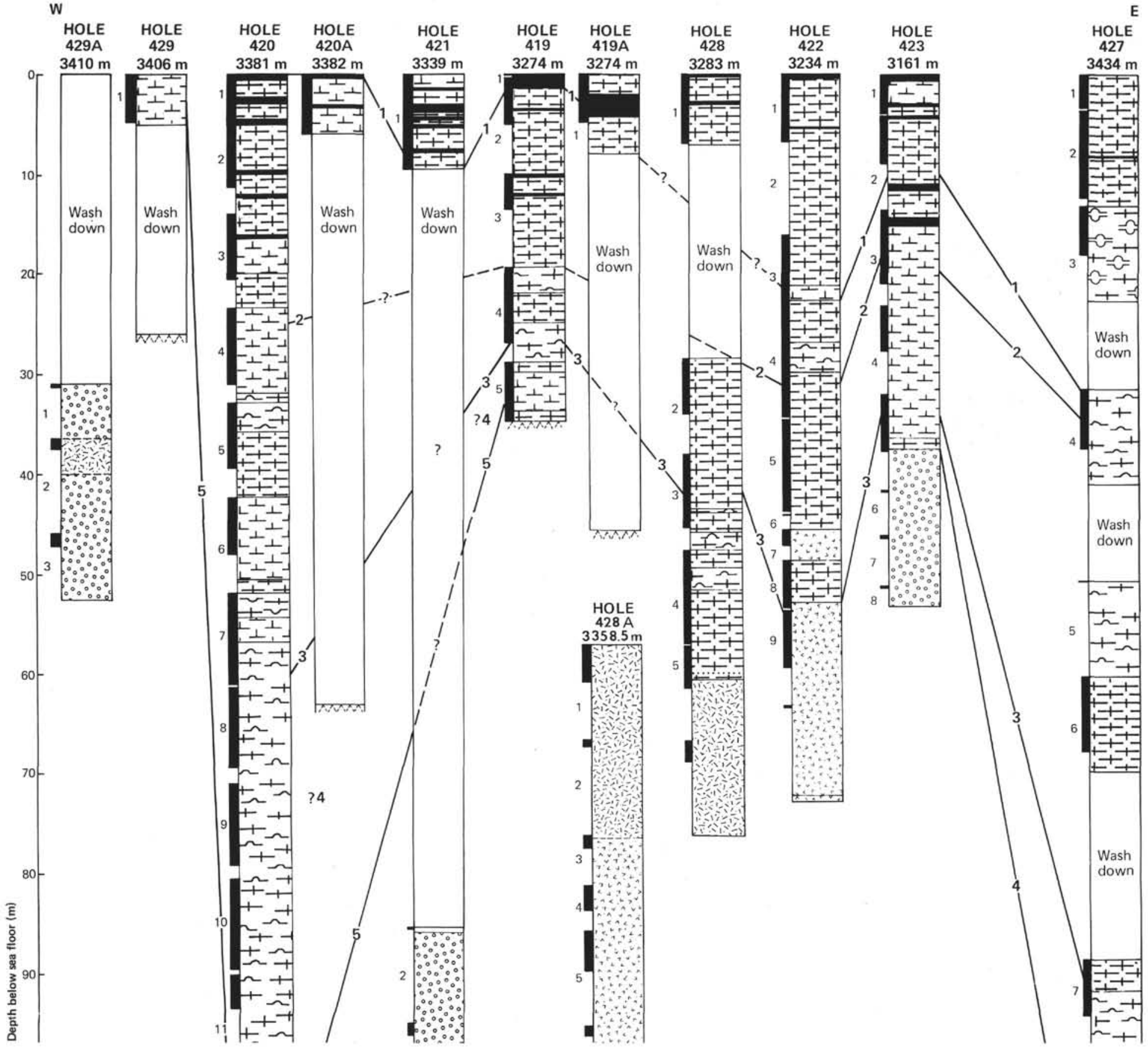




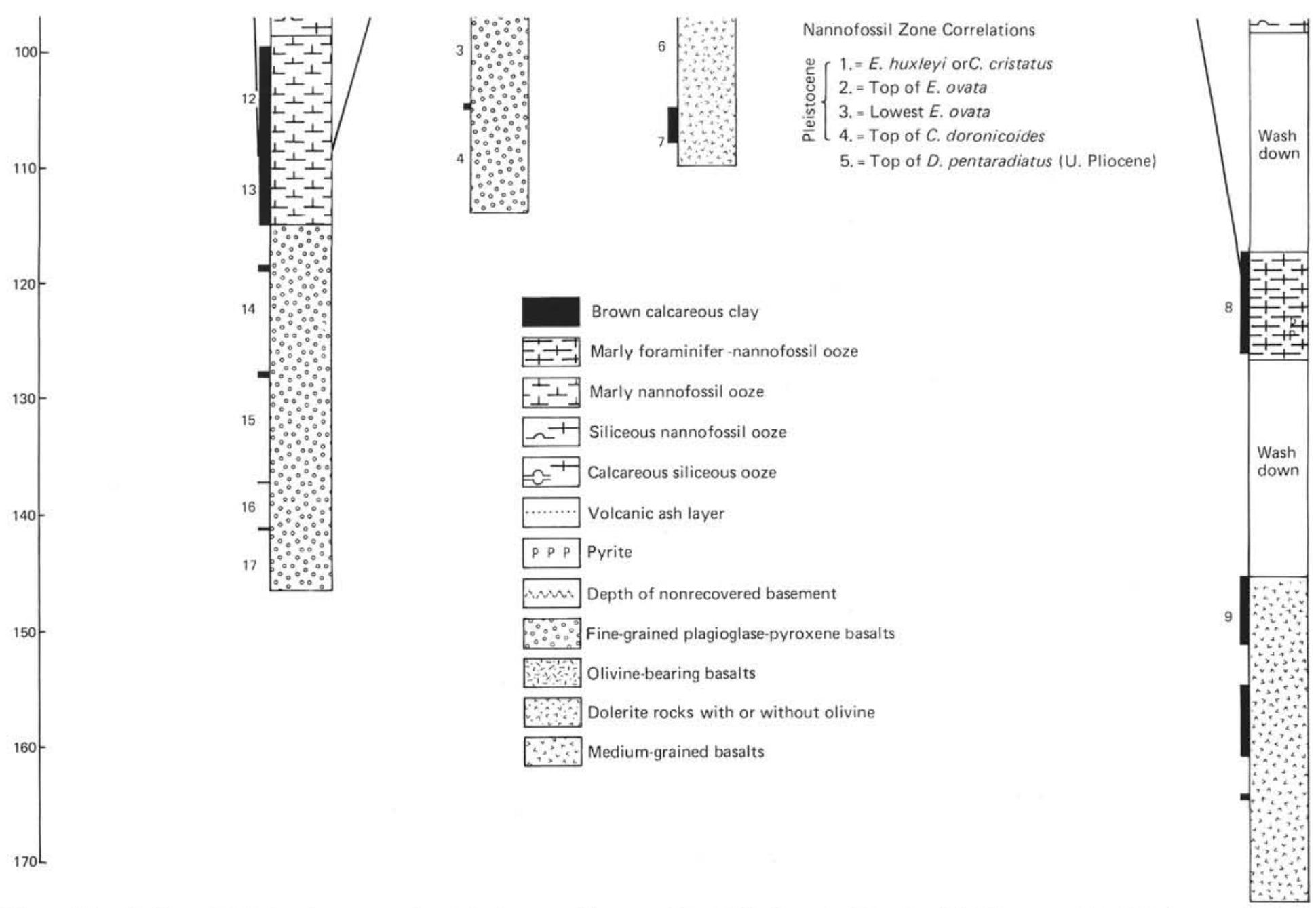

Figure 18. Sediment lithologies versus depth below sea floor at sites drilled on the East Pacific Rise near OCP Ridge and in the Siqueiros fracture zone on Leg 54. 
TABLE 9

Occurrences of Different Sediment Types at East Pacific Rise Sites, Leg 54

\begin{tabular}{|c|c|c|c|c|c|c|c|c|c|}
\hline & & \multicolumn{5}{|c|}{ Transect Sites } & \multirow{2}{*}{\multicolumn{2}{|c|}{$\begin{array}{l}\text { OCP Ridge } \\
\text { "Moat" }\end{array}$}} & \multirow{3}{*}{$\begin{array}{c}\text { Siqueiros } \\
\text { Fracture } \\
\text { Zone } \\
427\end{array}$} \\
\hline & & \multirow{2}{*}{$\begin{array}{l}\text { East } \\
423\end{array}$} & \multicolumn{3}{|c|}{$\leftrightarrow$} & \multirow{2}{*}{$\begin{array}{l}\text { West } \\
429 \mathrm{a}\end{array}$} & & & \\
\hline & & & 419 & 421 & 420 & & 422 & 428 & \\
\hline \multirow[t]{4}{*}{ I. } & Dominantly calcareous & & & & & & & & \\
\hline & A. Eoraminifer-nannofossil ooze & $\mathrm{X}$ & $\mathrm{X}$ & $\mathrm{X}$ & $\mathrm{X}$ & & $\mathrm{X}$ & & \\
\hline & B. Nannofossil ooze & $\mathrm{X}$ & & $\mathrm{x}$ & $\mathrm{X}$ & $\mathrm{X}$ & $\mathrm{X}$ & & \\
\hline & C. Nannofossil-foraminifer ooze & & & & & & $\mathrm{X}$ & & \\
\hline \multirow[t]{6}{*}{ II. } & $\begin{array}{l}\text { Moderately to dominantly } \\
\text { siliceous }\end{array}$ & & & & & & & & \\
\hline & A. Siliceous nannofossil ooze & $\mathrm{X}$ & & & $\mathrm{X}$ & & $\mathrm{X}$ & $\mathrm{X}$ & $\mathrm{X}$ \\
\hline & B. Radiolarian-nannofossil ooze & & $\mathrm{X}$ & & & & & & \\
\hline & C. Calcareous diatom ooze & & & & $\mathrm{X}$ & & & & \\
\hline & D. Calcareous siliceous ooze & & & & & & & & $\mathrm{X}$ \\
\hline & $\begin{array}{l}\text { E. Pyritic diatom nannofossil } \\
\text { ooze }\end{array}$ & & & & & & & & $\mathrm{X}$ \\
\hline \multirow[t]{3}{*}{ III. } & $\begin{array}{l}\text { Moderately to dominantly } \\
\text { clay-rich }\end{array}$ & & & & & & & & \\
\hline & $\begin{array}{l}\text { A. Marly foraminifer-nannofossil } \\
\text { ooze }\end{array}$ & & & & & & & $\mathrm{X}$ & $\mathrm{X}$ \\
\hline & B. Calcareous clay & $\mathrm{X}$ & $\mathrm{X}$ & $\mathrm{X}$ & $\mathrm{X}$ & & $\mathrm{x}$ & $\mathrm{X}$ & $\mathrm{X}$ \\
\hline \multirow[t]{2}{*}{ IV. } & Other & & & & & & & & \\
\hline & Basaltic volcanic sand & & & & & & & $\mathrm{X}$ & \\
\hline
\end{tabular}

${ }^{\mathrm{a}}$ Mud-line core only.

in the midst of virtually bare igneous outcrops. There can be no doubt that redistribution of sediments from these outcrops has been the single most important factor is filling these small depressions, and it is with this perspective that the origin of alternating sediment types in the Siqueiros region must be considered. From Figure 18 , it is evident that there is little or no correlation of calcareous mud layers from hole to hole. Some holes have several layers, others two, one or even none in corresponding intervals. Whatever the cause of the alternations, it cannot have been entirely a regional effect, one acting simultaneously at all sites. Rather, it appears to have depended on local factors, peculiar to each sediment pond. In our view, the probable cause is linked to patterns of redistribution and sorting of sediments by currents that have acted ever since sedimentation began at each site. For example, several of the minor sediment types, which have unusual concentrations of siliceous microfossils-in some cases pyritized-could have accumulated in this way. In the case of the calcareous clays, it seems plausible that accelerated dissolution of carbonate components in oozes could have occurred as they were being swept by currents. In this way, thin sediments eroded from sea-floor igneous outcrops could have collected in adjacent sediment ponds without their calcareous component. Thus both siliceous microfossil tests and clays would have been concentrated in these ponds. This would depend to some extent on the corrosive capabilities of cold bottom currents, on the rate of accumulation of detrital (eolian) and/or "hydrothermal" clays, and on the rate of formation of clays by diagenetic interaction of components in the sediments -mainly volcanic glass, siliceous microfossils, and $\mathrm{Fe}-\mathrm{Mn}$ oxides. The local topography would have ex- erted a critical control on the distribution of various sediment types, causing different patterns of sediment alteration at each site. In the several cases where basal contacts to calcareous clay layers can be seen (e.g., Figure 19), they are sharp, implying sufficiently rapid deposition of the clay-rich layers to suppress bioturbation that would have smeared the contacts. Sporadic sediment input to these ponds also seems supported by generally younger ages to basal sediments than inferred for basement from magnetic anomalies, by apparent diastems in the sediment columns, and by an occurrence of marker fossils in some holes but not others (see following sections).

Slumping and currents also seem to have been the causes for mixing of the ubiquitous brown basaltic glass in the sediments, although it is possible that some was added directly by violent volcanic discharge at the East Pacific Rise crest. At least one relatively pure volcaniclastic interbed rich in basaltic glass was cored at Site 428 , next to the OCP Ridge, from which it apparently slumped. Other, thinner interbeds at this and other sites were probably obliterated by bioturbation. This type of mixing of glass with calcareous and siliceous microfossil tests may have accelerated diagenetic alteration of the glass to clays, as observed by Rateev et al. (this volume). The generally more marly composition of sediments at Site 428 than at other sites with similar water depths (Table 9) could reflect a heightened volcanogenic or volcaniclastic input from the OCP Ridge.

There appears to have been a large, persistent input of an iron-rich component, probably hydrothermal in origin, to Site 420 throughout its sedimentation history. Hekinian, Rosendahl, and Natland (this volume) argue on chemical grounds that this component was primarily 


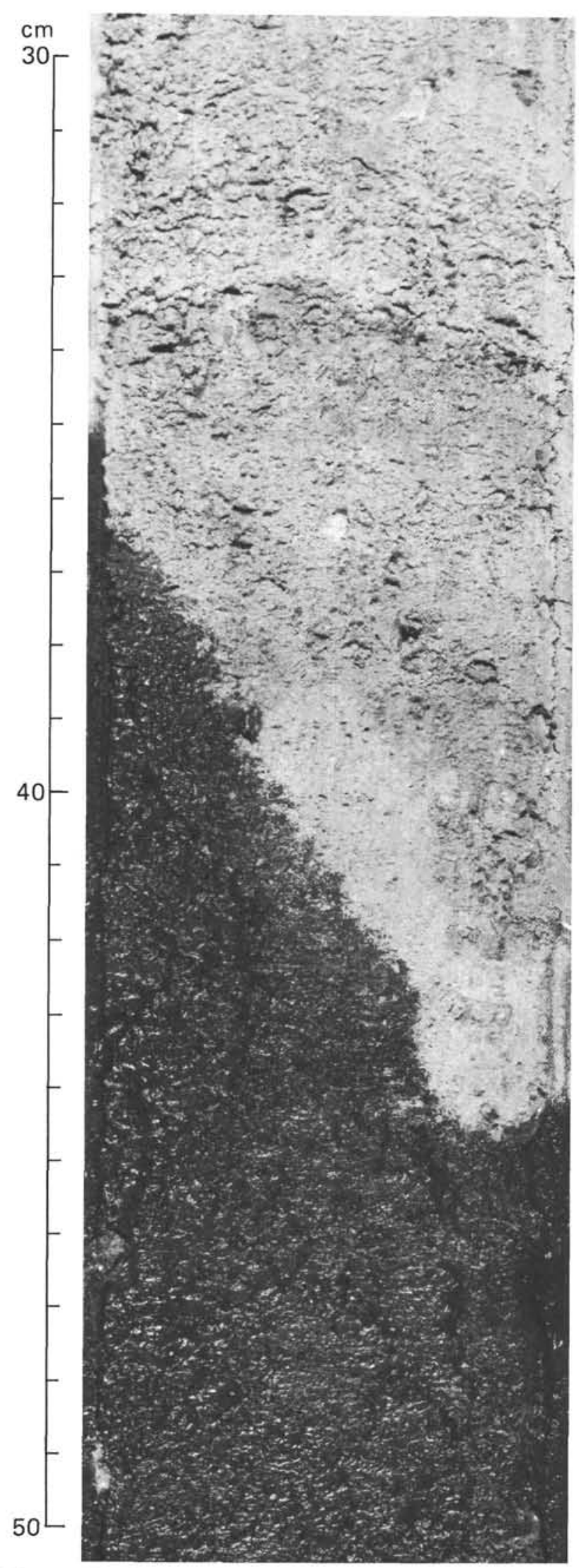

Figure 19. Contact between clay-rich (upper) and carbonate-rich sediments Sample 420-2-4, 30-50 cm, disturbed somewhat by drilling. amorphous iron hydroxides such as those typically found on the East Pacific Rise crest which have been inferred to have a hydrothermal origin (e.g., Boström and Peterson, 1966). These have reacted diagenetically mainly with siliceous microfossil remains, in a manner similar to that described by Heath and Dymond (1977), to produce the iron-rich clays described and analyzed by Rateev et al. (this volume). The proportion of iron in this component, compared with that provided by hydrogenous and detrital sources, is high and was remarkably constant through time, despite fluctuations in sediment type. The calcareous clay layers therefore do not appear to be related to pulses of East Pacific Rise geothermal activity.

This conclusion allows us to infer that shoaling of the lysocline has been an important factor in the formation of clay-rich sediments in the Siqueiros region. Both the detrital and the hydrothermal component are increased in these layers relative to the carbonate fraction. There is also considerable selective dissolution of foraminifers (Krasheninnikov, this volume; Lynts, this volume), lending credence to this notion. The mechanism of formation of the calcareous clay interbeds, then, probably has mainly to do with residence times of calcareous particles on current-swept outcrops in contact with corrosive bottom waters. Any local acceleration of accumulation rates would serve to bury, and thus protect, calcareous particles from dissolution. Any prolonged exposure reduces calcareous sediments to a clay-rich residuum.

Whether this mechanism acts as far west as DSDP Site $77\left(0^{\circ} 29^{\prime} \mathrm{N}, 133^{\circ} 14^{\prime} \mathrm{W}\right)$ to produce the cyclic member of the Clipperton Formation (Figure 20) is uncertain, if only because the sediment blanket there is so uniformly thick (Hays et al., 1972: Chapter 3, Figure 2) and has so little surface relief. It is also probable that the clay fraction of the sediments is primarily pelagic (detrital or eolian), with less of a hydrothermal component, because the rise crest is so distant. To the north of Site 77, between the Clipperton and Clarion fracture zones (Figure 20), sediments are not nearly so thick (they are located more on the flank of the equatorial sediment bulge than Site 77, which is nearly at its center), and surface topography in rougher (van Andel, Heath, et al., 1973), apparently reflecting greater basement relief. In this area, equivalents of the Clipperton Formation cyclic member were cored at DSDP Sites 159, 161, and 162 (van Andel, Heath, et al., 1973). Moreover, distinctive patterns of sea-floor erosion, dissolution, and redeposition have been documented by a nearbottom survey near Site 161 (Johnson, 1971) (Figure 20). Conditions here, therefore, are similar to those in the Siqueiros region. If anything, dissolution is more of a factor, since all these sites are roughly 1000 meters or more deeper than in the Siqueiros area. Thus it is not surprising that radiolarian- and clay-rich oozes are more predominant in the cyclic portions of these holes than in the Leg 54 sites. Van Andel et al. (1975) infer that the current depth of the CCD in this area is very nearly the depth of these sites $(4400-4900 \mathrm{~m})$.

In the Siqueiros region, only Site 427 in the Siqueiros fracture zone shows persistently greater effects of car- 


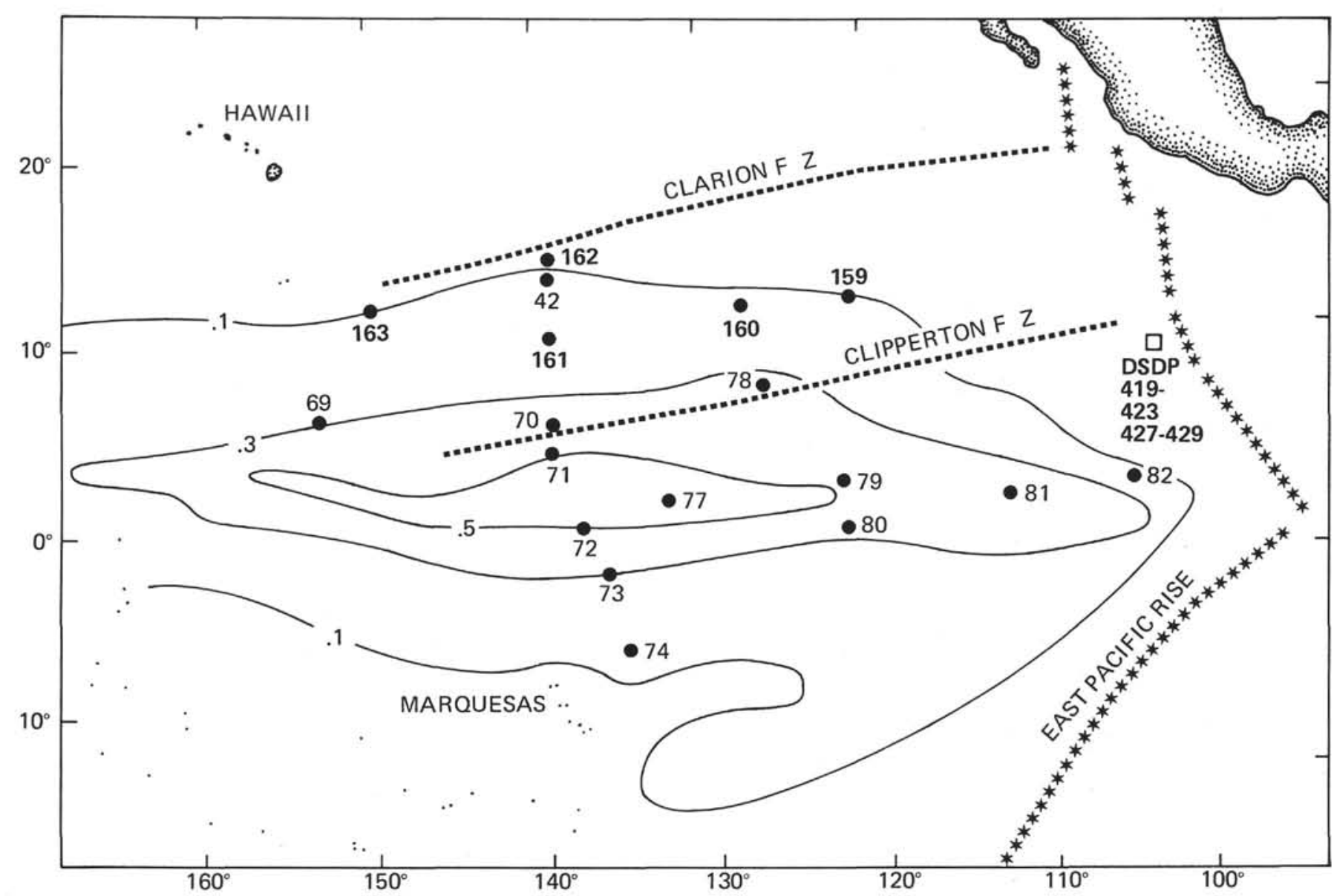

Figure 20. Location of DSDP sites where cyclic Pliocene-Pleistocene sediments have been recovered. Contours indicate sediment thicknesses above acoustic basement in seconds (approximately equivalent to $800 \mathrm{~m}$ ). Figure based on van Andel, Heath, et al. (1973), Chapter 8, Figure 1.

bonate dissolution than the other sites. This is reflected mainly in higher proportions of siliceous and marly sediments (Table 9) and resulted from the greater depth of the site (closer to the CCD). Sediments here are also darker in color because they a more pyritic, possibly reflecting limited oxygen availability in this deep trough in the Siqueiros fracture zone.

\section{INTERSTITIAL WATER ANALYSIS}

A standard shipboard program of squeezed-sediment interstitial water analysis was conducted at most sites, supplemented by analysis of water sampled in situ using the Barnes pore-water sampler. Quantities measured were salinity, chlorinity, alkalinity, $p \mathrm{H}, \mathrm{Ca}^{+2}$, and $\mathrm{Mg}^{+2}$. The most complete suite of analyses was carried out at Site 420, where three in situ samples and six squeezed samples was good, but it became apparent that partial re-equilibration of pore fluids to reduced pressure and elevated temperature occurred between the time of core retrieval and that of sample squeezing, which affected the results. Accordingly, a special test to gauge the effects of this was conducted at Site 427. The results of all this work are reported in Humphris and Hallman (this volume). The problem of re-equilibration notwithstanding, pore fluids sampled in the Siqueiros region show very little deviation from standard and local sea water compositions, hence reflect virtually no effects that might be ascribed to alteration of volcanic glass in the sediments, or in the basalts beneath. This accords with the usually fresh or very slightly altered aspect of the recovered basalts.

\section{MICROPALEONTOLOGY OF SIQUEIROS SITES}

The upper Pliocene and Quaternary sediment cored at Sites 419 through 423 and 427 through 429 is richly fossiliferous. Coccoliths and foraminifers predominate and are the most ubiquitous fossils; however, siliceous diatoms, silicoflagellates, and radiolarians are also common. Opal phytoliths, the siliceous fossils from terrestrial grasses, are fairly common at the Siqueiros sites and nearly absent at the Galapagos sites.

Tropical zonations for all microfossil groups are recognized (Table 10); however, the diversity of microfossil assemblages is more restricted at the Siqueiros than at the Galapagos sites because of greater dissolution.

\section{Planktonic Foraminifers}

Planktonic foraminifer assemblages are tropical, but selective dissolution has limited their diversity. The species array sometimes includes Globorotalia inflata, which can be used to identify levels of climatic cooling. The 
TABLE 10

Biozonations Used for Sediments Recovered on Leg 54

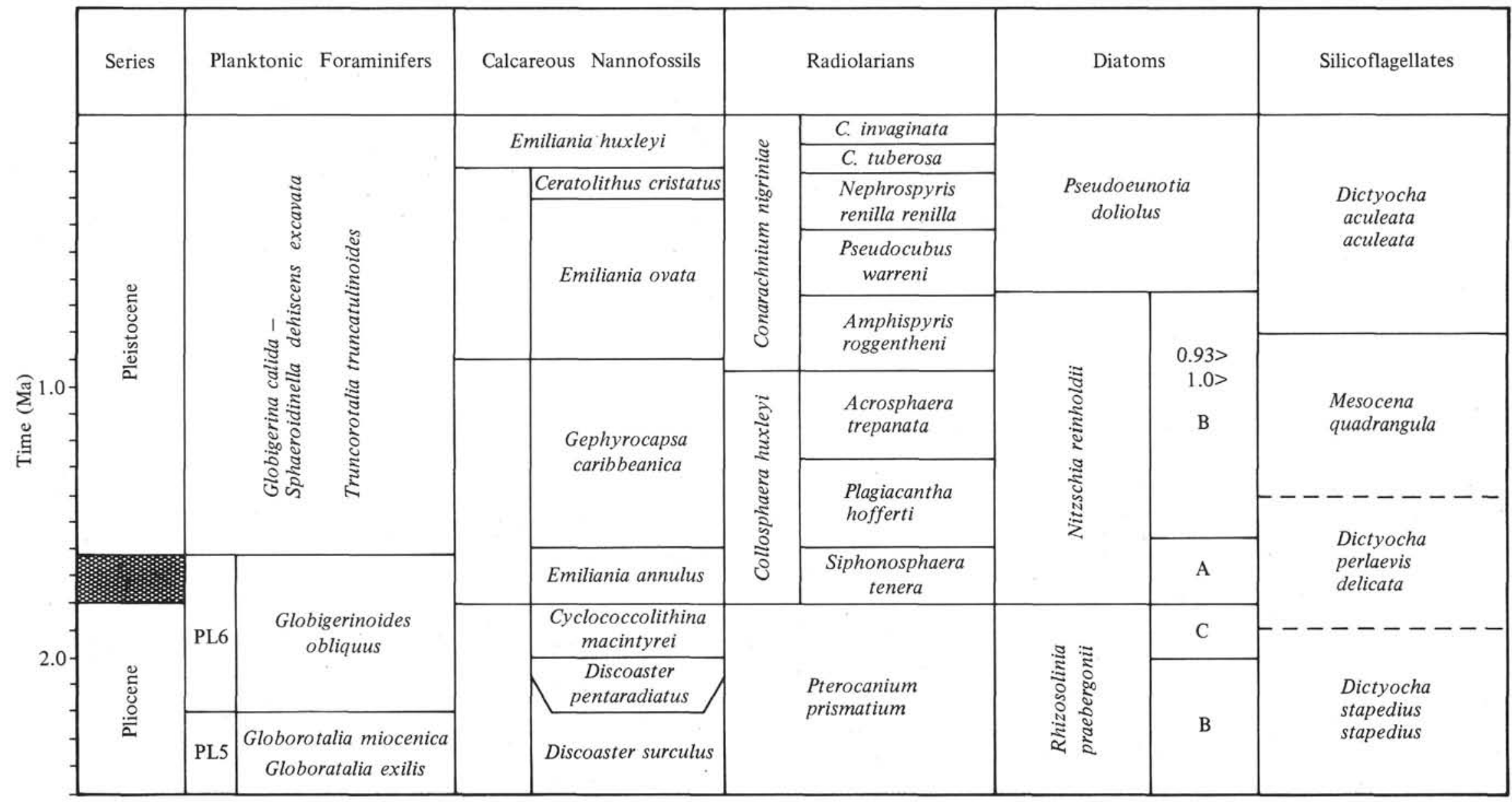


Pliocene/Pleistocene boundary at Sites 419 and 420 is identified by Globigerinoides obliquus extremus, because Globorotalia truncatulinoides is sparse and sporadic (Krasheninnikov; this volume).

\section{Coccoliths}

Upper Pliocene and Quaternary coccoliths are abundant and moderately etched in the short sediment sections of the Siqueiros area. Coccolith zonal ages for basement are all equal to or younger than paleomagnetic estimates. The most discordant ages are at Sites 421 and 427 (Bukry, coccolith chapter, this volume). Coccolith criteria for determining the Pliocene-Pleistocene include Cyclococcolithina macintyrei, Discoaster brouweri, and Gephyrocapsa caribbeanica. The extinction of Discoaster brouweri is used for the warm-water assemblages of the Siqueiros area.

\section{Radiolarians}

The quantity and quality of radiolarian preservation in the sediments recovered at Site 429 are not adequate for biostratigraphic determinations. The radiolarian biozonation can be applied to all of the other Siqueiros sites, although preservation is variable downhole. This suite of drill sites is located near the northern margin of the equatorial plankton province, and the radiolarian assemblages appear to include central and northern transition-province components as well. Consequently, diversity is quite high, but few species are abundant and some biostratigraphically useful species are absent or occur only sporadically. The youngest sediments (less than 200,000 years old in each hole) generally contain abundant, well-preserved radiolarians (two exceptions are Sites 420 and 427). Scarce specimens of Collosphaera invaginata occur in the top of Core 1 in Holes 420, 422, 423 , and 428 , and indicate that these sediments are less than 100,000 years old. This species was not found in the uppermost layers at the other Siqueiros holes, and these recoveries are regarded as lacking latest Pleistocene sediment, either as a drilling effect or as a natural occurrence, although $C$. invaginata has a delicate skeleton that may have a low preservation potential. Radiolarians are generally much less common and more poorly preserved in sub-surface sediments of the Nephrospyris renilla renilla Zone and the Pseudocubus warreni Zone. Below this intermediate unit of poor preservation, radiolarians are generally abundant and well preserved in sediments of the Amphispyris roggentheni Zone and older biozones. This lower sequence of abundant radiolarians includes the radiolarian-nannofossil ooze sediment type described in the Sediment Lithology section. Preservation degenerates again in the sediments directly above basement at Sites $419,420,422$, and 428 in a manner similar to the recovery at Leg 9 sites (Goll, 1972).

The absence of Stichocorys peregrina in Leg 54 radiolarian sediments indicates that this recovery is not older than the Pterocanium prismatium Zone (less than 2.5 m.y.), which supports the fossil age determination of basal sediments based on other microfossils, but is generally much younger than the basalt ages inferred from magnetic anomaly interpretations. The radiolarian zonation is generally in consistent good agreement with other biozonations in the Siqueiros suite except Site 421, where the radiolarian determination for the basal sediments (Plagiacantha hofferti Zone) is considerably younger than the coccolith determination ( $D$. pentaradiatus Zone). The coccolith determination is in close agreement with the results at Site 420 , and the radiolarian biostratigraphy appears to be anomalous at this site. A diastem is indicated in the recovery at both Sites 419 and 428 on the basis of radiolarian biostratigraphy. Both the Acrosphaera trepanata and $P$. hofferti zones are missing at Hole 419 between Cores 4 and 5, whereas only the $P$. hofferti Zone is missing in Section 428-4-3. This evidence of discontinuous sedimentation is not contradicted by other fossil data at Hole 419, but silicoflagellate biostratigraphy does not support the radiolarian interpretation at Site 428.

\section{Diatoms}

Upper Pliocene to Quaternary tropical diatom assemblages are present in sediments recovered at all of the East Pacific Rise sites, with the exception of Site 429 (Barron, diatom chapter, this volume). Within the sections, diatoms vary from abundant to sparse, and preservation ranges from good to poor. Nevertheless, all of the recovered sections are readily assignable to the lowlatitude diatom zonation. The most complete section occurs at Site 420, where the Pseudoeunotia doliolus Zone, the Nitzschia reinholdii Zone, and Subzones C and B of the Rhizosolenia praebergonii are represented.

\section{Silicoflagellates}

The youngest silicoflagellate zone of the Quaternary, Dictyocha aculeata aculeata Zone is preserved only at Site 427 as a result of reduced productivity and increased dissolution (Bukry, silicoflagellate chapter, this volume). The mid-Quaternary Mesocena quadrangula acme event is seen to correlate consistently with the upper Nitzschia reinholdii (b) Subzone of diatoms. The local eastern $\mathrm{Pa}$ cific Dictyocha perlaevis delicata Zone of the latest Pliocene and early Quaternary was first identified off Peru at DSDP Site 319. Its common occurrence at the Siqueiros sites extends its range $8^{\circ}$ farther north than previously recognized. Leg 54 drilling at the Siqueiros Sites 419 and 428 and Galapagos Site 425 has shown an apparently consistent correlation between lower Quaternary diatom and silicoflagellate zones. The base of the silicoflagellate Dictyocha perlaevis delicata Zone corresponds to the diatom lower Nitzschia reinholdii (b) Subzone $(<1.55$ m.y.). The top of the $D$. perlaevis delicata Zone and the base of the overlying Mesocena quadrangula Zone correspond to the upper $N$. reinholdii (b) Subzone, just below the Rhizosolenia matuyamai horizon $(0.98$ m.y.) (see Barron, diatom chapter, this volume). Two notable exceptions to these correlations occur at Siqueiros Site 420 and at Carnegie Ridge Site 157 (Bukry, 1976; Burckle and Opdyke, 1977), where the $D$. perlaevis delicata Zone is significantly thicker and corresponds, not only to the lower $N$. reinholdii (b) Subzone, but also to the underlying $N$. reinholdii (a) Subzone and even the upper 
Rhizosolenia praebergonii Zone. This extends the beginning of the $D$. perlaevis delicata Zone back to about 1.8 m.y.; it indicates an unusual variance in the range of this species in the eastern Pacific that needs investigation, because Leg 54 Sites 419 and 420 are adjacent. In fact, the nature of micropaleontologic variation within a limited area may be studied in the Siqueiros area, because many different sites were continuously cored.

\section{Opal Phytoliths}

Opal phytoliths, the silicified casts from epidermal cells of land plants, are unusually common and persistent in the Siqueiros area from upper Pliocene to Quaternary (Bukry, opal phytolith chapter, this volume). These accumulations are thought to represent eolian materials transported from grasslands in Mexico and Central America by trade winds. The carbonate-rich pelagic sediment of the East Pacific Rise makes it feasible to study opal phytolith assemblages, because acid residue concentrations can be made. Detailed studies may help in determining the history of winds of the region.

\section{BASAL SEDIMENT AGES AND RATES OF SEDIMENT ACCUMULATION FOR THE SIQUEIROS SITES}

A summary of the downhole biostratigraphies for each fossil group is shown for all sites but Site 429 on Figure 21 through 27 . Time versus depth in the sediment sections of Holes 519, 420, 422, 427, and 428 are shown in Figures 28 through 32. Similar graphs for Holes $419 \mathrm{~A}, 420 \mathrm{~A}, 421$, and 423 were not plotted because of inadequate control. Hole 420 was the deepest and stratigraphically most comprehensive hole drilled on Leg 54 , and it has been used as the reference section for age determinations at the other holes. Independent age estimates for all the microfossil indices were plotted for Hole 420 (Figure 29), and the rate curve was drawn as the best fit of these data. In order to reduce the scatter in the plots for the other Siqueiros and Galapagos holes, the ages of these fossil indices were projected horizontally to the curve and recorded as the "extrapolated Site 420 "' ages (Table 11). Our results are summarized in Table 12, and each hole is discussed individually below.

\section{Hole 419}

There is radiolarian evidence of a diastem between Cores 4 and 5, and the other microfossil data are generally in agreement with this interpretation (Figures 21 and 28). Scant control in the upper section indicates a higher average rate of accumulation during the past 0.4 m.y., but the rate below 20 meters sub-bottom ranges from 6.6 - 17 meters/m.y., and the overall average for the hole $(17.1 / \mathrm{m} . \mathrm{y}$. , disregarding the diastem) is the lowest of the Siqueiros suite. These values are in close agreement with the Pleistocene accumulation rate of $17 \pm 2$ meters/m.y. at DSDP Site 82 (located approximately $6.5^{\circ}$ south of Site 419). As is the case with other Leg 54 sites, the basal sediment age determined by microfossils is significantly younger than the magnetic anomaly interpretation of the basalt age. Sediments in- crease in age quite rapidly in the lowest 10 meters of the section, and it is possible that the oldest sediments were not sampled, because the actual sediment/basalt contact was not cored. Extrapolation of the rate curve to the basement horizon yields an age of only $2.2 \mathrm{~m}$.y., however.

\section{Hole 420}

The rate of sediment accumulation appears to have been almost constant throughout this hole, and the section includes modern surface sediments less than 100,000 years old. The rate of sediment accumulation in the upper 60 meters of the section is 47.5 meters $/ \mathrm{m}$.y. and increases to 60.7 meters/m.y. below this level (Figure 29). Because there are no fossil indices in the lowest 7 meters of the section, the basal sediment age has been determined by extrapolation of the rate curve; however, this estimate is $1.17 \mathrm{~m} . \mathrm{y}$. younger than the age of basement estimated from magnetic anomalies and there is no obvious explanation for this discrepancy.

\section{Hole 421}

Little can be said about the sediment column at Site 421 , because most of the sediments were not cored (Figure 23). There is poor agreement on the microfossil age of the drilling slurry above the basalt in Core 2, and the basement age is far greater than is indicated by the radiolarian or coccolith biostratigraphy.

\section{Hole 422}

We have not provided a basal sediment age determination or overall average rate of sediment accumulation value, because the fossil data are at variance in the lower part of the section (Figure 24), and there is not enough control to warrant extrapolation of the rate curve. The available data indicates that the rate of sediment accumulation in the upper 40 meters ( 52 meters/ m.y.) is about average for the Siqueiros sediments, but the rate appears to decrease to less than one-third this value below this level.

\section{Hole 423}

The overlap in the ages of the coccolith and radiolarian zones (Figure 25) in the basal sediments indicates an age of 0.9-1.09 Ma, which is 0.5-0.7 m.y. younger than the basalt age estimate.

\section{Hole 427}

The lowest 19 meters of the section was not cored, and the basal sediment age (1.12 Ma) was determined by extrapolation of the rate curve (Figure 31 ). There is so little control in the lower 80 meters of the section that this extrapolation is highly suspect, and the basalt age estimate is nearly twice the extrapolated sediment age (Table 12).

\section{Hole 428}

As at Hole 422, the available data indicate a decrease in the rate of sediment accumulation from 70 meters/ m.y. in the upper 30 meters to 24.4 meters $/ \mathrm{m}$.y. below (Figure 32). Two diastems in the lower 17 meters of the 


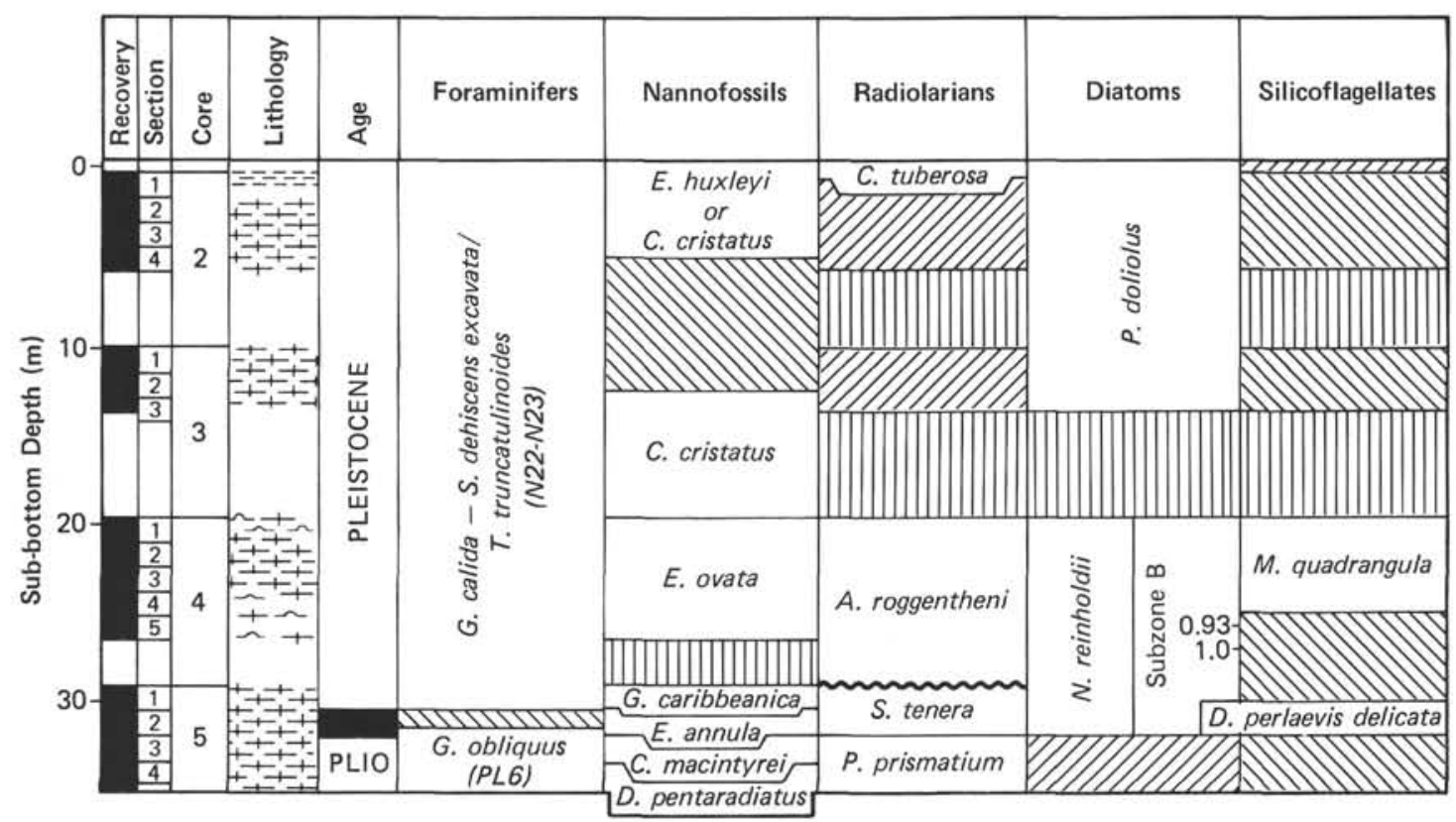

No Recovery

Barren or Preservation Too

Dot Sampled

Poor for Zonal Determination

Not Sampled

Figure 21. Biostratigraphic summary, Site 419, showing distribution of microfossil zones versus depth.

section are indicated by the coccolith and radiolarian zonations (Figure 27). Three other datums at 42 meters sub-bottom ranging in age from 1.05 to 1.29 Ma suggest the possibility of a third diastem at this horizon. These discontinuities indicate that the actual sedimentation rates were significantly greater than the average rate for the hole.

\section{Hole 429}

Ages for the top of Core 1, Hole 429A, are not consistent, and this sediment may not represent the in situ basal stratum. A late Pliocene age based on calcareous nannofossils is accepted as the mcst probable age for this sediment.

\section{IGNEOUS ROCK LITHOLOGY AND PETROGRAPHY}

Basalts were recovered in Holes 420, 421, 422, 423, $427,428,428 \mathrm{~A}$, and 429A, drilled on the west flank of the East Pacific Rise between the Clipperton and Clarion fracture zones (Figure 2). These holes were drilled in three distinct tectonic provinces:

1) typical block-faulted East Pacific Rise crust (Sites $420,421,423$, and 429);

2) moat-like depressions with ponded basalt flows on either side of the OCP Ridge (Figure 2, Sites 422 and 428); and

3) the Siqueiros fracture zone (Site 427).

At Site 422 , we apparently managed to penetrate the ponded basalts into normal East Pacific Rise crust, recovering a single piece of basalt lithologically, petro- graphically, and chemically akin to most of the basalts of group 1.

The lithology and petrography of these basalts follow, given in the order just listed. Penetration and recovery data are listed on Table 13.

\section{East Pacific Rise Sites}

Basalts recovered at Sites 420, 421, 423, and below the ponded basalts at Site 422 are remarkably similar lithologically and petrographically. All are very fine grained to glassy, aphyric or very sparsely phyric plagioclase-clinopyroxene basalts with abundant titanomagnetite. All are among the most rich in iron recovered on Leg 54 (see section on igneous rock geochemistry). Basalts at Site 429 are similar lithologically to these, but they are petrographically different and chemically are less rich in iron.

The basalts recovered at these sites are very fresh to slightly altered, most pieces having a distinctly darker gray alteration rind around part or all of their exteriors. Glass rinds occur on many pieces. In most cases they are flat, and probably represent the original tops or bottoms of individual pieces. In some cases (oriented pieces), they certainly do. Alteration rinds parallel glass and, on oriented pieces, their longitudinal (cored) dimension. Assuming that the alteration rinds paralleled fractures in the basalts, it is evident that maximum vertical fracture spacing must have been only slightly greater than the core diameter $(6 \mathrm{~cm})$. Some idea of the fragmental nature of these basalts can be obtained by considering how few oriented pieces were recovered (suit- 
able for determination of paleomagnetic inclinations), and how few of these were recovered consecutively (were originally linked).

Site 420: 29 pieces recovered, the largest $9 \mathrm{~cm}$ long, two oriented, none linked;

Site 421: 32 pieces recovered, the largest $9 \mathrm{~cm}$ long, two oriented, none linked;

Site 423: 29 pieces recovered, the largest $12 \mathrm{~cm}$ long, two oriented, none linked;

Site 429: 35 pieces recovered, the largest $12 \mathrm{~cm}$ long, 13 oriented, three linked.

Although lithologic evidence is thus meager, the occurrence of flat glassy rinds, the small dimensions of the pieces, and the occurrence of alteration rinds paralleling the cored direction of elongate (oriented) pieces, all suggest that these rocks were part of sheet flows no more than, perhaps, 5-20 cm thick.

With such thin flows, it is little wonder that the crystallinity of most of the rocks and the grain size in all of them is very low. Samples range from glassy or spherulitic, to intersertal-subophitic. Both crystallinity and grain size increase in that order. The mineralogy of the basalts and representative modes are given on Tables 14 and 15 . Neither of these tables, however, indicates accurately how different the basalts from the various sites really are. Apart from the minor occurrence of olivine and chromian spinel in relatively magnesian basalts from East Pacific Rise Site 429 and OCP Ridge Site 422 (Table 15), there is no fundamental mineralogic distinction among these basalts. Olivine, for example, also occurs in Site 420 (Table 14) and Site 421 (Thompson and Humphris, this volume) iron-rich basalts. Why this should be is unclear, inasmuch as glasses from Sites 420, 421, and 423 are virtually identical in composition (Natland and Melson, this volume), are all quartz-normative, and therefore have compositions supposedly incompatible with the formation of olivine, yet there is no olivine in Site 423 basalts.

The real petrographic distinctions among these basalts are not, therefore, in the simple occurrence or absence of minerals, but in mineral interrelationships, crystal morphologies, and to some degree, mineral abundances, especially of opaque minerals. The iron-rich basalts from Sites $420,421,422$, and 423 have minor euhedral plagioclase microphenocrysts and separate glomerophyric patches of intergrown euhedral plagioclase microlites and anhedral or euhedral clinopyroxene. The olivine in Site 420 basalts only occurs in glassy to spherulitic samples where it forms isolated, starkly skeletal crystals. All these crystals are set in an extremely dark brown, virtually opaque spherulitic mesostasis. The spherulites can be individually distinguished in glassy zones where they occur as dark brown spheres, or smaller trellis-like grids of crystal fibers a few microns across. Within a centimeter or so from glass zones, the spherulites coalesce as sheaves or fans centered on plagioclase microlites. Tiny titanomagnetites occur between these sheaves. Another 1 to $3 \mathrm{~cm}$ farther from glass zones, the fibers making up the sheaves are more distinctly skeletal. The coarser grained basalts from these sites have abundant euhedral plagioclase, anhedral to euhedral clinopyroxene, and coarsely skeletal titanomagnetite. The latter is heavily concentrated in intersertal patches which contain dark glass and/or secondary minerals. Sulfide minerals decorate vesicles in or near glass zones. In spherulitic samples they occur as tiny isolated spheres or irregular crystals. In coarser grained basalts spheres are less common, and irregular patches larger than 20 microns are more abundant.

In addition to these features, several spherulitic to glassy samples from Site 423 are unique in that they are macroscopically streaked or banded, a feature obviously imparted during flowage of the lava. In thin sections, these streaks have different crystallinity, with the darker streaks having fewer, smaller crystals (mainly tiny plagioclases), and more nearly opaque glassy mesostasis. There is evidently some compositional difference between the dark and light bands, since the different crystallinity reflects contrasting responses to essentially identical undercooling. The compositional differences may have been two contrasting (though clearly similar) magma types quenched at an incomplete stage of hybridization. Alternatively, the bands could reflect something as ephemeral as different concentrations of volatile constituents which affected the viscosity of the magma and consequently the rate of crystal growth at high undercoolings.

In summary, the three most distinctive features of East Pacific Rise ferrobasalts are:

1) the occurrence of small crystal clumps of intergrown plagioclase and brownish clinopyroxene in glassy or spherulitic samples;

2) the presence of a very dark, nearly opaque mesostasis in spherulitic samples, probably reflecting iron enrichment;

3) the occurrence of abundant, coarsely skeletal titanomagnetite in large intersertal patches or coarser grained plagioclase-clinopyroxene basalts where it is associated with dark glass.

Among the East Pacific Rise basalts, only those from Site $\mathbf{4 2 9}$ are less magnesian than the iron-rich basalts so far described (see section on igneous rock geochemistry). However, the thin sections prepared from Site 429 do not include glassy or spherulitic samples. Comparing strictly subophitic-intersertal samples, those from Site 429 contain olivine, whereas olivine is absent at the other sites, and chrome-spinel occurs in some samples. Intersertal patches have less abundant and smaller skeletal titanomagnetites at Site 429 , and more abundant pale brown dendritic clinopyroxene associated with spherulitic plagioclase. Glass is less abundant, and not nearly so dark. Grain size varies among the samples somewhat. In the finer grained samples plagioclases are microlitic and skeletal, whereas in coarser grained samples they are euhedral, less elongate, and tabular, not skeletal. Opaques are smaller (10-15 $\mu \mathrm{m})$ in the finer grained samples than in the coarser $(\sim 25 \mu \mathrm{m})$ ones. Sulfide spheres are more abundant at Site 429 than in the other East Pacific Rise sites.

The Site 429 samples are a bit more altered than at the other sites. Patches of glass are altered to a finegrained green smectite, sometimes associated with $\mathrm{Fe}$ 


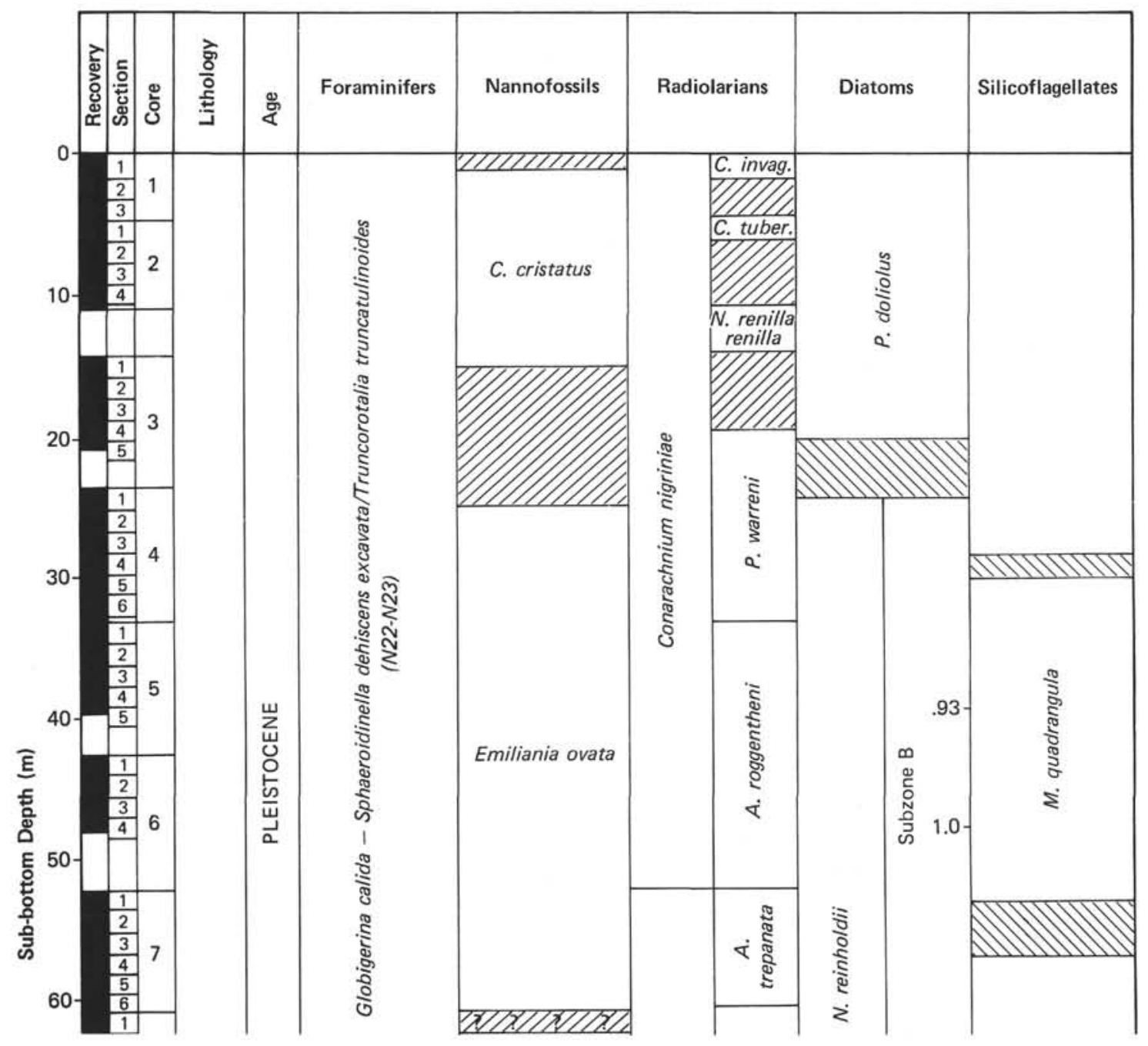




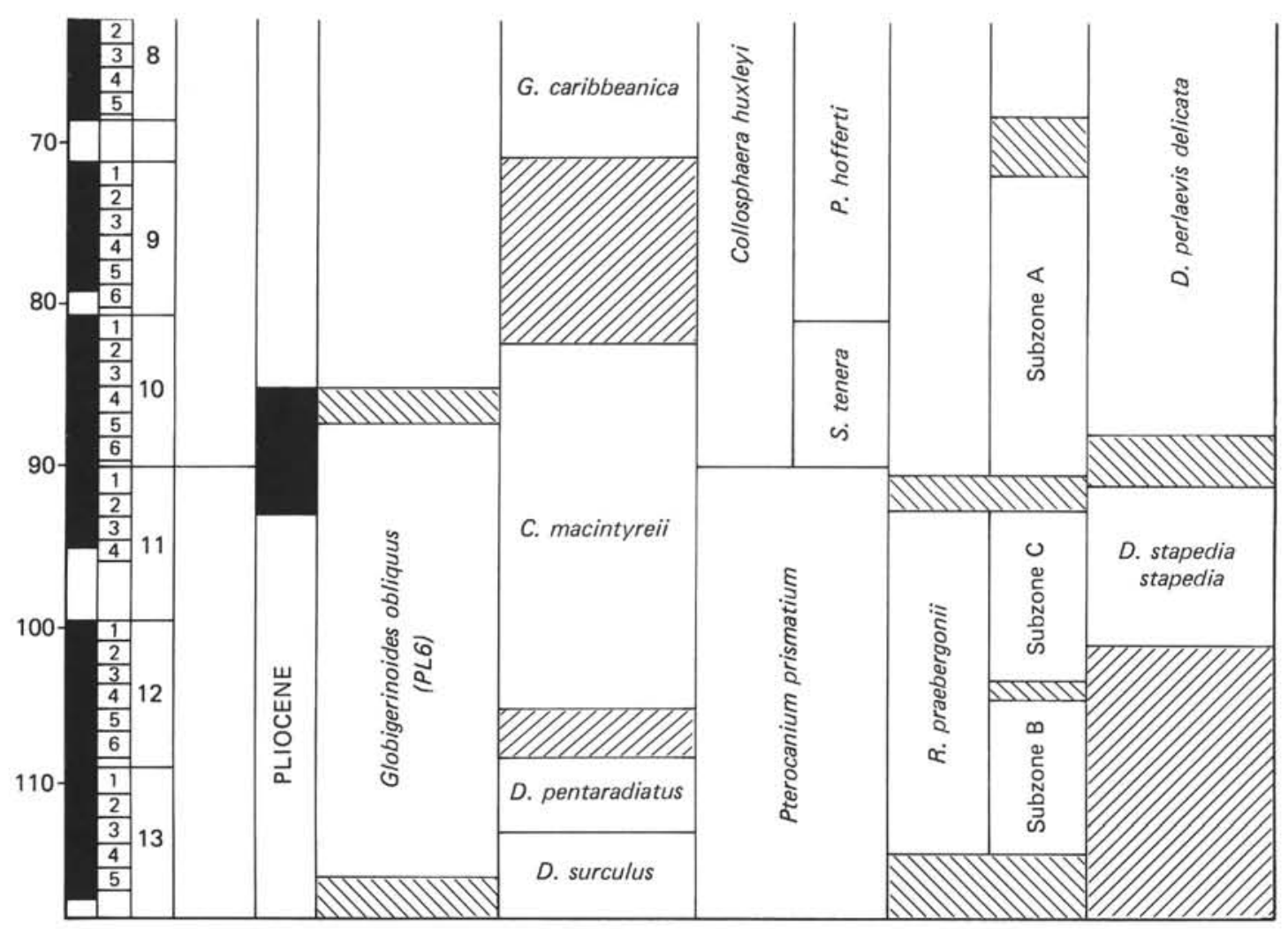

Figure 22. Biostratigraphic summary, Site 420, showing distribution of microfossil zones versus depth. Symbol code as in Figure 21. 


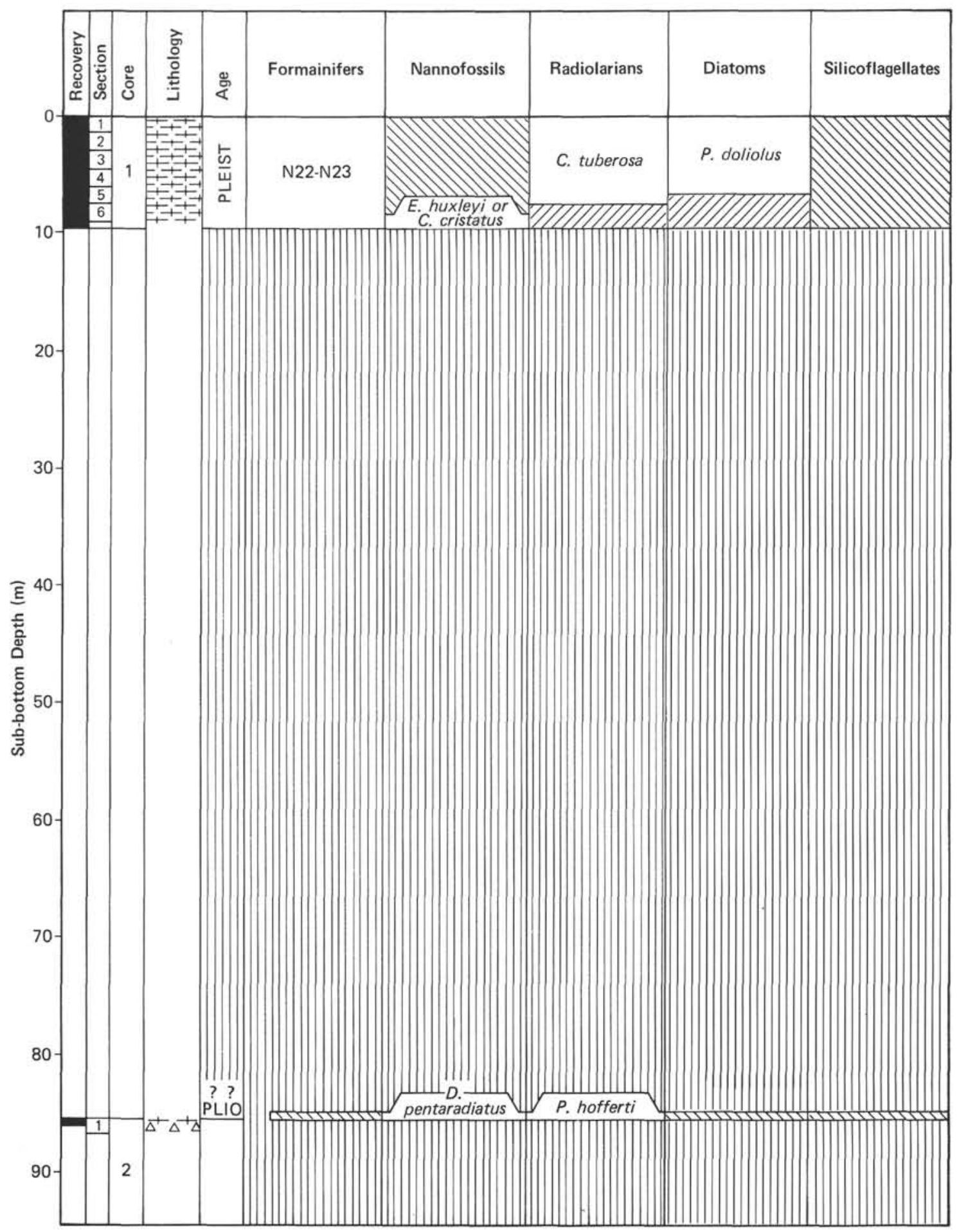

Figure 23. Biostratigraphic summary, Site 421, showing distribution of microfossil zones versus depth. Symbol code as in Figure 21.

oxyhydroxides. Calcite fills some veins as well as groundmass patches next to veins. All these minerals occur as linings or fillings of vesicles, particular in altered rinds. In thin sections, many Ti-magnetites are surrounded with iron staining. Small sulfide veinlets were emplaced after oxidation and cross-cut other secondary minerals (clays). The iron oxyhydroxides appear to in- clude both hematite and geothite, based on optical properties in reflected light.

\section{OCP Ridge Sites}

Sites 422 and 428 were drilled on opposite sides of the OCP Ridge. The targets were flat-lying, acoustically reverberant basalts apparently ponded in moat-like de- 


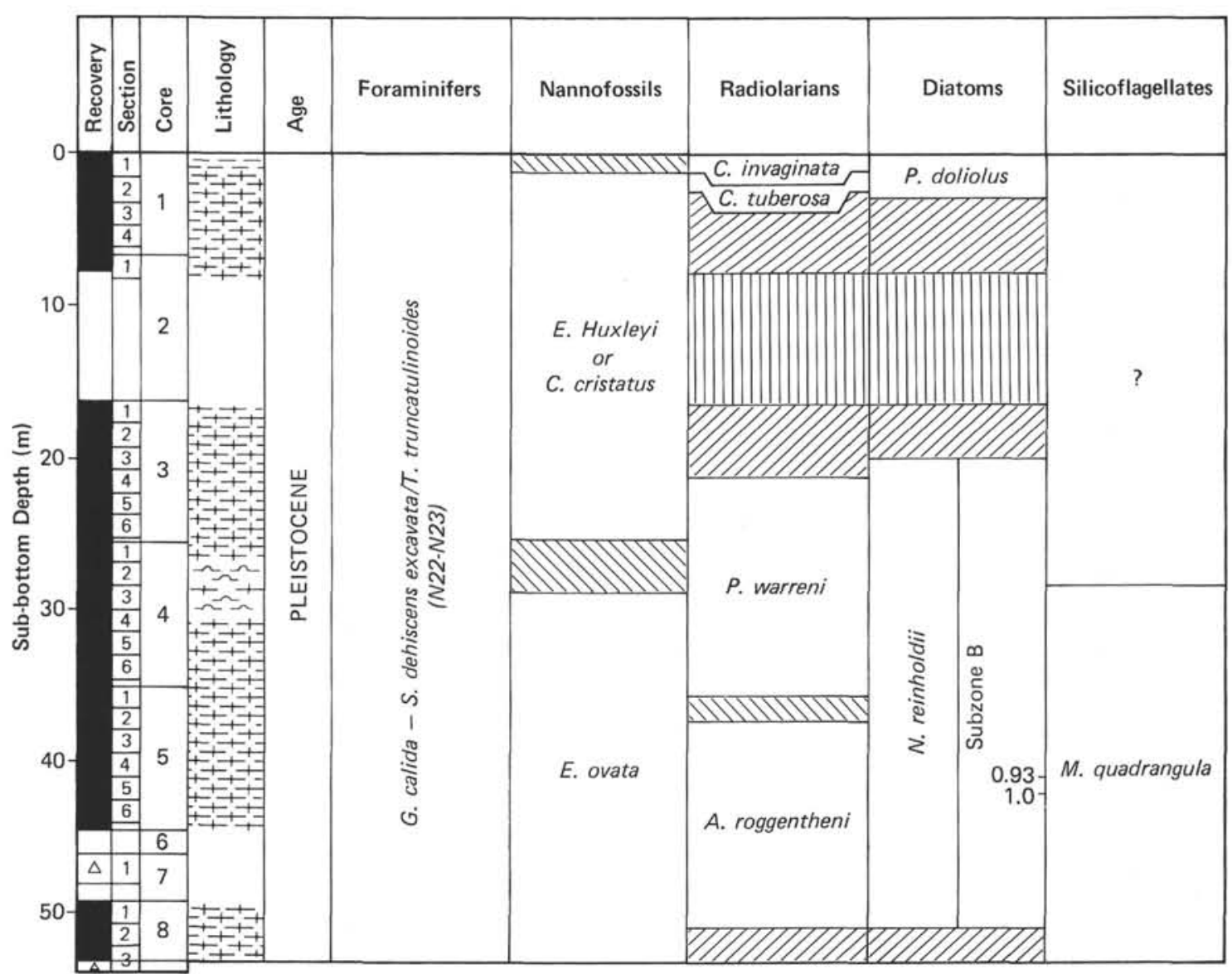

Figure 24. Biostratigraphic summary, Site 422, showing distribution of microfossil zones versus depth. Symbol code as in Figure 21.

pressions next the ridge. The basalts encountered at both sites are fairly massive and doleritic. At Site 422, two such doleritic intervals were cored separated by 3.5-4.0 meters of calcareous sediment. The upper interval is a single cooling unit and may have been intrusive. Both intervals were completely penetrated, since below them we apparently reached normal "fabric" basalts too difficult to drill. We recovered only a single glassy cobble of the latter. At Site 428, two holes were drilled about 500 meters apart with penetrations of 15.5 meters in Hole 428, and 52.5 meters at Hole 428A.

At both Sites 422 and 428 , most of the basalts recovered are highly crystalline and fairly coarse grained. Nevertheless, variations in grain size and to some extent crystallinity indicate that several units were penetrated at both sites - three at Site 422 (not including the lowest "fabric" ferrobasalt), four in Hole 428, and at least five in Hole 428A. Glassy edges to most of these cooling units were not recovered. The upper dolerite at Site 422 (above the sediment interlayer) has a symmetrical grain size variation away from its center; so does the upper four meters of the lower dolerite. Below this, however, is a cooling unit at least 5 meters thick which is subtly but distinctly different chemically, and which has an asymmetric grain size distribution. All of these rocks are aphyric or very sparsely phyric, with very rare plagioclase or plagioclase-clinopyroxene glomerocrysts.
The basalts from these two sites differ from each other petrographically only in subtle ways, since they are very similar chemically, but they are fairly easy to distinguish from the East Pacific Rise ferrobasalts already described, which are much more rich in iron. In the finest grained basalts, those from Sites 422 and 428 either lack plagioclase-clinopyroxene intergrowths or have only a few intergrowths with smaller crystals than in the iron-rich basalts. The concentrations of opaque minerals between spherulites are not as distinctive, nor is their grain size as great. Olivine microphenocrysts, though rare, are persistent, and generally euhedral, not skeletal. Spherulitic to glassy basalts from Site 428 contain abundant, fairly large $(0.01 \times 35-\mathrm{mm})$ acicular plagioclase microlites of labradoritic composition with swallow-tailed or spherulitic terminations, whereas similar basalts at Site 422 have much smaller $(0.005 \times$ $0.05-\mathrm{mm})$, more equant plagioclases. Coarser grained basalts from the two sites range in texture from intersertal to coarsely subophitic and are very similar petrographically, except for a greater abundance of olivine in some Site 422 samples. This may have resulted from crystal settling. These basalts are distinguishable from coarsegrained ferrobasalts by the occurrence of granular and hypidomorphic olivine and lower abundance and finer grain size of skeletal titanomagnetites concentrated in intersertal glassy patches. 


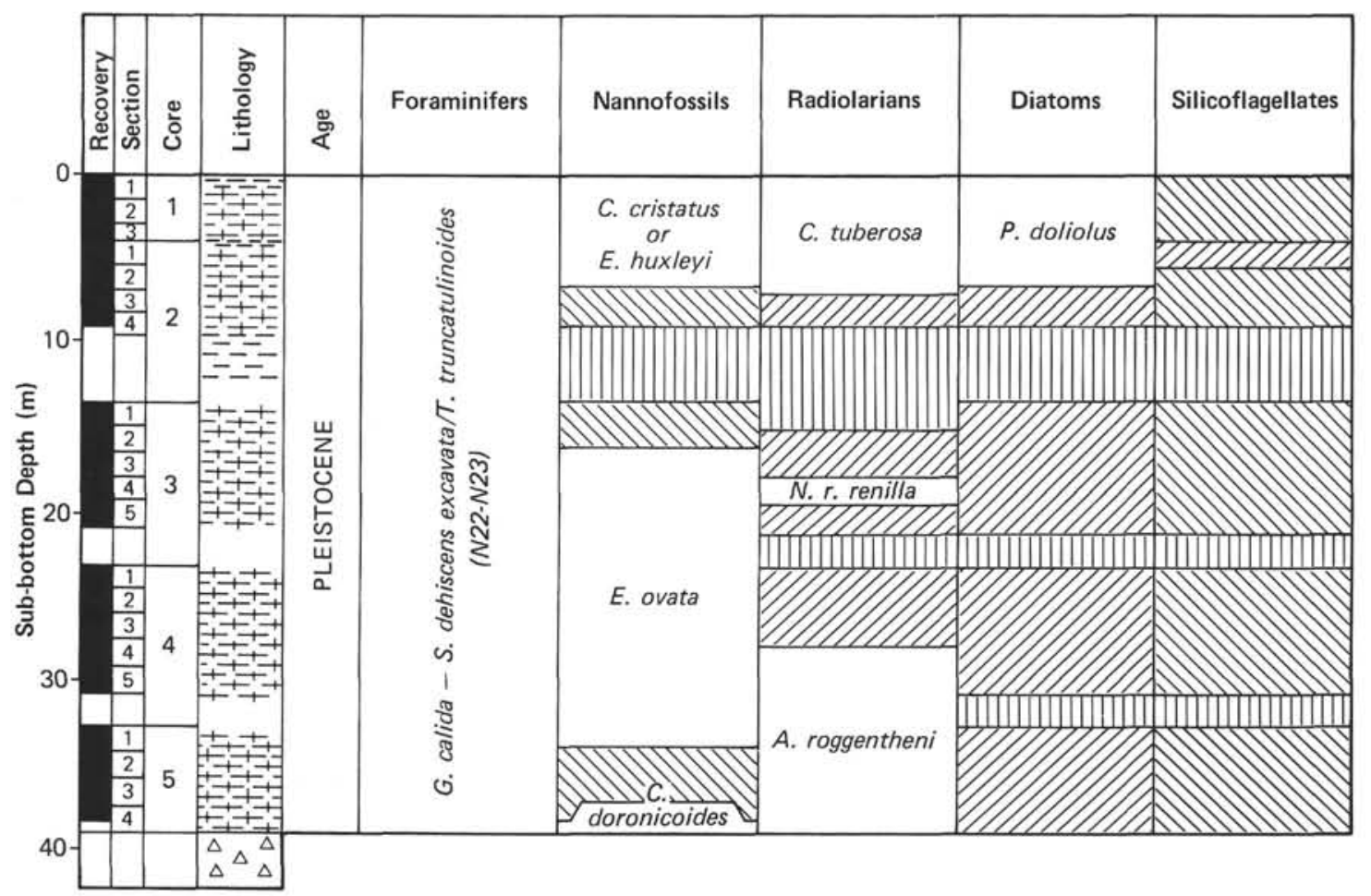

Figure 25. Biostratigraphic summary, Site 423, showing distribution of microfossil zones versus depth. Symbol code as in Figure 21.

Titanomagnetites at both sites increase in size, as the general grain size of silicate minerals increases. At Site 422 , they have an average length of 60 to 80 microns but reach up to 150 microns. At Site 428 , titanomagnetite grain size reaches a maximum of 25 microns, but is more typically only 5 microns.

Sulfides are more common in these holes than in the East Pacific Rise sites occurring as spheres or irregular patches, but not as veins. At Site 422 they are dominantly pyrite with probably a Co- or Ni-rich exsolution product in smaller $(\sim 5-10-\mu \mathrm{m})$ sulfide spheres. The larger pyrite masses apparently occur either as replacements of feldspars, or as late-crystallization products, and are interstitial to feldspars and clinopyroxene. The grain size and abundance increase toward the middle of cooling units, possibly indicating volatile retention or inward concentration as the units consolidated toward their interiors. At Site 422 , both pyrite and pyrrhotite occur as mutual exsolved spheres and masses in five samples.

Alteration products at the two sites are different. There is virtually none at Site 422 , where only two samples have alteration rinds. Vesicles (1-2\%) are either unlined or partially to completely filled with calcite, and dark red, optically, dispersive alteration minerals (clays + Fe hydroxides?). Fracture surfaces tend to be encrusted with a thin layer of blue clay minerals (celadonite?) or Fe oxides. No exsolved ilmenite was found in the titanomagnetites of any sample.

At Site 428 , however, alteration is more pervasive. Olivine is partially or completely replaced with a green or yellow green smectite (nontronite?). Vesicles (1-2\%) are filled with dull brown or yellowish green smectites and, in some cases, calcite. Some vesicles are filled with three concentrically zoned clay minerals. From the outside in these are: (1) green smectite; (2) dark brown smectites with dust-like iron hydroxide inclusions; and (3) a clear fibrous smectite. Alteration in the rocks varies along the cores, and is particularly intense in Core 428A-5. In such zones, even clinopyroxenes are replaced by clays, and cross-cutting smectite veins occur. Ilmenite has exsolved from titanomagnetite in such zones, and iron oxides and hydroxides (hematite, geothite, etc.) replace glass and groundmass minerals. The hematite apparently formed by a dehydration/crystallization mechanism from hydrous $\mathrm{Fe}$ oxyhydroxides, which still partially surround the hematite grains.

\section{Siqueiros Fracture Zone}

Three cores were taken in basement at Hole 427, penetrating 28.5 meters. The basalt recovered is remarkably uniform chemically and lithologically, apparently representing a single cooling unit, probably a ponded flow. Chemically, the basalt is the most iron-enriched recovered at any of the sites in the PT- 4 survey area. Finer grained basalts at the bottom of the hole could represent material fallen down the hole, or another cooling unit which we failed to penetrate further. Horizontal jointing is prevalent in these basalts, and vertical jointing occurs in Section 427-9-1 and Sections 427-10-3 through 5. Apart from an upper chilled margin, the basalts are medium-grained, massive, and sparsely plagioclase phyric. Large tubular vesicles and irregular vugs occur toward the top of the basalts, in Section 427-9-2. 
Rare plagioclase phenocrysts, and microphenocrysts of euhedral plagioclase and anhedral or euhedral clinopyroxene occur in the one spherulitic sample sectioned. These are commonly intergrown and are the largest such intergrowths in any of the ferrobasalts cored in the region. The matrix is dark reddish brown. Opaques are absent closest to the chilled margin but become abundant within a centimeter of the edge. Other sections are considerably coarser grained; those close to the center of the cooling unit (Section 427-10-2) are virtually holocrystalline, with nearly ophitic textures. Plagioclase crystals have normal or, more rarely, oscillatory zoning $\left(\mathrm{An}_{60}-\mathrm{An}_{30}\right)$. A coarser $(\sim 1-\mathrm{cm})$ plagioclase megacryst occurs in thin section 427-9-4 (Piece 3). Titanomagnetite are both abundant and extremely large toward the cooling unit interior, where they are also considerably cracked and pitted.

The basalts have the most diverse opaque mineralogy of all the sites. Titanomagnetite, of course, abounds. In one section [Section 10-4, 53-55 cm Piece 1E] it has exsolved ilmenite from 1 to 3 microns in width and up to 20 microns long. Opaque minerals in vesicles are pyrite, with exsolved pyrrhotite, Fe oxides (geothite), and specular hematite. These are associated with calcite and zeolites. The paragenesis of these minerals is texturally determinable as hematite $\rightarrow$ pyrite and pyrrhotite $\rightarrow$ calcite (small crystals) $\rightarrow$ calcite (large crystals) $\rightarrow$ geothite. The latter appears to be an oxidation product of the earlier produced $\mathrm{Fe}$-bearing phases.

\section{GEOCHEMISTRY OF THE BASALTS DRILLED AT EAST PACIFIC RISE}

Drilling in the $9^{\circ} \mathrm{N}$ region rcovered basement from three major structural features: the East Pacific Rise (EPR) flank fabric, the east-west trending OCP Ridge, and the Siqueiros fracture zone.

Chemical data produced both on board and in shorebased laboratory studies are presented in Joron et al. (this volume) and form the basis of this discussion.

All the basalts that were analyzed proved to be extremely fresh with almost all $\mathrm{H}_{2} \mathrm{O}^{+}$contents of less than 1 per cent and many less than 0.5 per cent (Humphris et al., alteration chapter, this volume). The geochemical characteristics of each structural feature, as indicated by the shipboard analyses, are discussed below. Further discussions will be found in later chapters of this volume (Joron et al.; Dmitriev et al.; Humphris et al.; Srivastava et al., and Hekinian and Morel).

\section{East Pacific Rise Flank Fabric}

Four holes were drilled into the flank fabric at distances of $95 \mathrm{~km}$ (Hole 423), $200 \mathrm{~km}$ (Holes 420 and 421 ), and $264 \mathrm{~km}$ (Hole 429A), west of the axis of the EPR. The plagioclase-clinopyroxene basalts appear to be a relatively uniform group of eruptive products that show no apparent systematic compositional variations either temporally or spatially within the Rise flank fabric. The analyzed basalts are generally moderately to extensively fractionated tholeiites with high $\mathrm{TiO}_{2}(1.7-$ $2.5 \%)$, total iron as $\mathrm{Fe}_{2} \mathrm{O}_{3}(10-13.5 \%)$, and $\mathrm{K}_{2} \mathrm{O}(0.2-$ $0.45 \%$ ). The only exceptions are the olivine-bearing basalts of Hole 429A, which display lower concentrations of $\mathrm{TiO}_{2}(1.2-1.6 \%)$ and $\mathrm{K}_{2} \mathrm{O}(0.08-0.1 \%)$ and more closely resemble the ponded basalts recovered from the OCP Ridge moat. The fractionated nature of the flank lavas and their relative uniformity in composition suggest that the individual eruptive units originated from similar depths in the axial magma reservoir thought to underlie the EPR, after the magmas had resided in the reservoir for long, but similar, periods. Of these sites, only Holes 421 and 429A contained as many as two chemicaly distinct basalt types.

\section{East-West-Trending OCP Ridge}

Drilling at two sites associated with the OCP Ridge reached basement. Hole 422 was drilled in the northern moat, and Holes 428 and 428A in the southern moat of the OCP Ridge. The massive, olivine-bearing basalts from these two sites are extremely similar in compostion and are less fractionated than the fabric basalts. The concentration of $\mathrm{TiO}_{2}$ is generally less than 1.5 per cent, and $\mathrm{K}_{2} \mathrm{O}$ is less than 0.25 per cent. The total iron content is also slightly lower and ranges from 7-11.5 per cent.

In Hole 422 two doleritic units were encountered, with minor differences in chemistry. The upper chemically uniform basalts consist of a short section, separated from the rest of the basement by a sediment layer, and a 4-meter thick section below this sediment (down to the top of Core 422-9-2). These basalts are characterized by $0.10-0.14$ per cent $\mathrm{K}_{2} \mathrm{O}, 1.43-1.44$ per cent $\mathrm{TiO}_{2}, 11.85-11.96$ per cent $\mathrm{CaO}$, and $13.77-14.50$ per cent $\mathrm{Al}_{2} \mathrm{O}_{3}$. The samples analyzed from the lower doleritic unit contain $0.19-0.23$ per cent $\mathrm{K}_{2} \mathrm{O}$, 1.37-1.41 per cent $\mathrm{TiO}_{2}, 11.48-11.53$ per cent $\mathrm{CaO}$, and 15.69-16.04 per cent $\mathrm{Al}_{2} \mathrm{O}_{3}$.

At the bottom of Hole 422, an aphyric basalt was recovered which had high $\mathrm{TiO}_{2}(1.88 \%)$ and $\mathrm{K}_{2} \mathrm{O}(0.31 \%)$ contents. Mineralogically and chemically, this basalt resembles the flank basalt of Holes 420, 421, and 423, and suggests that extrusion of flows associated with the formation of the OCP Ridge postdates the formation of the fabric.

\section{The Siqueiros Fracture Zone}

Site 427 was drilled in the deepest known trough of the Siqueiros fracture zone. The massive basalts recovered are rich in clinopyroxene and plagioclase; from their chemistry, they can be classified as ferrobasalts (Clague and Bunch, 1976). They contain greater than 13 per cent $\mathrm{Fe}_{2} \mathrm{O}_{3}$ (total iron), 2.35-2.48 per cent $\mathrm{TiO}_{2}$, but low $\mathrm{K}_{2} \mathrm{O}(0.05-0.19 \%)$. They form a distinctive, compositionally uniform group of basalts, and represent a single ponded flow. Their genetic relationship, if any, to the fabric basalts requires further studies.

In Figures 33 and 34, chemical characteristics of all the basalts analyzed on Leg 54 are compared with those of dredged samples from the same region (Batiza et al., 1977). These indicate that similar ranges in compositions of the tholeiites were observed in both drilled and dredged samples. In addition, the separation of the Leg 54 analyses into groups corresponding to the three struc- 


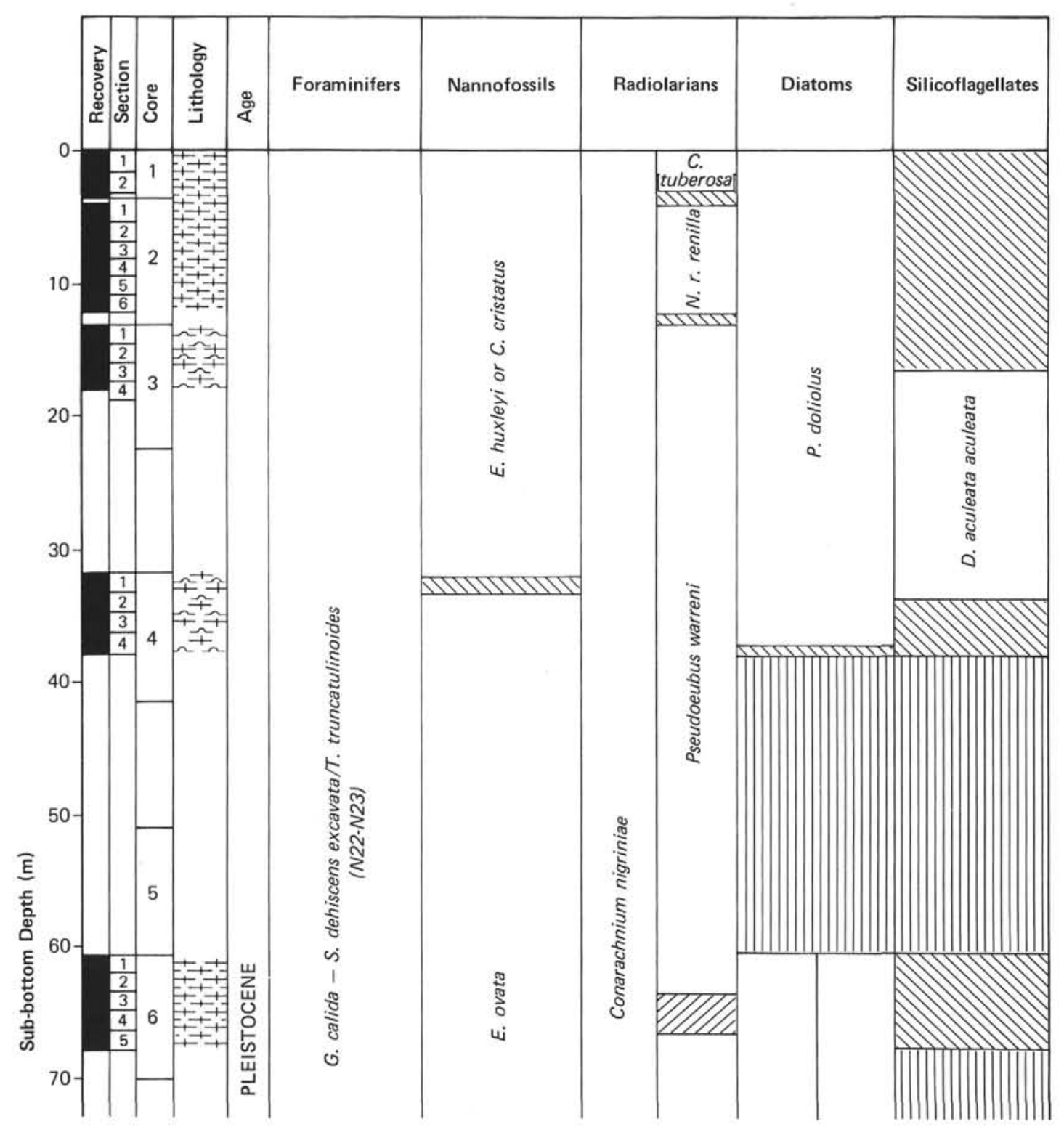




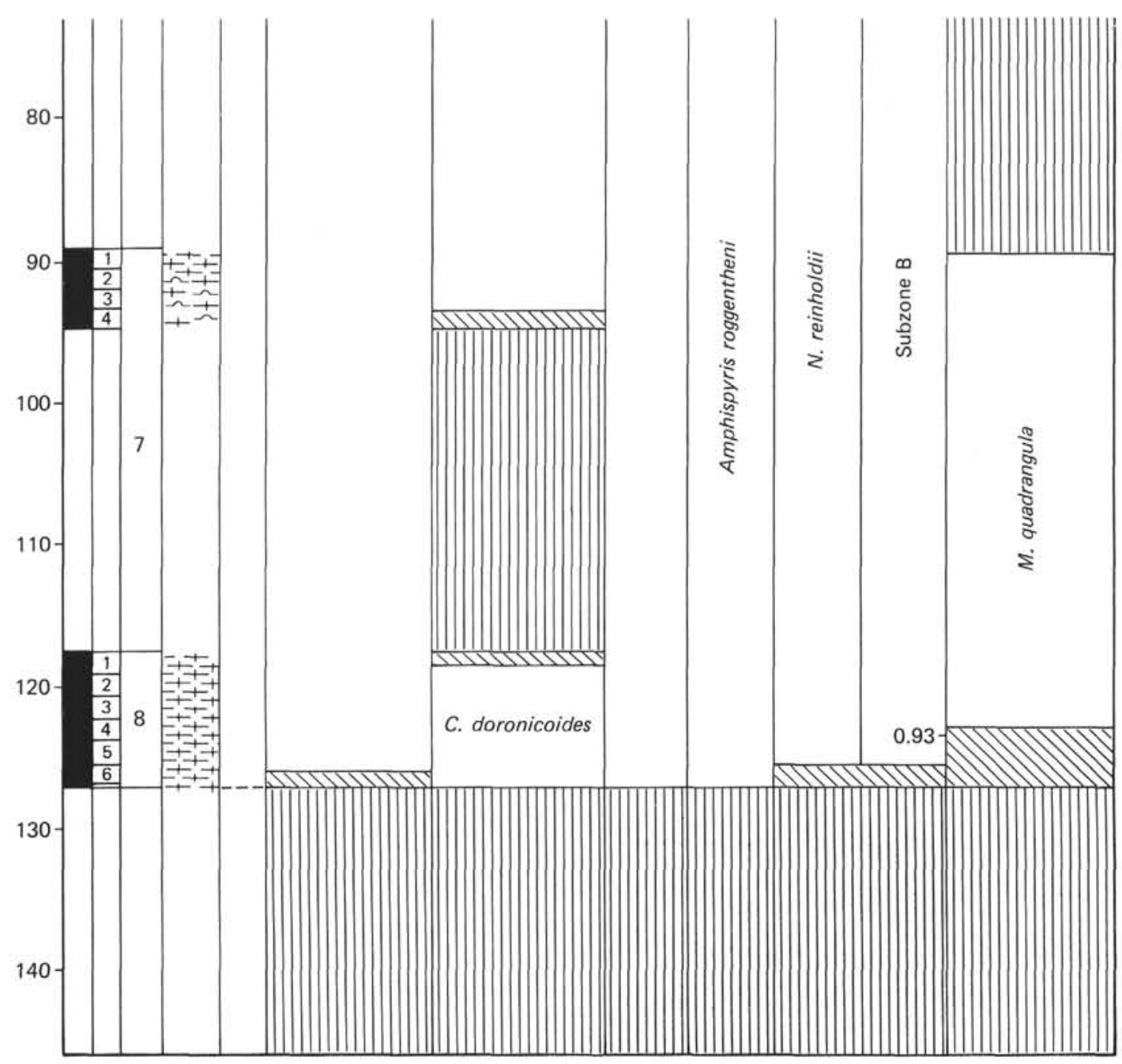

Figure 26. Biostratigraphic summary, Site 427, showing distribution of microfossil zones versus depth. Symbol code as in Figure 21. 


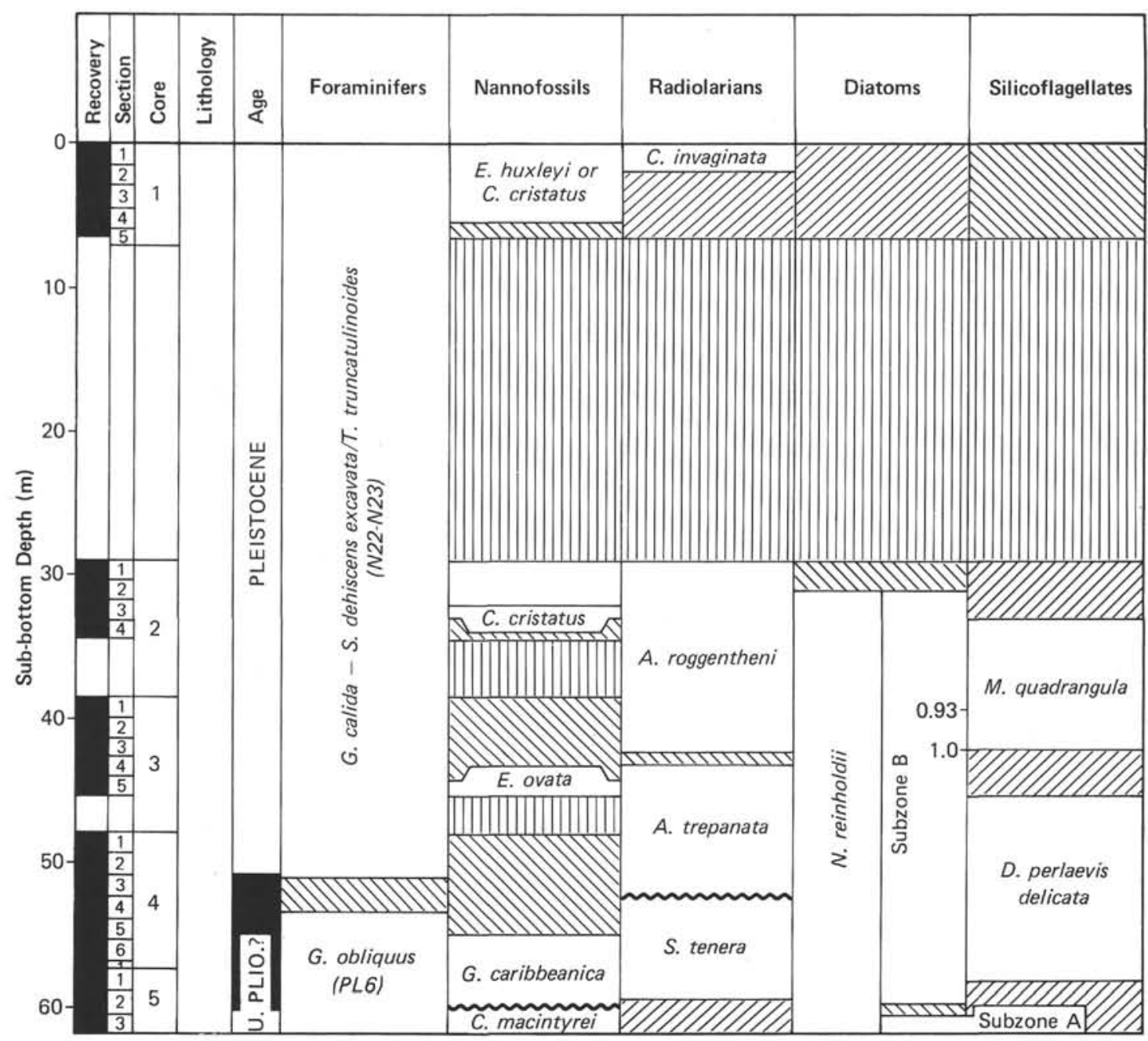

Figure 27. Biostratigraphic summary, Site 428, showing distribution of microfossil zones versus depth. Symbol code as in Figure 21.

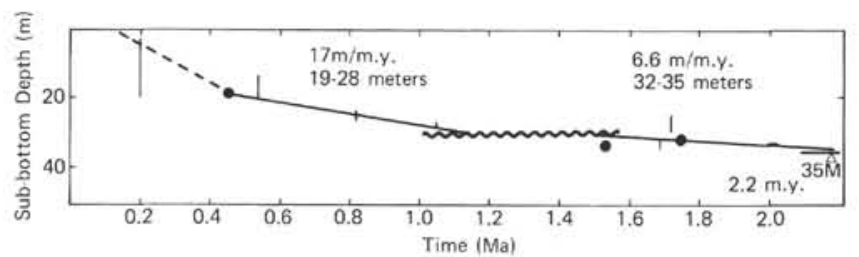

Figure 28. Age versus depth, Hole 419. Sedimentation rates are given in the figure.

tural features is evident. Within each group, particularly the OCP Ridge rocks, there also appears to be a range in the concentrations of $\mathrm{Fe}_{2} \mathrm{O}_{3}$ and $\mathrm{MgO}$ for a given $\mathrm{TiO}_{2}$ value. Such variations are difficult to produce by fractionation of the major mineral phases; this problem is discussed later in this volume (Humphris et al.).

All the tholeiitic basalts recovered from Leg 54 are moderately to extensively fractionated, and comparison of the atomic $\mathrm{Mg} /(\mathrm{Mg}+\mathrm{Fe})$ ratios of basalts from the East Pacific Rise sites with those from the Mid-Atlantic Ridge (Figure 35), indicates that the former are generally more differentiated than those of the latter, suggest-

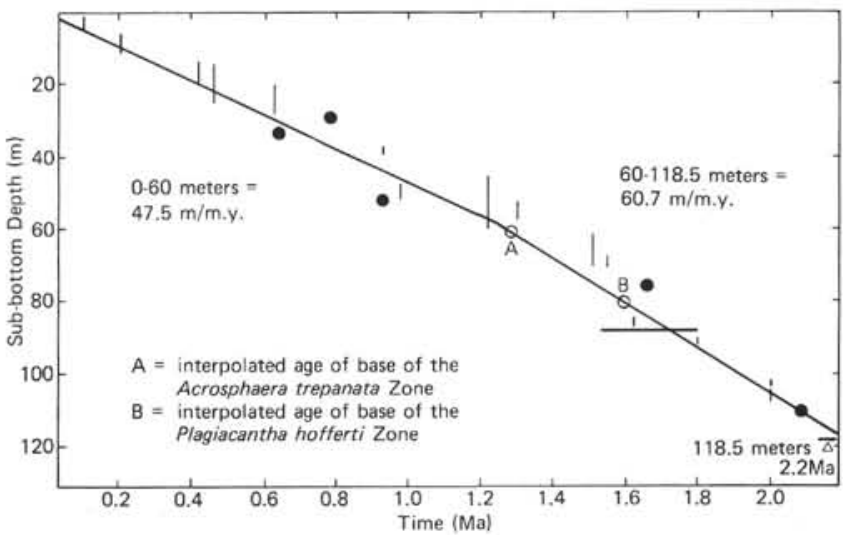

Figure 29. Age versus depth, Site 420. Sedimentation rates are given in the figure.

ing perhaps a longer residence time in the magma reservoir beneath the East Pacific Rise. The cause of this is as yet unknown, but may be related simply to the comparative size of the magma reservoirs (cf., Rosendahl, 1976), or to differences in the degree of partial melting. 


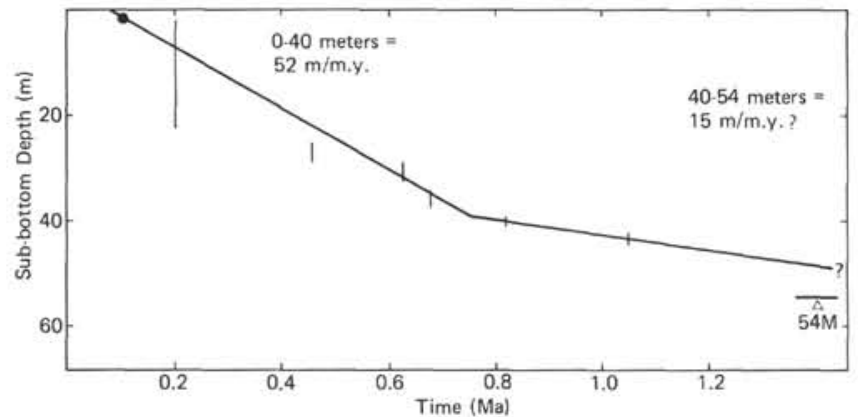

Figure 30. Age versus depth, Site 422. Sedimentation rates are given in the figure.

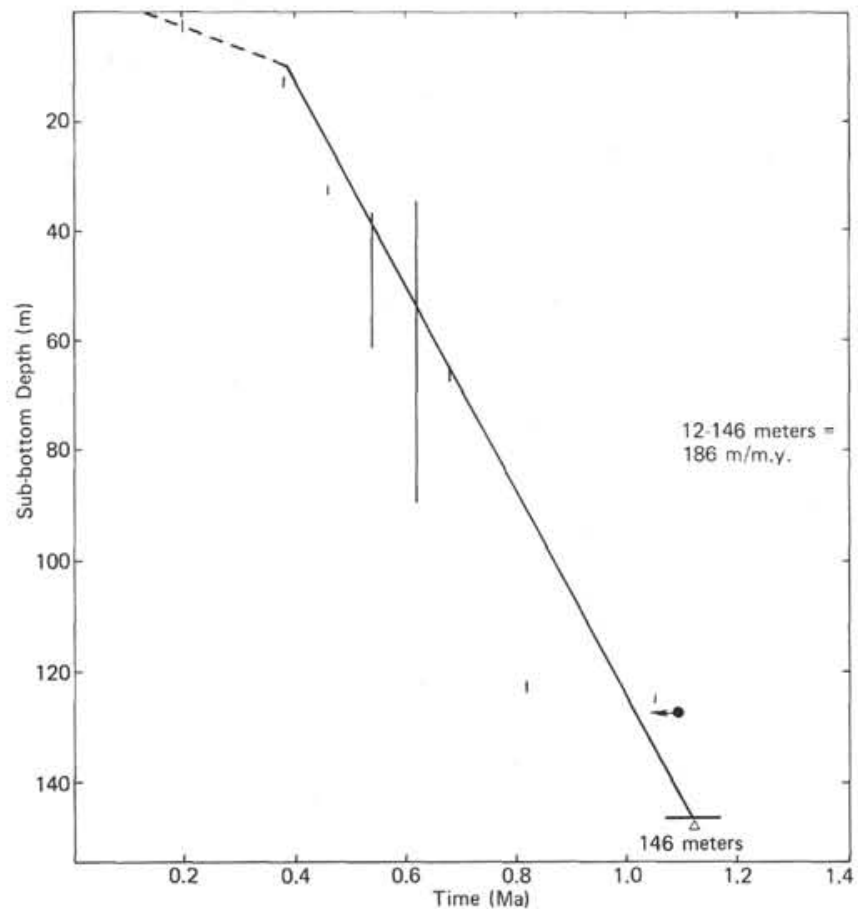

Figure 31. Age versus depth, Site 427. Sedimentation rate is given in the figure.

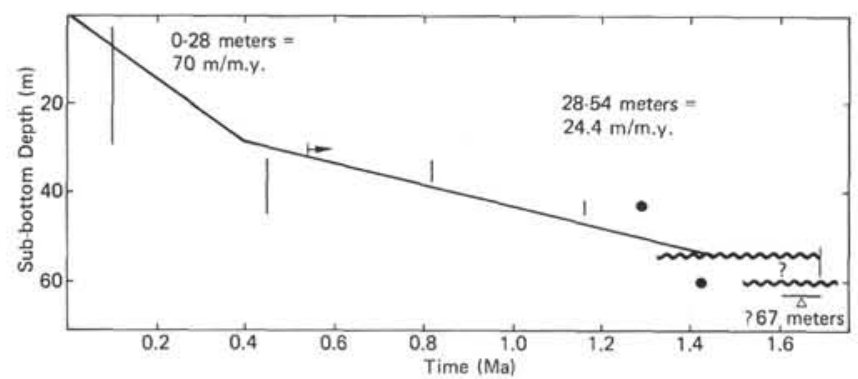

Figure 32. Age versus depth, Site 428. Sedimentation rates are given in the figure.

\section{PHYSICAL PROPERTIES OF SEDIMENTS}

The physical properties of the sediments cored at the East Pacific Rise sites are virtually identical with the
TABLE 11

Micropaleontologic Events Used for Leg 54 Basal Sediment

Dating and Sedimentation Rate Calculation, Using Relationships at Site $\mathbf{4 2 0}$ as a Standarda

\begin{tabular}{llcc}
\hline Event & \multicolumn{1}{c}{ Taxon } & $\begin{array}{c}\text { General } \\
\text { Age } \\
\text { (m.y.) }\end{array}$ & $\begin{array}{c}\text { Extrapolated Age } \\
\text { at Site } 420 \\
\text { (m.y.) }\end{array}$ \\
\hline LOS-R1 & C. invaginata & 0.10 & same \\
LOS-R2 & C. tuberosa & 0.20 & same \\
HOS-R3 & S. universus & 0.41 & 0.38 \\
HOS-C1 & E. ovata & 0.46 & same \\
HOS-D1 & N. reinholdii & 0.63 & 0.54 \\
HOS-R4 & A. roggentheni & 0.65 & 0.68 \\
HOS-S1 & M. quadrangula & 0.79 & 0.62 \\
LOS-R5 & C. nigriniae & 0.91 & 1.09 \\
HOS-D2 & R. matuyamai & 0.93 & 0.82 \\
LOS-D3 & R. matuyamai & 0.98 & 1.05 \\
HOS-C2 & H. sellii & 1.22 & same \\
HOS-R6 & S. crassus & none & 1.28 \\
LOS-S2 & M. quadrangula (acme) & $1.0-1.3$ & 1.16 \\
HOS-C3 & C. macintyrei & 1.51 & 1.39 \\
LOS-R7 & P. hofferti & none & 1.58 \\
HOS-D4 & R. praebergonii robusta & 1.55 & 1.42 \\
HOS-F1 & G. obliquus & 1.62 & 1.69 \\
HOS-C4 & D. Jrouweri & 1.65 & 1.52 \\
LOS-R8 & C. huxleyi & 1.8 & 1.74 \\
LOS-D5 & P. doliolus & 1.8 & 1.78 \\
LOS-S3 & D. perlaevis delicata & $1.5-1.8$ & 1.72 \\
HOS-D6 & T. convexa & 2.0 & 1.96 \\
HOS-C5 & D. pentaradiatus & 2.0 & same \\
HOS-C6 & D. surculus & 2.1 & same \\
\hline & & &
\end{tabular}

${ }^{a}$ Compiled from information supplied by J. A. Barron, D. Bukry, and R. M. Goll, in June 1978. LOS = lowest occurrence surface. HOS $=$ highest occurrence surface. $\mathrm{C}=$ coccolith, $\mathrm{D}=$ diatom, $\mathrm{R}=$ radiolarian, $\mathrm{S}=$ silicof lage llate .

average properties of the softer sediments from similar sub-bottom depths, recovered on other DSDP Legs in or near the Panama basin.

The pelagic sediments are generally soft, having low velocities and densities, high porosity, and low shear strengths. Typically, the sediments cored on this Leg have velocities of about 1.45 to $1.55 \mathrm{~km} / \mathrm{s}$, densities of 1.15 to $1.3 \mathrm{~g} / \mathrm{cm}^{3}$, porosities of 80 to over 90 per cent and water contents of 60 to 80 per cent. Shear strengths are on the order of 0.01 to 0.04 tons per square foot, with higher values associated with less disturbed sediments. These numbers are very similar to those obtained, for example, in the younger sediments cored at Sites 83 and 84, east of the Pacific Rise between $4^{\circ}$ and $6^{\circ} \mathrm{N}$ and $83^{\circ}$ and $96^{\circ} \mathrm{W}$ (Hays et al., 1972). At our East Pacific Rise sites, the properties of the sediments varied little from mud-line to basement contact and there was no overall systematic relationship between visual layers within a core and physical properties. An average grain density over all the sites (including the Galapagos) was estimated from the water content data. Excluding all values greater than $4.0 \mathrm{~g} / \mathrm{cm}^{3}$, the average grain density was $2.764 \mathrm{~g} / \mathrm{cm}^{3}$, close to standard values of $2.7 \mathrm{~g} / \mathrm{cm}^{3}$ used by DSDP for reducing GRAPE data for the plots here. 
TABLE 12

Micropaleontologic Age Estimates for Basal Fossil Assemblages or Extrapolated Micropaleontologic Age Based on Sedimentation Curves for the Siqueiros Sites Compared with Magnetic Age Estimates for Basement

\begin{tabular}{|c|c|c|c|c|c|c|}
\hline Site & $\begin{array}{c}\text { Depth } \\
\text { Sub-Bottom } \\
\text { to Basement } \\
(\mathrm{m})\end{array}$ & $\begin{array}{l}\text { Basal } \\
\text { Sediments } \\
\text { Sampled? }\end{array}$ & $\begin{array}{l}\text { Basal Sediment Age } \\
\text { Determined by Microfossils } \\
\text { or Extrapolation }\end{array}$ & $\begin{array}{l}\text { Fossil Age } \\
\text { Estimate } \\
\text { (m.y.) }\end{array}$ & $\begin{array}{c}\text { Magnetic Age } \\
\text { Estimate } \\
\text { of Basalt } \\
\text { (m.y.) }\end{array}$ & $\begin{array}{c}\text { Average Rate } \\
\text { of Sediment } \\
\text { Accumulation } \\
\text { (meters/m.y.) }\end{array}$ \\
\hline 419 & 35 & ? yes? & coccoliths & $2.0-2.1$ & 2.43 to 2.93 & 17.1 \\
\hline 420 & 118.5 & yes & extrapolation & 2.2 & 3.37 & 53.8 \\
\hline 421 & 95 & yes & coccoliths + radiolarians & $1.3-2.1$ & 3.37 & $45.2-73.0$ \\
\hline 422 & 54 & yes & - & ? & 1.79 & - \\
\hline 423 & 42 & yes & coccoliths + radiolarians & $0.9-1.09$ & 1.6 & 42 \\
\hline 427 & 146 & $\begin{array}{c}\text { no } 19-m \\
\text { discontinuity }\end{array}$ & extrapolation & 1.12 & $\sim 2^{\mathrm{a}}$ & 130.4 \\
\hline 428 & 67 & yes & coccoliths + diatoms & $1.42-2.0$ & 2.0 to 2.5 & $33.5-47.2$ \\
\hline 429 & 31 & no & coccoliths & $>2.06$ & 4.6 & - \\
\hline
\end{tabular}

${ }^{\mathrm{a}}$ Petersen and Roggenthen, this volume.

TABLE 13

Basement Coring and Recovery Data, East Pacific Rise, Leg 54

\begin{tabular}{|c|c|c|c|}
\hline Hole & $\begin{array}{l}\text { Length Cored } \\
\text { (m) }\end{array}$ & $\begin{array}{l}\text { Length Recovered } \\
\qquad(\mathrm{m})\end{array}$ & $\begin{array}{c}\text { Recovery } \\
(\%)\end{array}$ \\
\hline \multicolumn{4}{|c|}{ East Pacific Rise } \\
\hline $\begin{array}{l}420 \\
421 \\
423 \\
429 \mathrm{~A}\end{array}$ & $\begin{array}{l}31.5 \\
30.0 \\
11.5 \\
21.5\end{array}$ & $\begin{array}{l}1.39 \\
1.60 \\
0.87 \\
2.95\end{array}$ & $\begin{array}{r}4.4 \\
5.3 \\
7.6 \\
13.7\end{array}$ \\
\hline Total & 94.5 & 6.81 & 7.2 \\
\hline \multicolumn{4}{|c|}{ OCR Ridge ("Moat") } \\
\hline $\begin{array}{l}422 \\
428 \\
428 \mathrm{~A}\end{array}$ & $\begin{array}{l}13.5 \\
15.5 \\
52.5\end{array}$ & $\begin{array}{r}9.56 \\
2.14 \\
16.37\end{array}$ & $\begin{array}{l}70.8 \\
13.8 \\
31.2\end{array}$ \\
\hline Total & 81.5 & 28.07 & 34.4 \\
\hline \multicolumn{4}{|c|}{ Siqueiros Fracture Zone } \\
\hline 427 & 28.5 & 12.51 & 43.9 \\
\hline $\begin{array}{l}\text { Grand } \\
\text { Total }\end{array}$ & 204.5 & 47.39 & 23.2 \\
\hline
\end{tabular}

\section{Hole 419}

Compressional velocities (Table 16) and log densities (analog GRAPE: Table 17) were run on sections of Cores 2 through 5 (Figure 36). Velocities were determined both immediately upon core receipt and after a minimum of five hours in order to determine the effect of temperature (about $19^{\circ} \mathrm{C}$ on core recovery) and loss of saturation with time over the five hours. Syringe and bulk samples were taken for water content, wet and dry density, and porosity determinations (Table 18).

The scaling-wave technique (Chapter 1 , this volume) proved to be very flexible and accurate. Cores could be logged quickly and easily, with accuracy limited predominantly by signal rise time and the need to assume standard corrections for liner thickness and delay time.

The physical properties of the sediments were uniform throughout the sediment column (Figure 36), but were affected by the moderate to severe level of disturbance of all the cores. This level of disturbance makes it difficult to draw firm conclusions about local, in situ, fluctuations in the physical properties of the sediments.

The room-temperature velocities of the sediments ranged between about $1.54 \mathrm{~km} / \mathrm{s}$ and $1.46 \mathrm{~km} / \mathrm{s}$ (one value as low as 1.42 was measured at $18^{\circ} \mathrm{C}$, which reflects both temperature effects and disturbance), with the mean being about $1.5 \mathrm{~km} / \mathrm{s}$.

The low bottom-water velocity was estimated to be about 1.52 to $1.53 \mathrm{~km} / \mathrm{s}$. The in situ velocities of the sediments are estimated to be within a few per cent of the velocity of sound of the bottom water, all the way to basement. The suggestion in the data of an inverse correlation between velocity and density indicates that the sediments were completely unconsolidated. Minimum velocities are in good agreement with mean values published for medium silt and clay fine silts (Nafe and Drake, 1966) - namely 1.46 to $1.47 \mathrm{~km} / \mathrm{s}$ - and with the results from Leg 9 (Hays et al., 1972).

The densities of the cores, as GRAPE, were similar to results from Sites 82 and 83 (latitudes $3^{\circ}-5^{\circ} \mathrm{N}$, longitudes $97^{\circ}-106^{\circ} \mathrm{W}$ ): about 1.2 to $1.3 \mathrm{~g} / \mathrm{cm}^{3}$. Corrected GRAPE densities were about 1.1 to $1.2 \mathrm{~g} / \mathrm{cm}^{3}$, with porosities averaging $85-90$ per cent.

Syringe samples were taken from water content determinations but the density and porosity results are inaccurate, giving porosities over 100 per cent. The major source of error apparently resides in measuring the $3-\mathrm{cm}^{3}$ sample volume. The data are not reproduced here.

\section{Site $\mathbf{4 2 0}$}

The velocities (Table 16) average $1.5 \mathrm{~km} / \mathrm{s}$ and are essentially uniform with depth as at Site 419 (Figure 37). Any anisotropy in velocity is limited to less than 2 per cent with the fast direction vertical. These measured velocities can be compared to the average in situ sediment velocity estimated from the EDO records. The two-way travel time through the sediments is about $0.145 \pm 0.005$ $\mathrm{km} / \mathrm{s}$ and the cored sediment thickness was 115 meters, giving an average velocity of about $1.57 \pm 0.04 \mathrm{~km} / \mathrm{s}$.

Sediment densities (Table 17) were similar to those at Site 419 , averaging about $1.2 \mathrm{~g} / \mathrm{cm}^{3}$ and 85 per cent to 
TABLE 14

Primary Mineralogy of Basalts Cored on the East Pacific Rise, Leg 54

\begin{tabular}{|c|c|c|c|c|c|c|c|c|c|c|}
\hline Hole & $\begin{array}{l}\text { Plagio- } \\
\text { clase }\end{array}$ & $\begin{array}{l}\text { Clinopy- } \\
\text { roxene }\end{array}$ & Olivine & $\begin{array}{l}\text { Titano- } \\
\text { magnetite }\end{array}$ & $\begin{array}{l}\text { Ilmen- } \\
\text { ite }\end{array}$ & $\begin{array}{c}\text { Chromian } \\
\text { Spinel }\end{array}$ & $\begin{array}{c}\text { Spherical } \\
\text { (Round) } \\
\text { Pyrite }\end{array}$ & $\begin{array}{l}\text { Irreg- } \\
\text { ular } \\
\text { Pyrite }\end{array}$ & $\begin{array}{l}\text { Chalca- } \\
\text { pyrite }\end{array}$ & $\begin{array}{c}\text { Pyrrho- } \\
\text { tite }\end{array}$ \\
\hline \multicolumn{11}{|c|}{ East Pacific Rise } \\
\hline 420 & $\mathrm{x}$ & $x$ & $(x)^{b}$ & $x(S)$ & $x$ & & $x$ & $x$ & $\mathrm{x}$ & \\
\hline 421 & $\mathrm{x}$ & $\mathrm{x}$ & & $x(L, S)$ & & & $\mathrm{x}$ & $\mathrm{x}$ & & \\
\hline 423 & $\mathrm{x}$ & $\mathrm{x}$ & & $x(S)$ & & & $\mathrm{x}$ & $\mathrm{x}$ & & \\
\hline 429 & $\mathrm{x}$ & $\mathrm{x}$ & $\mathrm{x}$ & $x(L, S)$ & & $\mathrm{x}$ & $\mathrm{x}$ & $x$ & & \\
\hline$(422)^{\mathrm{c}}$ & $\mathrm{x}$ & $\mathrm{x}$ & & $x(S)$ & & & $\mathrm{x}$ & $\mathrm{x}$ & & \\
\hline \multicolumn{11}{|c|}{ OCP Ridge } \\
\hline 422 & $\mathrm{x}$ & $\mathrm{x}$ & $\mathrm{x}$ & $\mathrm{x}(\mathrm{L})$ & & $\mathrm{x}$ & $\mathrm{x}$ & $\mathrm{x}$ & $?$ & $\mathrm{x}$ \\
\hline 428 & $\mathrm{x}$ & $\mathrm{x}$ & $\mathrm{x}$ & $x(L)$ & & & $\mathrm{x}$ & $\mathrm{x}$ & & \\
\hline $428 \mathrm{~A}$ & $\mathrm{x}$ & $\mathrm{x}$ & $\mathrm{x}$ & $x(L)$ & $\mathrm{x}$ & & $\mathrm{x}$ & $\mathrm{x}$ & & \\
\hline \multicolumn{11}{|c|}{ Siqueiros Fracture Zone } \\
\hline 427 & $\mathrm{x}$ & $\mathrm{x}$ & & $x(L)$ & & & $\mathrm{x}$ & $\mathrm{x}$ & & $\mathrm{x}$ \\
\hline
\end{tabular}

at least 90 per cent porosity. Two 2 -minute GRAPE measurements on the cores gave comparable density to those reduced from the analogue GRAPE records.

The results of the syringe technique are consistent with those obtained from GRAPE measurement (Table 18 ). Without salt corrections, porosities average about 85 to 90 per cent, and densities range from about 1.15 to $1.34 \mathrm{~g} / \mathrm{cm}^{3}$. Water contents average about 70 per cent. Salt corrections change these values by about 3 per cent. Calculations of grain densities (equation 5 in Chapter 1, Introduction, this volume) indicate that for any one sample, the measured values of the water content and porosities are not fully self-consistent. The calculated grain densities range from about 1.7 to over $4.0 \mathrm{~g} / \mathrm{cm}^{3}$. High grain densities probably indicate that the samples had dehydrated before measurement, or contained considerable air-filled void space. The average value, excluding all densities over $4.0 \mathrm{~g} / \mathrm{cm}^{3}$ is $2.591 \mathrm{~g} / \mathrm{cm}^{3}$ -lower than the $2.7 \mathrm{~g} / \mathrm{cm}^{3}$ assumed in the GRAPE reductions or typical of calcite. However, differences are within the variance of the data. Equation (4) in the introduction (Chapter 1, this volume) gives a mean grain density of $2.602 \mathrm{~g} / \mathrm{cm}^{3}$. A theoretical grain density of $2.710 \mathrm{~g} / \mathrm{cm}^{3}$ is compatible with a water content of 76.3 per cent and a porosity of 89.9 per cent.

\section{Hole 421}

At Hole 421 only a mud-line core was taken. Velocity mesurements in Section 1-4, were $1.504 \mathrm{~km} / \mathrm{s}$ and in Section 1-6, $1.524 \mathrm{~km} / \mathrm{s}$. Densities of these sediments were 1.20 to $1.25 \mathrm{~g} / \mathrm{cm}^{3}$.

Water content, bulk densities, and porosity were determined for four samples of sediment from the mudline core (Table 18). The values are comparable with those at Site 420.

\section{Hole 422}

The sediments at Hole 422 are quite homogeneous in their physical properties, but relatively more disturbed than those at the previous sites on this Leg (Figure 38). Velocity measurements cluster around $1.50 \mathrm{~km} / \mathrm{s}$ (Table 16), with one relatively undisturbed section giving velocities as high as $1.54 \mathrm{~km} / \mathrm{s}$. In split cores that visually were judged to be little disturbed, shear strength measurements were taken with the Torvane (Table 19). The shear strength values are very low $(\sim 0.016$ to 0.05 tons /square foot) and fall consistently within those reported for soft water-saturated clays (i.e., Leg 51, Site 417).

GRAPE densities were generally between 1.20 and $1.25 \mathrm{~g} / \mathrm{cm}^{3}$ (Table 17). The sediments cored beneath the upper doleritic units were too disturbed for reliable measurements, but it was clear from their lithology that their original physical properties were quite similar to those of the overlying sediments.

The site survey seismic reflection profile across the "moat" drilled at Site 419 (and to a lesser degree the Challenger profile, Leg 54) show an unusually strong, horizontal, and thick basement reflector lying about $0.06-0.65 \mathrm{~s}$ (two-way reflection time) below the sea floor at Hole 419 . Using the 0.06 value and the measured sediment thickness of 46 meters, we computed a mean in situ velocity of $1.54 \mathrm{~km} / \mathrm{s}$, which agrees very well with the laboratory in situ $V_{P}$ estimates on the less disturbed sections of sediment at this site.

Sediment water content, bulk densities, and porosities were determined on eight samples from Hole 422 (Table 18). Results show that the sediments are homogeneous in their physical properties. These measurements also agree with the GRAPE data. However, theoretical grain densities determined from the syringe method are 
TABLE 15

Modal Analyses of Basalts from the East Pacific Rise, Leg 54 ${ }^{\mathrm{a}}$

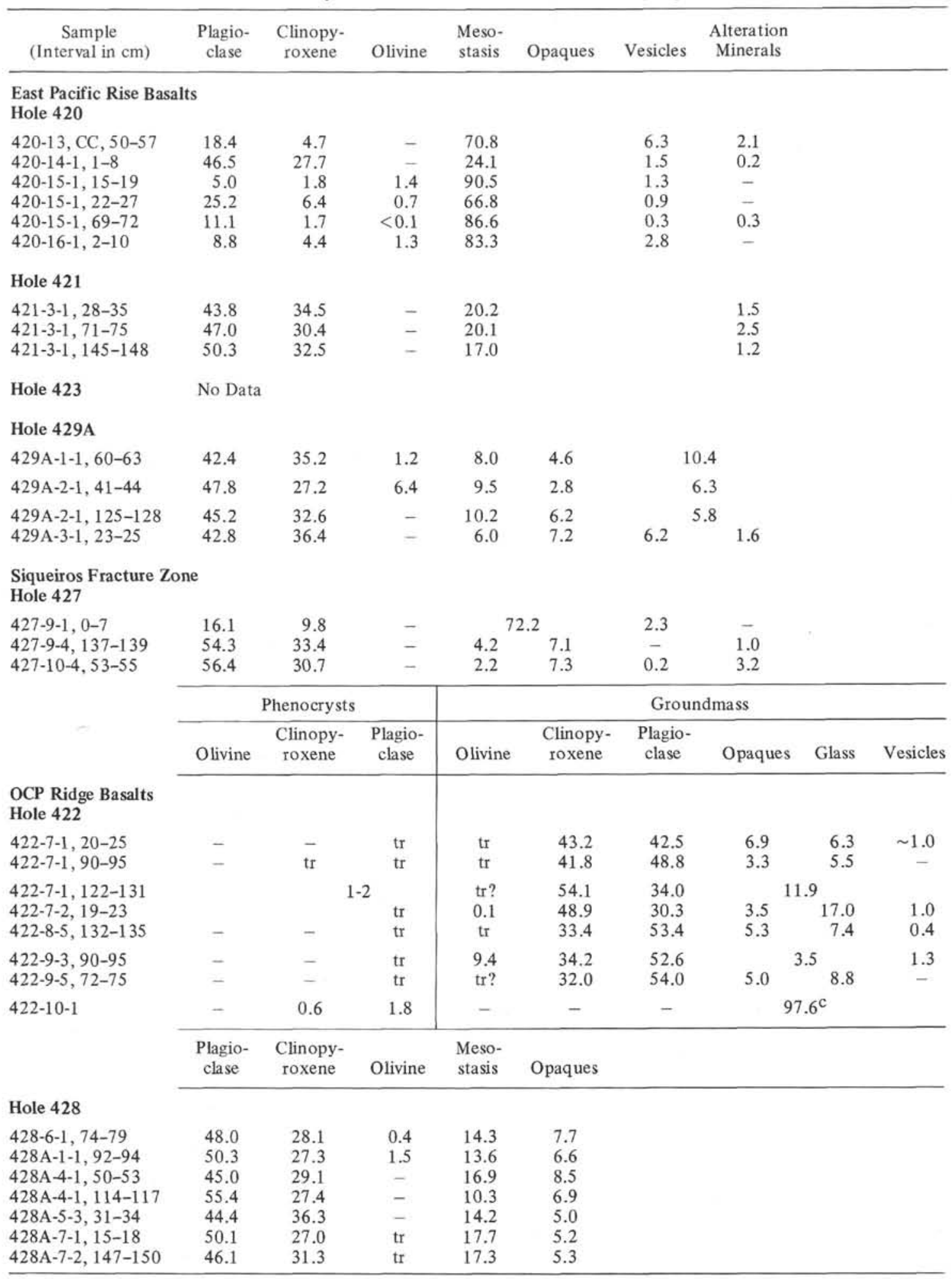

${ }^{a}$ Number of counts for all samples $=1000$.

$\mathrm{b}$ Includes alteration minerals and vesicles.

${ }^{\mathrm{c}}$ Includes microlites. 


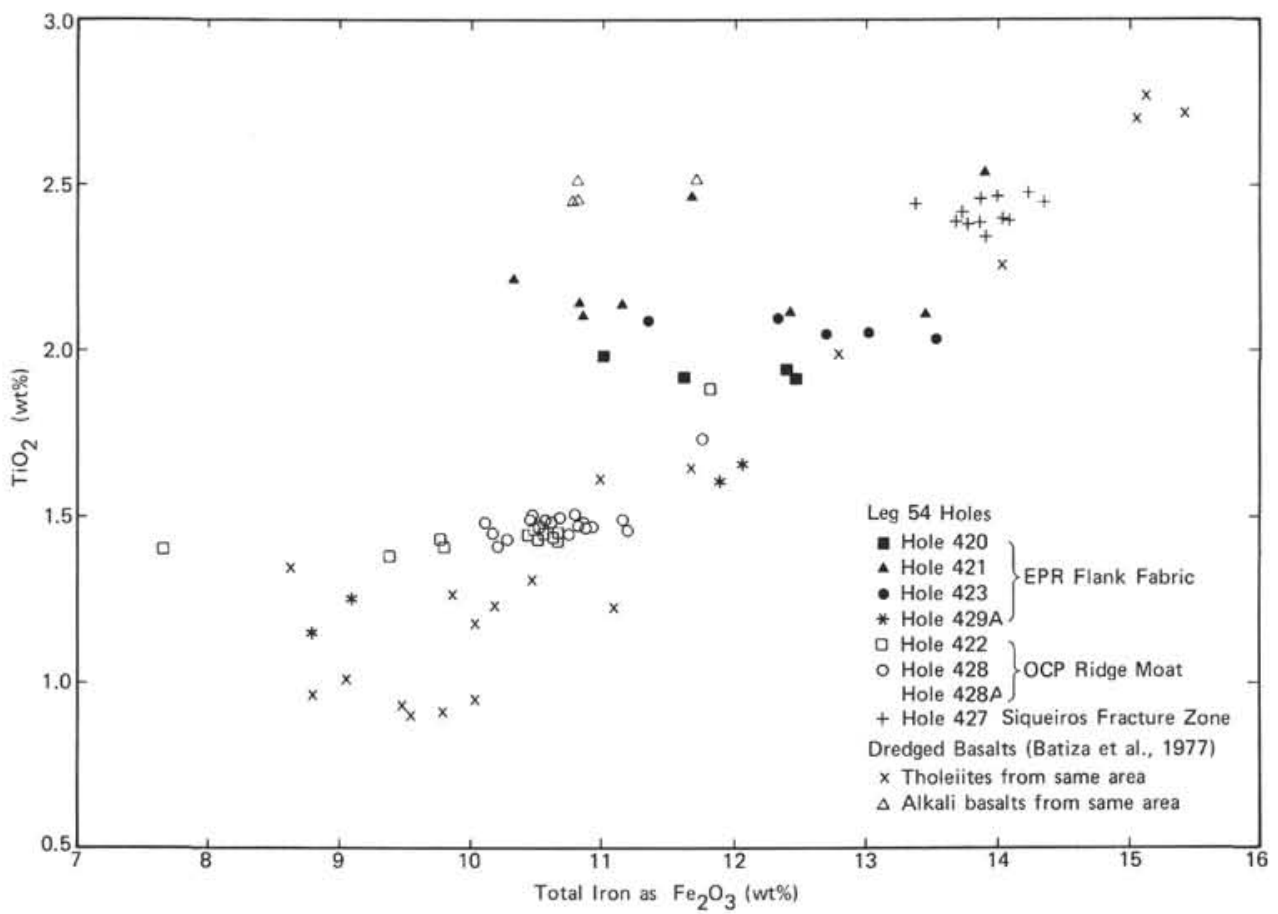

Figure 33. $\mathrm{Fe}_{2} \mathrm{O}_{3}$ versus $\mathrm{TiO}_{2}$ for basalts from the $9^{\circ} \mathrm{N}$ region, East Pacific Rise.

too high, indicating small inconsistencies between the values of the water content and porosity.

\section{Hole 423}

Sediment velocities and densities again group near $1.50 \mathrm{~km} / \mathrm{s}$ and $1.20 \mathrm{~g} / \mathrm{cm}^{3}$, respectively (Table 20). The sediment lithologies are basically uniform, and velocity and density do not resolve lithologic variations (Figure 39).

The water contents and porosities (Table 18) are generally of larger values than at previous sites. Selfconsistent grain densities for these samples are too high to be reliable.

\section{Hole 427 (Siqueiros Fracture Zone)}

The physical properties of the sediments sampled at this site are similar to those elsewhere in the PT- 4 area. Velocities (Table 16), densities (Table 17). and shear strengths (Table 19) are typically $1.5 \mathrm{~km} / \mathrm{s}, 1.2 \mathrm{~g} / \mathrm{cm}^{3}$, and $0.04-0.1$ tons/square foot, respectively (Figure 40). Some fairly stiff zones in the sediments presumably have higher velocities, but they attenuated the acoustic signal too greatly for velocities to be measured accurately. One stiff ("indurated") sample taken from near a pyrite-rich zone had a velocity of about $2 \mathrm{~km} / \mathrm{s}$, but two others sampled from nearby had lower velocities, between 1.51 and $1.55 \mathrm{~km} / \mathrm{s}$.

\section{Hole 428 and 429A}

At Hole 428 the sediments were disturbed; only a few velocity (Table 16) and water content (Table 18) data were taken.

At Hole 429A no sediment velocities were measured. One water content determination (from Sample 1-3, 0-6 $\mathrm{cm}$ ) gave a water content of 68.1 per cent, a porosity of 90.2 per cent, and a wet-bulk density of $1.32 \mathrm{~g} / \mathrm{cm}^{3}$; the self-consistent grain density was $4.432 \mathrm{~g} / \mathrm{cm}^{3}$, a high value, indicating that the other parameters are only accurate to a few per cent.

\section{PHYSICAL PROPERTIES OF BASALTS}

This section presents a summary of shipboard physical properties data on basalts. In addition, grain densities were measured by the pycnometer method in the laboratory at UCLA. These data are compiled in Tables 21 and 22 of this chapter.

As discussed in Warren and Rosendahl (this volume), the velocity and density data, listed in Table 23 , satisfy a Birch's law relationship. They fall on a trend that parallels the one defined by basalts from the Mid-Atlantic Ridge. Furthermore, the data for groups of sites show systematics which are controlled by the iron content of the samples. The three groups are the East Pacific Rise sites (Sites 419 through 423; 428 and 429), the Siqueiros fracture zone site (Site 427) and the Galapagos sites (Sites 424 and 425 ). Within each group there are also sub-groups such as the OCP Ridge "moat" sites (Sites 422 and 428 of the EPR group).

These systematics are observable in plots of velocity versus density discussed below. On these plots, the data for various sites are plotted against outlines of fields which characterize the velocity-data distribution. The fields are: (1) Sites 420 and 421; (2) Site 422; (3) Hole 424; (4) Holes 424A, B, and C; and (5) Site 425.

\section{Hole 419}

No igneous samples. 


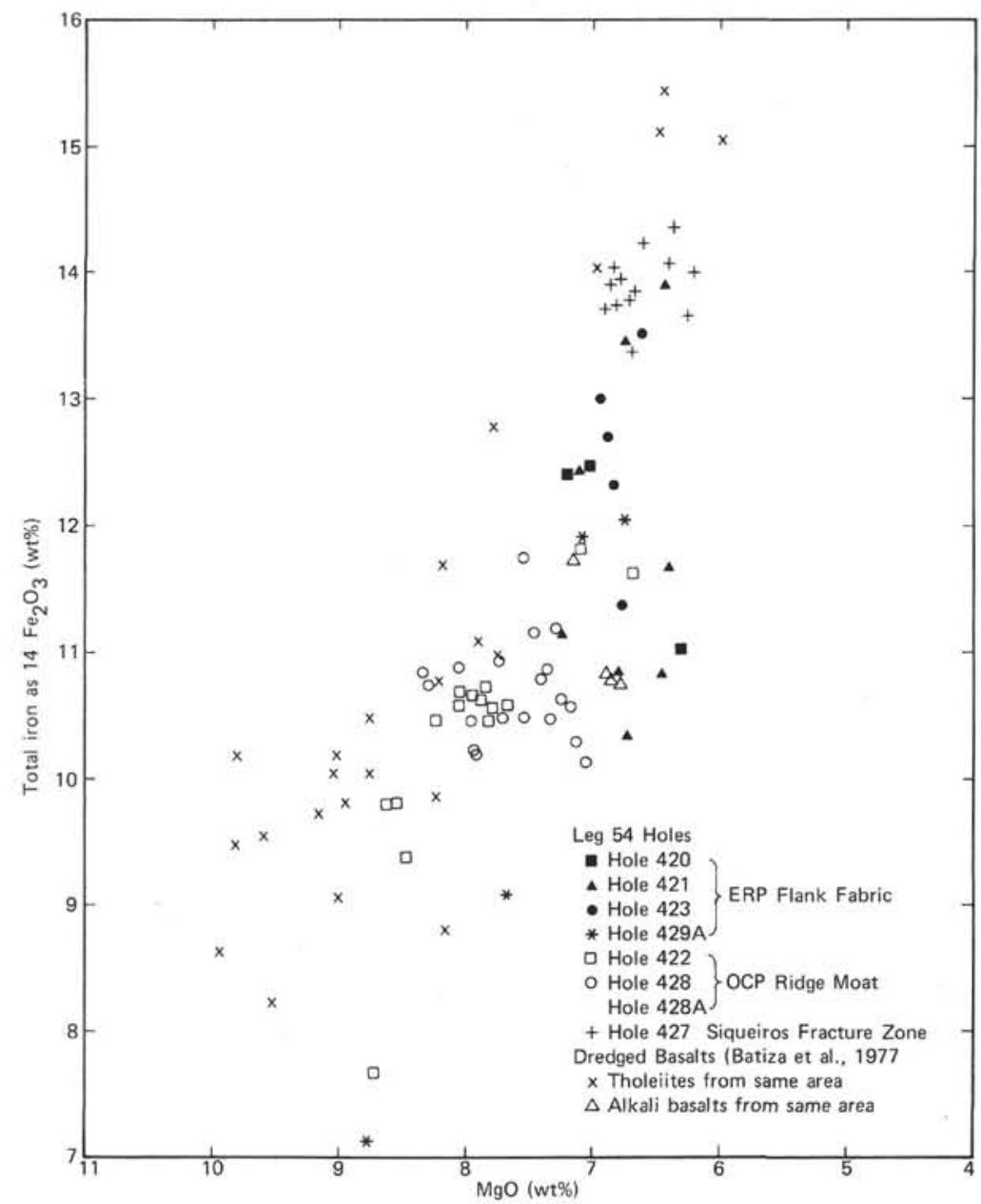

Figure 34. $\mathrm{Fe}_{2} \mathrm{O}_{3}$ versus $\mathrm{MgO}$ for basalts from the $9^{\circ} \mathrm{N}$ region, East Pacific Rise.

\section{Hole 420}

Physical properties were measured on three minicore samples of basalt (Table 23). Velocities were determined immediately for wet saturated samples, but unfortunately the samples could not be lapped for parallelism. The data for Sample 420-15-1, 69-72 cm, are the least reliable. The average velocity for these samples is about $5.5 \mathrm{~km} / \mathrm{s}$, the mean density about $2.8 \mathrm{~g} / \mathrm{cm}^{3}$. These data have not been plotted because of the uncertainties in the velocity data.

\section{Hole 421}

Densities and velocities were measured in seven minicores of basalts (Table 23). Five of the samples could not be lapped, so the data for these minicores are of variable reliability. The results for Sample 421-4-1 (Piece 7) and 421-3-1 (Piece 11) have the highest accuracy, and those for Sample 421-2-1 (Piece 1) are least certain. Densities on the five samples were determined from two-minute GRAPE counts using the GRAPE program for the HP-97 calculator. The mean values and spreads in the velocities and densities of these rocks are very similar to those obtained on the samples from Hole 420 . Two additional minicores were subsequently re-saturated with sea water for two days under a negative pressure and lapped for more careful measurements. Wet densities for these samples were determined from weight and dimension measurements. The data, summarized in Table 23, are included on the Birch diagram plot for Hole 422 (Figure 41).

\section{Hole 422}

Two rock types were recovered. There were two doleritic units underlain by aphyric glassy basalt (one sample recovered). Rock velocities were obtained with the Hamilton Frame on parallel cut and lapped minicores, and weight and length measurements on the minicores were used to determine density (Table 23). Wet densities of all the doleritic basalt samples group tightly about a density of about $2.92 \mathrm{~g} / \mathrm{cm}^{3}$, with a range of \pm 0.02 . Velocities and densities are plotted versus depth on Figure 42. The densities are within the upper end of the range obtained from two-minute GRAPE counts for the Hole 420 and 421 basalts. However, these doleritic rocks are clearly distinguishable in velocity from the 

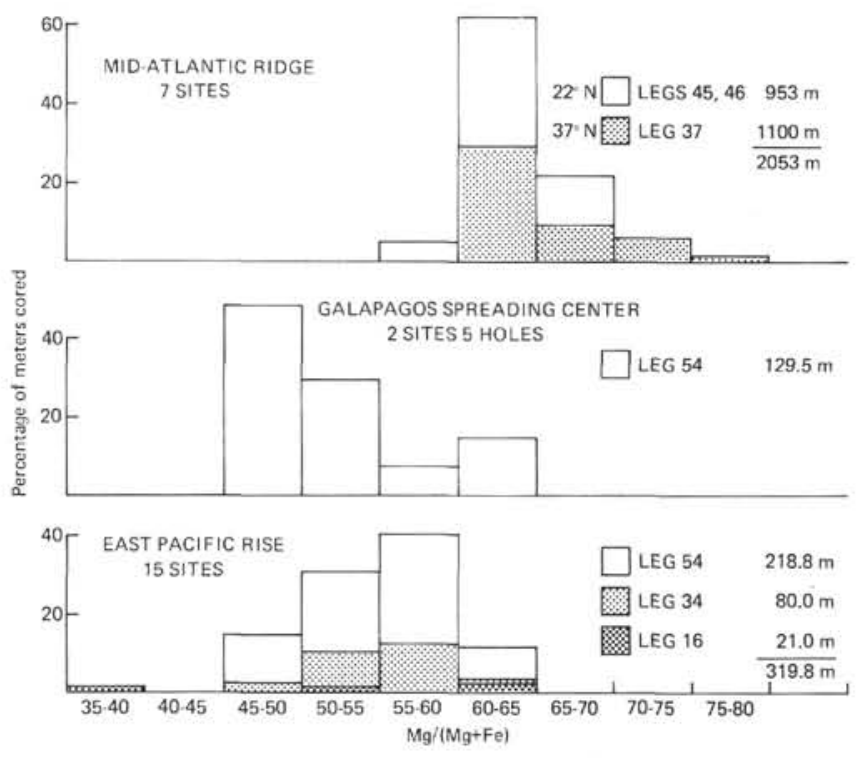

Figure 35. Histogram of $\mathrm{Mg} /(\mathrm{Mg}+\mathrm{Fe})$ for $D S D P$ basalts from the Mid-Atlantic Ridge Sites 332 through 335 (Bougault, 1977); 395 (Bougault et al., 1978a); and 396 (Bougault et al., 1978b), compared with data from the East Pacific Rise (Yeats et al., 1973; Rhodes et al., 1976; and Joron et al., this volume). Histogram is constructed by weighting according to the thickness of clearly identified chemical units. Iceland data are based on number of analyses (35 from Sigvaldason, 1974; 118 from Jakobson, 1972). Figure originally appeared in Natland (1978).

basalt obtained at the previous sites. The mean velocity of the doleritic samples at zero pressure is $5.985 \mathrm{~km} / \mathrm{s}$ with a range of $5.842-6.200 \mathrm{~km} / \mathrm{s}$, which is almost 0.5 $\mathrm{km} / \mathrm{s}$ more than the mean velocity of the Hole 420 and 421 basalts. Comparison of these measurements with data obtained on the standard aluminum sample indicates that their accuracy is about \pm 2 per cent or at 6.00 $\mathrm{km} / \mathrm{s}$, about $\pm 0.12 \mathrm{~km} / \mathrm{s}$. Hence, the velocity range observed is on the same order as the accuracy of the measurements. One sample was dried for two days at $60^{\circ} \mathrm{C}$, and the resulting velocity and density were 5.423 $\mathrm{km} / \mathrm{s}$ and $2.88 \mathrm{~g} / \mathrm{cm}^{3}$, respectively. The average porosity of the sample is not more than about 4 per cent with grain densities very close to $3.0 \mathrm{~g} / \mathrm{cm}^{3}$.

\section{Site $\mathbf{4 2 3}$}

This site was the original prime site for drilling on Leg 54. It is located in Survey Area PT-4A, just north of the OCP moat on what appears to be East Pacific Rise fabric. The attempt to drill here provided at least an opportunity to test the question of PT-4A normality by comparison of results with those obtained at Sites 420 and 421 . Recovery per core was low in the basalt $(5 \%$ to $14 \%$ ), and only two samples were of sufficient size to provide minicores after splitting. Velocity and density measurements on these samples fall within the ranges reported for basalts from Holes 420 and 421; they contrast with those from the doleritic units sampled from Hole 422. The data are plotted on Figure 41.

\section{Hole 427 (Siqueiros Fracture Zone)}

Velocity and wet-bulk density were measured on 16 samples of igneous rock. The data define a single "flow unit" with almost constant velocity (about $5.73 \mathrm{~km} / \mathrm{s}$ ) throughout the main body sampled (Figure 43). The top of the flow is marked by a sample with low velocity and density (from the glassy margin). A small but definite velocity increase (to about $5.95 \mathrm{~km} / \mathrm{s}$ ) occurs near the base. The reality of this increase was tested by repeated velocity measurements on a number of samples, after the original set of data had been reduced and plotted.

The velocity variation, therefore, is established, even though the differences in velocities are only on the order of the accuracy of the data. As noted previously, accuracy is controlled (for the lapped samples) predominantly by the signal rise time. This is on the order of one tenth of a quarter wavelength of the transducer frequency $(400 \mathrm{kHz})$, or about $0.06 \mu \mathrm{s}$. For these samples, typical time-of-flights of the acoustic signals are about $3.5 \mu \mathrm{s}$, so the absolute accuracy is about 2 per cent $(0.06 / 3.5 \mu \mathrm{s})$.

The velocity-wet-bulk density data from the body of the flow fall tightly within the field defined by the data from Hole 424A, B, and C (Figure 44). Velocity and grain densities were measured on two rocks aboard ship. They have porosities of about 4 per cent and grain densities of 3.00 to $3.02 \mathrm{~g} / \mathrm{cm}^{3}$, which agree with the laboratory measurement of grain densities made at UCLA (Table 21).

\section{Holes 428 and 428A}

Nine samples of basalt from Hole 428 and 28 samples from Hole 428A were minicored, lapped, weighed and GRAPED. On the basis of shipboard petrography, grain size, and drillability, rocks from this site are more similar to the doleritic rocks from Hole 422 than to rocks recovered at the other East Pacific Rise sites. The rock units in the upper portion of Hole 428 correspond to those from the upper portion of Hole 428A, which was offset by only 500 feet.

The data form a fairly well defined field in the velocity-wet bulk density plot (Figure 45 ) but a fairly complicated distribution as a function of depth (Figures 46 and 47 ). The density-velocity data are not as tightly correlated as at other sites (with the exception of Site 422). The rocks at Holes 428 and $428 \mathrm{~A}$ show variable degrees of weathering and alteration, some vugs and cracks, and some grain-size variations, which may influence the observed velocity-density profile. Also, density measurements were made by two individuals.

In comparison with previous sites, the data fall within the trend defined at Site 425 (field 5 in velocitydensity space; Figure 45 ). The highest velocity-density samples cluster near the data from Site 422 (field 2), independently suggesting that similar mineralogies characterize some of the rocks.

\section{Site 429}

The velocity-density relationship of the basalts from this site is well defined as a function of depth (Figure 
TABLE 16

Sonic Velocities of Sediments from the East Pacific Rise, Leg 54

TABLE 16 - Continued

\begin{tabular}{ccccc}
\hline Core & Section & $\begin{array}{c}\text { Interval } \\
(\mathrm{cm})\end{array}$ & $\begin{array}{c}\text { Velocity } \\
(\mathrm{km} / \mathrm{s})\end{array}$ & $\begin{array}{c}\text { Temperatu } \\
\left({ }^{\circ} \mathrm{C}\right)\end{array}$ \\
\hline Hole 419 & \multicolumn{5}{c}{} \\
1 & Intensely disturbed \\
2 & 2 & 10 & 1.510 & 19 \\
2 & 2 & 50 & 1.464 & 19 \\
2 & 2 & 90 & 1.499 & 19 \\
2 & 2 & 123 & 1.490 & 19 \\
2 & 3 & 36 & 1.488 & 19 \\
2 & 3 & 106 & 1.490 & 19 \\
2 & 3 & $?(130)$ & 1.492 & 19 \\
3 & 1 & 109 & $1.481^{\mathrm{a}}$ & $18 \mathrm{~b}$ \\
3 & 1 & 109 & 1.510 & 22 \\
3 & 2 & 8 & 1.503 & 22 \\
3 & 2 & 17 & 1.508 & 18 \\
3 & 2 & 78 & 1.486 & 20 \\
3 & 2 & 129 & 1.423 & 18 \\
4 & 1 & 33 & 1.520 & 21 \\
4 & 1 & 110 & 1.455 & 21 \\
5 & 5 & $0-9$ & $1.54 \mathrm{a}$ & 21 \\
5 & 5 & 16 & 1.464 & 21
\end{tabular}

Hole 419A

\begin{tabular}{crrll}
1 & 3 & \multicolumn{3}{l}{ Sample failed } \\
Hole 420 & \multicolumn{5}{l}{} \\
1 & 2 & 15 & 1.515 & 22 \\
1 & 2 & 35 & 1.511 & 22 \\
1 & 3 & 43 & 1.482 & 18 \\
1 & 3 & 87 & 1.493 & 18 \\
1 & 3 & 130 & 1.486 & 18 \\
2 & 4 & 12 & 1.490 & 19 \\
2 & 4 & 52 & 1.488 & 19 \\
2 & 4 & 108 & 1.493 & 19 \\
3 & 3 & 80 & 1.505 & 22 \\
3 & 3 & 80 & $1.528 \mathrm{a}$ & \\
4 & 4 & 36 & 1.517 & 21 \\
5 & 4 & 28 & 1.498 & 22 \\
5 & 4 & 108 & 1.511 & 22 \\
5 & 4 & 110 & $1.484 \mathrm{a}$ & 22 \\
5 & 4 & 143 & 1.500 & 22 \\
6 & 3 & 30 & 1.508 & 21 \\
7 & 1 & 143 & 1.512 & 20 \\
7 & 1 & 143 & $1.538 \mathrm{a}$ & \\
8 & 3 & 56 & 1.496 & 21 \\
11 & 2 & 34 & 1.491 & 22 \\
11 & 2 & 34 & 1.504 & 22 \\
13 & 4 & 92 & 1.488 & 20 \\
13 & 4 & 93 & $1.659 ?$ & 21 \\
13 & 4 & 94 & 1.481 & 18 \\
13 & 4 & 145 & 1.515 & 22
\end{tabular}

Hole 420A

$\begin{array}{rrrrr}1 & 3 & 13 & 1.494 & 23 \\ 1 & 3 & 128 & 1.517 & 23\end{array}$

Hole 422

\begin{tabular}{rrrrr}
1 & 4 & 8 & 1.485 & 19 \\
1 & 4 & 30 & 1.488 & 19 \\
1 & 4 & 64 & 1.490 & 19 \\
1 & 4 & 80 & 1.492 & 19 \\
1 & 4 & 92 & 1.485 & 19 \\
1 & 4 & 120 & 1.503 & 19 \\
3 & 1 & 70 & 1.507 & 19 \\
\hline
\end{tabular}

\begin{tabular}{|c|c|c|c|c|}
\hline Core & Section & $\begin{array}{c}\text { Interval } \\
(\mathrm{cm})\end{array}$ & $\begin{array}{l}\text { Velocity } \\
(\mathrm{km} / \mathrm{s})\end{array}$ & $\begin{array}{c}\text { Temperature } \\
\left({ }^{\circ} \mathrm{C}\right)\end{array}$ \\
\hline \multicolumn{5}{|c|}{ Hole 422} \\
\hline $\begin{array}{l}3 \\
3 \\
3 \\
3 \\
3\end{array}$ & $\begin{array}{l}1 \\
1 \\
3 \\
3 \\
3\end{array}$ & $\begin{array}{r}108 \\
133 \\
12 \\
50 \\
81\end{array}$ & $\begin{array}{l}1.497 \\
1.463 \\
1.509 \\
1.509 \\
1.507\end{array}$ & $\begin{array}{l}19 \\
19 \\
21 \\
21 \\
21\end{array}$ \\
\hline $\begin{array}{l}3 \\
3 \\
3 \\
3 \\
3\end{array}$ & $\begin{array}{l}3 \\
4 \\
4 \\
5 \\
5\end{array}$ & $\begin{array}{r}106 \\
20 \\
90 \\
15 \\
19\end{array}$ & $\begin{array}{l}1.511 \\
1.454 \\
1.499 \\
1.543 \\
1.584\end{array}$ & $\begin{array}{l}21 \\
23 \\
23 \\
22 \\
22\end{array}$ \\
\hline $\begin{array}{l}4 \\
4 \\
4 \\
4 \\
4\end{array}$ & $\begin{array}{l}1 \\
1 \\
1 \\
4 \\
4\end{array}$ & $\begin{array}{r}30 \\
68 \\
127 \\
10 \\
63\end{array}$ & $\begin{array}{l}1.504 \\
1.504 \\
1.492 \\
1.494 \\
1.517\end{array}$ & $\begin{array}{l}21 \\
21 \\
21 \\
22 \\
22\end{array}$ \\
\hline $\begin{array}{l}4 \\
4 \\
4 \\
4 \\
4\end{array}$ & $\begin{array}{l}4 \\
4 \\
6 \\
6 \\
6\end{array}$ & $\begin{array}{r}73 \\
135 \\
25 \\
80 \\
108\end{array}$ & $\begin{array}{l}1.503 \\
1.505 \\
1.522 \\
1.483 \\
1.512\end{array}$ & $\begin{array}{l}22 \\
22 \\
22 \\
22 \\
22\end{array}$ \\
\hline $\begin{array}{l}5 \\
5 \\
5 \\
5 \\
5\end{array}$ & $\begin{array}{l}2 \\
2 \\
2 \\
3 \\
3\end{array}$ & $\begin{array}{r}18 \\
52 \\
104 \\
30 \\
135\end{array}$ & $\begin{array}{l}1.508 \\
1.505 \\
1.494 \\
1.515 \\
1.510\end{array}$ & $\begin{array}{l}22 \\
22 \\
22 \\
24 \\
24\end{array}$ \\
\hline $\begin{array}{l}5 \\
5 \\
5 \\
5 \\
8 \\
8\end{array}$ & $\begin{array}{l}5 \\
5 \\
6 \\
6 \\
2 \\
2\end{array}$ & $\begin{array}{r}50 \\
106 \\
32 \\
85 \\
35 \\
88\end{array}$ & $\begin{array}{l}1.480 \\
1.495 \\
1.480 \\
1.500 \\
1.477 \\
1.507\end{array}$ & $\begin{array}{l}21 \\
21 \\
21 \\
21 \\
21 \\
21\end{array}$ \\
\hline
\end{tabular}

Hole 427

$\begin{array}{llrll}2 & 4 & 35 & 1.504 & 20 \\ 2 & 4 & 94 & 1.495 & 20 \\ 3 & 3 & 74 & 1.507 & 22 \\ 3 & 3 & 129 & 1.509 & 22 \\ 4 & 2 & 15 & 1.493 & 22 \\ 7 & 3 & 31 & 1.513 & 22 \\ 8 & 1 \mathrm{c} & 27 & 2.045 & 22 \\ 8 & 1 & 43 & 1.536 & 22 \\ 8 & 1 & 60 & 1.511 & 22 \\ 8 & 3 & 50 & 1.491 & 23 \\ 8 & 3 & 82 & 1.501 & 23 \\ 8 & 3 & 118 & 1.487 & 23 \\ 8 & 4 & 56 & 1.512 & 23 \\ 8 & 4 & 114 & 1.501 & 23\end{array}$

Hole 428

\begin{tabular}{rrrrr}
1 & 3 & 15 & 1.495 & 24 \\
1 & 3 & 80 & 1.498 & 24 \\
2 & 3 & 13 & 1.504 & 24 \\
5 & 3 & 42 & 1.510 & 24 \\
5 & 3 & 102 & 1.479 & 24 \\
\hline
\end{tabular}

${ }^{a}$ Velocity measured on sample removed from liner.

${ }^{b}$ Different temperatures indicate velocities were measured at different times.

$\mathrm{c}_{\text {Individual indurated lumps removed from disturbed zone: }}$ showed banding measured parallel to bedding planes. 
TABLE 17

East Pacific Rise Sediment GRAPE Data Summary, Leg 54

\begin{tabular}{|c|c|c|c|c|}
\hline Core & Section & $\begin{array}{c}\text { Interval } \\
(\mathrm{cm})\end{array}$ & $\begin{array}{l}\text { Wet-Bulk } \\
\text { Density } \\
\mathrm{g} / \mathrm{cm}^{3}\end{array}$ & $\begin{array}{c}\text { Porosity } \\
(\%)\end{array}$ \\
\hline \multicolumn{5}{|l|}{ Hole 419} \\
\hline $\begin{array}{l}2 \\
2 \\
2 \\
2 \\
2\end{array}$ & $\begin{array}{l}2 \\
2 \\
2 \\
2 \\
3\end{array}$ & $\begin{array}{r}10 \\
50 \\
90 \\
123 \\
36\end{array}$ & $\begin{array}{l}1.17 \\
1.17 \\
1.16 \\
1.20 \\
1.26\end{array}$ & $\begin{array}{l}90.97 \\
90.97 \\
91.60 \\
89.06 \\
85.87\end{array}$ \\
\hline $\begin{array}{l}2 \\
2 \\
3 \\
3 \\
3\end{array}$ & $\begin{array}{l}3 \\
3 \\
2 \\
2 \\
2\end{array}$ & $\begin{array}{r}106 \\
130 \\
8 \\
17 \\
78\end{array}$ & $\begin{array}{l}1.23 \\
1.25 \\
1.20 \\
1.20 \\
1.29\end{array}$ & $\begin{array}{l}87.79 \\
86.51 \\
89.69 \\
89.69 \\
83.96\end{array}$ \\
\hline $\begin{array}{l}3 \\
4 \\
4 \\
4 \\
4\end{array}$ & $\begin{array}{l}2 \\
2 \\
2 \\
2 \\
2\end{array}$ & $\begin{array}{r}129 \\
10 \\
50 \\
100 \\
130\end{array}$ & $\begin{array}{l}1.23 \\
1.14 \\
1.12 \\
1.12 \\
1.14\end{array}$ & $\begin{array}{l}87.79 \\
92.87 \\
94.15 \\
94.15 \\
92.87\end{array}$ \\
\hline $\begin{array}{l}4 \\
4 \\
4 \\
4 \\
5\end{array}$ & $\begin{array}{l}3 \\
3 \\
3 \\
3 \\
2\end{array}$ & $\begin{array}{r}10 \\
50 \\
100 \\
130 \\
10\end{array}$ & $\begin{array}{l}1.20 \\
1.23 \\
1.25 \\
1.26 \\
1.17\end{array}$ & $\begin{array}{l}89.69 \\
87.79 \\
86.51 \\
85.87 \\
90.97\end{array}$ \\
\hline $\begin{array}{l}5 \\
5 \\
5 \\
5 \\
5\end{array}$ & $\begin{array}{l}2 \\
2 \\
2 \\
3 \\
3\end{array}$ & $\begin{array}{r}50 \\
100 \\
130 \\
10 \\
50\end{array}$ & $\begin{array}{l}1.16 \\
1.17 \\
1.17 \\
1.17 \\
1.20\end{array}$ & $\begin{array}{l}91.60 \\
90.97 \\
90.97 \\
90.97 \\
89.69\end{array}$ \\
\hline $\begin{array}{l}5 \\
5 \\
5 \\
5 \\
5 \\
5\end{array}$ & $\begin{array}{l}3 \\
3 \\
4 \\
4 \\
4 \\
4\end{array}$ & $\begin{array}{r}100 \\
130 \\
10 \\
50 \\
100 \\
130\end{array}$ & $\begin{array}{l}1.26 \\
1.28 \\
1.26 \\
1.25 \\
1.29 \\
1.26\end{array}$ & $\begin{array}{l}85.87 \\
84.60 \\
85.87 \\
86.51 \\
83.96 \\
85.82\end{array}$ \\
\hline
\end{tabular}

Hole 419A

3

mean of

1.20

87.78

Hole 420

\begin{tabular}{rrrrr}
1 & 3 & 43 & 1.23 & 87.79 \\
1 & 3 & 87 & 1.23 & 87.79 \\
1 & 3 & 130 & 1.23 & 87.79 \\
2 & 2 & 10 & 1.17 & 90.97 \\
2 & 2 & 50 & 1.16 & 91.60 \\
2 & 2 & 100 & 1.16 & 91.60 \\
2 & 2 & 130 & 1.16 & 91.60 \\
2 & 4 & 12 & 1.23 & 87.79 \\
2 & 4 & 52 & 1.20 & 89.06 \\
2 & 4 & 108 & 1.14 & 92.87 \\
3 & 3 & 10 & 1.17 & 90.97 \\
3 & 3 & 50 & 1.25 & 86.51 \\
3 & 3 & 80 & 1.29 & 83.96 \\
3 & 3 & 100 & 1.29 & 83.96 \\
3 & 3 & 130 & 1.23 & 87.79 \\
3 & 4 & 10 & 1.20 & 89.06 \\
3 & 4 & 50 & 1.20 & 89.69 \\
3 & 4 & 100 & 1.23 & 87.79 \\
3 & 4 & 130 & 1.16 & 91.60 \\
4 & 2 & 10 & 1.20 & 89.06 \\
\hline
\end{tabular}

48). Plotted against each other (Figure 49), they form a field which parallels field 1 , extends into the field for
TABLE 17 - Continued

\begin{tabular}{|c|c|c|c|c|}
\hline Core & Section & $\begin{array}{l}\text { Interval } \\
(\mathrm{cm})\end{array}$ & $\begin{array}{l}\text { Wet-Bulk }{ }^{\mathrm{a}} \\
\text { Density } \\
\mathrm{g} / \mathrm{cm}^{3}\end{array}$ & $\begin{array}{c}\text { Porosity } \\
(\%)\end{array}$ \\
\hline \multicolumn{5}{|c|}{ Hole 420} \\
\hline 4 & 2 & 50 & 1.14 & 92.87 \\
\hline 4 & 2 & 100 & 1.20 & 89.69 \\
\hline 4 & 2 & 130 & 1.16 & 91.60 \\
\hline 4 & 4 & 36 & 1.16 & 91.60 \\
\hline 4 & 4 & 50 & 1.16 & 91.60 \\
\hline 4 & 4 & 100 & 1.20 & 89.69 \\
\hline 4 & 4 & 130 & 1.20 & 89.06 \\
\hline 5 & 2 & 10 & 1.25 & 86.51 \\
\hline 5 & 2 & 50 & 1.23 & 87.79 \\
\hline 5 & 2 & 100 & 1.20 & 89.69 \\
\hline 5 & 2 & 130 & 1.16 & 91.60 \\
\hline 5 & 4 & 10 & 1.25 & 86.51 \\
\hline 5 & 4 & 28 & 1.20 & 89.06 \\
\hline 5 & 4 & 50 & 1.16 & 91.60 \\
\hline 5 & 4 & 110 & 1.25 & 86.51 \\
\hline 5 & 4 & 143 & 1.28 & 84.60 \\
\hline 6 & 2 & 10 & 1.17 & 90.97 \\
\hline 6 & 2 & 50 & 1.20 & 89.69 \\
\hline 6 & 2 & 100 & 1.17 & 90.97 \\
\hline 6 & 2 & 130 & 1.16 & 91.60 \\
\hline 6 & 3 & 30 & 1.25 & 86.51 \\
\hline 6 & 3 & 50 & 1.26 & 85.87 \\
\hline 6 & 3 & 100 & 1.16 & 91.60 \\
\hline 6 & 3 & 130 & 1.16 & 91.60 \\
\hline 7 & 2 & 80 & 1.16 & 91.60 \\
\hline 7 & 5 & 80 & 1.16 & 91.60 \\
\hline 7 & 6 & 80 & 1.16 & 91.60 \\
\hline 8 & 2 & 10 & 1.16 & 91.60 \\
\hline 8 & 2 & 40 & 1.16 & 91.60 \\
\hline 8 & 2 & 50 & 1.16 & 91.60 \\
\hline 8 & 2 & 130 & 1.17 & 90.97 \\
\hline 8 & 2 & 150 & 1.23 & 87.79 \\
\hline 8 & 3 & 80 & 1.23 & 87.79 \\
\hline 8 & 4 & 80 & 1.20 & 89.69 \\
\hline 11 & 2 & 10 & 1.31 & 82.70 \\
\hline 11 & 2 & 50 & 1.33 & 81.42 \\
\hline 11 & 2 & 100 & 1.23 & 87.70 \\
\hline 11 & 2 & 130 & 1.25 & 86.51 \\
\hline 11 & 3 & 50 & 1.23 & 87.79 \\
\hline 11 & 3 & 100 & 1.23 & 87.79 \\
\hline 11 & 3 & 130 & 1.23 & 87.79 \\
\hline 12 & 2 & 34 & 1.26 & 85.87 \\
\hline 12 & 2 & 80 & 1.26 & 85.87 \\
\hline 12 & 4 & 80 & 1.26 & 85.87 \\
\hline 12 & 6 & 80 & 1.28 & 84.60 \\
\hline 13 & 2 & 80 & 1.20 & 89.06 \\
\hline 13 & 4 & 30 & 1.17 & 90.97 \\
\hline 13 & 4 & 90 & 1.28 & 84.60 \\
\hline 13 & 4 & 140 & 1.29 & 83.96 \\
\hline
\end{tabular}

Site $\mathbf{4 2 2}$ dolerites, and also parallels the general velocitydensity trend for the cumulative data.

The samples from Hole 429A form the largest suite of low velocity/low density samples that we have recovered, with the majority of the absolute values falling within the field defined for samples of thin, glassy flows representing the normal fabric basalts (Sites 421 and 

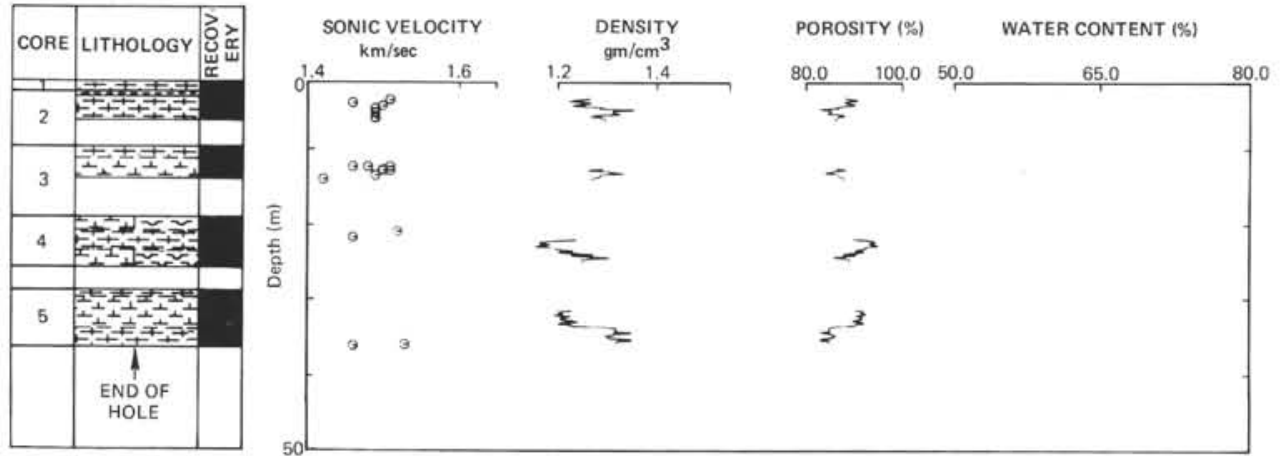

Figure 36. Plot of physical properties of sediments versus depth, Hole 419.

423). Only samples from the base of the lowest unit have velocities and densities approaching those of the more massive rock units (e.g., Site 422).

\section{MAGNETIC PROPERTIES OF SEDIMENTS}

Only a few samples of sediments from Holes 419 , 419A, 420, and 421 were measured magnetically; results are listed in Table 24. Most sediments were too disturbed to obtain reasonable paleomagnetic stratigraphy. In Hole 419, all specimens seem to possess a fairly stable remanent magnetization with the exception of Sample $419-5-5,28-30 \mathrm{~cm}$. The latter though, changes its magnetization direction from negative (opposite to the present Earth's magnetic field) to positive (parallel to the present Earth's magnetic field) during alternating field demagnetization. Samples 419A-1-3, $72-75 \mathrm{~cm}$ and $419 \mathrm{~A}-1-3,87-89 \mathrm{~cm}$ were taken from directly above and below a lithologic boundary.

Sediment samples from the upper cores of Hole 420 have negative magnetization and from the lower cores positive magnetization. Therefore, we tentatively assume that upper sediments were deposited during the Matuyama reversed epoch (0.69-2.43 m.y.), the lower ones during the earlier Gauss normal epoch (2.43-3.37 m.y.).

\section{MAGNETIC PROPERTIES OF BASALTS}

As the Glomar Challenger approached each site we carefully monitored the total magnetic field recorded by the ship's towed proton magnetometer, and the bathymetry, in order to identify magnetic anomalies and thus infer the "age" of basement. Water depth and the total magnetic field along these tracks are shown on Figures 50 through 52 , along with estimated boundaries and ages of magnetic polarity events (Heirtzler et al., 1968). The following discussion, presented in sequence for East Pacific Rise sites (Sites 419, 420, 421, 423, and 429), OCP Ridge sites (Sites 422 and 428) and the Siqueiros fracture zone site (Site 427), deals primarily with the agreement between stable inclinations in the basalts with the inferred magnetic ages. We shall also discuss any correlations between intensities of magnetizations, grain size, and lithology.
Sites 419, 420, 421, 423, and 429 (East Pacific Rise)

\section{Site 419}

From the anomaly pattern, Site 419 was identified as lying within the Gauss normal epoch, which yields a basement rock age between 2.43 and 2.93 m.y. (see Figure 50), using the marine magnetic time scale of Heirtzler et al. (1968). As can be seen from Table 24, most of the sediments from Hole 419 have a negative magnetization, which most likely is related to the Matuyama reversed epoch. This would indicate an age for these sediments of between 0.69 and 2.43 m.y.

The positive magnetization of the two investigated samples from the uppermost core of Hole 419A probably did not form during the Gauss normal epoch, but rather during the Brunhes normal epoch, giving an age not older than 0.69 m.y. No basement samples were cored at Site 419.

\section{Sites 420 and $\mathbf{4 2 1}$}

The magnetic anomalies at these sites have been identified as belonging to the upper portion of the Gilbert reversed epoch, with Site 421 being very close to the boundary of the Gauss normal epoch (see Figure 50). This suggests an age for the basement rocks of slightly more than 3.37 m.y.

The results of the rock magnetic measurements for Site 420 are listed in Table 25 . Of the drilled basalt specimens from Hole 420, only Sample 14-1, 14-17 cm, could be reliably oriented. The stable inclination of this sample $-19.5 \%$, agrees well with the Gilbert reversed epoch as deduced from the marine anomaly pattern. The amount of the inclination angle comes close to the theoretical inclination value of $18^{\circ}$ for the latitude of the drill site, as calculated for a centered Earth magnetic dipole. The positive inclination of the other two measured basalt samples from Site 420 is most likely due to misorientation.

The results of the rock magnetic measurements for Site $\mathbf{4 2 1}$ are listed in Table 25. The negative magnetization inclination of all investigated basalt samples from this hole agrees well with the forementioned assumption that they have been formed during the Gilbert reversed epoch. The basalt samples from both Holes 420 and 421 have very high magnetic stability, as expressed in the 
TABLE 18

Water Contents of Sediments from the East Pacific Rise, Leg $\mathbf{5 4}$

\begin{tabular}{|c|c|c|c|c|c|c|}
\hline Core & Section & $\begin{array}{c}\text { Interval } \\
(\mathrm{cm})\end{array}$ & $\begin{array}{c}\text { Water } \\
\text { Content } \\
(\%)\end{array}$ & $\begin{array}{c}\text { Porosity } \\
(\%)\end{array}$ & $\begin{array}{l}\text { Wet-Bulk } \\
\text { Density } \\
\left(\mathrm{g} / \mathrm{cm}^{3}\right)\end{array}$ & $\begin{array}{l}\text { Grain } \\
\text { Density } \\
\left(\mathrm{g} / \mathrm{cm}^{3}\right)\end{array}$ \\
\hline \multicolumn{7}{|c|}{ Hole 420} \\
\hline $\begin{array}{l}1 \\
1 \\
1 \\
1 \\
2\end{array}$ & $\begin{array}{l}2 \\
3 \\
3 \\
3 \\
2\end{array}$ & $\begin{array}{r}28 \\
90 \\
124 \\
140 \\
91\end{array}$ & $\begin{array}{l}70.7 \\
68.8 \\
77.0 \\
73.7 \\
78.9\end{array}$ & $\begin{array}{l}89 \\
80.4 \\
87.7 \\
89.9 \\
92.1\end{array}$ & $\begin{array}{l}1.26 \\
1.17 \\
1.14 \\
1.22 \\
1.17\end{array}$ & $\begin{array}{l}3.3626 \\
1.7935 \\
2.0326 \\
3.1674 \\
3.0968\end{array}$ \\
\hline $\begin{array}{l}2 \\
2 \\
2 \\
3 \\
4\end{array}$ & $\begin{array}{l}4 \\
4 \\
4 \\
3 \\
2\end{array}$ & $\begin{array}{l}14 \\
16 \\
57 \\
73 \\
50\end{array}$ & $\begin{array}{l}62.3 \\
64.7 \\
68.7 \\
57.9 \\
72.7\end{array}$ & $\begin{array}{l}78.7 \\
84.4 \\
87.2 \\
73.4 \\
85.8\end{array}$ & $\begin{array}{l}1.26 \\
1.30 \\
1.27 \\
1.27 \\
1.18\end{array}$ & $\begin{array}{l}2.1922 \\
2.9324 \\
3.0913 \\
1.9669 \\
2.1976\end{array}$ \\
\hline $\begin{array}{l}4 \\
5 \\
5 \\
6 \\
7\end{array}$ & $\begin{array}{l}2 \\
4 \\
4 \\
3 \\
1\end{array}$ & $\begin{array}{r}55 \\
115 \\
116 \\
39 \\
50\end{array}$ & $\begin{array}{l}70.1 \\
63.7 \\
59.9 \\
64.0 \\
78.1\end{array}$ & $\begin{array}{l}83.7 \\
85.2 \\
71.9 \\
85.5 \\
93.8\end{array}$ & $\begin{array}{l}1.20 \\
1.34 \\
1.20 \\
1.34 \\
1.20\end{array}$ & $\begin{array}{l}2.1256 \\
3.2823 \\
1.6678 \\
3.3212 \\
4.4414^{b}\end{array}$ \\
\hline $\begin{array}{l}7 \\
8 \\
8 \\
9 \\
9\end{array}$ & $\begin{array}{l}1 \\
3 \\
3 \\
5 \\
6\end{array}$ & $\begin{array}{l}88 \\
55 \\
68 \\
15 \\
-\end{array}$ & $\begin{array}{l}71.1 \\
60.7 \\
74.0 \\
70.7 \\
68.3\end{array}$ & $\begin{array}{l}92.1 \\
77.5 \\
92.9 \\
95.0 \\
92.4\end{array}$ & $\begin{array}{l}1.28 \\
1.28 \\
1.26 \\
1.34 \\
1.35\end{array}$ & $\begin{array}{l}4.8018^{b} \\
2.1893 \\
4.8255^{b} \\
9.1114^{b} \\
6.0160^{b}\end{array}$ \\
\hline $\begin{array}{l}10 \\
10 \\
11 \\
11 \\
12\end{array}$ & $\begin{array}{l}5 \\
5 \\
3 \\
3 \\
2\end{array}$ & $\begin{array}{l}64 \\
76 \\
41 \\
42 \\
71\end{array}$ & $\begin{array}{l}68.9 \\
69.7 \\
69.8 \\
67.8 \\
62.5\end{array}$ & $\begin{array}{l}90.1 \\
90.6 \\
90.1 \\
93.2 \\
81.0\end{array}$ & $\begin{array}{l}1.31 \\
1.30 \\
1.26 \\
1.38 \\
1.30\end{array}$ & $\begin{array}{l}4.2039 \mathrm{~b} \\
4.3021^{\mathrm{b}} \\
4.0144^{\mathrm{b}} \\
7.0944^{\mathrm{b}} \\
2.5232\end{array}$ \\
\hline $\begin{array}{l}12 \\
13 \\
13\end{array}$ & $\begin{array}{l}2 \\
4 \\
4\end{array}$ & $\begin{array}{l}76 \\
79 \\
80\end{array}$ & $\begin{array}{l}64.8 \\
61.9 \\
59.3\end{array}$ & $\begin{array}{l}84.7 \\
87.7 \\
79.9\end{array}$ & $\begin{array}{l}1.31 \\
1.42 \\
1.33 \\
\text { average: }\end{array}$ & $\begin{array}{l}2.9909 \\
4.4863^{b} \\
2.7040 \\
2.5910\end{array}$ \\
\hline
\end{tabular}

Hole 421

Hole 422

1
1
3
3
4
4
5
5

Hole 423

$$
\begin{aligned}
& 1 \\
& 1 \\
& 2 \\
& 2 \\
& 3 \\
& 3 \\
& 4 \\
& 4 \\
& 5 \\
& 5
\end{aligned}
$$

Hole 427

\begin{tabular}{rrrrrrr}
1 & 1 & 120 & 80.0 & 95.8 & 1.20 & $6.533^{\mathrm{b}}$ \\
2 & 2 & 120 & 78.6 & 91.1 & 1.16 & 2.726 \\
2 & 4 & 110 & 76.0 & 96.8 & 1.27 & $12.744^{\mathrm{b}}$ \\
3 & 3 & 65 & 83.2 & 88.3 & 1.06 & 1.365 \\
4 & 2 & 100 & 76.4 & 89.3 & 1.17 & 2.508 \\
4 & 4 & 10 & 75.1 & 79.6 & 1.06 & 1.205 \\
8 & 3 & 33 & \multicolumn{5}{c}{ insufficient sample size } \\
8 & 3 & 87 & & insufficient sample size \\
8 & 4 & 12 & 71.0 & 82.0 & 1.16 & 1.786 \\
8 & 4 & 51 & 87.4 & 87.4 & 1.17 & 0.811 \\
\hline
\end{tabular}

TABLE 18 - Continued

\begin{tabular}{|c|c|c|c|c|c|c|}
\hline Core & Section & $\begin{array}{c}\text { Interval } \\
(\mathrm{cm})\end{array}$ & $\begin{array}{c}\text { Water } \\
\text { Content } \\
(\%)\end{array}$ & $\begin{array}{c}\text { Porosity } \\
(\%)\end{array}$ & $\begin{array}{c}\text { Wet-Bulk } \\
\text { Density } \\
\left(\mathrm{g} / \mathrm{cm}^{3}\right)\end{array}$ & $\begin{array}{l}\text { Grain } \\
\text { Density } \\
\left(\mathrm{g} / \mathrm{cm}^{3}\right)\end{array}$ \\
\hline \multicolumn{7}{|c|}{ Hole 427} \\
\hline 8 & 4 & 106 & & \multirow{2}{*}{\multicolumn{3}{|c|}{ insufficient sample size }} \\
\hline 8 & 5 & 62 & & & & \\
\hline 1 & 5 & $146-150$ & 74.4 & 90.4 & 1.22 & 3.238 \\
\hline 2 & 5 & $140-150$ & 74.8 & 92.6 & 1.24 & $4.371^{b}$ \\
\hline 7 & 3 & $140-150$ & 74.2 & 90.2 & 1.22 & 3.194 \\
\hline & & & & & average: & 2.104 \\
\hline \multicolumn{7}{|c|}{ Hole 428} \\
\hline 1 & 3 & 28 & 68.3 & 86.2 & 1.26 & 2.872 \\
\hline 2 & 3 & $144-150$ & 68.2 & 88.2 & 1.29 & 3.506 \\
\hline 2 & 3 & $144-150$ & 70.9 & 90.3 & 1.27 & 3.886 \\
\hline 3 & 4 & 112 & 74.7 & 90.1 & 1.21 & 3.063 \\
\hline 4 & 4 & 45 & 74.4 & 90.2 & 1.21 & 3.156 \\
\hline 5 & 2 & 90 & 64.6 & 78.8 & 1.22 & 1.984 \\
\hline 2 & 3 & $144-150$ & 68.2 & 88.2 & 1.29 & 3.506 \\
\hline 2 & 3 & $144-150$ & 70.9 & 90.3 & 1.27 & 3.886 \\
\hline
\end{tabular}

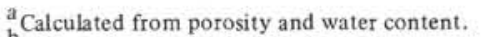

${ }^{b}$ High grain density implies inconsistent porosity and water content, excluded from average grain density calculation.

${ }^{\mathrm{c}}$ Measured porosity is above maximum allowable.

high MDF values. This is because of the fine-grained nature of the rocks, with the magnetic mineral component titanomagnetite being in or close to the single domain state. This also is reflected in the high $Q$-factors (ratio of natural remanent magnetization to the magnetization induced by the present Earth's magnetic field). In this respect, the rocks resemble pillow basalts from the Mid-Atlantic Ridge.

\section{Site $\mathbf{4 2 3}$}

This Site is well within the Matuyama reversed epoch (see Figure 51). Hence, an age of slightly less than 1.6 m.y. should be expected for the basement rocks here.

Only two samples from Hole 423 were measured (see Table 25). Both have a rather low intensity of NRM compared with the basalt samples from the previous holes. Sample 423-5, CC (Piece 4) was the only specimen that could be oriented directly. Sample 423-7-1, 4-7 cm (Piece 1) was oriented indirectly by analyzing its viscous magnetization and assuming that this viscous remanence represented the direction of the present Earth's magnetic field. The negative magnetic inclination of both samples agrees well with the sign of the associated marine magnetic anomaly.

\section{Site 429}

This site is centered inside a relatively narrow negative anomaly (about $8 \mathrm{~km}$ wide) west of the Nunivak Positive Event inside the Gilbert epoch (see Figure 52). The age of the drill site is therefore estimated to be 4.6 m.y. according to the scale of Heirtzler et al. (1968). The results of rock magnetic measurements for Site 429 are summarized in Table 25 . The lower part of the drilled basement has a negative magnetization polarity which agrees with the associated magnetic anomaly; the upper part, however, has a positive magnetization polarity and therefore almost certainly is of a younger age. 

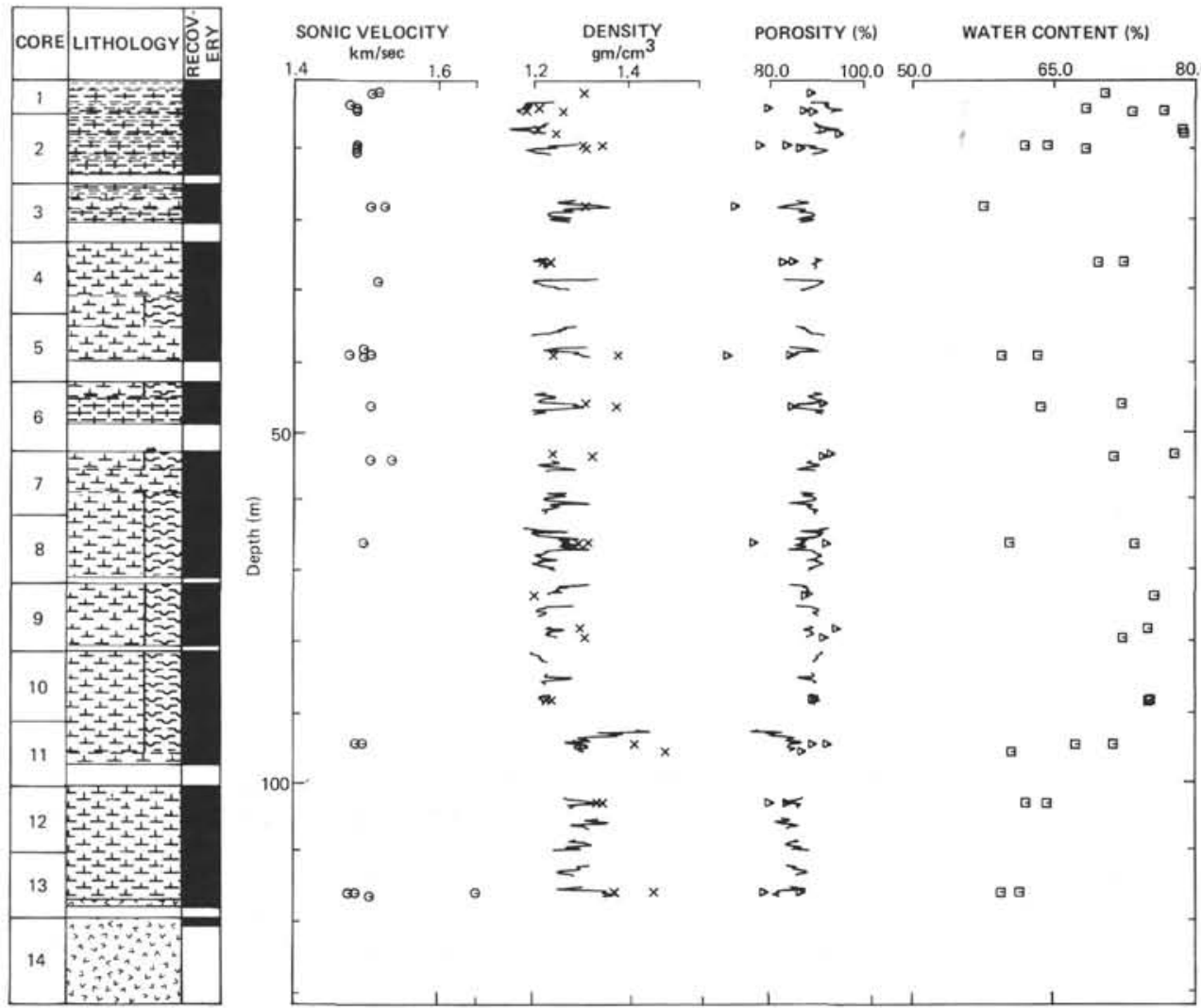

Figure 37. Plot of physical properties of sediments versus depth, Hole 420.
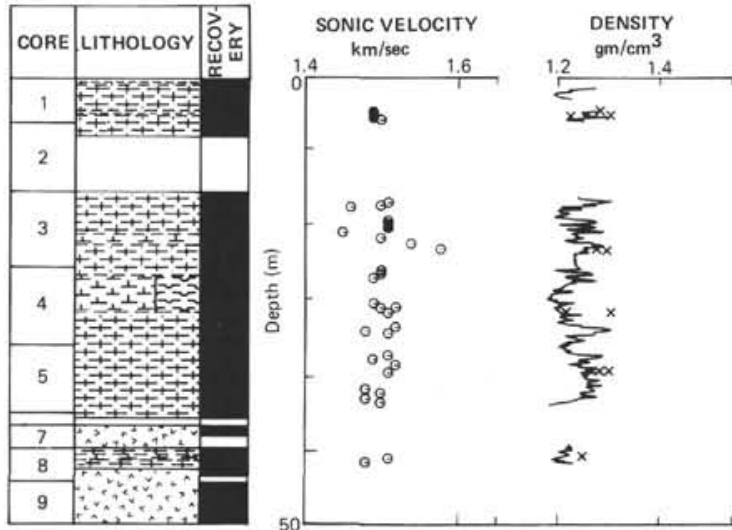

POROSITY (\%) WATER CONTENT $(\%)$

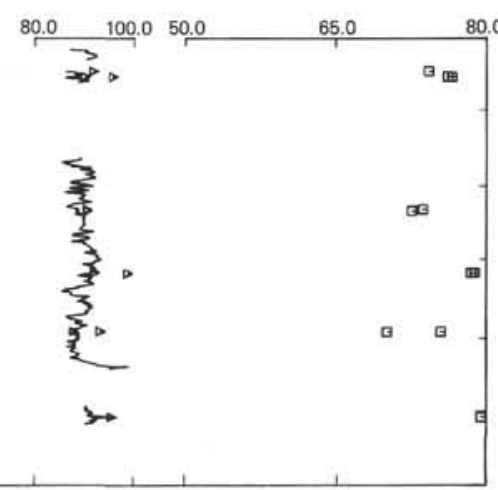

Figure 38. Plot of physical properties of sediments versus depth, Hole 422.

Sites 422 and 428 (OCP Ridge)

\section{Site $\mathbf{4 2 2}$}

As can be seen from Figure 51, Site 422 is within the positive anomaly corresponding to the Olduvai Normal Event. Accordingly, an age between 1.64 and 1.79 m.y. should be expected for the basement rocks. However, a drift rate of $5.7 \mathrm{~cm} / \mathrm{y}$. produces a block of normal magnetization about $8 \mathrm{~km}$ wide, which means Site 422 is close to the transition boundary, probably the older boundary.

The results of rock magnetic measurements are listed in Table 25. All samples measured were taken from the doleritic unit and have a negative inclination, contrary to what we expect from the corresponding anomaly. Two possibilities exist:

1) The doleritic unit postdates the rocks that produce anomaly 2, probably in the upper part of the Matuyama reversed epoch; and

2) Site 422 is too close to the boundary of the Matuyama reversed block (see Figure 51), resulting in interlayering of positively and negatively magnetized rock units. The stability of magnetization (MDF) and also the $Q$-factor are distinctly lower in the doleritic unit compared with the basalts from Sites 420 and 421 . This reflects the larger grain size of the magnetic titanomagnetites. 
TABLE 19

Shear Strengths of Sediments from the East Pacific Rise, Leg 54

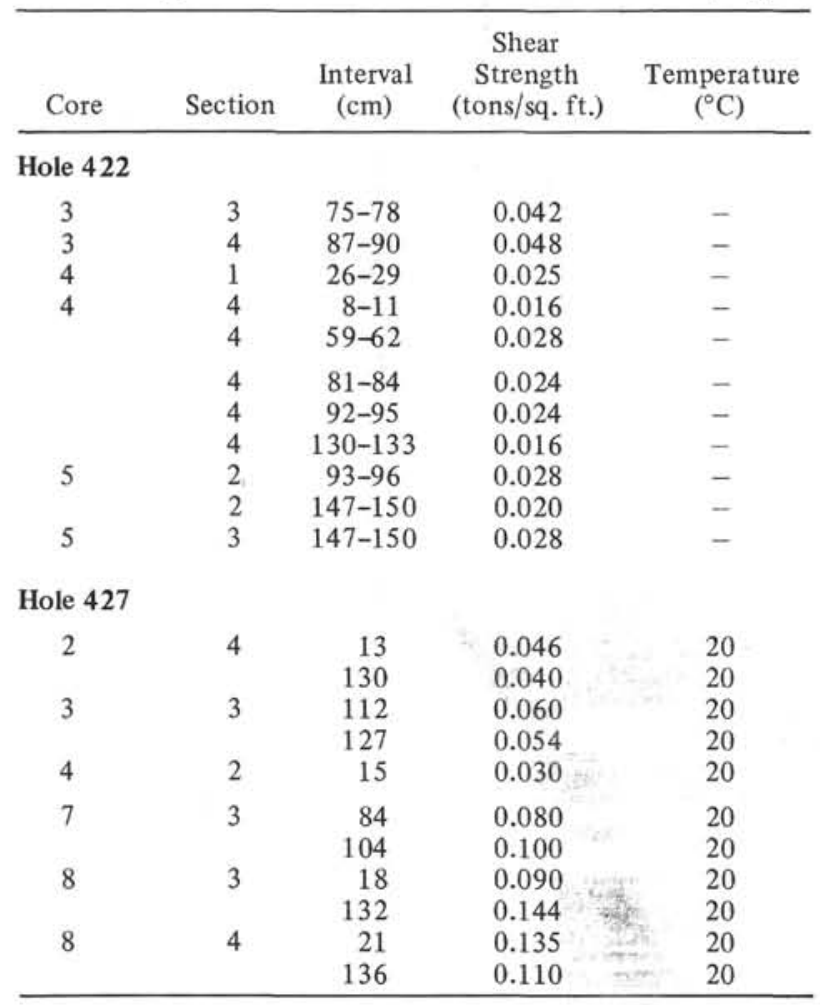

\section{Site 428}

Holes 428 and 428A are located within the Matuyama negative epoch, between the Olduvai Positive Event (anomaly 2) and the Gauss normal epoch. Usg the scale of Heirtzler et al. (1968), its age should therefore be between 2 and 2.5 m.y. The observed negative magnetization polarity of the drilled rocks agrees with the associated marine magnetic anomaly, although an origin of the basalts and magnetization coeval with the adjacent portion of the OCP Ridge cannot be eliminated at this time.

The results of the rock magnetic measurements for Site 428 are summarized in Table 25 and Figure 53. Hole $428 \mathrm{~A}$ is the deepest drill hole of this Leg and consists of a number of petrographic units. The hole is therefore likely to cover a time span sufficiently large to make
TABLE 20

Sediment Sonic Velocity and GRAPE Data Summary, Hole 423, Leg 54

\begin{tabular}{ccccccc}
\hline & Section & Interval & $\begin{array}{c}\text { Sub-Bottom } \\
\text { Depth } \\
(\mathrm{m})\end{array}$ & $\begin{array}{c}\text { Velocity } \\
(\mathrm{km} / \mathrm{s})\end{array}$ & $\begin{array}{c}\text { Densitya } \\
\left(\mathrm{g} / \mathrm{cm}^{3}\right)\end{array}$ & $\begin{array}{c}\text { Temperature } \\
\left({ }^{\circ} \mathrm{C}\right)\end{array}$ \\
\hline 1 & 2 & 10 & 1.60 & 1.498 & 1.19 & 23 \\
1 & 2 & 30 & 1.80 & 1.508 & 1.16 & 23 \\
1 & 2 & 84 & 2.34 & 1.501 & 1.20 & 23 \\
1 & 2 & 126 & 2.76 & 1.509 & 1.21 & 23 \\
2 & 2 & 52 & 6.02 & 1.497 & 1.16 & 23 \\
2 & 2 & 91 & 6.41 & 1.509 & 1.16 & 23 \\
2 & 2 & 130 & 6.80 & 1.501 & 1.17 & 23 \\
2 & 3 & 14 & 7.14 & 1.490 & 1.17 & 23 \\
2 & 3 & 46 & 7.46 & 1.522 & 1.17 & 23 \\
2 & 3 & 91 & 7.91 & 1.497 & 1.16 & 23 \\
2 & $3 \mathrm{~b}$ & 127 & 8.27 & 1.480 & 1.26 & 23 \\
2 & $3 \mathrm{~b}$ & 127 & 8.27 & 1.479 & 1.26 & 23 \\
3 & 3 & 30 & 16.80 & 1.488 & 1.20 & 23 \\
3 & 3 & 69 & 17.19 & 1.480 & 1.20 & 23 \\
3 & 3 & 125 & 17.25 & 1.484 & 1.22 & 23 \\
4 & 4 & 12 & 27.72 & 1.507 & 1.20 & 23 \\
4 & 4 & 127 & 28.77 & 1.492 & 1.20 & 23 \\
\hline
\end{tabular}

A Assuming corrected grain density equals true grain density $=2.7 \mathrm{~g} / \mathrm{cm}^{3}$.

bTwo measurements.

possible determinations of the paleosecular variation of the inclination of the Earth's magnetic field at this location.

As can be seen from Figure 53, the inclination values vary between about $20^{\circ}$ and $35^{\circ}$. While secular variation probably causes most of the deviations, orientation errors and demagnetization insufficient to determine the stable magnetic inclination add to the observed scatter in inclination values. Therefore, the amount of secular variation must be smaller than $15 \%$ for the investigated drill core.

\section{Site 427 (Siqueiros Fracture Zone)}

Because of its location within the Siqueiros fracture zone and the approach path to the site, it was not possible to identify the associated magnetic anomaly from the observed anomaly pattern. Site 427 is located on the southern flank of the fracture zone and may belong to the block of oceanic crust to the south. If this assumption is true, then it is possible to make an estimate of the age of the drilled basalt by its distance from the ridge crest. Assuming a spreading rate similar to the East $\mathrm{Pa}$ cific Rise north of the fracture zone $(5.7 \mathrm{~cm} / \mathrm{y}$.), and observing that the distance to the ridge crest is $196 \mathrm{~km}$, this
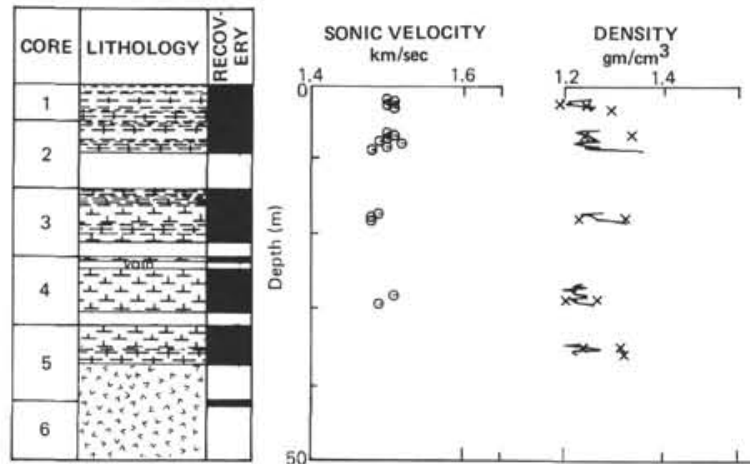

POROSITY (\%) WATER CONTENT (\%)
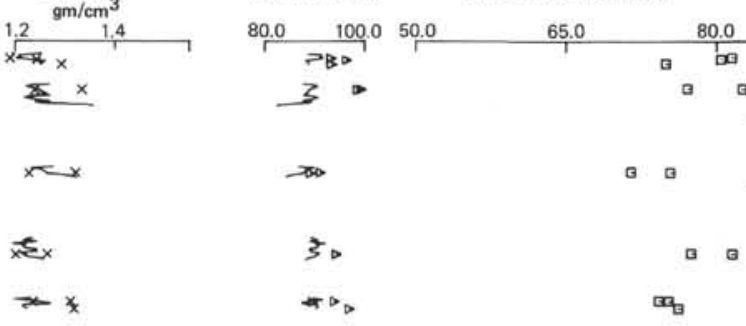

30

Figure 39. Plot of physical properties of sediments versus depth, Hole 423. 


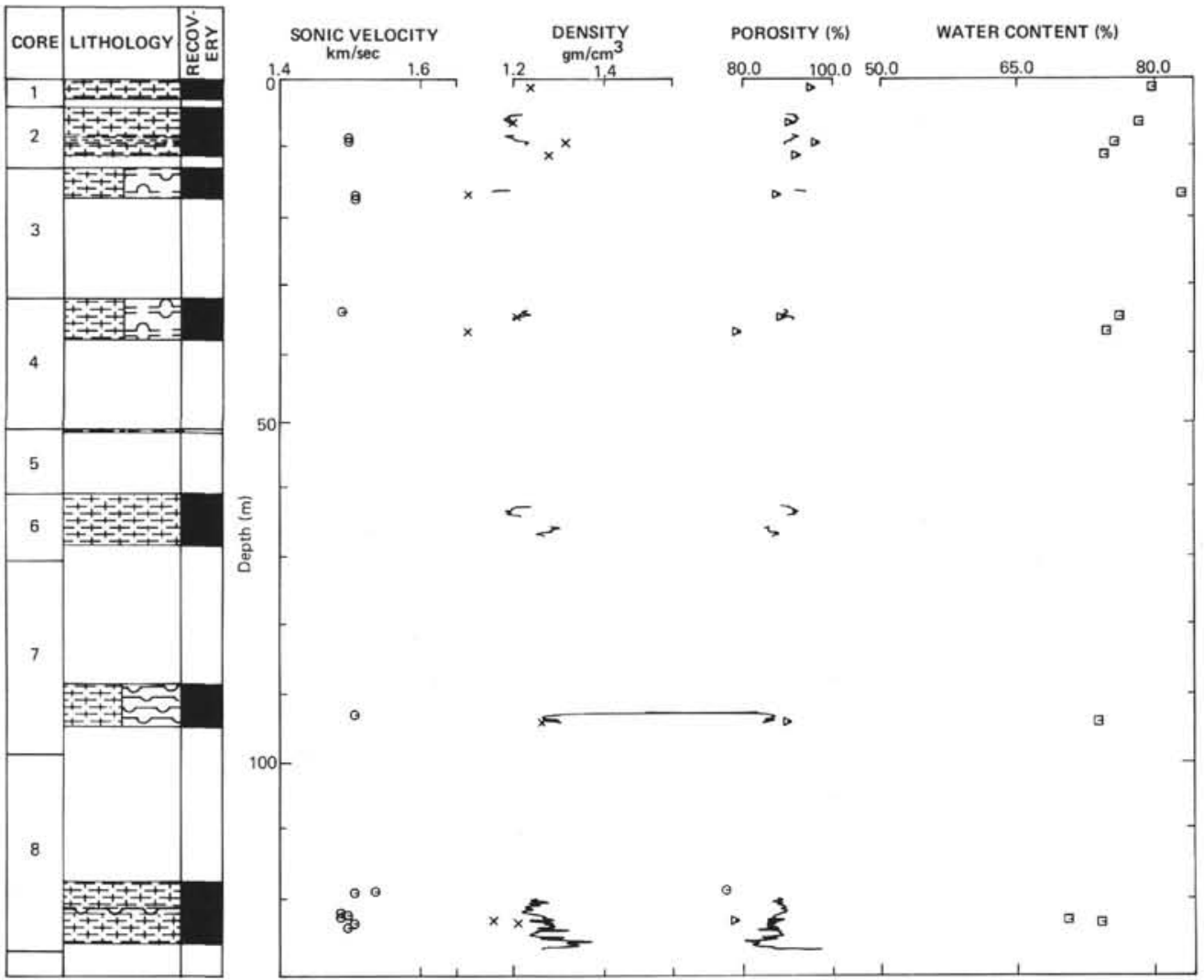

Figure 40. Plot of physical properties of sediments versus depth, Hole 427.

results in an estimated age of about $3.4 \mathrm{~m} . \mathrm{y}$. This age falls within the first reversed interval of the Gilbert reversed epoch. The observed negative polarity of the recovered basalts agrees with this prediction. The age estimated from rock magnetic properties and the degree of oxidation of titanomagnetite, however, is only 2 m.y. (Petersen and Roggenthen, this volume).

Rock magnetic measurements for Site 427 are summarized in Table 25 and Figure 54.

Although petrographically the drilled rock column consists of only one unit, we observed different magnetic subdivisions. There are three maxima in the magnetization intensity. The uppermost maximum is probably associated with a grain size variation due to the chilled margin. The two other maxima are more difficult to explain; they are possibly caused by local concentrations of volatiles during the cooling of the magma body. In this context, it is interesting to note that the lower maximum coincides with the occurrence of ilmenite exsolution within the titanomagnetite grains.

\section{General Conclusions}

1) It has been argued by different authors that a determination of the magnetization polarity in DSDP drill cores obtained at latitudes lower than $20 \%$ is not possible. Our results indicate that the determination of magnetization polarity is possible for the PT- 4 area $\left(9^{\circ} \mathrm{N}\right)$, since the paleosecular variation of the magnetic field in this area seems to be low.
2) Apart from Hole 422 and the upper portion of Hole 429, the magnetization polarities of the drilled rocks agree with the associated marine magnetic anomalies. The polarities of Site 422 basalts are thus consistent with an off-axis origin possibly related to OCP Ridge volcanism. For Site 428, also in an OCP Ridge "moat," an off-axis origin is neither supported nor refuted by paleomagnetic data.

3) Compared with rocks from the Atlantic Ocean, the investigated samples from the PT- 4 area generally have higher susceptibilities, distinctly lower magnetic stability (expressed in MDF), and lower Königsberger $Q$ factors.

4) The intensity of the natural remanent magnetization after partial alternating field demagnetization can be a valuable tool in identifying petrographic units or zones within basalt flows and sills.

\section{SUMMARY AND CONCLUSIONS}

From a number of points of view, the single most important result of Leg 54 drilling on the East Pacific Rise was the inability to establish a multiple re-entry hole on fast-spreading crust. The causes of drilling difficulties seem to be a combination of factors of which the most important are:

1) The rocks are highly fractured, possibly as a result of block-faulting on the flanks of the East Pacific Rise axial block. 
TABLE 21

Dry-Bulk Densities and Grain Densities of Basalts from All Sites, Leg 54

\begin{tabular}{|c|c|c|c|c|c|c|c|}
\hline Hole & Core & Section & $\begin{array}{l}\text { Interval } \\
(\mathrm{cm})\end{array}$ & $\begin{array}{l}\text { Piece } \\
\text { No. }\end{array}$ & $\begin{array}{l}\text { Dry Bulk } \\
\text { Density } \\
\left(\mathrm{g} / \mathrm{cm}^{3}\right)\end{array}$ & $\begin{array}{l}\text { Grain } \\
\text { Density } \\
\left(\mathrm{g} / \mathrm{cm}^{3}\right)\end{array}$ & Shipboard Visual Description \\
\hline
\end{tabular}

East Pacific Rise

$\begin{array}{rrrr}420 & 14 & 1 & 31-34 \\ 421 & 3 & 1 & 79-82 \\ 422 & 8 & 5 & 19-22 \\ 422 & 8 & 5 & 91-94 \\ 422 & 9 & 1 & 80-83 \\ 422 & 9 & 2 & 44-47\end{array}$

$\begin{array}{rcc}5 & - & 2.9802^{\mathrm{a}} \\ 12 & - & 2.9873^{\mathrm{a}} \\ 3 & 2.8839 \mathrm{a} & 2.9661^{\mathrm{a}} \\ 10 & 2.8831^{\mathrm{a}} & 2.9931^{\mathrm{a}} \\ 4 \mathrm{~d} & - & 3.0306^{\mathrm{a}} \\ 4 \mathrm{c} & 2.879 \mathrm{~b} & -\end{array}$

$1-2 \%$ plagioclase crystals, $10-20 \%$ vesicles aphyric, fine-grained

rare plagioclase phyric, fine-grained

sparsely plagioclase phyric, medium coarse grained, $2 \%$ vesicles

coarse-grained aphyric

fine-grained aphyric, vesicles

\section{Galapagos}

$\begin{array}{lllccll}424 & 5 & 1 & 31-33 & 5 & 2.845^{\mathrm{b}} & 3.001^{\mathrm{b}} \\ 424 & 5 & 3 & 22-25 & 2 & 2.886^{\mathrm{a}} & 2.9886^{\mathrm{a}} \\ 424 & 6 & 1 & 29-32 & 5 & 2.8804^{\mathrm{a}} & 3.0015^{\mathrm{a}} \\ 424 & 6 & 1 & 107-109 & 10 \mathrm{c} & 2.872^{\mathrm{b}} & 3.060^{\mathrm{b}} \\ 424 \mathrm{~A} & 4 & 1 & 61-63 & 8 & 2.8540^{\mathrm{a}} & 3.0778^{\mathrm{a}} \\ 424 \mathrm{~B} & 5 & 1 & 27-30 & 4 & 2.8601^{\mathrm{a}} & 2.9996^{\mathrm{a}} \\ 424 \mathrm{~B} & 5 & 1 & 139-141 & 17 & 2.8598^{\mathrm{a}} & 2.9482^{\mathrm{a}} \\ 424 \mathrm{~B} & 6 & 1 & 65-68 & 10 & 2.899 \mathrm{~b} & 3.021^{\mathrm{b}} \\ 424 \mathrm{C} & 3 & 1 & 20-23 & 2 & - & 2.9930^{\mathrm{a}} \\ 424 \mathrm{C} & 3 & 1 & 46-49 & 4 & 2.889 \mathrm{~b} & 3.003^{\mathrm{b}} \\ 425 & 7 & 1 & 130-133 & 17 \mathrm{a} & 2.7995^{\mathrm{b}} & 3.0285^{\mathrm{c}} \\ & & & & & 2.7963^{\mathrm{a}} & 3.0569^{\mathrm{a}} \\ 425 & 7 & 2 & 115-117 & 11 & 2.8800^{\mathrm{b}} & 3.0162^{\mathrm{c}} \\ & & & & & 2.8950^{\mathrm{a}} & 3.0490^{\mathrm{a}} \\ 425 & 8 & 1 & 44-47 & 6 & 2.7980^{\mathrm{b}} & 3.0115^{\mathrm{b}} \\ & & & & & & \\ 425 & 8 & 1 & 70-73 & 9 & 2.9040^{\mathrm{a}} & 2.9927^{\mathrm{a}} \\ 425 & 8 & 1 & 145-148 & 16 & 2.9200^{\mathrm{b}} & 3.0265^{\mathrm{b}} \\ 425 & 9 & 3 & 69-72 & 10 & - & 2.9873^{\mathrm{a}}\end{array}$

Siqueiros Fracture Zone

$\begin{array}{lrrrlll}427 & 9 & 1 & 11-13 & 2 & - & 2.9777^{\mathrm{a}} \\ 427 & 9 & 3 & 62-65 & 5 \mathrm{~b} & - & 2.9853^{\mathrm{a}} \\ 427 & 9 & 4 & 132-135 & 6 & - & 2.9919^{\mathrm{a}} \\ 427 & 10 & 4 & 74-77 & 1 \mathrm{~g} & - & 3.0243^{\mathrm{a}}\end{array}$

\section{East Pacific Rise}

\begin{tabular}{lllcccc}
428 & 5 & 4 & $35-38$ & 4 & $2.873^{\mathrm{a}}$ & $2.9471^{\mathrm{a}}$ \\
428 & 6 & 1 & $87-90$ & $8 \mathrm{e}$ & - & $2.9328^{\mathrm{a}}$ \\
428 & 6 & 1 & $121-124$ & $10 \mathrm{~b}$ & - & $2.9835^{\mathrm{a}}$ \\
428 & 6 & 2 & $73-76$ & 8 & - & $2.9171^{\mathrm{a}}$ \\
$428 \mathrm{~A}$ & 4 & 2 & $116-119$ & 8 & - & $2.9699^{\mathrm{a}}$ \\
$428 \mathrm{~A}$ & 5 & 2 & $101-104$ & $5 \mathrm{e}$ & - & $3.0100^{\mathrm{a}}$ \\
$429 \mathrm{~A}$ & 2 & 1 & $14-17$ & 3 & $2.7315^{\mathrm{a}}$ & $3.0055^{\mathrm{a}}$ \\
$429 \mathrm{~A}$ & 2 & 1 & $53-56$ & 7 & $2.7227^{\mathrm{a}}$ & $2.9615^{\mathrm{a}}$ \\
$429 \mathrm{~A}$ & 3 & 1 & $103-106$ & 5 & $2.7920^{\mathrm{a}}$ & $2.9717^{\mathrm{a}}$ \\
\hline
\end{tabular}

\author{
fine-grained, rare pinpoint vesicles filled with green mineral \\ fine-grained, tiny sparse vesicles \\ fine-grained basalt, rare pinpoint vesicles \\ fine-grained, some less crystallized parts, vugs
}
fine-grained, sparsely plagioclase phyric, variolitic texture, filled vesicles sparsely plagioclase phyric: variolitic texture, filled tube vesicles fine-grained, some vesicles and vugs
fine-grained with rare microphenocrysts, vesicles and vugs
very fine grained with few pinpoint vesicles
fine grained clusters of vugs

medium-grained plagioclase phyric basalt ( $2 \%$ up to $2 \mathrm{~mm}$ crystals)

coarse-grained, sparsely plagioclase phyric, some weathering, blue minerals in vesicles

coarse-grained, sparsely plagioclase phyric

plagioclase and clinopyroxene porphyritic crystals up to $3 \mathrm{~mm}$

plagioclase phyric without glass or grain size variation, coarse-grained

very fine grained basalt

medium-grained, aphyric, vesicles are rare, rock is fresh

medium-grained, sparsely plagioclase and clinopyroxene phyric; massive non-vesicular

aphyric, medium-grained basalt; Section $10-4$ is one continuously cored unit

fine-grained basalt with rare pinpoint vesicles

medium-grained with very sparse pinpoint vesicles

fine-grained, aphyric, rare empty vesicles

massive, non-vesicular, aphyric, medium-grained

aphyric plagioclase-pyroxene basalt

medium-grained, oxidized aphyric

fine-grained, aphyric, glassy edges

fine-grained, aphyric, glassy edges

slightly coarse grained, aphyric

a Laboratory measurement.

bShipboard measurement.

cShipboard: calculated from wet and dry density measurements.

2) The lavas consist of a large proportion of sheet flows rather than pillows, and therefore do not have an interlocking joint structure which would prevent them from dropping down the hole and binding the bit during drilling.

3) The rocks are very fresh and very hard, with few if any fractures healed by alteration.

On the basis of Leg 54 drilling, no deep-penetration hole into fast-spreading crust appears feasible unless that crust is significantly altered. In all likelihood, this means that the crust will have to be old or, if young, uniformly and thickly sedimented in an area of high sediment accumulation rates, either near a continental margin or beneath the thick belt of equatorial pelagic sediments in the central Pacific. (We note that such a hole was recently drilled $561 \mathrm{~m}$ into basement of late Miocene age at Site 504 on the Costa Rica Rift. There, high heat flow and thickened sediments appear to have combined to alter the young crust sufficiently to allow drilling). Alternatively, some method must be devised to 
TABLE 22

Basalt Grain Density Averages, All Leg 54 Data

\begin{tabular}{|c|c|c|c|}
\hline Hole & $\begin{array}{l}\text { Number of } \\
\text { Samples }\end{array}$ & $\begin{array}{c}\text { Main Grain } \\
\text { Density } \\
\left(\mathrm{g} / \mathrm{cm}^{3}\right)\end{array}$ & $\begin{array}{c}\text { Mean Grain Density } \\
\text { Over All Sites }\end{array}$ \\
\hline \multicolumn{4}{|l|}{ East Pacific Rise } \\
\hline $\begin{array}{l}420,421,422 \\
428,428 \mathrm{~A}, 429 \mathrm{~A}\end{array}$ & $\begin{array}{l}5 \\
9\end{array}$ & $\begin{array}{l}2.9914 \\
2.9665\end{array}$ & 2.9753 \\
\hline Total & 14 & & \\
\hline \multicolumn{4}{|l|}{ Siqueiros Fracture Zone } \\
\hline 427 & 4 & 2.998 & 2.998 \\
\hline \multicolumn{4}{|l|}{ Galapagos } \\
\hline $\begin{array}{l}424 \\
424 \mathrm{~A}, \mathrm{~B}, \mathrm{C} \\
425\end{array}$ & $\begin{array}{l}4 \\
6 \\
6 \\
\end{array}$ & $\begin{array}{l}3.0153 \\
3.0071 \\
3.0162\end{array}$ & 3.0128 \\
\hline Total & 16 & & \\
\hline
\end{tabular}

allow drilling on the unsedimented East Pacific Rise axial block, where high upper crustal velocities (Figure 3) imply that little fracturing has yet taken place. The life expectancy of bits currently in use, however, will be very low in such rocks.

Leg 54 succeeded in drilling a number of single-bit holes on the flanks of the East Pacific Rise and one in the Siqueiros fracture zone despite several daunting obstacles. Sediments were continuously cored at several of these, including Site 420 where the thickest sediment accumulation $(119.5 \mathrm{~m})$ was cored. Bits were taken to destruction, or nearly so, in basement at Sites 420, 421, 423,427 , and 428 , although penetration was generally low. The deepest basement penetration was 52.5 meters in Hole 428A.

The principal results of the sediment coring concern the nature of what has been termed the "cyclic member" (Hays et al., 1972; Cook, 1972) of the equatorial Pacific Clipperton formation (Tracey, Sutton, et al., 1971), and the extent to which hydrothermal components produced at the rise crest may have become incorporated into the sediments. In the uppermost cores at most sites, the sediments consist of alternating grayish green, calcareoussiliceous oozes and reddish brown marls or calcareous muds. From the fact that all of our sites were targeted in small sediment ponds amid nearly bare igneous outcrops, redistribution by slumping and currents must have been a factor in accumulating the small thicknesses of sediments we managed to core. Although drilling disturbance is great, several factors support such a view:

1) Locally sharp bedding contacts occur between marly and calcareous sediments that are not disturbed by bioturbation.

2) There are local concentrations of siliceous, pyritic, and, in one instance, vitric sediments, indicative of size and density sorting by currents as well as slumping.

3) There are contrasting sedimentation rates at different sites with diastems in some but not in others.

4) There is clear biostratigraphic evidence for intervals of very rapid sedimentation in some cores (i.e., redeposition or slumping).
5) There is general lack of correlation of individual marly and calcareous mud zones among holes.

6) There is lack of agreement between basement ages inferred from magnetic anomalies and the oldest recovered (generally younger) sediments in several holes (Table 12).

The clay-rich intervals do not seem to have an appreciably higher "hydrothermal" component in their non-calcareous fraction, as estimated from chemical data (Hekinian, Rosendahl, and Natland, this volume). Instead, they seem to reflect dissolution effects on calcareous microfossils (Krasheninnikov, this volume; Lynts, this volume; Goll, this volume), enhanced particularly in the Pleistocene by shoaling of the CCD. Consequently, we suggest that long residence time on the sea floor on igneous highs swept by bottom currents has promoted locally greater dissolution on the sea floor than in adjacent troughs or hollows. In such lows, sediments can collect, be buried, and thus be removed from contact with corrosive bottom waters. Hence they will preserve their carbonate fraction. Redistribution by currents will result in alternating lithologies that do not correlate from pond to pond.

Turning to the hydrothermal question, at Site 420, based on data in Donnelly (this volume), there appears to have been a significant steady contribution of nonhydrogenous hydrothermal iron to the sediments, which is variably diluted by carbonate and siliceous pelagic material (Hekinian, Rosendahl, and Natland, this volume). This far exceeds the "pelagic clay" component which is primarily derived from eolian sources, and which is markedly more predominant at Site 425 , in the nearly enclosed Panama Basin. The East Pacific Rise hydrothermal component appears to have been in the form of amorphous iron hydroxides which have since reacted with siliceous microfossils to form $\mathrm{K}-\mathrm{Fe}$ montmorillonites (described by Rateev et al., this volume). This component does not resemble the iron nontronites of the Galapagos holes at Site 424 (see Chapter 10, this volume), which have a very specific $\mathrm{Fe} / \mathrm{Si}$ ratio. Hekinian, Rosendahl, and Natland (this volume) infer that the East Pacific Rise hydrothermal sediment component reflects geothermal activity at the rise crest, rather than lower temperature cellular-type circulation of water in consolidated crust away from axial regions, such as inferred to exist beneath Site 424 on the Galapagos Rift (see Galapagos Site Report, this volume).

From a biostratigraphic point of view, the East Pacific Rise sites provide a good variety and diversity of microfossils in a tropical eastern Pacific setting. Detailed correlations of Pliocene to Quaternary nannofossils, foraminifers, diatoms, radiolarians, and silicoflagellates have been made for each site. Only the foraminifers appear to have been affected by dissolution to the extent that cerain marker fossils cannot be identified (Krasheninnikov, this volume). Nevertheless, Lynts (this volume) has used foraminiferal morphological indicators to indicate a heightened alternation of environmental factors, mainly climatic, in the Pleistocene. 
Goll (this volume) has refined and extended the tropical radiolarian zonation scheme and Bukry (this volume) described opal phytoliths added to the sediments apparently by winds from Mexico and Central America.

The primary objectives of Leg 54 relate to drilling in the ocean crust. With short penetration holes, we can say little about the cause of the upper crustal velocity gradients occurring in the region (Figure 3), nor about crustal magnetic structure. Lithologic observations in the cores, and our poor drilling record, however, imply that the upper crustal rocks are probably fractured sufficiently to account for low velocities in the uppermost crust. To a reasonable degree, we can also say that magnetic inclinations of surficial basalts tend to agree with the sign of magnetic anomalies between 1.2 and $4.6 \mathrm{~m}$.y. old (Petersen and Roggenthen, this volume). despite low latitudes and the implication that magnetic structure in Layer 2 should be complex, based on the numerous reversals and scattered inclinations observed in drill holes on the Mid-Atlantic Ridge (e.g., Hall and Ryall, 1977).

Our most significant results are petrologic. By combining dredge and drill data, we can now say with some assurance that depleted tholeiitic ferrobasalts, rich in $\mathrm{TiO}_{2}$, are an important component of "normal" faultblock East Pacific Rise fast-spreading crust, and appear to be more abundant there than in the adjacent Siqueiros fracture zone. This is shown on Table 26, which uses $\mathrm{TiO}_{2}$ as a general petrochemical indicator of evolution toward ferrobasalt compositions. A number of studies have indicated that close coherence between $\mathrm{TiO}_{2}$ and total iron concentrations in the abyssal tholeiite suite (e.g., Rhodes et al., 1976; Clague and Bunch, 1976). $\mathrm{TiO}_{2}$ is also one of the most useful discriminants of basalt compositions, since it is usually resolvable analytically to within \pm 0.02 weight per cent and behaves incompatibly during crystal-liquid segregation processes. Using $\mathrm{TiO}_{2}$ as well as other discriminants, a total of 38 distinct chemical types have been dredged or drilled in the Siqueiros region (Batiza et al., 1977; Johnson, 1979; Lonsdale and Spiess, 1979; Schrader et al., this volume; Natland and Melson, this volume; Joron et al., this volume) -11 of these were drilled. Ferrobasalts are also evidently more abundant on the East Pacific Rise than on the Mid-Atlantic Ridge (Figure 35). There is no indication that ferrobasalts cored at Site 423 are in any way anomalous. This site indeed is on normal block-faulted East Pacific Rise crust.

Table 26 also shows that more magnesian basalts occur sporadically on the flanks and crest of the East Pacific Rise, in close association with ferrobasalts. From this, we infer that they alternate stratigraphically with ferrobasalts, and that there is no single "steadystate" product of the axial magma reservoir. The implications of this are considered further in Natland (Axial Magma Chambers chapter, this volume).

Basalts from the moat-like structure adjacent to the OCP Ridge drilled at Sites $\mathbf{4 2 2}$ and $\mathbf{4 2 8}$ have most of the characteristics of depleted abyssal tholeiites; however, those from Site $\mathbf{4 2 2}$ differ sufficiently in trace element and certain major oxide characteristics to suggest some mantle heterogeneity in the region (Humphris et al., this volume). The extreme examples of this appear to be isotopically and chemically undepleted transitional and alkalic basalts dredged from a seamount and from the OCP Ridge (Batiza and Johnson, this volume). Unlike the Mid-Atlantic Ridge, however, the scale of heterogeneity seems to be local and restricted, since such lavas have only been sampled from two off-axis seamounts.

Within the rise tholeiite suite, crystal fractionation appears to have been a dominant cause of compositional variation. On a small scale, this appears to explain chemical variations within a single ferrobasalt flow at Site 427 (Humphris et al., this volume). It is more difficult to evaluate crystal fractionation on a larger scale, because of the difficulty in identifying suitable parentdaughter pairs with the scattered suite of rock types available. However, enrichment factors of various lowpartition-coefficient trace elements between olivine tholeiites and ferrobasalts are consistent, and in accord with models requiring about 60 per cent fractionation of major silicate phases (Srivastava et al., this volume; Humphris et al, this volume). One dredge station includes basalts which seem to have fractionated a slightly different mineral assemblage than usual, one involving either more clinopyroxene or possibly late titanomagnetite (Natland and Melson, this volume).

Mineralogical evidence for magma mixing does not occur in the drilled and more dredged basalts, since very few contain more than a per cent or so of large phenocrysts. At Site 423 , iron-rich aphyric basalts have a streaked appearance-the result of bands of contrasting crystallinity - which may have resulted from blending of two very similar magma types. But this could also have been caused by different concentrations of volatiles.

Two surprising mineralogical facts have emerged from shipboard and post-cruise studies. The first is that despite a wide range in chemical compositions between olivine tholeiites and ferrobasalts, there is no definitive mineralogical distinction that can be used to distinguish them petrographically in all cases (Tables 14 and 15). In addition to having clinopyroxene and plagioclase, for example, some ferrobasalts also contain olivine, thus matching the mineralogy of some considerably less fractionated basalts. The reasons for this are explored in Natland (this volume), where criteria based on crystal morphologies are set out to provide a basis for accurate identification of various abyssal tholeiites in thin sections. The second surprising fact is that mineral compositions within an individual rock may cover much or all of the range of mineral compositions in the abyssal tholeiite suite. This apparently reflects highly variable conditions of crystallization at high undercooling, and possibly including an early stage of volatile (mainly water) retention in the magmas, producing unusually calcic cores to small plagioclase microphenocrysts (Thompson et al., this volume). This would appear to make a selection of phenocryst compositions for use in modeling fractionation at different compositional stages both difficult and somewhat arbitrary.

One additional, unexpected petrological result was that in whatever way ferrobasalts are produced, they are 
TABLE 23

Physical Properties of Basalts from the East Pacific Rise, Leg 54

\begin{tabular}{cccccccc}
\hline Core & Section & $\begin{array}{c}\text { Interval } \\
(\mathrm{cm})\end{array}$ & Piece No. & $\begin{array}{c}\text { Velocity } \\
(\mathrm{km} / \mathrm{s})\end{array}$ & $\begin{array}{c}\text { Number of } \\
\text { Measurements }\end{array}$ & $\begin{array}{c}\text { Wet-Bulk } \\
\text { Density } \\
\left(\mathrm{g} / \mathrm{cm}^{3}\right)\end{array}$ & $\begin{array}{c}\text { Porosity } \\
(\%)\end{array}$ \\
\hline Hole 420 & & & & & & & \\
13 & CC & $53-56$ & - & $5.133^{\mathrm{b}}$ & - & 2.79 & - \\
14 & 1 & $14-17$ & - & $5.144^{\mathrm{b}}$ & - & 2.89 & - \\
15 & 1 & $69-72$ & - & 5.786 & - & 3.09 & -
\end{tabular}

Hole 421

$\begin{array}{lccrllll}2 & 1 & 14-17 & 1 & 5.97^{\mathrm{b}} & - & 2.98 & \sim 0 \\ 3 & 1 & 30-33 & 5 & 5.19 & - & 2.78 & 8.91 \\ 3 & 1 & 72-75 & 11 & 5.65 & - & 2.89 & 2.87 \\ 3 & 1 & 117-120 & 17 & 5.55 & - & 3.00 & \sim 0 \\ 4 & 1 & 4-7 & 1 & 5.18 & - & 2.88 & 3.48 \\ 3 & 1 & 80-83 & 12 & 5.492 & 1 & 2.85 & - \\ 4 & 1 & 15-18 & 2 & 5.485 & 1 & 2.84 & -\end{array}$

Hole 422

$\begin{array}{rccccccc}7 & 1 & 39-42 & 6 \mathrm{a} & 6.200 & 1 & 2.922 & - \\ 7 & 1 & 89-92 & 7 \mathrm{e} & 5.983 & 1 & 2.921 & - \\ 7 & 2 & 14-17 & 3 & 6.077 & 1 & 2.919 & - \\ 8 & 5 & 23-36 & 5 & 6.021 & 1 & 2.920 & - \\ 8 & 5 & 132-135 & 14 & 5.902 & 1 & 2.928 & - \\ 9 & 1 & 70-73 & 4 \mathrm{c} & 5.866 & 1 & 2.934 & - \\ 9 & 2 & 135-138 & 6 & 5.898 & 1 & 2.898 & - \\ 9 & 3 & 91-94 & 6 \mathrm{c} & 5.842 & 1 & - & - \\ 9 & 4 & 135-138 & 13 \mathrm{a} & 6.127 & 1 & 2.90 & - \\ 9 & 5 & 72-75 & 6 & 5.908 & 1 & 2.91 & - \\ 10 & 1 & 20-23 & 3 & 6.015 & 1 & 2.93 & - \\ 9 & 2 & 44-47 & 46 & 5.423 & 1 & 2.879 & -\end{array}$

Hole 423

$\begin{array}{cccccccc}5 & \mathrm{CC} & 41-43 & 4 & 5.742 & 2 & 2.878 & - \\ 7 & 1 & 4-7 & 1 & 5.602 & 3 & 2.818 & -\end{array}$

Hole 427

$\begin{array}{rrrrrrrr}9 & 1 & 11 & 2 & 4.763 & 3 & 2.846 & - \\ 9 & 1 & 41 & 4 \mathrm{~b} & 5.675 & 3 & 2.880 & - \\ 9 & 1 & 103 & 10 \mathrm{a} & 5.762 & 1 & 2.918 & - \\ 9 & 2 & 4 & 1 & 5.670 & 1 & 2.903 & - \\ 9 & 2 & 94 & 11 \mathrm{a} & 5.765 & 1 & 2.917 & - \\ 9 & 3 & 62 & 5 \mathrm{~b} & 5.732 & 1 & 2.939 & - \\ 9 & 4 & 36 & 4 \mathrm{a} & 5.766 & 1 & 2.919 & - \\ 9 & 4 & 132 & 6 & 5.636 & 4 & 2.908 & - \\ 9 & 5 & 96 & 7 & 5.795 & 2 & 2.924 & - \\ 10 & 1 & 67 & 4 \mathrm{a} & 5.665 & 1 & 2.912 & - \\ 10 & 2 & 5 & 1 \mathrm{a} & 5.727 & 1 & 2.924 & - \\ 10 & 2 & 131 & 4 & 5.694 & 2 & 2.931 & - \\ 10 & 3 & 39 & 3 & 5.709 & 1 & 2.936 & - \\ 10 & 3 & 144 & 9 \mathrm{c} & 5.980 & 3 & 2.933 & - \\ 10 & 4 & 74 & 1 \mathrm{~g} & 5.947 & 2 & 2.936 & - \\ 10 & 5 & 64 & 4 \mathrm{~b} & 5.780 & 2 & 2.934 & -\end{array}$

Hole 428

\begin{tabular}{rrrrrrrr}
5 & 4 & 15 & 2 & 5.547 & 1 & 2.904 & - \\
5 & 4 & 36 & 4 & 6.130 & 2 & 2.881 & - \\
5 & 4 & 72 & 8 & 5.518 & 1 & 2.892 & - \\
5 & 4 & 81 & 9 & 5.629 & 1 & 2.896 & - \\
6 & 1 & 18 & 3 & 6.070 & 1 & 2.906 & - \\
6 & 1 & 74 & $8 \mathrm{c}$ & 6.219 & 1 & 2.927 & - \\
6 & 1 & 127 & $10 \mathrm{~b}$ & 5.342 & 1 & 2.867 & - \\
6 & 2 & 6 & 1 & 5.833 & 1 & 2.908 & - \\
6 & 2 & 75 & 8 & 5.792 & 1 & 2.882 & - \\
\hline
\end{tabular}


TABLE 23 - Continued

\begin{tabular}{|c|c|c|c|c|c|c|c|}
\hline Core & Section & $\begin{array}{l}\text { Interval } \\
(\mathrm{cm})\end{array}$ & Piece No. & $\begin{array}{l}\text { Velocity } \\
(\mathrm{km} / \mathrm{s})\end{array}$ & $\begin{array}{l}\text { Number of } \\
\text { Measurements }\end{array}$ & $\begin{array}{l}\text { Wet-Bulk } \\
\text { Density } \\
\left(\mathrm{g} / \mathrm{cm}^{3}\right)\end{array}$ & $\begin{array}{c}\text { Porosity }^{\mathrm{a}} \\
(\%)\end{array}$ \\
\hline \multicolumn{8}{|c|}{ Hole 428A } \\
\hline 1 & 1 & 32 & 4 & 5.640 & 1 & 2.899 & - \\
\hline 1 & 1 & 89 & 10 & 5.937 & 1 & 2.904 & - \\
\hline 1 & 2 & 4 & 1 & 6.075 & 1 & 2.947 & - \\
\hline 1 & 2 & 47 & 6 & 6.090 & 1 & 2.936 & - \\
\hline 1 & 2 & 125 & $13 b$ & 6.176 & 1 & 2.923 & - \\
\hline 1 & 3 & 65 & $3 b$ & 5.786 & 1 & 2.932 & - \\
\hline 1 & 4 & 6 & 1 & 6.052 & 1 & 2.936 & - \\
\hline 1 & 4 & 72 & 9 & 5.932 & 1 & 2.897 & - \\
\hline 2 & 1 & 20 & 3 & 6.177 & 1 & $\begin{array}{l}>2.9 \\
\text { (chipped) }\end{array}$ & - \\
\hline 2 & 1 & 77 & 8 & 6.134 & 1 & 2.934 & - \\
\hline 3 & 1 & 112 & 8 & 5.813 & 1 & 2.910 & - \\
\hline 3 & 1 & 134 & $12 \mathrm{a}$ & 5.734 & 1 & 2.883 & - \\
\hline 4 & 1 & 50 & $9 a$ & 5.800 & 1 & 2.933 & - \\
\hline 4 & 2 & 3 & 1 & 5.800 & 1 & 2.897 & - \\
\hline 4 & 2 & 118 & 8 & 5.737 & 1 & 2.896 & - \\
\hline 4 & 3 & 57 & 5 & 5.883 & 1 & 2.916 & - \\
\hline 5 & 1 & 21 & $3 a$ & 6.097 & 1 & 2.927 & - \\
\hline 5 & 1 & 115 & 9 & 5.336 & 1 & 2.853 & - \\
\hline 5 & 2 & 12 & $1 \mathrm{a}$ & 5.905 & 1 & 2.931 & - \\
\hline 5 & 2 & 93 & $5 e$ & 5.707 & 1 & 2.903 & - \\
\hline 5 & 2 & 114 & 6 & 5.835 & 1 & 2.942 & - \\
\hline 5 & 3 & 123 & 12 & 5.706 & 1 & 2.921 & - \\
\hline 5 & 4 & 89 & 6 & 5.964 & 1 & 2.934 & - \\
\hline 6 & 1 & 52 & 8 & 6.131 & 1 & 2.925 & - \\
\hline 6 & 1 & 100 & 13 & 5.357 & 1 & 2.809 & - \\
\hline 7 & 1 & 88 & $6 \mathrm{e}$ & 6.011 & 1 & 2.922 & - \\
\hline 7 & 1 & 15 & 18 & 5.999 & 1 & 2.918 & - \\
\hline 7 & 2 & 147 & 12 & 5.621 & 1 & 2.922 & - \\
\hline \multicolumn{8}{|c|}{ Hole 429A } \\
\hline 1 & 1 & 60 & 3 & 5.531 & - & 2.827 & - \\
\hline 2 & 1 & 26 & 4 & 5.468 & - & 2.808 & - \\
\hline 2 & 1 & 41 & $5 b$ & 5.782 & - & 2.851 & - \\
\hline 2 & 1 & 53 & 7 & 5.712 & - & 2.826 & - \\
\hline 2 & 1 & 87 & 12 & 5.611 & - & 2.827 & - \\
\hline 2 & 1 & 125 & 17 & 5.622 & - & 2.848 & - \\
\hline 2 & 2 & 10 & 2 & 5.567 & - & 2.808 & - \\
\hline 3 & 1 & 103 & 5 & 5.741 & - & 2.889 & - \\
\hline 3 & 1 & 120 & $7 \mathrm{a}$ & 5.908 & - & 2.902 & - \\
\hline
\end{tabular}

Note: Wet-bulk densities on Hole 422, 423, 427, 428, 428A, and 429A samples, as well as samples $421-3-1,80-83 \mathrm{~cm}$ and $421-4-1,15-18 \mathrm{~cm}$ are from length and weight measurements; velocities and densities are of lapped, resaturated samples. Measurements on Hole 428A and 429A samples, as well as Sample 422-9-2, 44-47 cm, were on dried rock.

aDensities and porosities are from 2-minute GRAPE counts, assuming corrected grain density equals true grain density $=2.95 \mathrm{~g} / \mathrm{cm}^{3}$.

bHighly non-parallel sample.

amazingly similar from place to place (Natland and Melson, this volume). Unlike granitic compositions, which appear to be similar because of eutectic phase relations in petrogeny's residual system (e.g., Tuttle and Bowen, 1958), the similar ferrobasalt compositions imply both remarkably similar parental olivine tholeiite compositions and virtually identical lines of evolution from such parents. Apparently, conditions for both melting and fractionation have remained virtually unchanged over the past $4.6 \mathrm{~m} . \mathrm{y}$. along this segment of the East Pacific Rise. We infer that the depth and degree of melting, and the source composition of East Pacific Rise olivine tholeiites fed into the axial magma chamber have stayed the same, perhaps because of melting at nearly invariant pressure and temperature conditions (Presnall et al., 1979), and that the dimensions and thermal structure of the axial magma chamber and its crustal capping have also remained substantially unchanged. Ferrobasalts, which have a considerably lower liquidus temperature than olivine tholeiites, evolved either in the upper, cooler, reaches of the axial magma reservoir or in small bodies (dikes, lava lakes, etc.) in the crust.

A variety of olivine tholeiite compositions appear to erupt mainly in the fracture zone and on seamounts and ridges built on older crust. These do not appear to be simply relatable by crystal fractionation processes (Nat- 


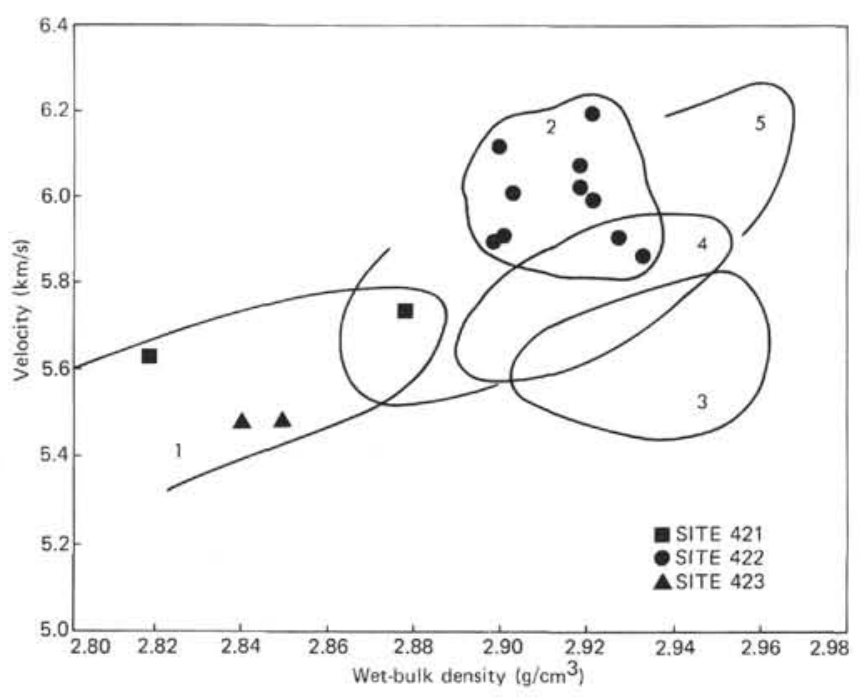

Figure 41 . Sonic velocity $(\mathrm{km} / \mathrm{s})$ versus wet-bulk density $\left(\mathrm{g} / \mathrm{cm}^{3}\right)$ for basalts, Sites 421,422 and 423 . Fields are (1) Sites 420 and 421; (2) Site 422; (3) Hole 424 (Galapagos Rift); (4) Holes 424A, B, and C (Galapagos Rift); and (5) Hole 425 (Galapagos Rift).

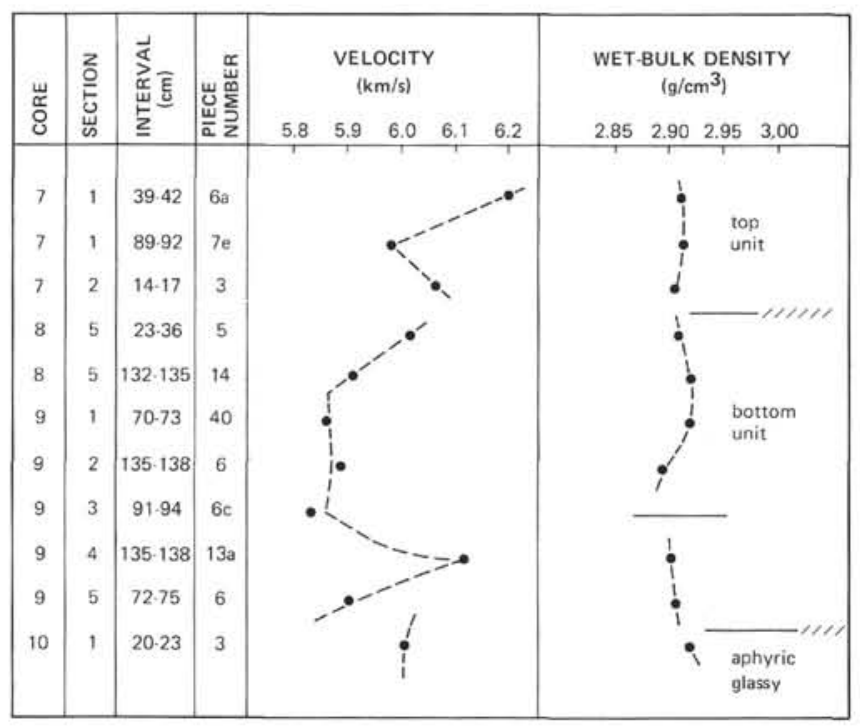

Figure 42. Velocity $(\mathrm{km} / \mathrm{s})$ and wet-bulk density $(\mathrm{g} /$ $\left.\mathrm{cm}^{3}\right)$ versus downhole sample sequence basalts, Hole 422. Top and bottom units are separated by 3 meters of sediment. Aphyric glassy sample is below two massive units.

land and Melson, this volume), and include some highly magnesian types (Schrader et al., picrites chapter, this volume). The different compositions suggest more diverse conditions of melting in the fracture zone and in off-axis settings than beneath the rise axis. Ferrobasalts recovered at Site 427 in the fracture zone may have spilled into it from the distorted extension of the rise axis into the fracture-zone trough (e.g., Lonsdale, 1978). Petersen and Roggenthen (this volume) have estimated from the degree of oxidation of titanomagnetites in Site 427 basalts that they are about 2

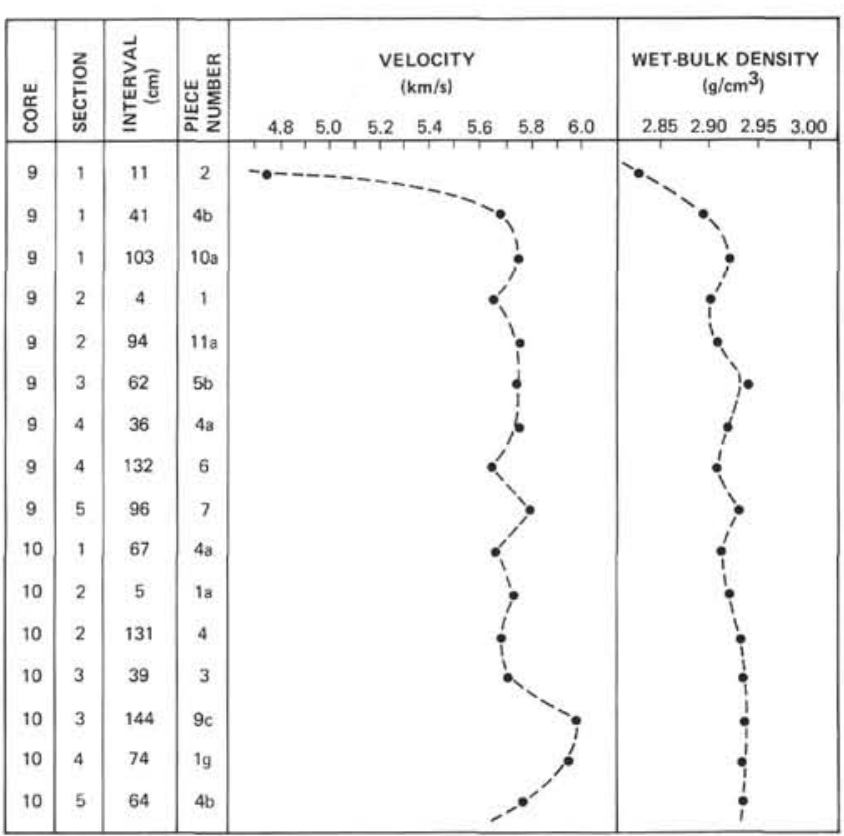

Figure 43. Velocity $(\mathrm{km} / \mathrm{s})$ and wet-bulk density $(\mathrm{g} /$ $\left.\mathrm{cm}^{3}\right)$ versus downhole sample sequence for basalts.

Hole 427. A single massive flow was cored.

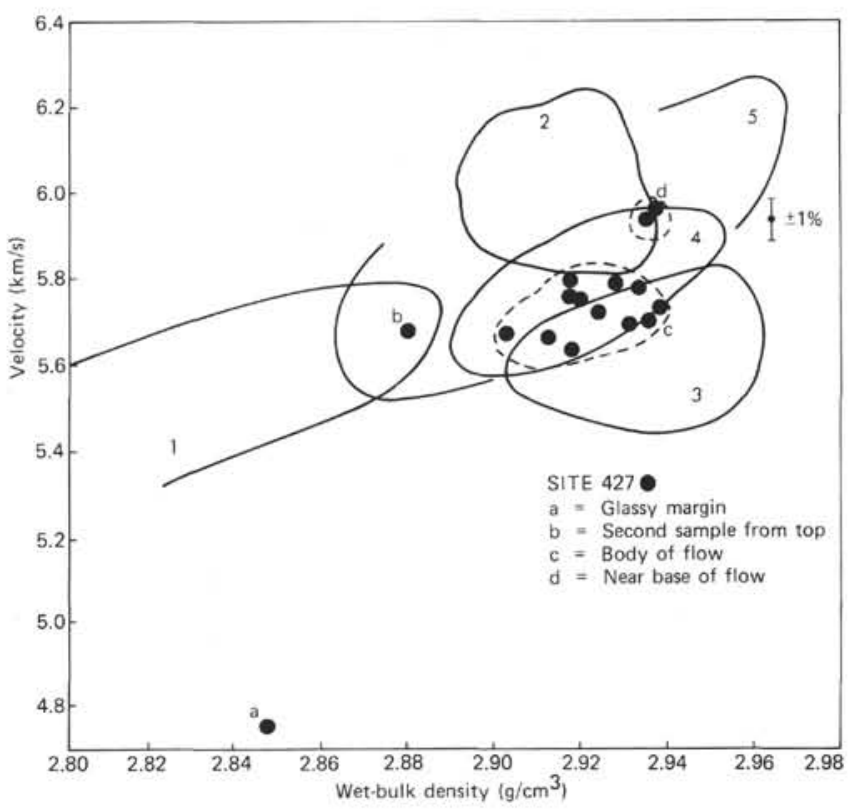

Figure 44. Sonic velocity $(\mathrm{km} / \mathrm{s})$ versus wet-bulk density $\left(\mathrm{g} / \mathrm{cm}^{3}\right)$ for Site 427 basalts. Fields are as in Figure 41. Site 427 ferrobasalts overlap field 4, Holes $424 \mathrm{~A}$, $B$, and C (Galapagos Rift) ferrobasalts.

m.y. old, which is older than the oldest recovered sediments (Table 12) but younger than the adjacent (southern) segment of block-faulted East Pacific Rise crust.

Alteration in the drilled East Pacific Rise basalts is confined mainly to distinctive 1 to 3 -cm-wide alteration rinds. Even in these rinds, combined water $\left(\mathrm{H}_{2} \mathrm{O}^{+}\right)$is rarely more than 1 per cent (Humphris et al., alteration 


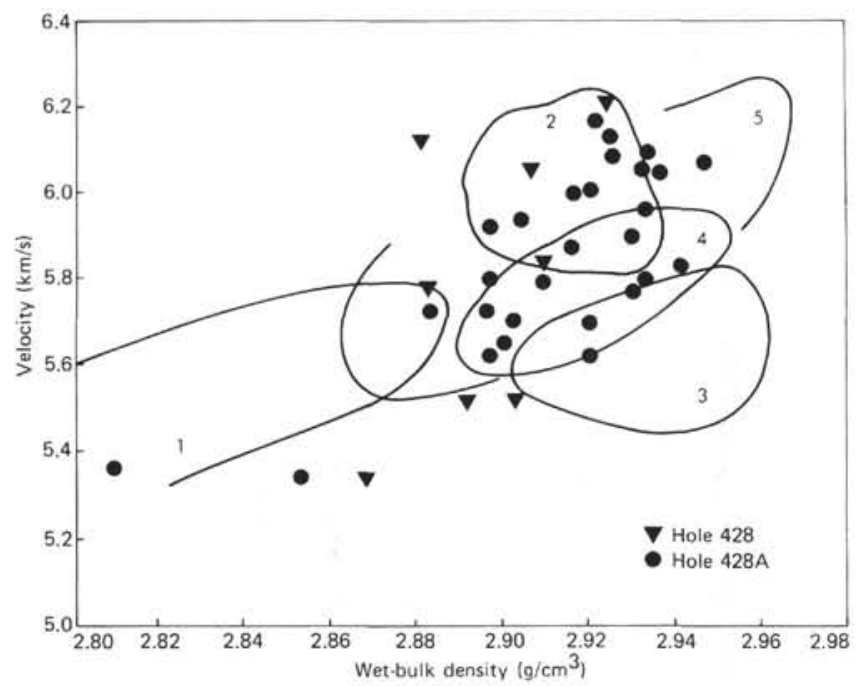

Figure 45 . Sonic velocity $(\mathrm{km} / \mathrm{s})$ versus wet-bulk density $\left(\mathrm{g} / \mathrm{cm}^{3}\right)$ for Site 428 basalts. Fields are as in Figure 41. Site 428 aphyric olivine basalts and dolerites overlap field of Site 425 (Galapagos Rift) sparsely plagioclase-olivine phyric basalts.

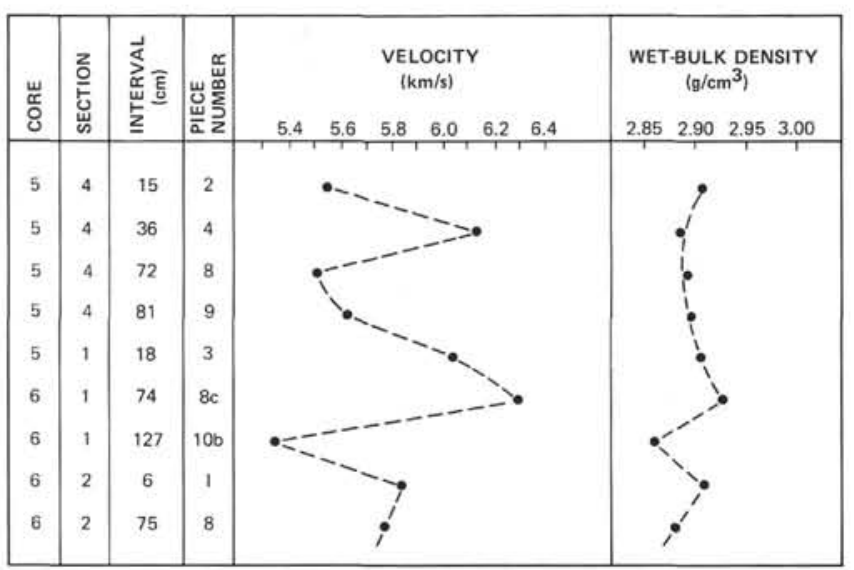

Figure 46. Velocity $(\mathrm{km} / \mathrm{s})$ and wet-bulk density $(\mathrm{g} /$ $\left.\mathrm{cm}^{3}\right)$ versus downhole sample sequence for basalts, Hole 428.

chapter, this volume). The principal alteration minerals are smectites, with lesser calcite and rarely zeolite. There is no evidence for high-temperature (i.e., hydrothermal) alteration whatsoever. Chemically, the principal effects of the alteration have been (1) increase in the $\mathrm{Fe}_{2} \mathrm{O}_{3}$ $\mathrm{FeO}$ ratio in the rims compared with the fresher cores, and (2) uptake of $\mathrm{K}_{2} \mathrm{O}$ from sea water (Humphris et al., alteration chapter, this volume). Within the basalts, the mineral most affected by alteration is olivine, which tends to be partly or completely replaced in alteration rinds by smectites and iron hydroxides. Titanomagnetites are also affected by oxidation which releases a considerable amount of $\mathrm{Fe}$ from the spinel structure. Petersen and Roggenthen (this volume) have demonstrated that most titanomagnetite oxidation occurs within a very few million years of extrusion, and they suggest that this could be a source of the iron found in

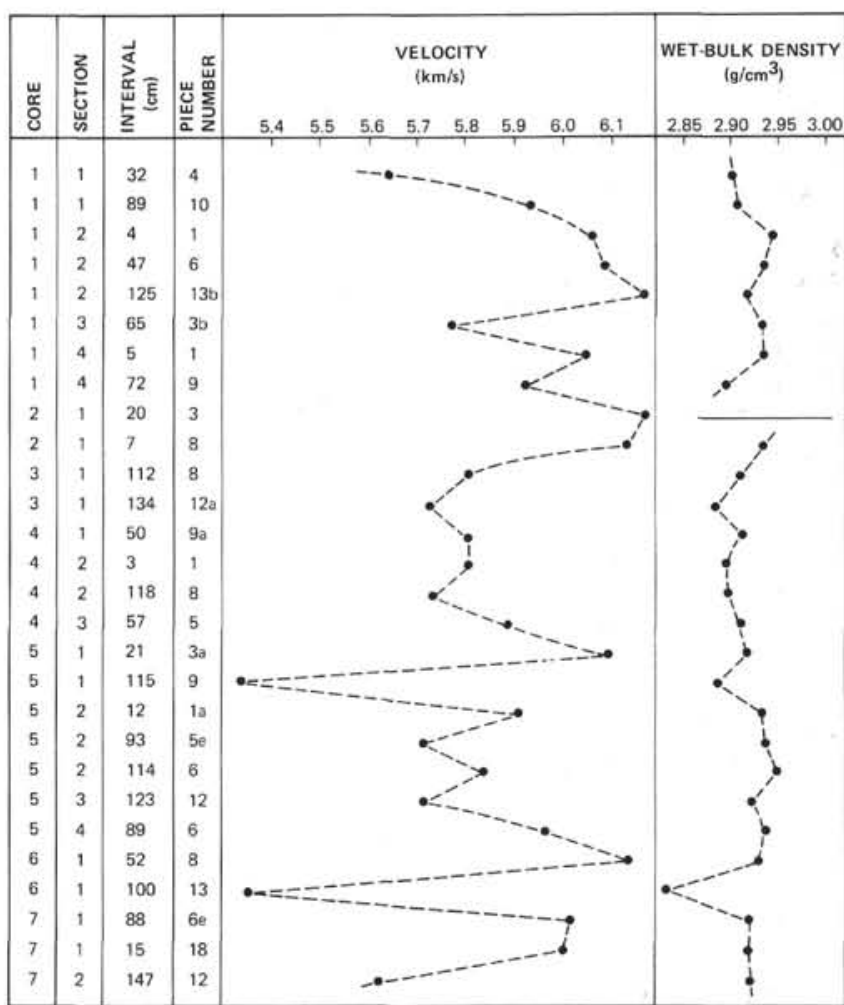

Figure 47. Velocity $(\mathrm{km} / \mathrm{s})$ and wet-bulk density $(\mathrm{g} /$ $\mathrm{cm}^{3}$ ) versus downhole sample sequence for basalts, Hole 428 A.

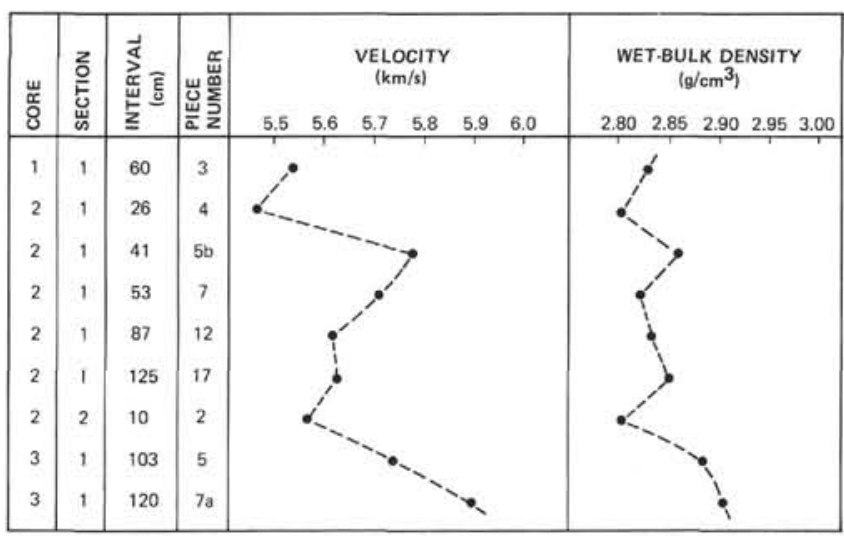

Figure 48. Velocity $(\mathrm{km} / \mathrm{s})$ and wet-bulk density $(\mathrm{g} /$ $\left.\mathrm{cm}^{3}\right)$ versus downhole sample sequence for basalts, Hole 429 A.

risecrest hydrothermal precipitates. The ultimate product of this oxidation is cation-deficient titanomagnetite. Oxidation is inferred to occur at low temperatures, most likely bottom-water temperatures.

During Leg 54, precise bulk density and sonic velocity measurements were made on carefully trimmed, lapped basalts re-saturated with water. Velocity measurements were made using the scaling wave technique outlined in the introductory chapter. With the precise data obtained by these techniques, refinements in Birch-law systematics (velocity-density relationships) have been 


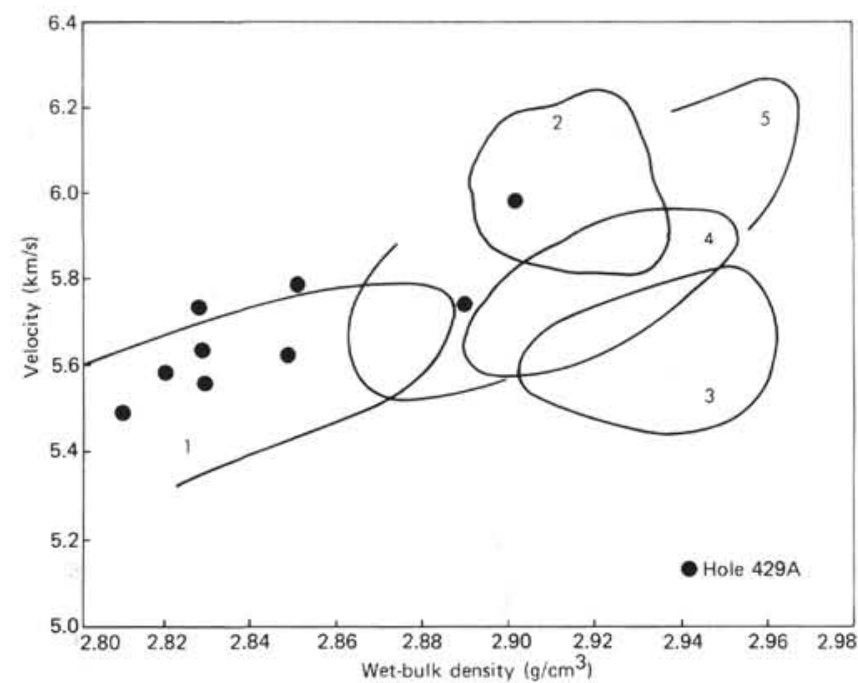

Figure 49. Sonic velocity $(\mathrm{km} / \mathrm{s})$ versus wet-bulk density $\left(\mathrm{g} / \mathrm{cm}^{3}\right)$ for Hole $429 \mathrm{~A}$ basalts. Field as in Figure 41. Samples overlap field of near-glassy and finegrained pillow or sheet-flow samples from Sites 420, 421 , and 423 which have intermediate iron enrichment.

made possible. The most important result of this is that basalts from the different sites plot in distinct fields with different velocities at given densities. The factors controlling this appear to be (1) level of iron enrichment in
TABLE 24

Magnetic Properties of Sediments from Sites 419,420 , and 421 , Leg 54

\begin{tabular}{|c|c|c|c|c|}
\hline \multirow[b]{2}{*}{$\begin{array}{c}\text { Sample } \\
\text { (Interval in } \mathrm{cm} \text { ) }\end{array}$} & \multicolumn{2}{|c|}{ NRM } & \multirow{2}{*}{$\begin{array}{c}\text { Stable } \\
\text { Inclination } \\
\left({ }^{\circ}\right)\end{array}$} & \multirow[b]{2}{*}{$\begin{array}{l}\text { MDF } \\
(\mathrm{Oe})\end{array}$} \\
\hline & $\begin{array}{c}\text { Intensity } \\
\left(10^{-6} \mathrm{emu} / \mathrm{cm}^{3}\right)\end{array}$ & $\begin{array}{c}\text { Inclination } \\
\left({ }^{\circ}\right)\end{array}$ & & \\
\hline \multicolumn{5}{|l|}{ Hole 419} \\
\hline $\begin{array}{l}2-2,133-135 \\
3-3,23-25 \\
5-1,83-85 \\
5-5,28-30\end{array}$ & $\begin{array}{r}12.25 \\
12.99 \\
0.92 \\
1.98\end{array}$ & $\begin{array}{r}-3.4 \\
-22.8 \\
-29.7 \\
-24.2\end{array}$ & $\begin{array}{l}-11 \\
-22 \\
-33 \\
+39\end{array}$ & $\begin{array}{l}235 \\
215 \\
170 \\
100\end{array}$ \\
\hline \multicolumn{5}{|l|}{ Hole 419A } \\
\hline $\begin{array}{l}1-3,72-75 \\
1-3,87-89\end{array}$ & $\begin{array}{l}12.49 \\
13.77\end{array}$ & $\begin{array}{r}+8.5 \\
+40.5\end{array}$ & $\begin{array}{l}+16 \\
+41\end{array}$ & $\begin{array}{l}140 \\
240\end{array}$ \\
\hline \multicolumn{5}{|l|}{ Hole 420} \\
\hline $\begin{array}{l}4-2,99-101 \\
6-3,135-137 \\
12-7,39-41 \\
13-6,77-79\end{array}$ & $\begin{array}{r}9.23 \\
.63 \\
6.07 \\
1.02\end{array}$ & $\begin{array}{r}+12.2 \\
+38.9 \\
-36.4 \\
-8.6\end{array}$ & $\begin{array}{l}-15^{\circ} \\
-40^{\circ} \\
+41^{\circ} \\
+10^{\circ}\end{array}$ & $\begin{array}{c}320 \\
470 \\
440 \\
\text { not } \\
\text { defined }\end{array}$ \\
\hline \multicolumn{5}{|l|}{ Hole 421} \\
\hline $1-4,117-119$ & 6.40 & +17.3 & $+19^{\circ}$ & 185 \\
\hline
\end{tabular}

the basalts, (2) crystallinity and grain size of the basalts, and (3) vesicularity and scale of microfracturing in the basalts (Warren and Rosendahl, this volume). In all cases, velocities and densities exceed those inferred for the uppermost bulk oceanic crust in the region (Figure

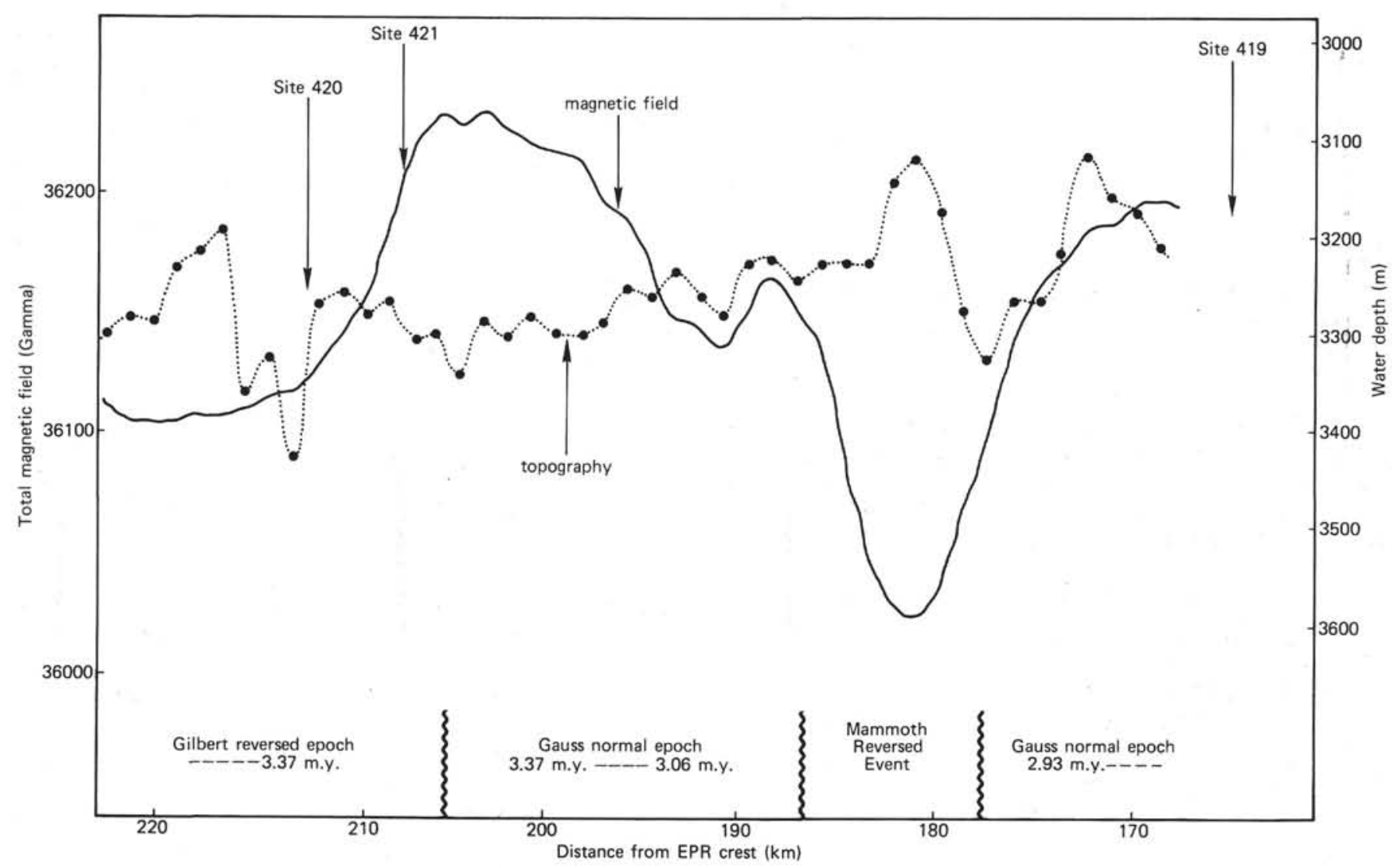

Figure 50. Water depth and total magnetic field, based on the Glomar Challenger underway records between Sites 419, 420, and 421. Ages of magnetic epochs and distance from the East Pacific Rise crest are also given. 


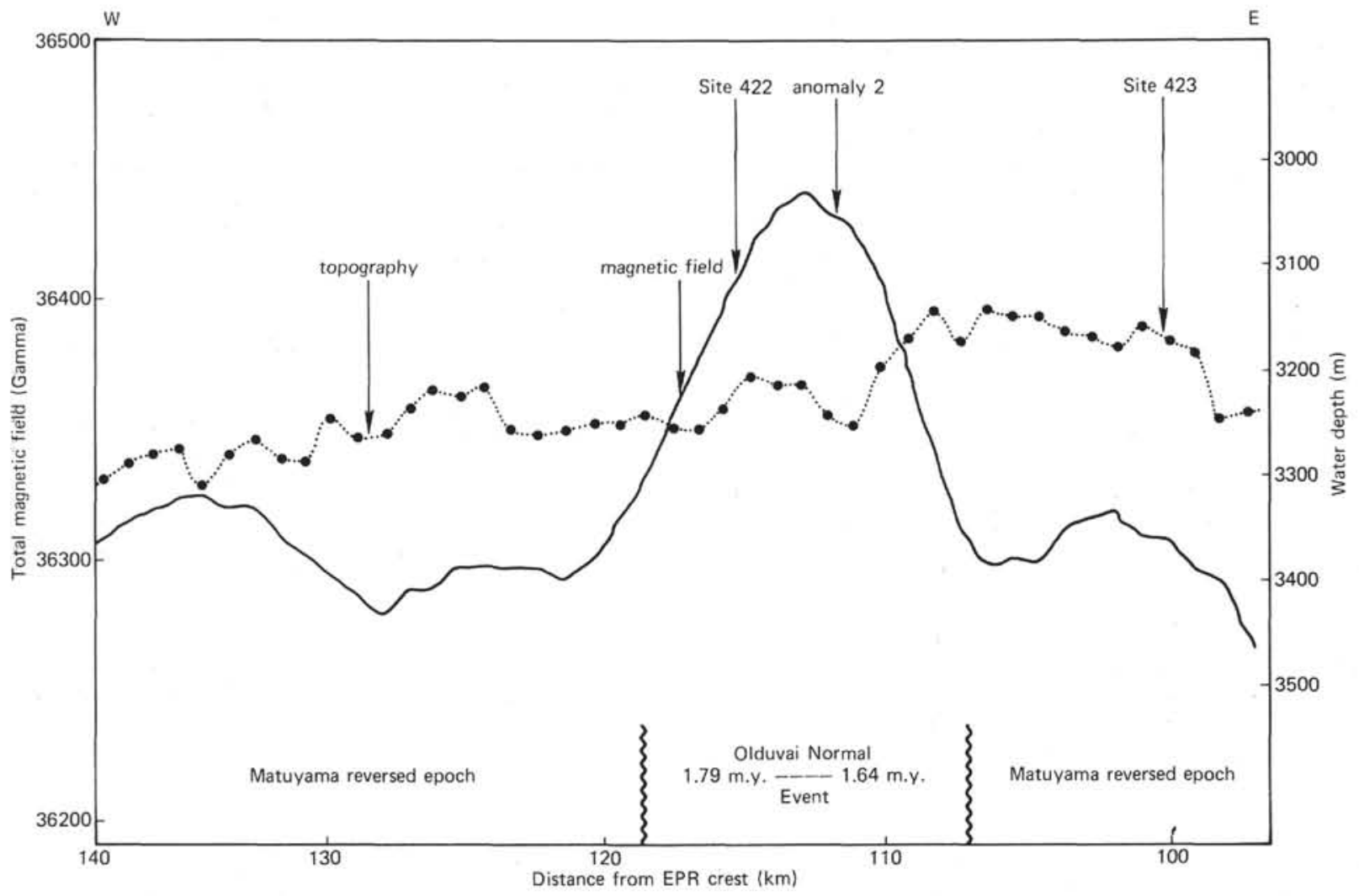

Figure 51. Water depth and total magnetic field based on the Glomar Challenger underway records near Sites 422 and 423. Ages of magnetic epochs and distance from the East Pacific Rise crest are also given.

3 ); hence, fractures and void space must be abundant in the crust.

\section{REFERENCES}

Aumento, F., Melson, W. G., et al., 1977. Initial Reports of the Deep Sea Drilling Project, v. 37: Washington (U.S. Government Printing Office).

Bass, M. N., 1971. Variable abyssal basalt populations and their relation to sea-floor spreading rates. Earth Planet. Sci. Lett., v. 11, p. 18-22.

Batiza, R., Rosendahl, B. R., and Fisher, R. L., 1977. Evolution of oceanic crust 3: petrology and chemistry of basalts from the East Pacific Rise and the Siqueiros transform fault. J. Geophys. Res., v. 82, p. 265-276.

Bostrom, K., and Peterson, M. N. A., 1966. Precipitates from hydrothermal exhalations on the East Pacific Rise. Econ. Geol., v. 61, p. $1258-1265$.

Bougault, H., 1977. Major elements: analytical chemistry on board and preliminary results. In Aumento, F., Melson, W. G., et al., Initial Reports of the Deep Sea Drilling Project, v. 37: Washington (U.S. Government Printing Office), p. 643-657.

Bougault, H., Cambon, P., Joron, L., and Treuil, M., 1978b. Trace elements: fractional crystallization and partial melting processes, heterogeneity of upper mantle material. In Dmitriev, L., Heirtzler, J., et al., Initial Reports of the Deep Sea Drilling Project, v. 46: Washington (U.S. Government Printing Office), p. 247-252.

Bougault, H., Joron, L., and Treuil, M., 1979. Alteration, fractional crystallization, partial melting, mantle properties from trace elements in basalts recovered in the North Atlantic. In Talwani, M., Harrison, C. G., and Hayes, D.
E. (Eds.), Deep Drilling Results in the Atlantic Ocean: Ocean Crust, Maurice Ewing Series 2: Washington (American Geophysical Union), p. 352-368.

Bougault, H., Treuil, M., and Joron, J. L., 1978a. Trace elements in basalts from $23^{\circ} \mathrm{N}$ and $37^{\circ} \mathrm{N}$ in the Atlantic Ocean: fractional crystallization, partial melting, and heterogeneity of the upper mantle. In Melson, W. G., Rabinowitz, P. D., et al., Initial Reports of the Deep Sea Drilling Project, v. 45: Washington (U.S. Government Printing Office), p. 493-506.

Bukry, D., 1976. Silicoflagellate and coccolith stratigraphy, southeastern Pacific Ocean, Deep Sea Drilling Project Leg 34. In Yeats, R. S., Hart, S. R., et al., Initial Reports of the Deep Sea Drilling Project, v. 34: Washington (U.S. Government Printing Office), p. 715-735.

Burckle, L. H., and Opdyke, N. D., 1977. Late Neogene diatom correlations in the circum-Pacific. 1st Internat. Cong. Pacific Neogene Stratigraphy Proc., Tokyo, p. 255-284.

Carlson, R. W., Macdougall, J. D., and Lugmair, G. W., 1978. Differential Sm/Nd evolution in oceanic basalts. Geophys. Res. Lett., v. 5, p. 229-232.

Clague, D. A. and Bunch, T. E., 1976. Formation of ferrobasalt at east Pacific mid-ocean spreading centers. J. Geophys. Res., v. 81, p. 4247-4256.

Cook, H. E., 1972. Stratigraphy and sedimentation. In Hays, J. D., Cook, H. E., et al., Initial Reports of the Deep Sea Drilling Project, v. 9: Washington (U.S. Government Printing Office), p. 933-944.

Crane, K., 1976. The intersection of the Siqueiros transform fault and the East Pacific Rise, Mar. Geol., v. 21, p. 25-46.

Dmitriev, L., Heirtzler, J., et al., 1978. Initial Reports of the Deep Sea Drilling Project, v. 46: Washington (U.S. Government Printing Office). 
Donnelly, T., Francheteau, J., Bryan, W., Robinson, P., Flower, M., Salisbury, M., et al., 1980. Initial Reports of the Deep Sea Drilling Project, v. 51, 52, 53: Washington (U.S. Government Printing Office).

Goll, R. M., 1972. Radiolaria. In Hays, J. D., Cook, H. E., et al., Initial Reports of the Deep Sea Drilling Project, v. 9: Washington (U.S. Government Printing Office), p. 947-1058.

Hall, J. M., and Ryall, P. J. C., 1977. Paleomagnetism of basement rocks, Leg 37, In Aumento, F., Melson, W. G., et al., Initial Reports of the Deep Sea Drilling Project, v.37: Washington (U.S. Government Printing Office), p. 425-445.

Hays, J. D., Cook, H. E., et al., 1972. Initial Reports of the Deep Sea Drilling Project, v. 9: Washington (U.S. Government Printing Office).

Heath, G. R. and Dymond, J., 1977. Genesis and transformation of metalliferous sediments from the East Pacific Rise, Bauer Deep, and Central Basin, northwest Nazca plate. Geol. Soc. Am. Bull. v. 88, p. 723-733.

Heirtzler, J. R., Dickson, G. O., Herron, E. M., Pitman, W. C. III, and Le Pichon, X., 1968. Marine magnetic anomalies, geomagnetic field reversals, and motions of the ocean floor. J. Geophys. Res., v. 73, p. 2119-2136.

Jakobssen, S. P., 1972. Chemistry and distribution pattern of Recent basaltic rocks in Iceland, Lithos, v. 5, p. 365-386.

Johnson, D. A., 1971. Studies of deep sea erosion using deeptowed instrumentation. Ph.D. thesis, University of California, San Diego.

Johnson, J. R., 1979. Transitional basalts and tholeiites from the East Pacific Rise, $9^{\circ} \mathrm{N}$. J. Geophys. Res., v. 84, p. 1635-1652.

Lonsdale, P., 1977. Structural geomorphology of a fastspreading rise crest: the East Pacific Rise near 3\%25'S. Mar. Geophys. Res., v. 3, p. 251-293.

1978. Near-bottom reconnaisance of a fast-slipping transform fault at the Pacific-Nazca plate boundary. $J$. Geol., v. 86, p. 451-472.

Lonsdale, P. and Spiess, F. N., 1979. A pair of young cratered volcanoes on the East Pacific Rise. Ibid., v. 87, p. 157-173.

Luyendyk, B. P., Cann, J. R., et al., 1979. Initial Reports of the Deep Sea Drilling Project, v. 49: Washington (U.S. Government Printing Office).

Melson, W. G., Rabinowitz, P. D., et al., 1978. Initial Reports of the Deep Sea Drilling Project, v. 45: Washington (U.S. Government Printing Office).

Nafe, J. E. and Drake, C. L., 1966. Physical properties of marine sediments. In Hill, M. N. (Ed.) The Sea, v. 3: New York (Wiley Interscience), p. 794-815.

Natland, J. H., 1978. Comparison of the chemical and magnetic stratigraphy of DSDP Sites 332 and 395. In Melson, W. G., Rabinowitz, P. D., et al., Initial Reports of the Deep Sea Drilling Project, v. 45: Washington (U.S. Government Printing Office), p. 657-677.

Nisbet, E. G. and Fowler C. M. R., 1978. The Mid-Atlantic Ridge and 37 and $45^{\circ} \mathrm{N}$ : some geophysical and petrological constraints. Geophys. J. Roy. Astron. Soc., p. 631-660.

O'Hara, M. J., 1977. The geochemistry of lavas erupted from a magma chamber undergoing fractional crystallisation with periodic addition and intermingling of more primitive magma. Nature, v. 266, p. 503-507.

Orcutt, J., Kennett, B., and Dorman, L., 1976. Structure of the East Pacific Rise from an ocean-bottom seismometer survey. Geophys. J. Roy. Astron. Soc., v. 45, p. 305-320.

Orcutt, J., Kennett, B., Dorman, L., and Prothero, W., 1975. A low velocity zone underlying a fast-spreading rise crest. Ibid., v. 256, p. 475-476.
Presnall, D. C., Dixon, J. R., O'Donnell, T. H., and Dixon, S. A., 1979. Generation of mid-ocean ridge tholeiites, $J$. Petrol., v. 20, p. 3-35.

Rhodes, J. M., Blanchard, D. P., Rodgers, K. V., Jacobs, J. W., and Brannon, J. C., 1976. Petrology and chemistry of basals from the Nazca plate: part 2 - major and trace element chemistry. In Yeats, R. S., Hart, S. R., et al., Initial Reports of the Deep Sea Drilling Project, v. 34: Washington (U.S. Government Printing Office), p. 239246.

Rosendahl, B. R., 1976. Evolution of oceanic crust, 2, Constraints, implications, and inferences, J. Geophys. Res., v. 81, p. $5305-5314$.

Rosendahl, B. R., Raitt, R. W., Dorman, L. M., Bibee, L. D., Hussong, D. M., and Sutton, G. H., 1976. Evolution of oceanic crust, 1, A geophysical model of the East Pacific Rise derived from seismic refraction data. Ibid., v. 81, p. 5294-5304.

Scheidegger, K. F., 1973. Temperatures and compositions of magmas ascending along mid-ocean ridges. Ibid., v. 78, p. 3340-3355.

Shor, G. G., Jr., Menard, H. W., and Raitt, R. W., 1970. Structure of the Pacific Basin. In Maxwell, A. E., (Ed.) The Sea, v. 4, part 2: New York (Wiley Interscience), p. 3-27.

Sigvaldason, G. E., 1974. Basalts from the center of the assumed Icelandic mantle plume, J. Petrol., v. 15, p. 367-370.

Tarney, J., Wood, J. A., Varet, J., Saunders, A. D., and Cann, J. R., 1979. Nature of mantle heterogeneity in the North Atlantic: evidence from Leg 49 basalts. In Talwani, M., Harrison, C. G., and Hayes, D. E. (Eds.), Deep Drilling Results in the Atlantic Ocean: Ocean Crust, Maurice Ewing Series 2: Washington (American Geophysical Union), p. 285-301.

Tracey, J. I., Jr., Sutton, G. H., et al., 1971. Initial Reports of the Deep Sea Drilling Project, v. 8: Washington (U.S. Government Printing Office).

Tuttle, O. F. and Bowen, N. L., 1958. Origin of granite in the light of experimental studies in the system $\mathrm{NaA}_{1} \mathrm{Si}_{3} \mathrm{O}_{8}-$ KA1Si ${ }_{3} \mathrm{O}_{8}-\mathrm{SiO}_{2}-\mathrm{H}_{2} \mathrm{O}$. Geol. Soc. Amer. Mem., v. 74, p. 153.

Usselman, T. M. and Hodge, D. S., 1978. Thermal control of low-pressure fractionation processes. J. Volcan. Geotherm. Res., v. 4, p. 265-281.

van Andel, Tj. H., Heath, G. R., et al., 1973. Initial Reports of the Deep Sea Drilling Project, v. 16: Washington (U.S. Government Printing Office).

van Andel, Tj. H., Heath, G. R., and Moore, T. C., 1975. Cenozoic history and paleoceanography of the central equatorial Pacific ocean: a regional synthesis of Deep Sea Drilling Project data. Geol. Soc. Amer. Mem., 143.

Yeats, R. S., Forbes, W. C., Heath, G. R., and Scheidegger, K. F., 1973. Petrology and geochemistry of DSDP Leg 16 basalts, eastern equatorial Pacific. In van Andel, Tj. H., Heath, G. R., et al., Initial Reports of the Deep Sea Drilling Project, v. 45: Washington (U.S. Government Printing Office), p. 617-640.

Yeats, R. S., Hart, S. R., et al., 1976a. Initial Reports of the Deep Sea Drilling Project, v. 34: Washington (U.S. Government Printing Office).

1976b. Preliminary evaluation of DSDP coring experience in basalt. In Yeats, R. S., Hart, S. R., et al., Initial Reports of the Deep Sea Drilling Project, v. 34: Washington (U.S. Government Printing Office), p. 183-186. 


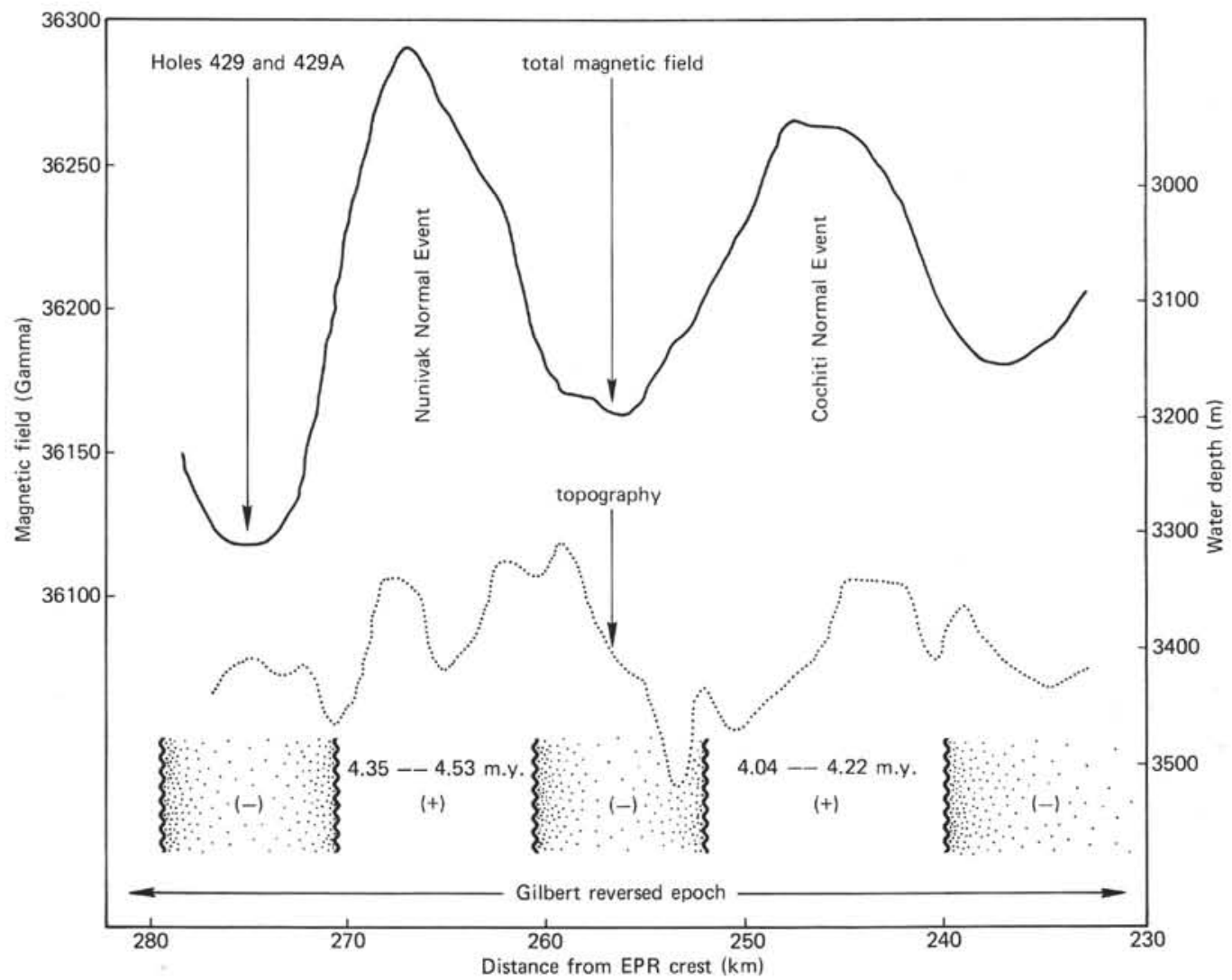

Figure 52. Water depth and total magnetic field, based on the Glomar Challenger underway records approaching Site 429. Ages of magnetic epochs and distance from the East Pacific Rise are also given.

TABLE 25

Magnetic Properties of Basalts from the East Pacific Rise (EPR), OCP Ridge, and Siqueiros Fracture Zone (SFZ), Leg 54

\begin{tabular}{|c|c|c|c|c|c|c|c|c|}
\hline \multirow{2}{*}{$\begin{array}{c}\text { Sample } \\
\text { (Interval in cm; } \\
\text { Piece Number in } \\
\text { parentheses) }\end{array}$} & \multicolumn{2}{|l|}{ NRM } & \multirow[b]{2}{*}{$\begin{array}{c}\text { Stable } \\
\text { Inclination } \\
\left.{ }^{\circ}\right)\end{array}$} & \multirow[b]{2}{*}{$\begin{array}{l}\text { MDF } \\
(\mathrm{Oe})\end{array}$} & \multirow[b]{2}{*}{$\begin{array}{l}\text { Susceptibility } \\
\left(\mathrm{emu} / \mathrm{cm}^{3}\right)\end{array}$} & \multirow[b]{2}{*}{ Factor } & \multirow[b]{2}{*}{ Rock Type } & \multirow[b]{2}{*}{ Orientation } \\
\hline & $\begin{array}{c}\text { Intensity } \\
\left(\mathrm{emu} / \mathrm{cm}^{3}\right)\end{array}$ & $\begin{array}{l}\text { Inclination } \\
\left(\left(^{\circ}\right)\right.\end{array}$ & & & & & & \\
\hline \multicolumn{9}{|l|}{ Hole 420 (EPR) } \\
\hline $\begin{array}{l}13, \mathrm{CC}, 53-56 \\
14-1,14-17 \\
15-1,70-72(9) \\
17-1,27-30\end{array}$ & $\begin{array}{l}1.977 \times 10^{-3} \\
1.020 \times 10^{-3} \\
7.943 \times 10^{-3} \\
9.996 \times 10^{-4}\end{array}$ & $\begin{array}{l}+12.5 \\
-20.4 \\
+15.6 \\
-\end{array}$ & $\begin{array}{l}+13.5^{\circ} ? \\
-19.5^{\circ} \\
+16^{\circ} ? \\
-\end{array}$ & $\begin{array}{l}610 \\
720 \\
530 \\
960\end{array}$ & $\begin{array}{l}1.36 \times 10^{-4} \\
1.20 \times 10^{-4} \\
1.43 \times 10^{-4}\end{array}$ & $\begin{array}{r}40 \\
24 \\
154\end{array}$ & $\begin{array}{l}\text { Basalt } \\
\text { Basalt } \\
\text { Basalt } \\
\text { Basalt }\end{array}$ & $\begin{array}{l}\text { Very poor } \\
\text { Good } \\
\text { Very poor } \\
\text { Not determined }\end{array}$ \\
\hline Mean Values & $2.985 \times 10^{-3} \pm 3.337$ & & & $\begin{array}{r}705 \\
\pm 187\end{array}$ & $1.33 \times 10^{-4} \pm 0.12$ & $73 \pm 71$ & & \\
\hline \multicolumn{9}{|l|}{ Hole 421 (EPR) } \\
\hline $\begin{array}{l}3-1,30-33(5) \\
3-1,72-75(11) \\
3-1,117-120(17) \\
4-1,4-7(1) \\
\text { Bit, } 10-13(2)\end{array}$ & $\begin{array}{r}8.67 \times 10^{-4} \\
1.079 \times 10^{-3} \\
1.489 \times 10^{-3} \\
1.059 \times 10^{-3} \\
1.544 \times 10^{-3}\end{array}$ & $\begin{array}{r}-5.8 \\
-14.7 \\
-40.5 \\
-49.1 \\
-58.7\end{array}$ & $\begin{array}{l}-6^{\circ} \\
-15^{\circ} \\
-42^{\circ} \\
-49^{\circ} \\
-57.5^{\circ}\end{array}$ & $\begin{array}{l}840 \\
950 \\
790 \\
860 \\
930\end{array}$ & $\begin{array}{r}1.6 \times 10^{-4} \\
1.76 \times 10^{-4} \\
9.3 \times 10^{-5} \\
8.4 \times 10^{-5} \\
1.6 \times 10^{-4}\end{array}$ & $\begin{array}{l}15 \\
17 \\
44 \\
35 \\
27\end{array}$ & $\begin{array}{l}\text { Basalt } \\
\text { Basalt } \\
\text { Basalt } \\
\text { Basalt } \\
\text { Basalt }\end{array}$ & $\begin{array}{l}\text { Poor } \\
\text { Fair/poor } \\
\text { Poor } \\
\text { Poor } \\
\text { Fair/poor }\end{array}$ \\
\hline Mean Values & $1.208 \times 10^{-3} \pm 0.295$ & & & $\begin{array}{r}874 \\
+\quad 66\end{array}$ & $1.35 \times 10^{-4} \pm 0.43$ & $28 \pm 12$ & & \\
\hline \multicolumn{9}{|l|}{ Hole 422 (EPR) } \\
\hline $7-1,89-92(7 e)$ & $3.446 \times 10^{-3}$ & -31.9 & $\begin{array}{l}-14^{\circ} ? \\
-5^{\circ} ?\end{array}$ & 45 & $1.99 \times 10^{-3}$ & 5 & Basalt & Good \\
\hline $\begin{array}{l}7-1,39-42(6 a) \\
7-2,14-17(3)\end{array}$ & $\begin{array}{l}1.272 \times 10^{-3} \\
4.329 \times 10^{-3}\end{array}$ & $\begin{array}{l}-14.8 \\
-34.2\end{array}$ & $\begin{array}{r}-9^{\circ} \\
-17^{\circ}\end{array}$ & $\begin{array}{l}20 \\
50\end{array}$ & $\begin{array}{l}2.27 \times 10^{-3} \\
2.04 \times 10^{-3}\end{array}$ & $\begin{array}{l}1.6 \\
6\end{array}$ & $\begin{array}{l}\text { Basalt } \\
\text { Basalt }\end{array}$ & $\begin{array}{l}\text { Good } \\
\text { Good }\end{array}$ \\
\hline $8-5,23-26(5)$ & $3.196 \times 10^{-3}$ & -47.6 & $\begin{array}{l}-14^{\circ} ? \text { ? } \\
-5^{\circ}\end{array}$ & $<110$ & $1.57 \times 10^{-3}$ & 6 & Basalt & Good \\
\hline $8-5,132-135(14)$ & $5.685 \times 10^{-3}$ & -40.8 & $\begin{array}{l}-19^{\circ} \\
-7^{\circ} ?\end{array}$ & 45 & $2.24 \times 10^{-3}$ & 7 & Basalt & Good \\
\hline $9-1,70-73(4 c)$ & $3.259 \times 10^{-3}$ & -37.8 & $-20^{\circ}$ & 40 & $2.38 \times 10^{-3}$ & 4 & Basalt & Good \\
\hline $\begin{array}{l}9-2,45-48(4 b) \\
9-2,135-138(6)\end{array}$ & $\begin{array}{l}3.323 \times 10^{-3} \\
4.235 \times 10^{-3}\end{array}$ & $\begin{array}{l}-46.6 \\
-42.5\end{array}$ & $-24^{\circ}$ & 85 & $2.08 \times 10^{-3}$ & 4 & Basalt & Good \\
\hline $\begin{array}{l}9-2,135-138(6) \\
9-3,91-94(6 \mathrm{c})\end{array}$ & $\begin{array}{l}4.235 \times 10^{-3} \\
3.930 \times 10^{-3}\end{array}$ & $\begin{array}{l}-42.5 \\
-34.4\end{array}$ & $\begin{array}{l}-30^{\circ} \\
-28^{\circ}\end{array}$ & $\begin{array}{l}75 \\
85\end{array}$ & $\begin{array}{l}1.66 \times 10^{-3} \\
1.84 \times 10^{-3}\end{array}$ & $\begin{array}{l}7 \\
6\end{array}$ & $\begin{array}{l}\text { Basalt } \\
\text { Basalt }\end{array}$ & $\begin{array}{l}\text { Good } \\
\text { Good }\end{array}$ \\
\hline $9-4,135-138(13 a)$ & $6.386 \times 10^{-3}$ & -27.8 & $-23^{\circ}$ & 80 & $1.57 \times 10^{-3}$ & 11 & Basalt & Good \\
\hline $9-5,72-75(6)$ & $2.587 \times 10^{-3}$ & -31.2 & $-25^{\circ}$ & 75 & $1.65 \times 10^{-3}$ & 4 & Basalt & Good \\
\hline Mean Values & $3.786 \times 10^{-3} \pm 1.400$ & & $\begin{array}{l}20.3 \\
\pm 6.4 \\
\end{array}$ & $60 \pm 23$ & $1.94 \times 10^{-3} \pm 0.30$ & $5.6 \pm 2.4$ & & \\
\hline
\end{tabular}


TABLE 25 - Continued

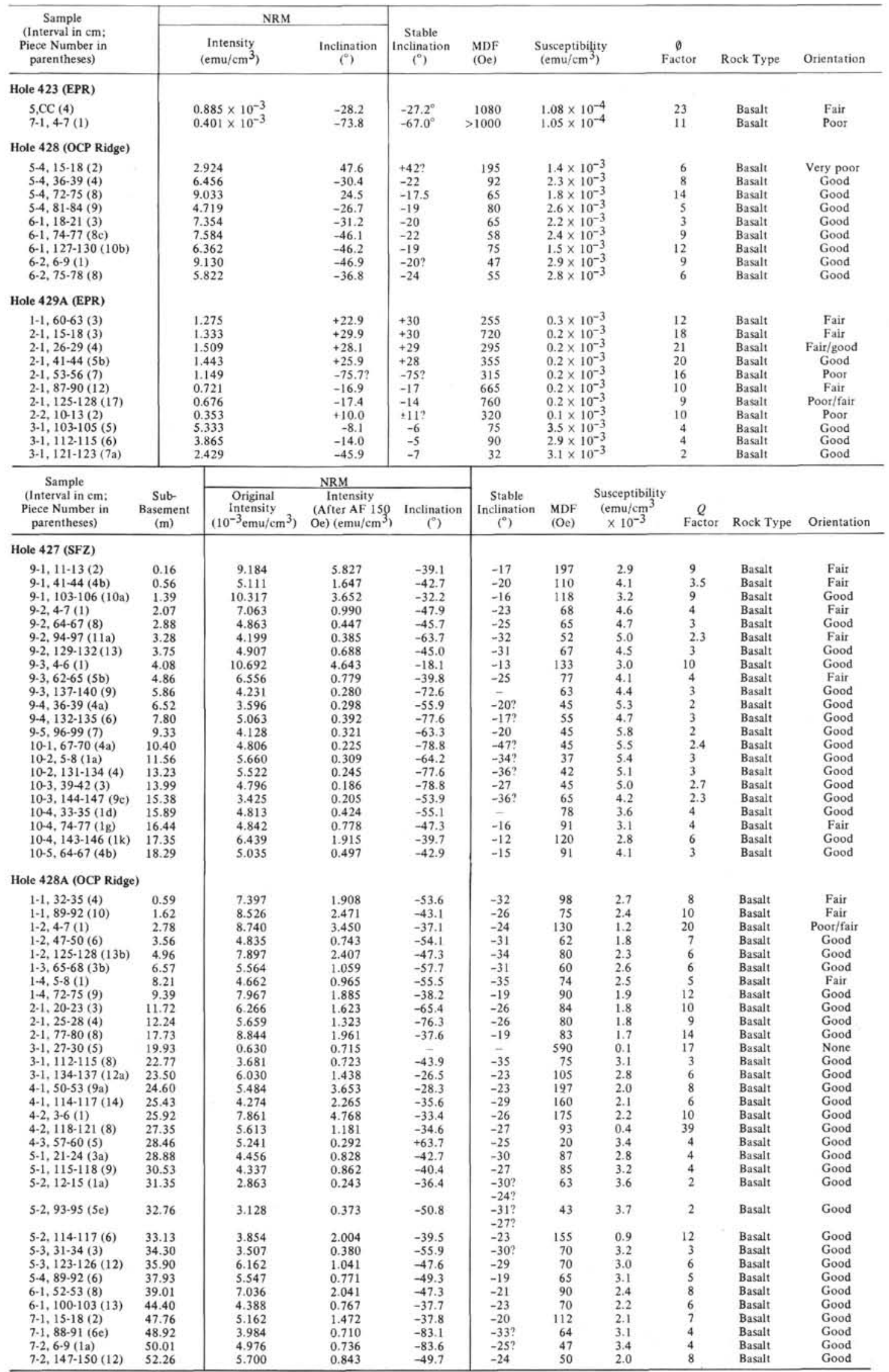




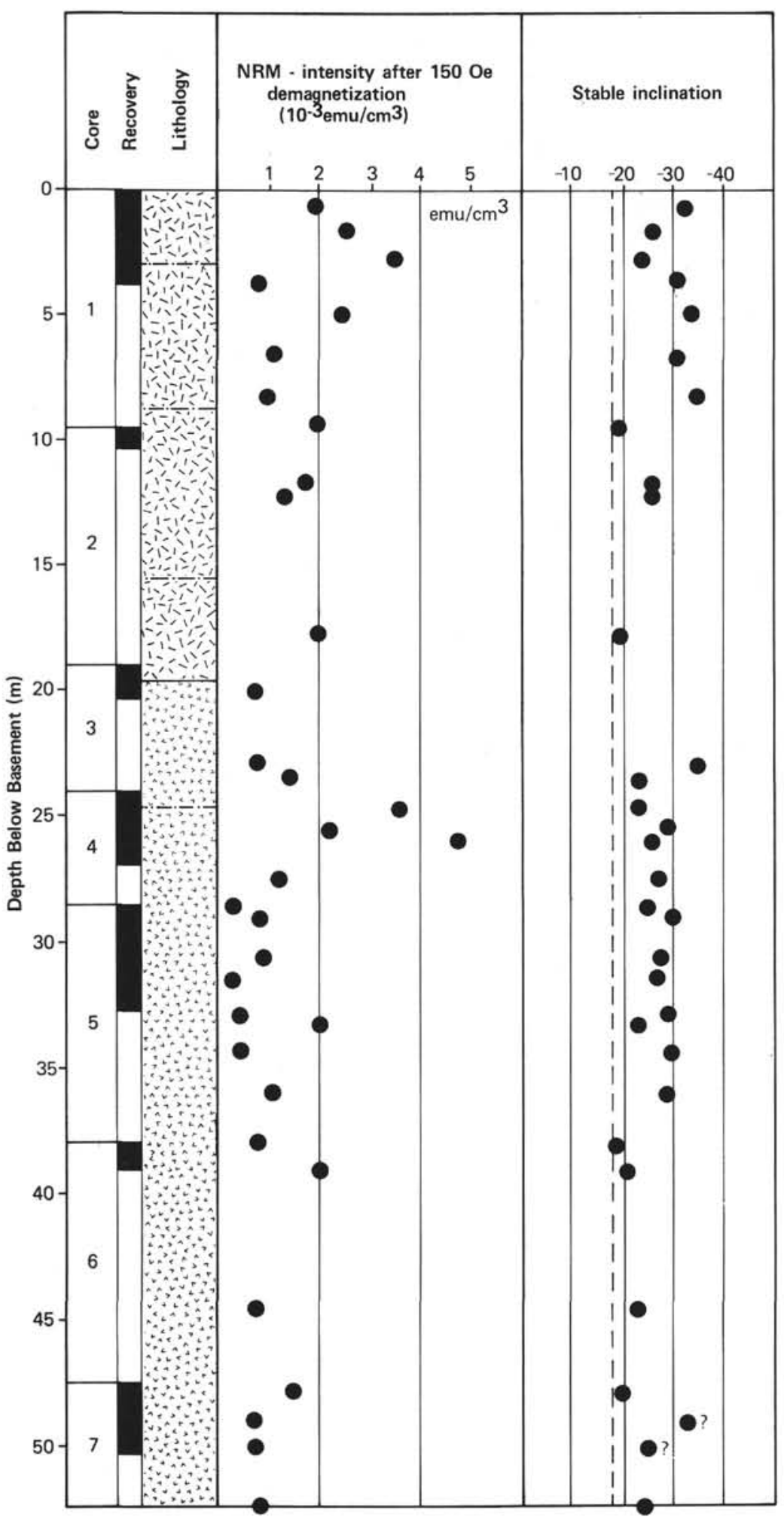

Figure 53. NRM intensity after demagnetization and stable inclination of basalts plotted versus depth for Hole 428A. Depths have been calculated assuming proportional distribution of the recovered material over the entire respective core lengths. Cores 1,2 , and top of 3 are fine-grained, olivine basalts. Cores 3 (lower part) through 7 are dolerites. Flow boundaries or margins are indicated by horizontal lines on lithology column. Vertical dashed lines is predicted paleoinclination. 


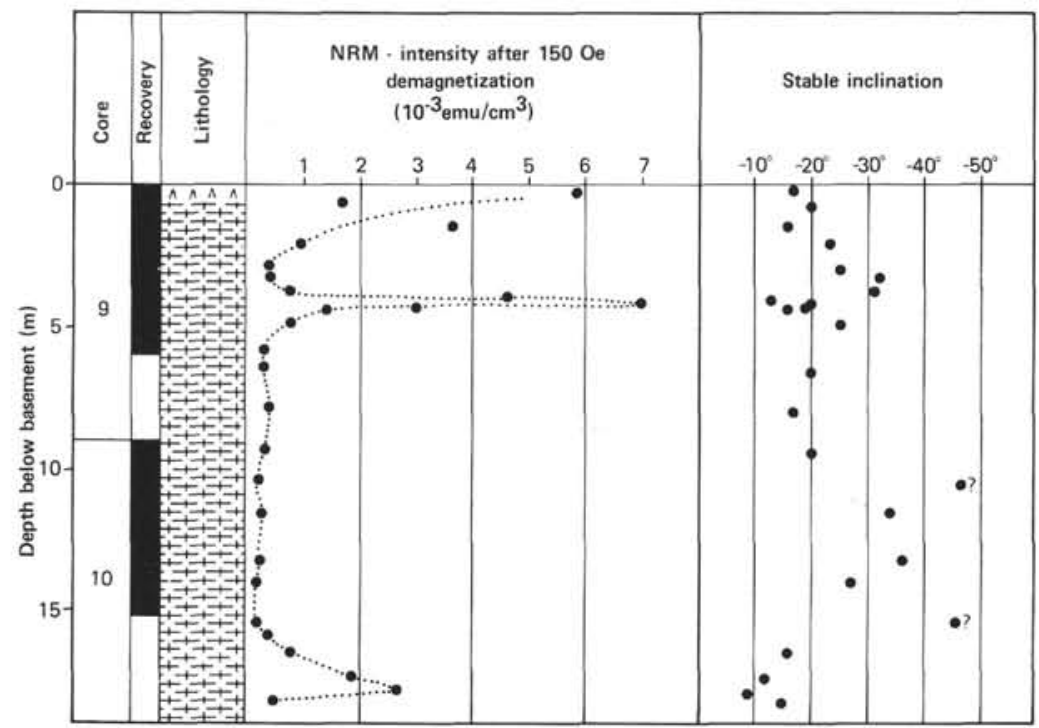

Figure 54. NRM intensity after demagnetization and stable inclination of basalts plotted versus depth for Site 427. Depth convention, symbols, as in Figure 53.

TABLE 26

Distribution of Distinct Chemical Types of Basalt at All DSDP Sites and Dredge Stations in the Siqueiros (PT-4 Survey) Region, Based on $\mathrm{TiO}_{2}$ Contents

\begin{tabular}{ccccccc}
\hline & Distance From Rise & \multicolumn{4}{c}{$\mathrm{TiO}_{2}$} & \\
Crest (EPR Sites & \multicolumn{2}{c}{ Abyssal Tholeite Suite } & & Transitional/ \\
Dredge Station & Only) & $0.8-1.4$ & $1.4-1.9$ & $1.9-2.4$ & $>2.4$ & Alkalic \\
\hline
\end{tabular}

East Pacific Rise

$\begin{array}{lllll}\text { SD-5 } & 0-5 & & 1 & 1 \\ 423^{\mathrm{a}} & 101 & 1 & 1 & 1 \\ \text { DS-3 } & 104-101 & & & 1 \\ \text { DS-5 } & 104-103 & & 1 & \\ \text { DS-1 } & 108-104 & & & 2 \\ 421^{\mathrm{a}} & 209 & & & 1 \\ 420^{\mathrm{a}} & 213 & 1 & 1 & \\ 429^{\mathrm{a}} & 276 & & \end{array}$

OCP Ridge

$422^{\mathrm{a}}$

$428^{\mathrm{a}}$

$428 \mathrm{~A}^{\mathrm{a}}$

DS-4

Seamounts

IMED-1
SD-8
QBR-22

1

Siqueiros Fracture Zone

QBR-19

QBR-17

SD-7

SD-6

SD-3

CD-1

SD-4

$427^{\mathrm{a}}$

Totals

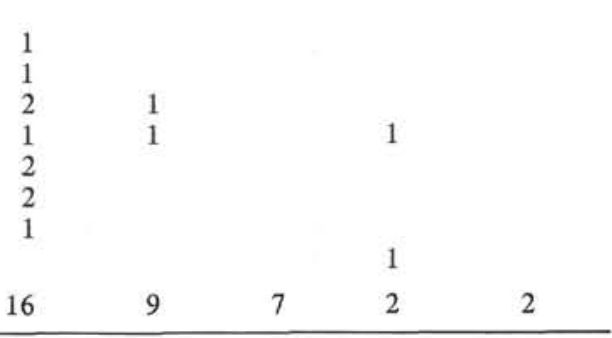

Note: Data for dredges SD, QBR, and CD in Batiza et al., 1977. Data for dredges DS in Johnson, 1979. Data for dredge IMED-1 in Lonsdale and Spiess, 1979.

${ }^{\mathrm{a}} \mathrm{DSDP}$ sites, data this volume. 

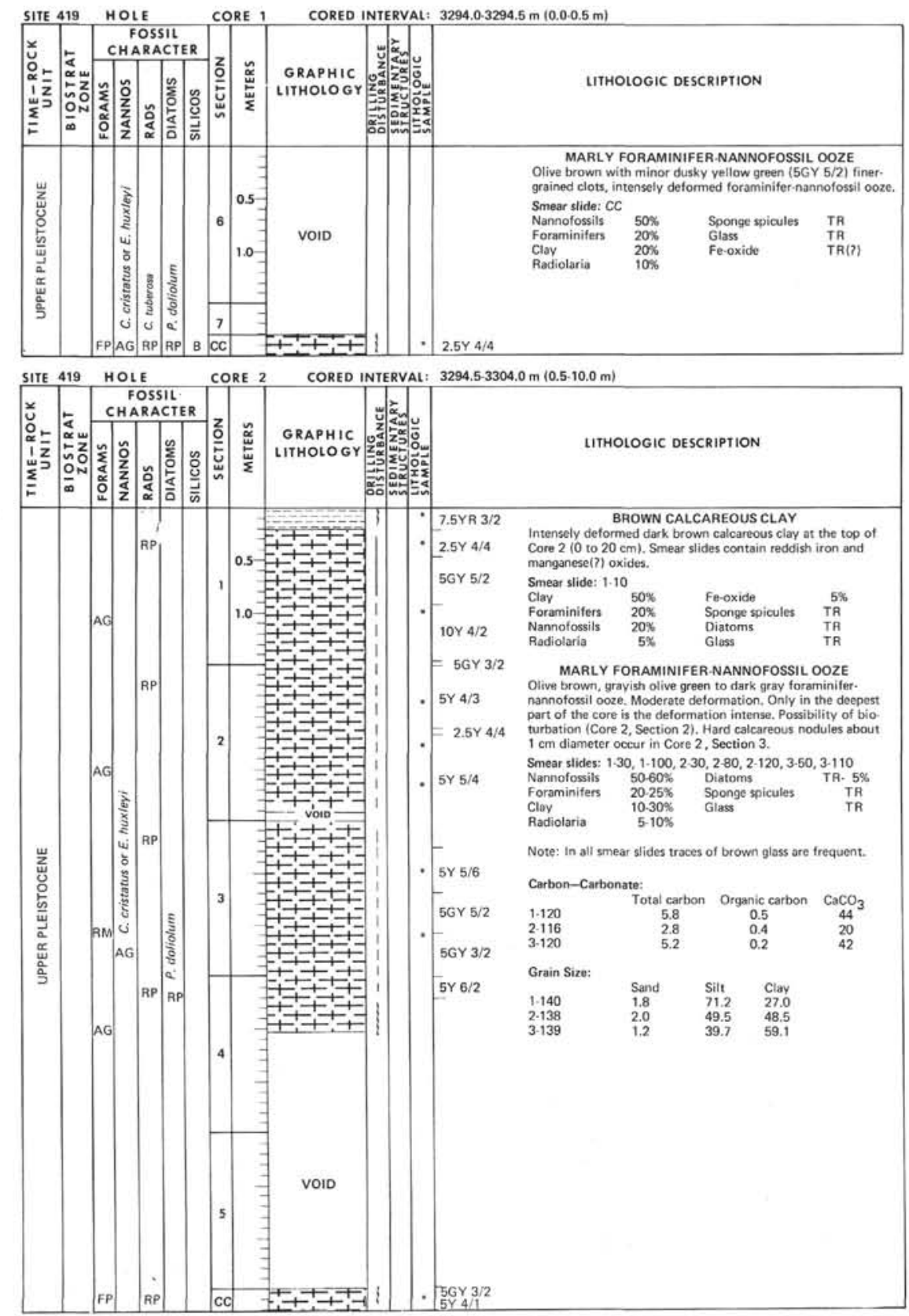

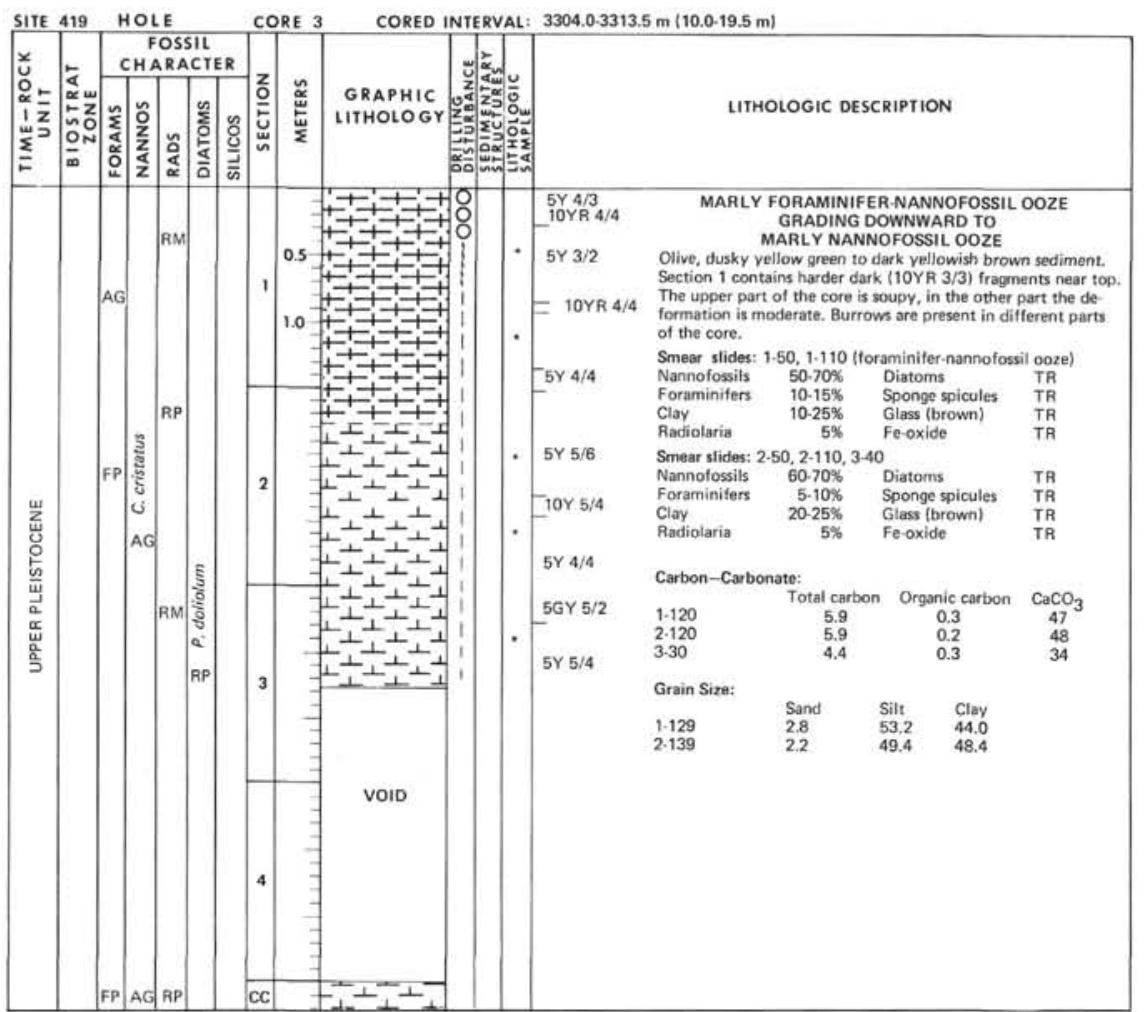



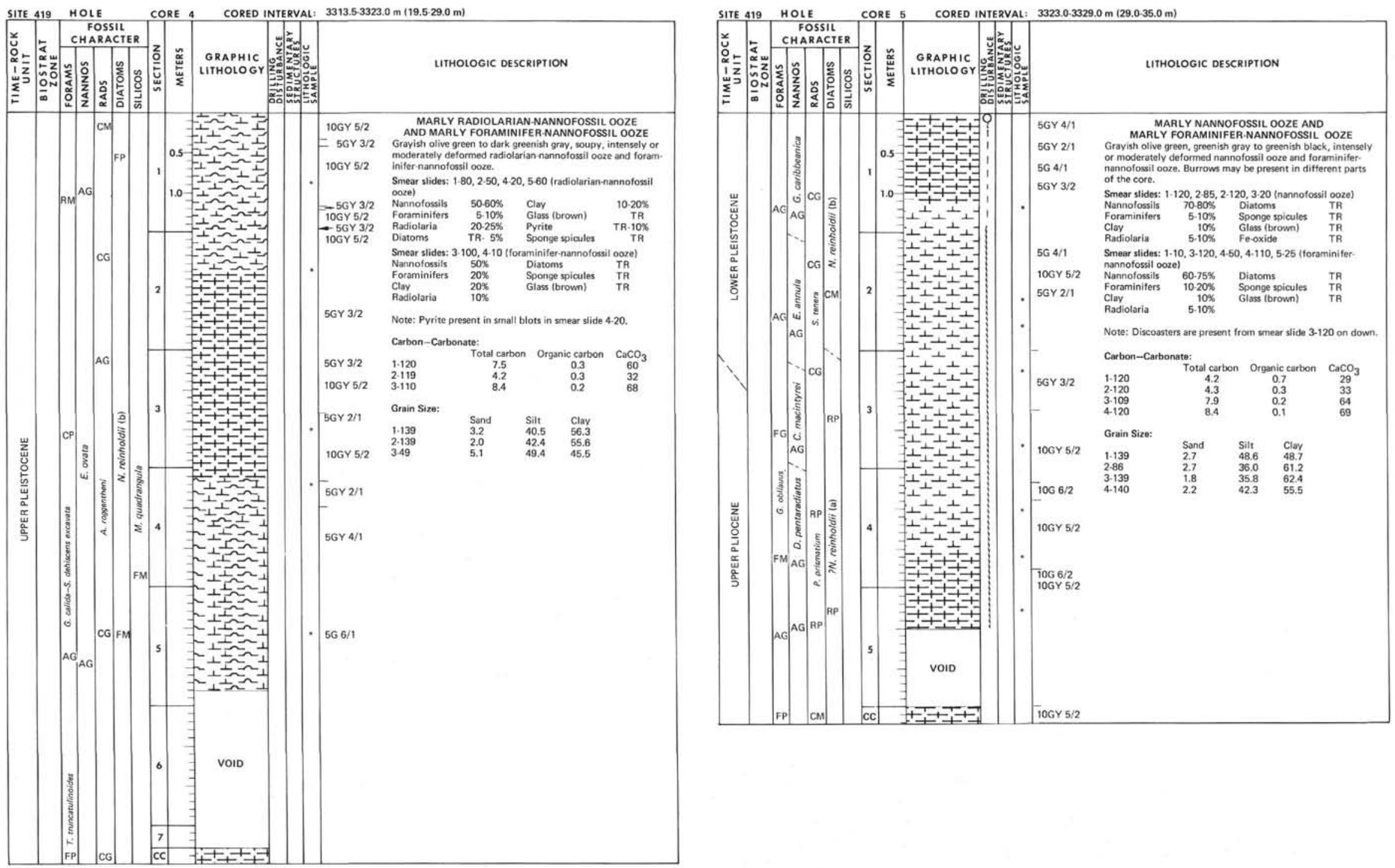


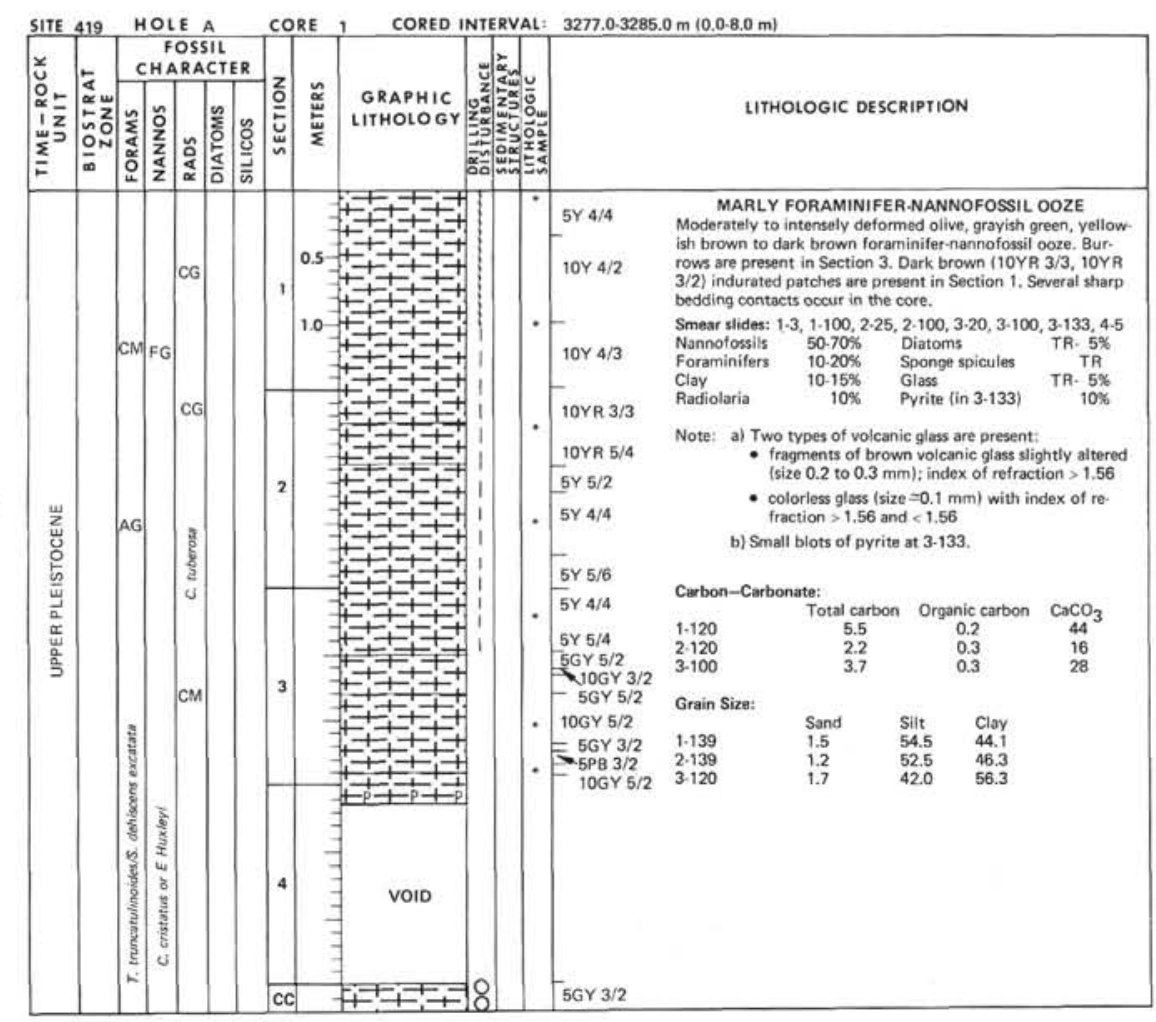




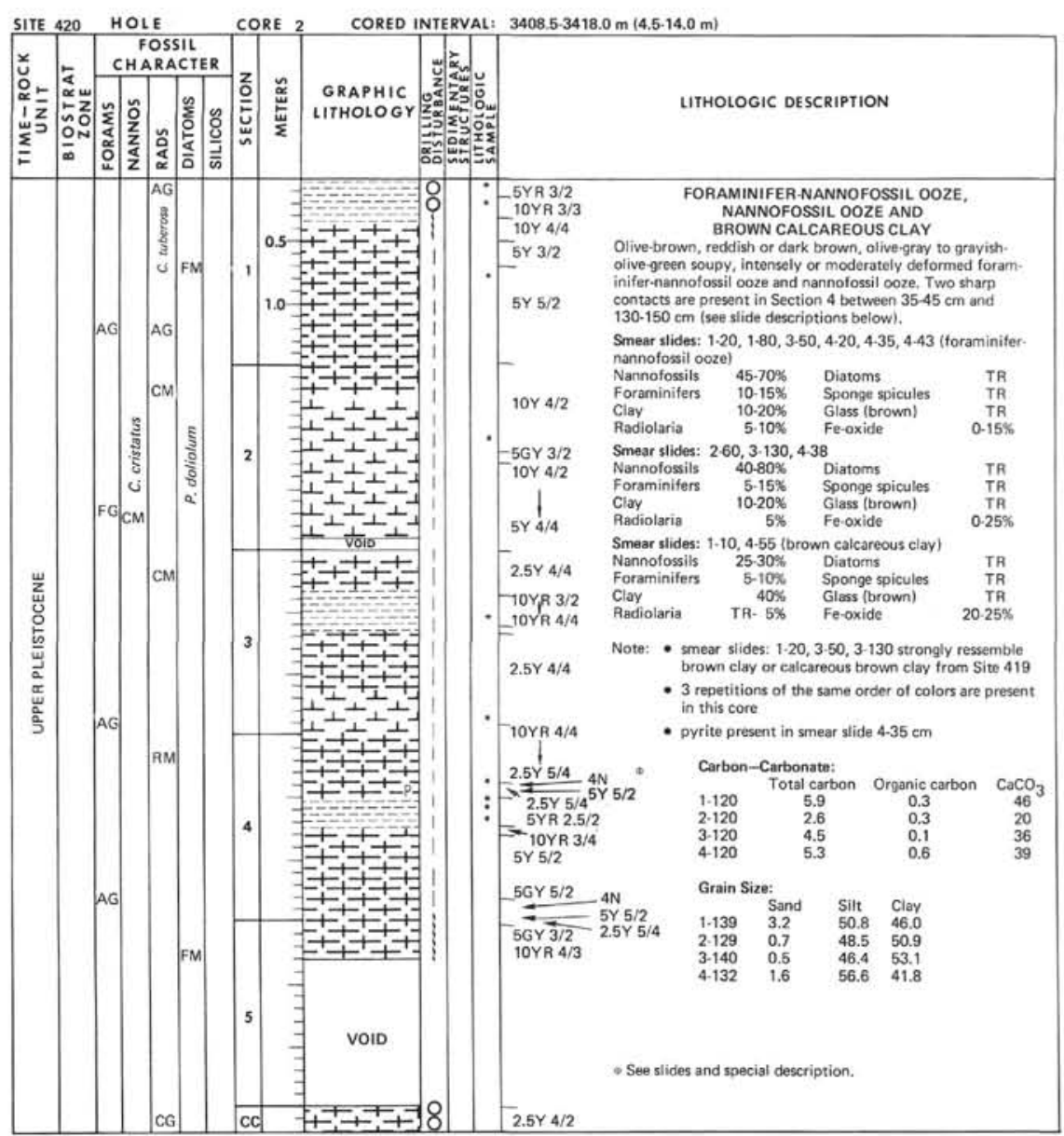



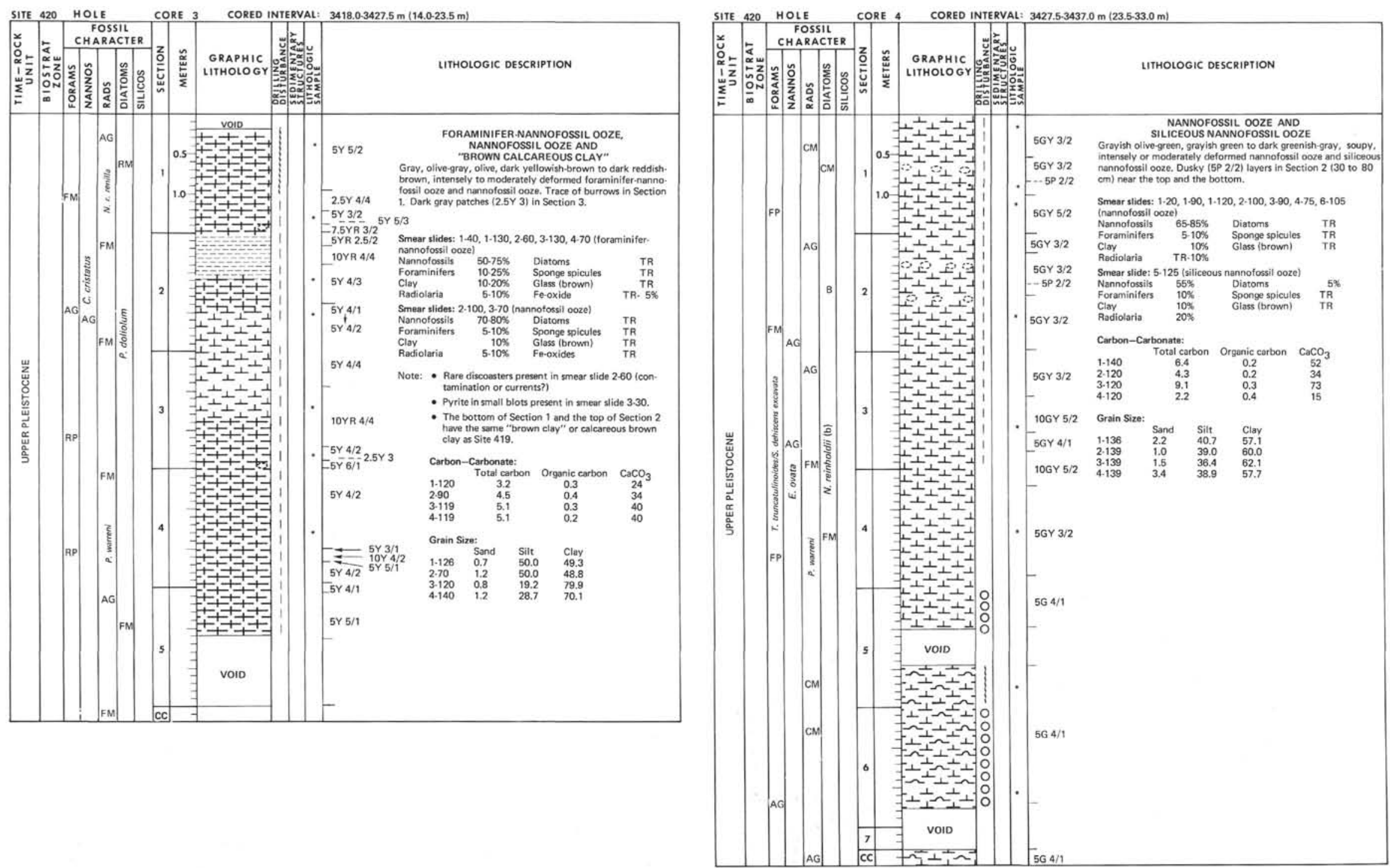

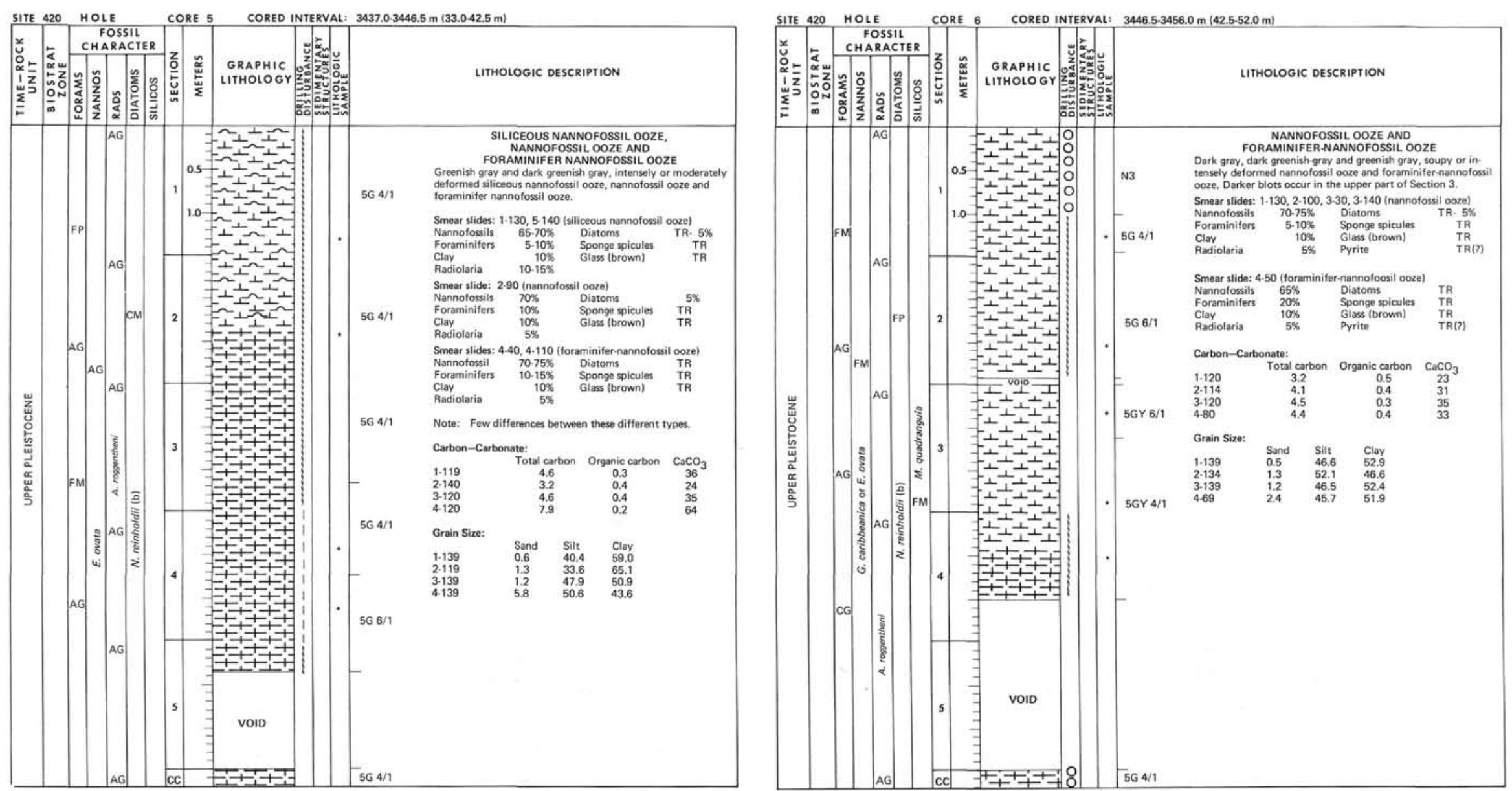

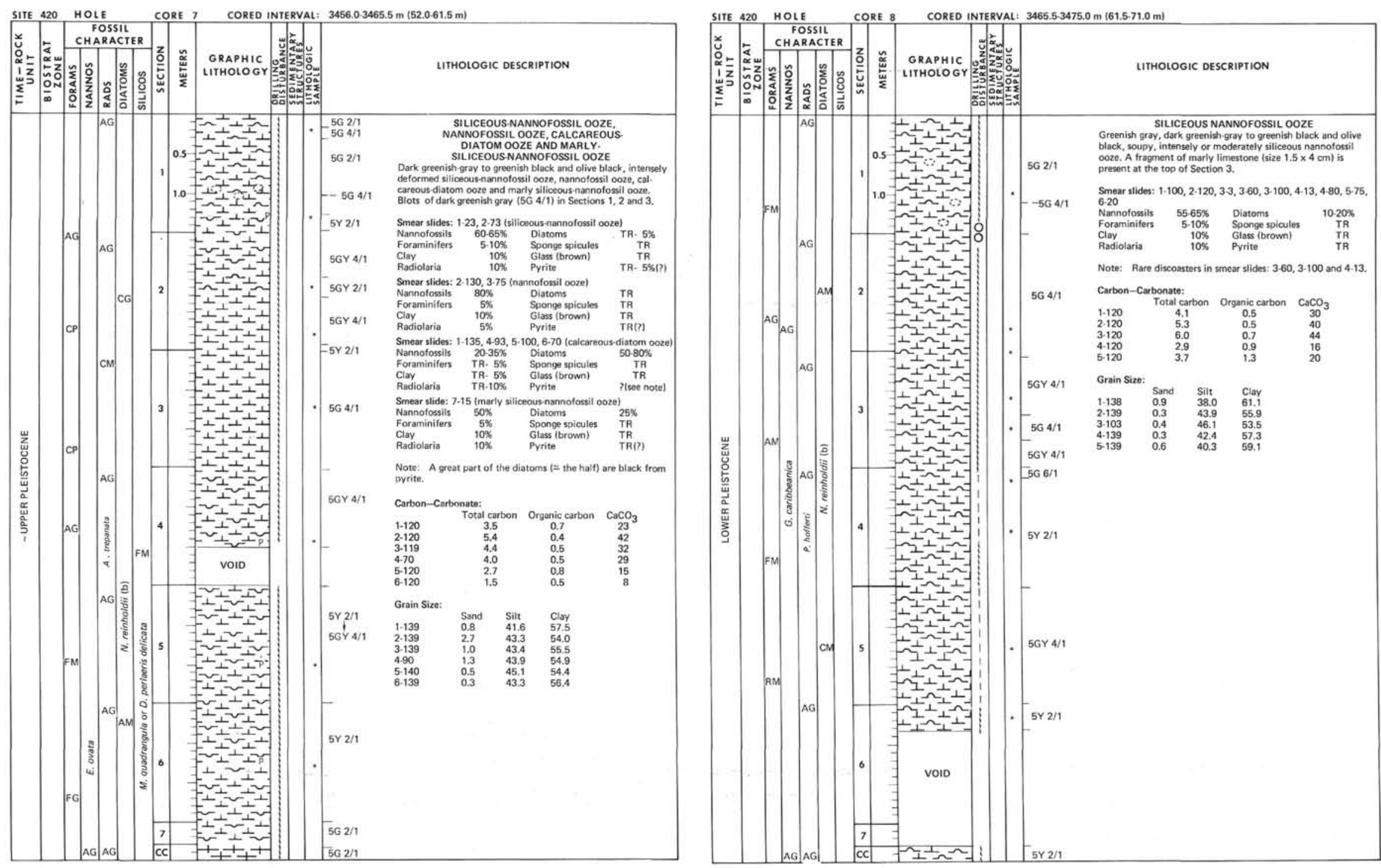

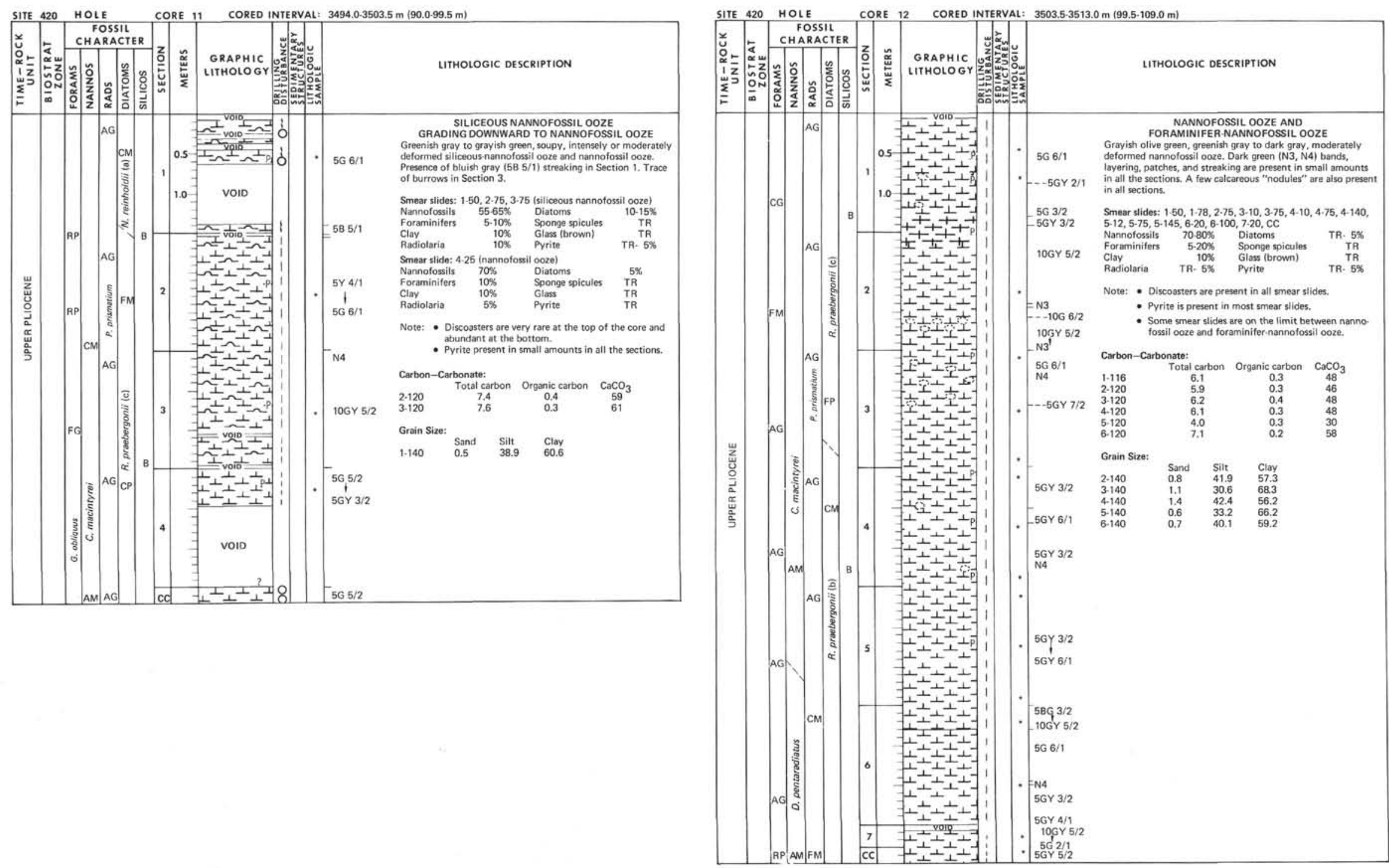


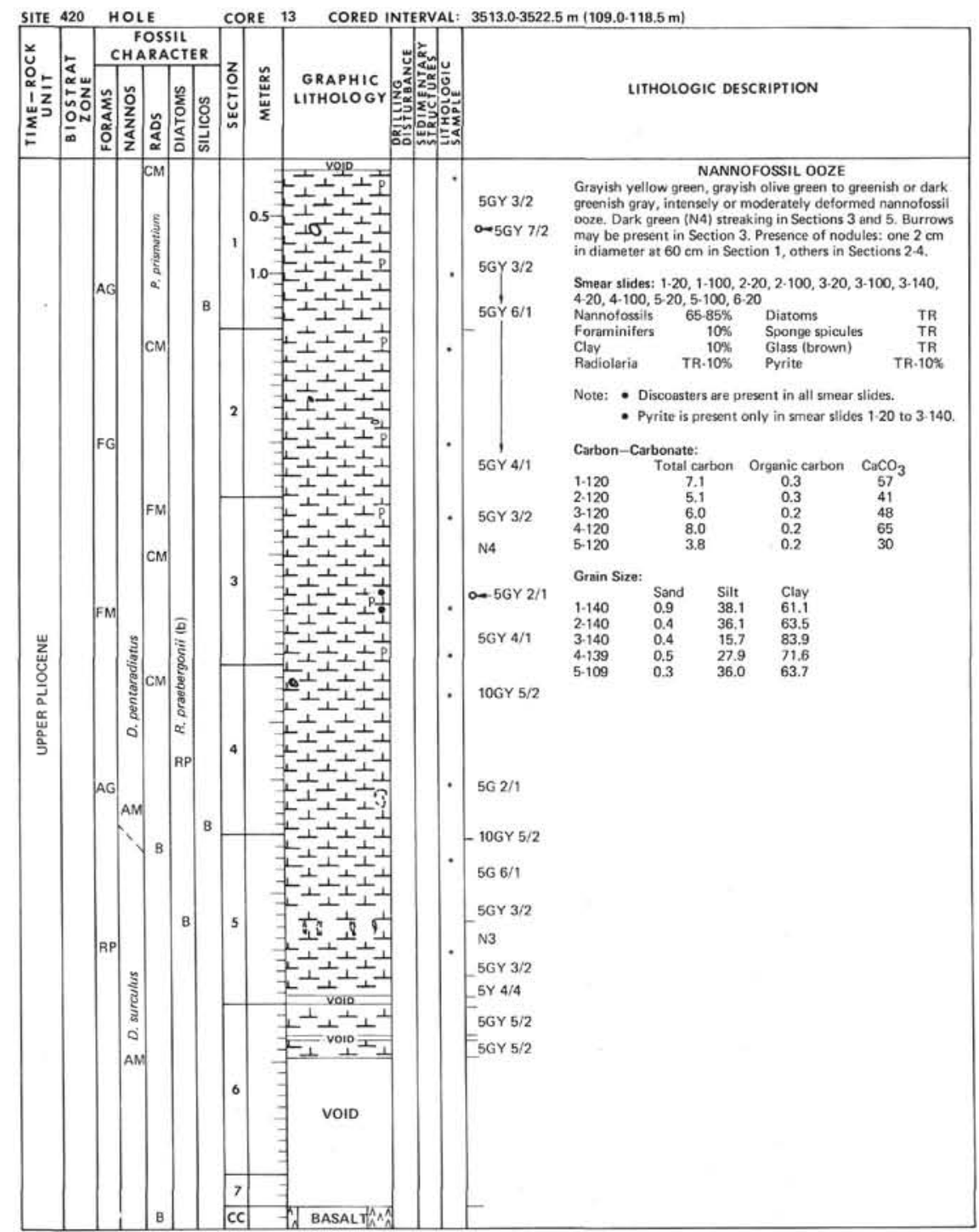




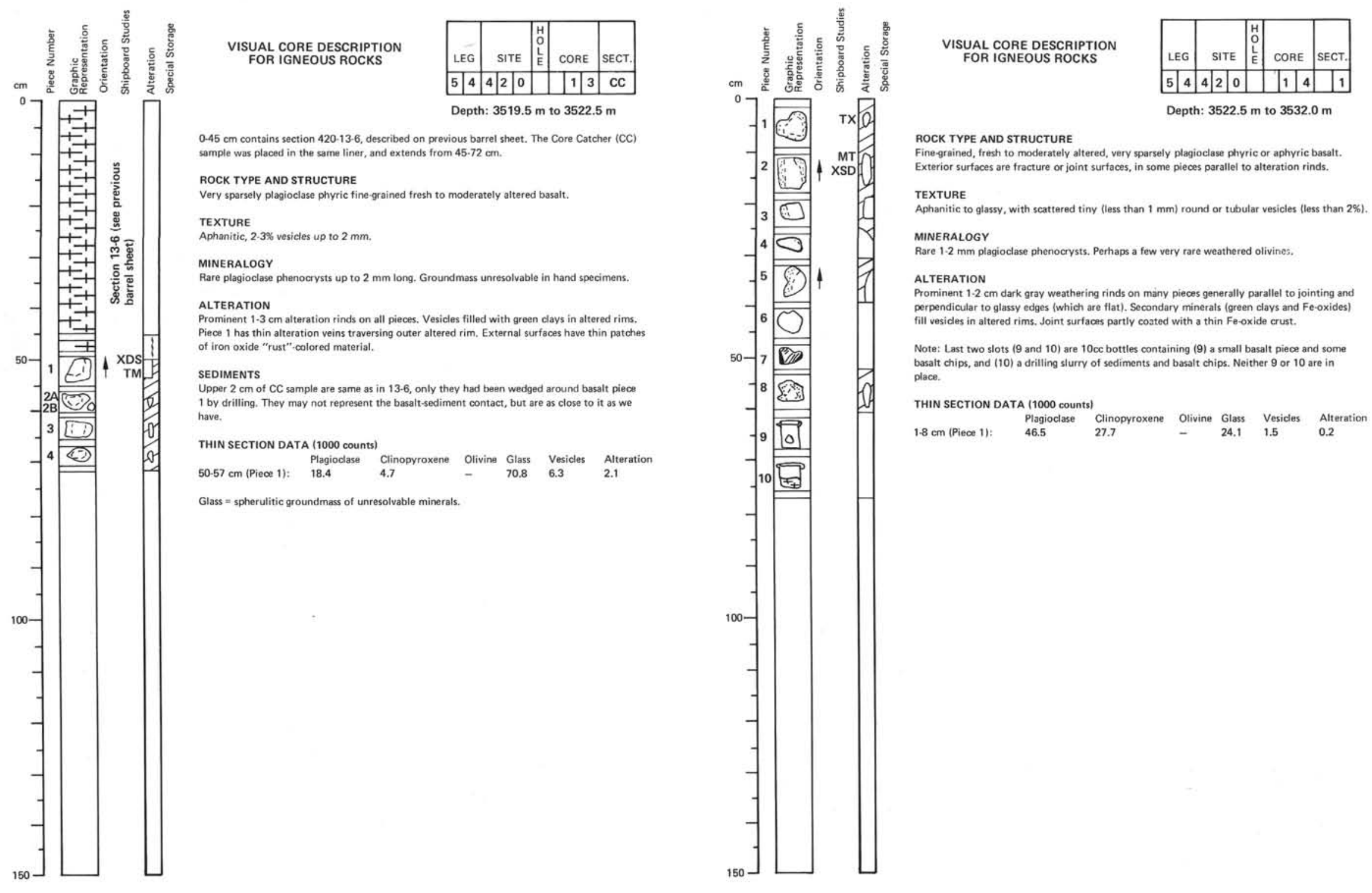



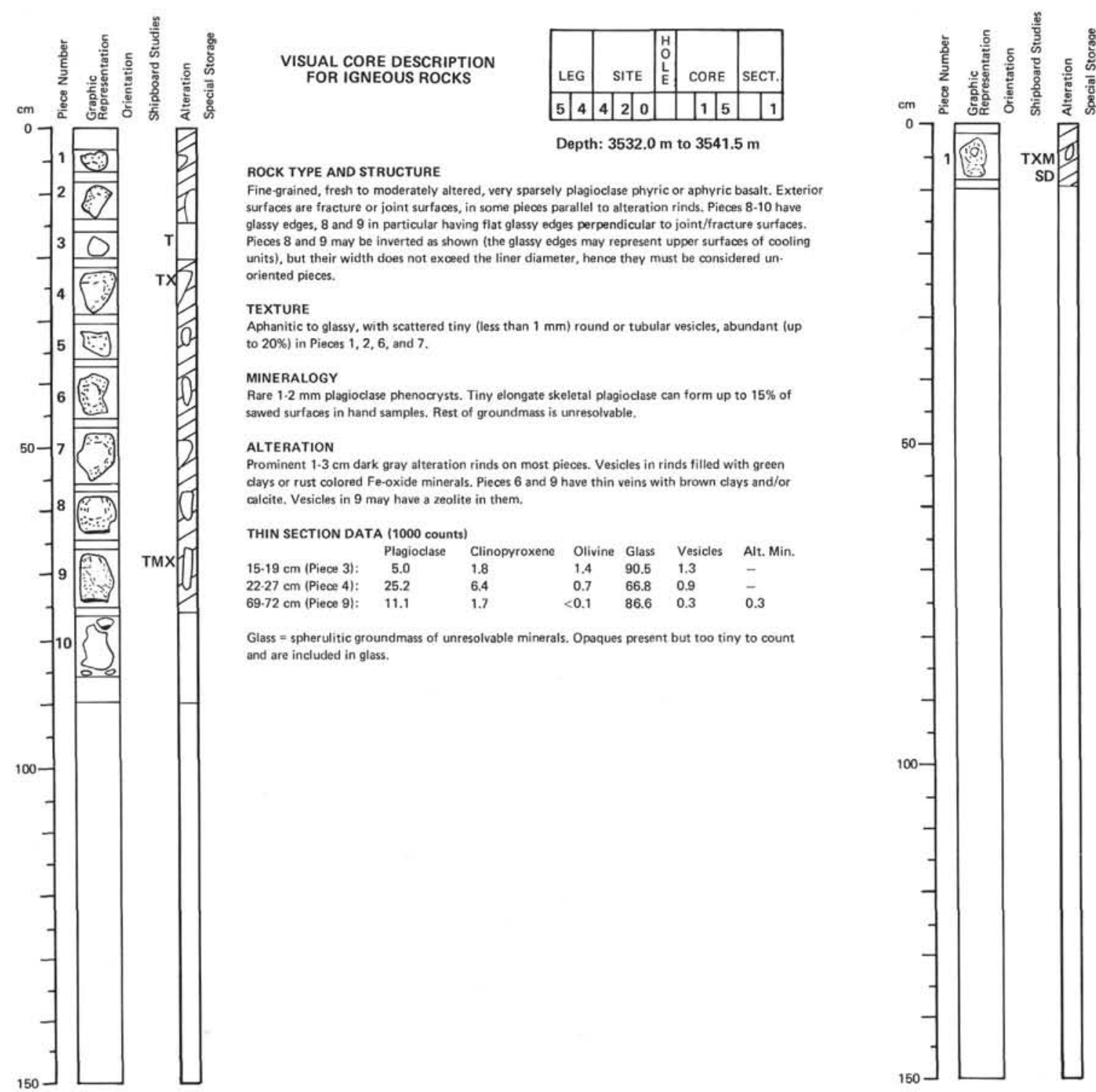
VISUAL CORE DESCRIPTION FOR IGNEOUS ROCKS

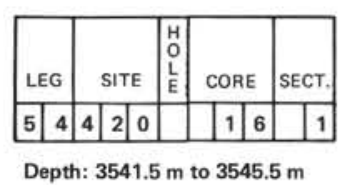
Depth: $3541.5 \mathrm{~m}$ to $3545.5 \mathrm{~m}$

Piece 1:

Very sparsely plagioclase phyric fine-grained basalt. Vesicles in weathering rind filled by whit custs and green clay. Possibly some sulfides in vesicles. Irridescent Fe-oxide and Fe-stained

THIN SECTION DATA (1000 counts) $\begin{array}{lllllll} & & & & & & \\ 2-10 \mathrm{~cm} \text { (Piece 1): } & \text { Plagioclase } & \text { Clinopyroxene } & \text { Olivine } & \text { Glass } & \text { Vesicles } & \text { Alteration } \\ & 4.4 & 1.3 & 83.3 & 2.8 & \text { - }\end{array}$ Glass - spherulitic groundmass of unresolvable minerals. Includes opaques, which were too tiny to count

$\left(\frac{10}{0}\right.$




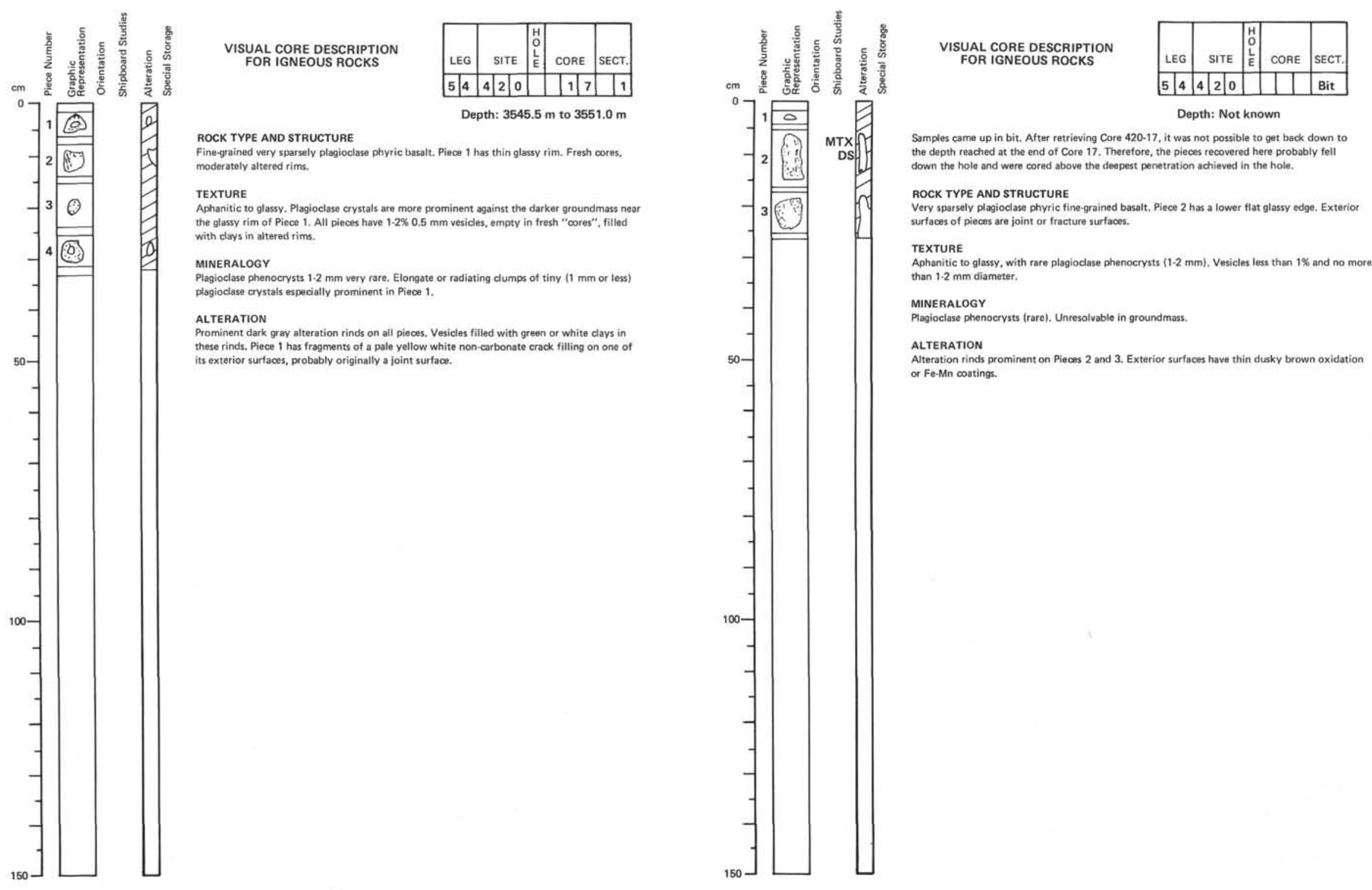




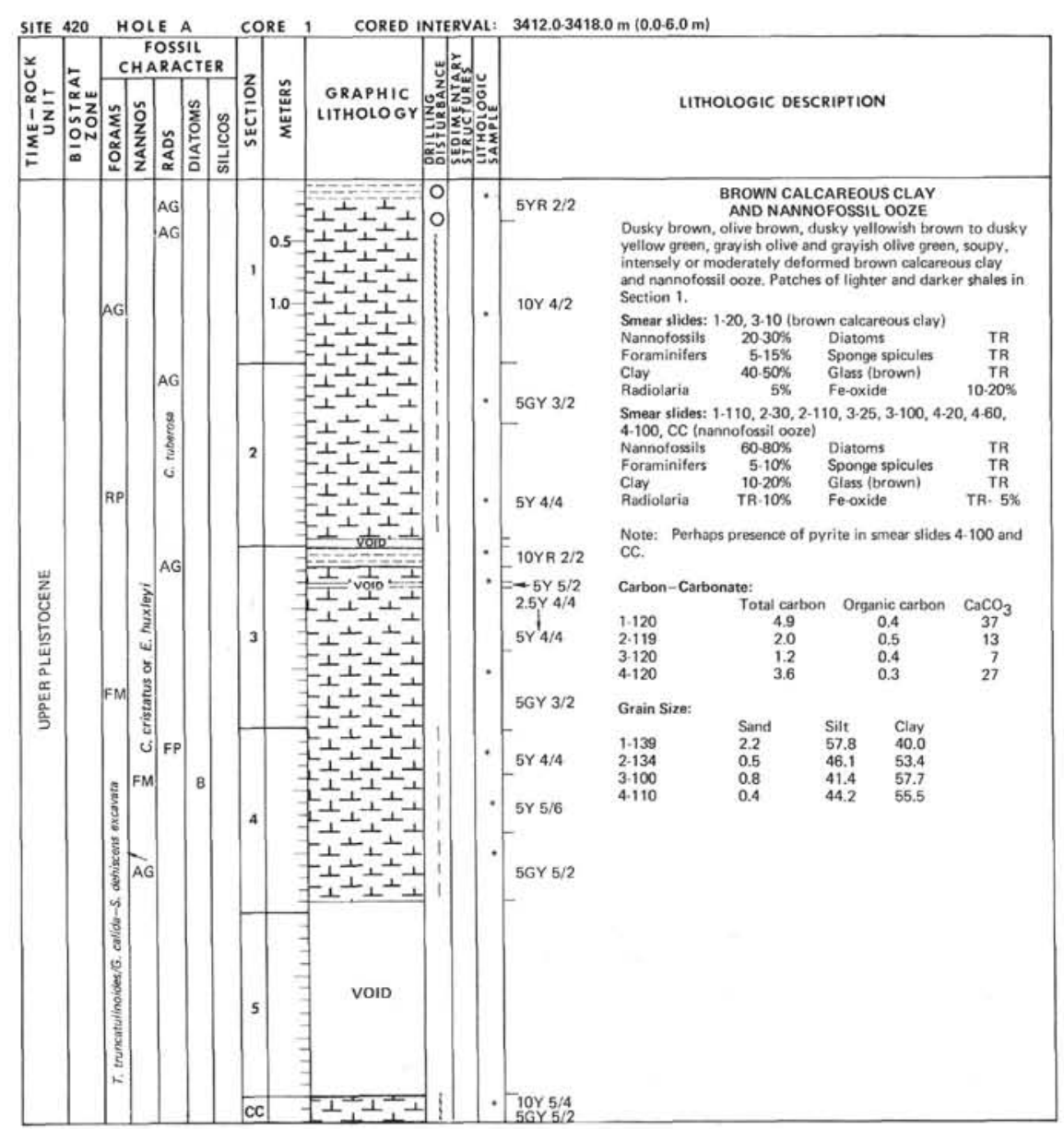




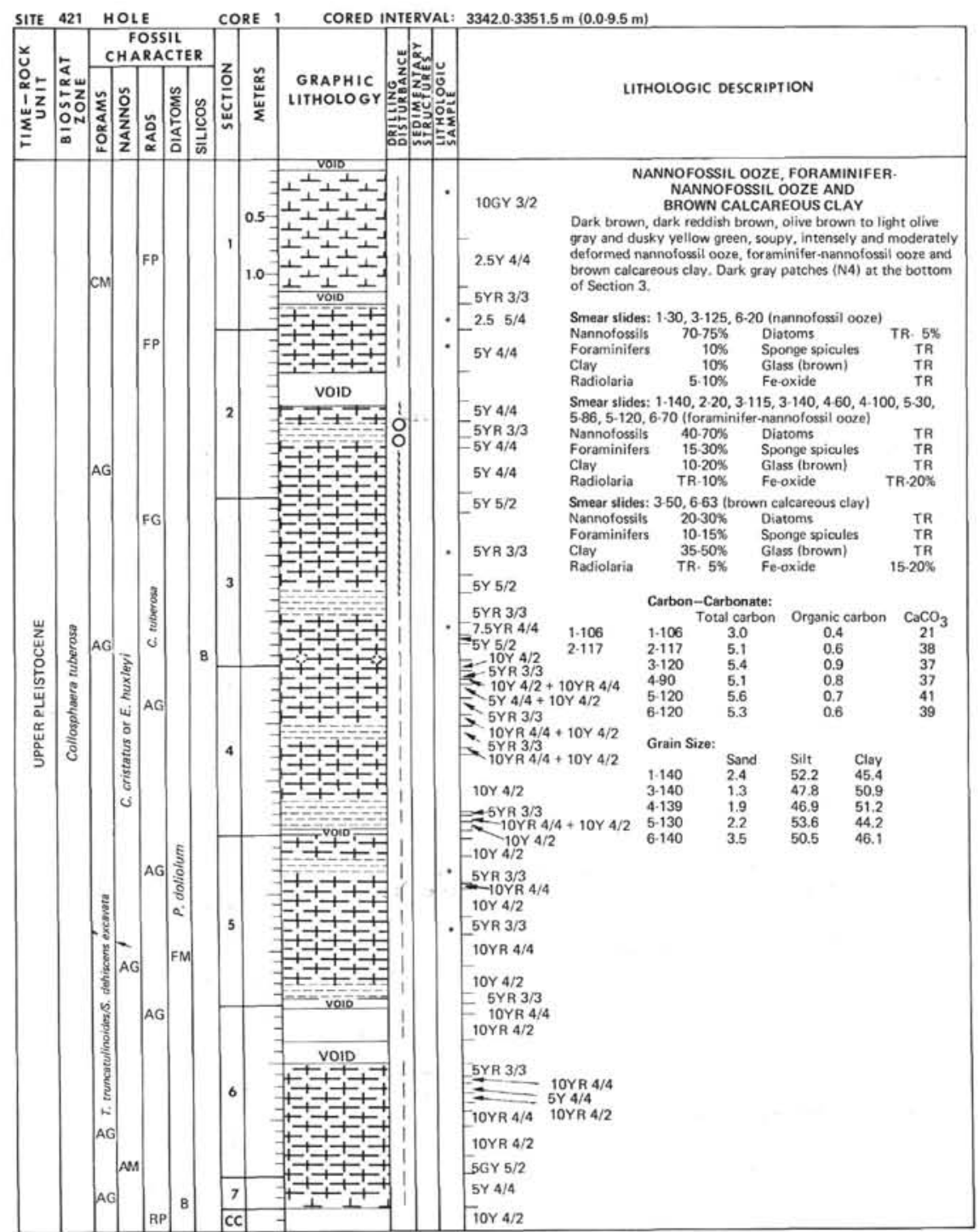



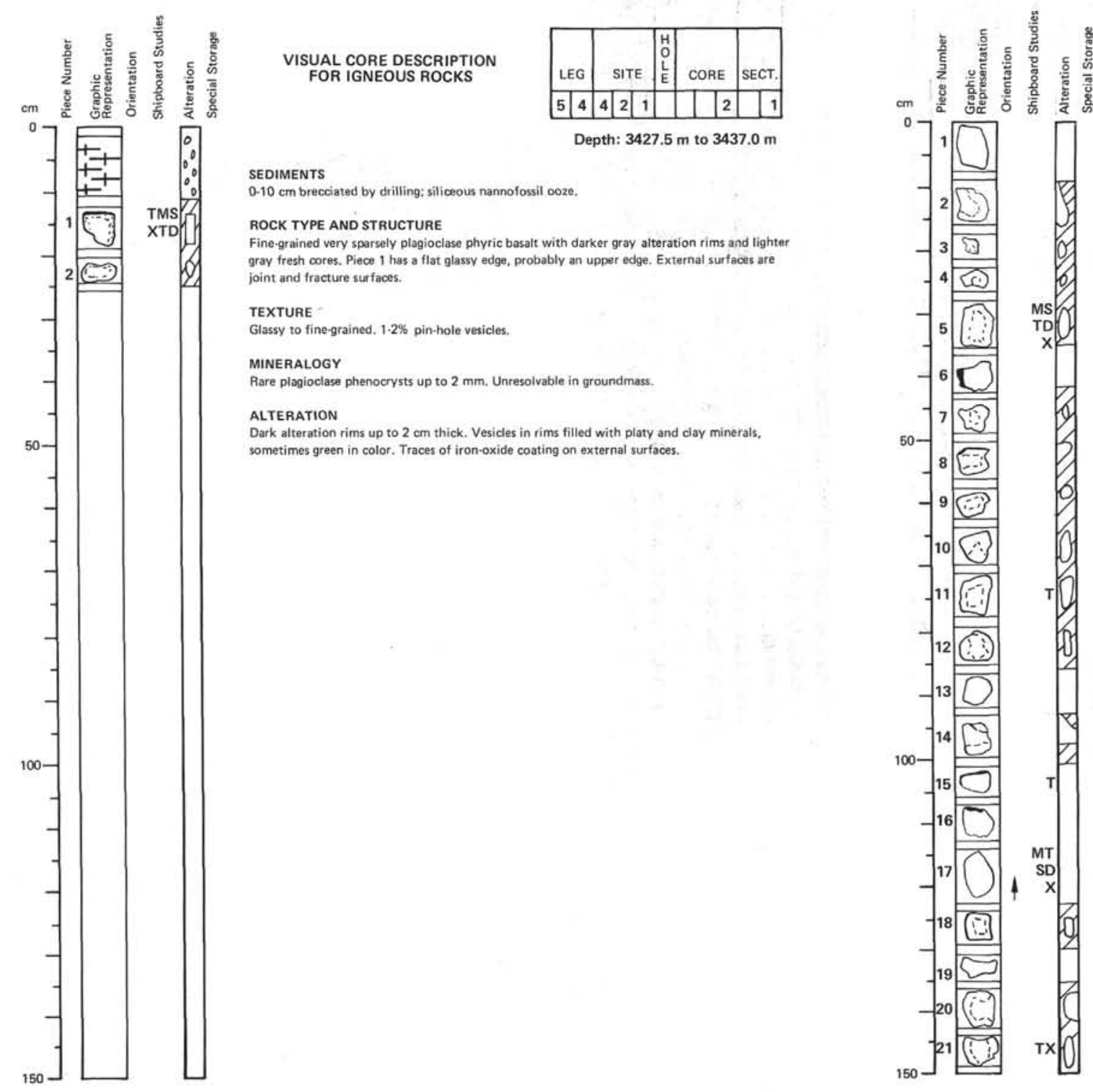

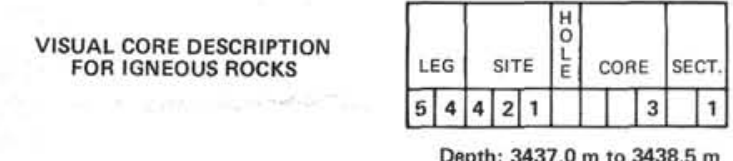

ROCK TYPE AND STRUCTURE

Depth: $3437.0 \mathrm{~m}$ to $3438.5 \mathrm{~m}$

Aphyric to very sparsely plagioclase phyric fine-grained bassalt, some pieces with glassy edges. External suracas of most pieces are joint:

TEXTURE

glassy, with less than $1 \%$ vesicles.

MINERALOGY

作 resolve in hand specimens.

aLteration

Alteration rims $1.2 \mathrm{~cm}$ thick surround fresher cores in many pieces. In altered rims, vesides filled whith platy and clav minerals. some samples sparsely veined with secondary minerals. Scattered time have darker color than cores.

THIN SECTION DATA (1000 counts)

Plagioclase Clinopyroxene Olivine Glass Alteration $\begin{array}{lllll}28.35 \mathrm{~cm} \text { (Piece 5): } 43.8 \quad 34.5 & - & 20.2 & 1.5 \\ 7.75 & & \end{array}$

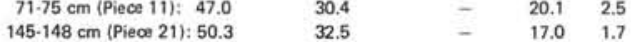

Glass = spherulitic or sub-microcrystalline mesostasis and includes opaques. 

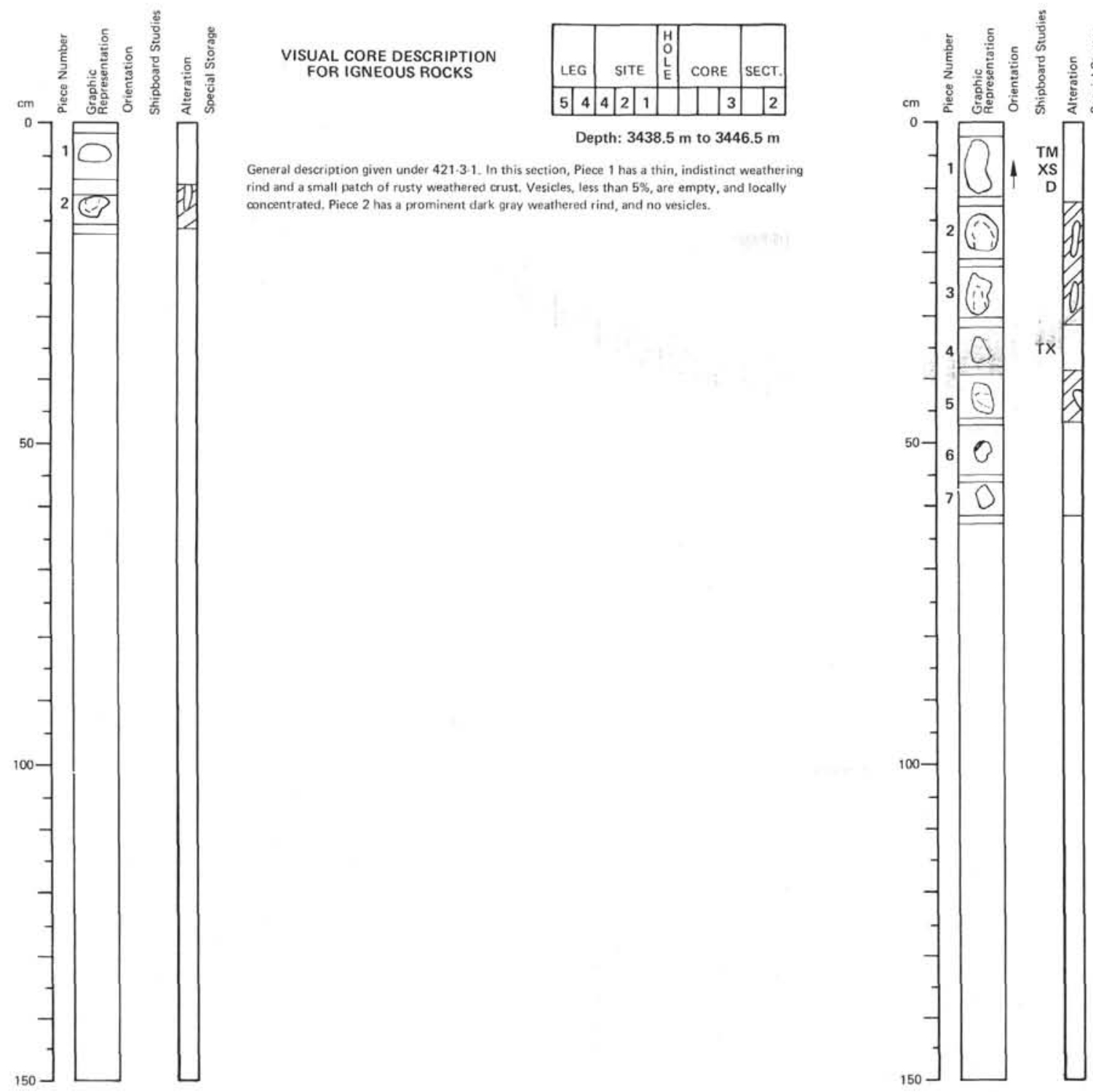
VISUAL CORE DESCRIPTION

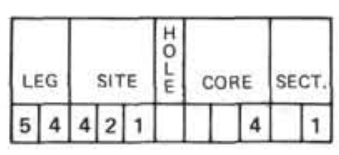

Depth: $3446.5 \mathrm{~m}$ to $3456.5 \mathrm{~m}$

\section{ROCK TYPE AND STRUCTURE}

Very fine-grained to glassy sparsely plagioclase phyric or aphyric basalt, with distinct alteration rims, and exterior joint/fracture surfaces.

TEXTURE

than $2 \mathrm{~mm}$ and $5 \%$ excopt Piece 1 where long tubular vesicles

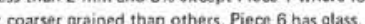

MINERALOGY

Plagioclase phenoccysts less than $3 \mathrm{~mm}$ and less than $1 \%$ in Pieces 4 and 6

WEATHERING

Thes vesicles are filled with plary The 

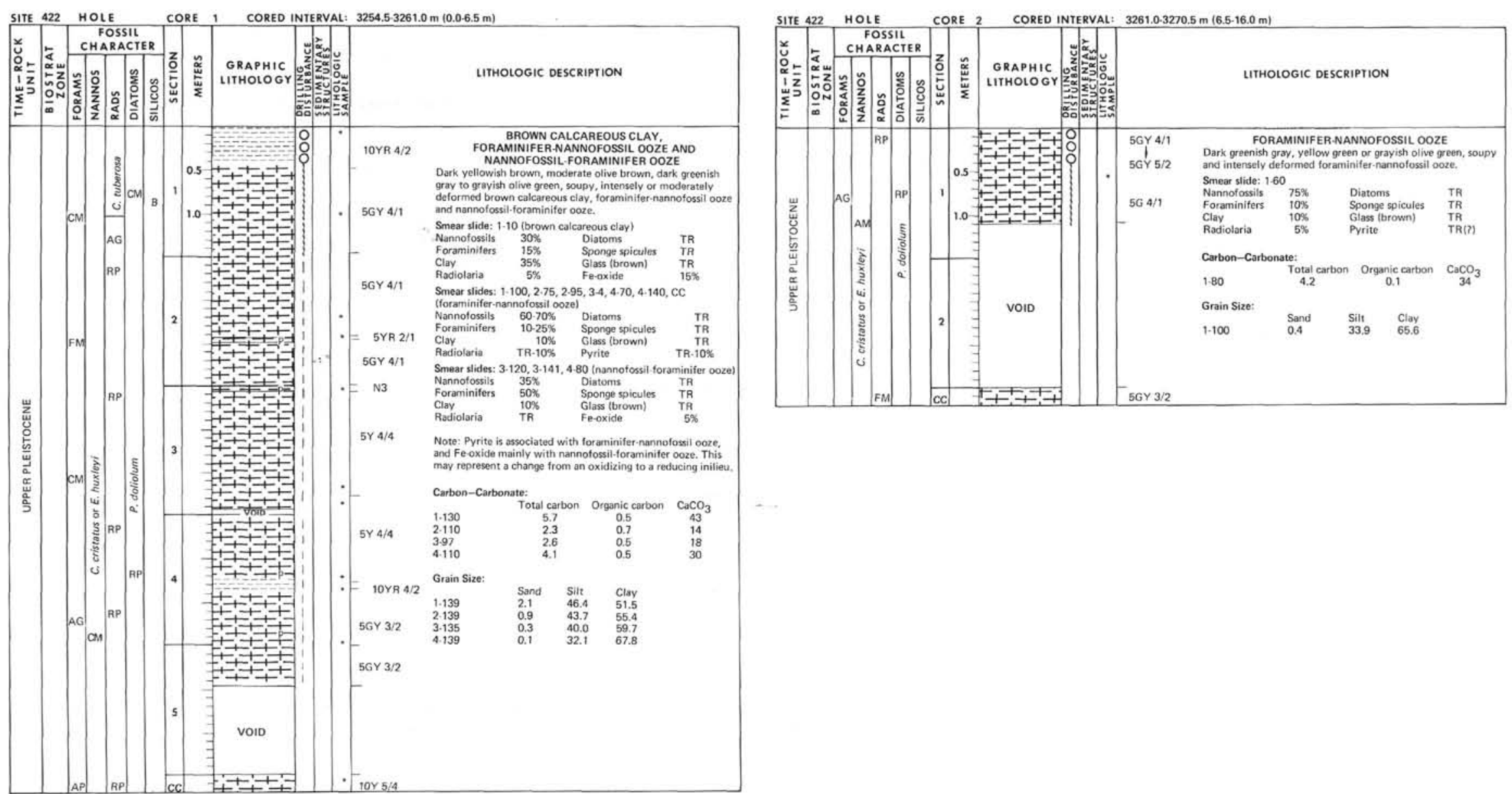

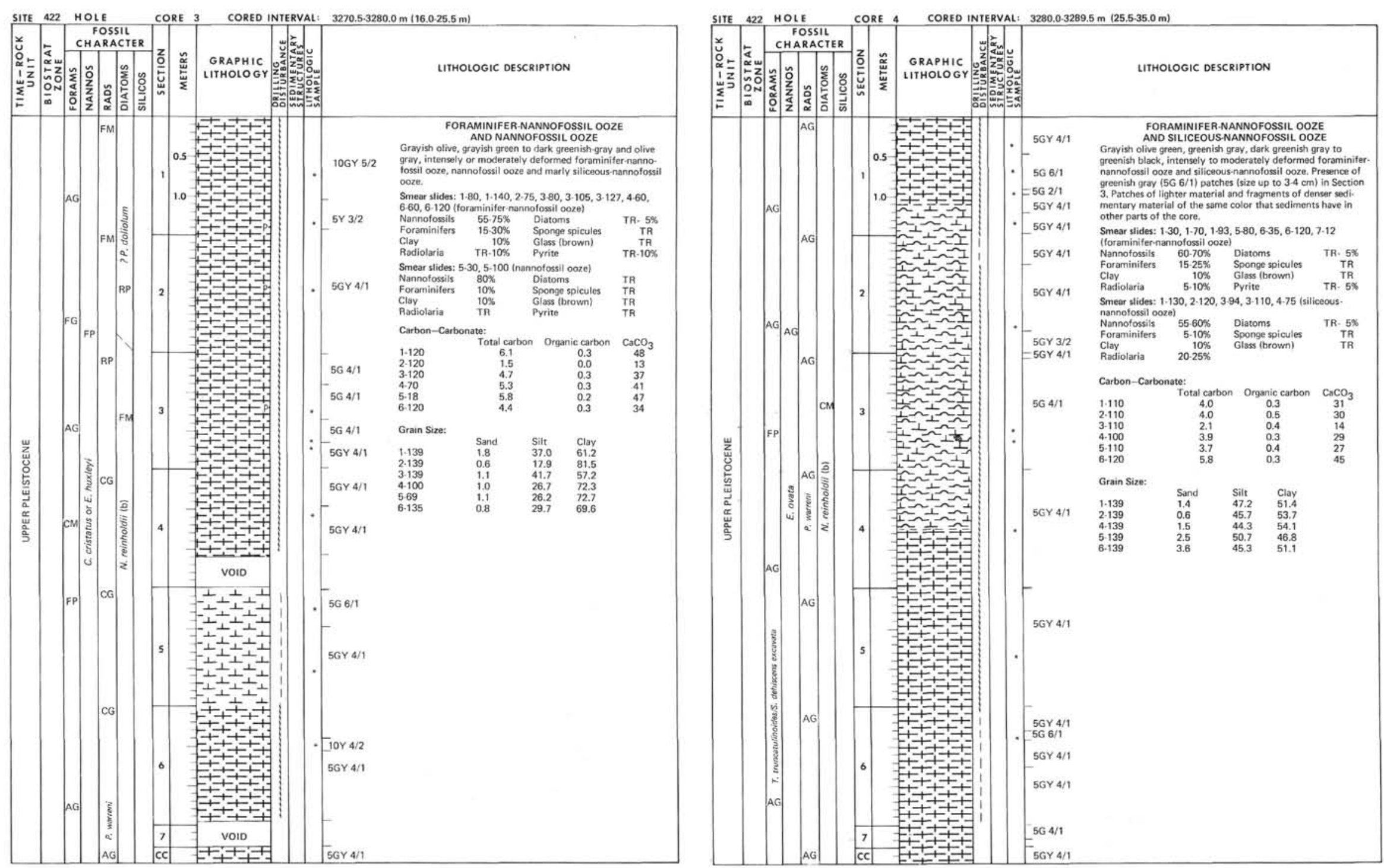


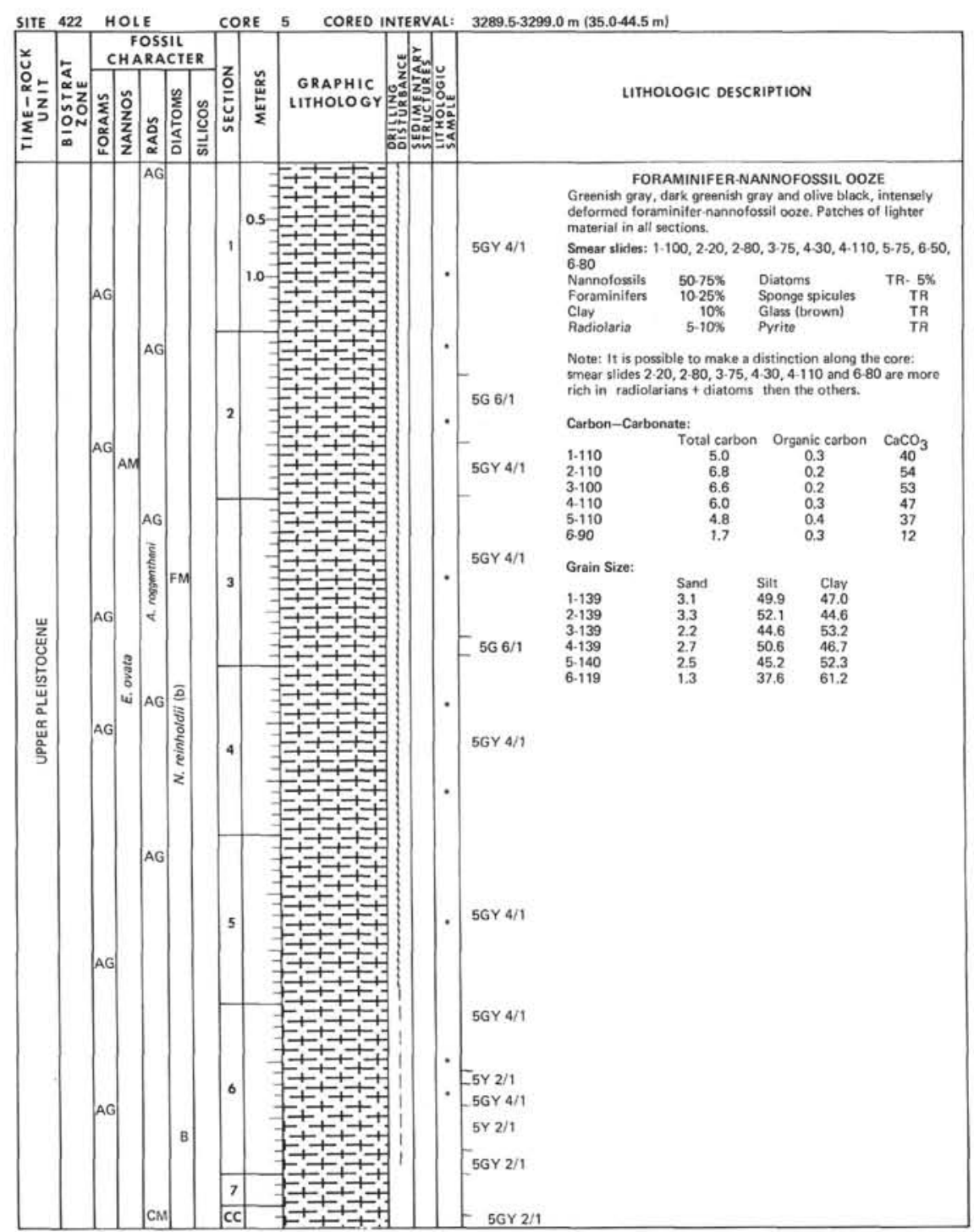

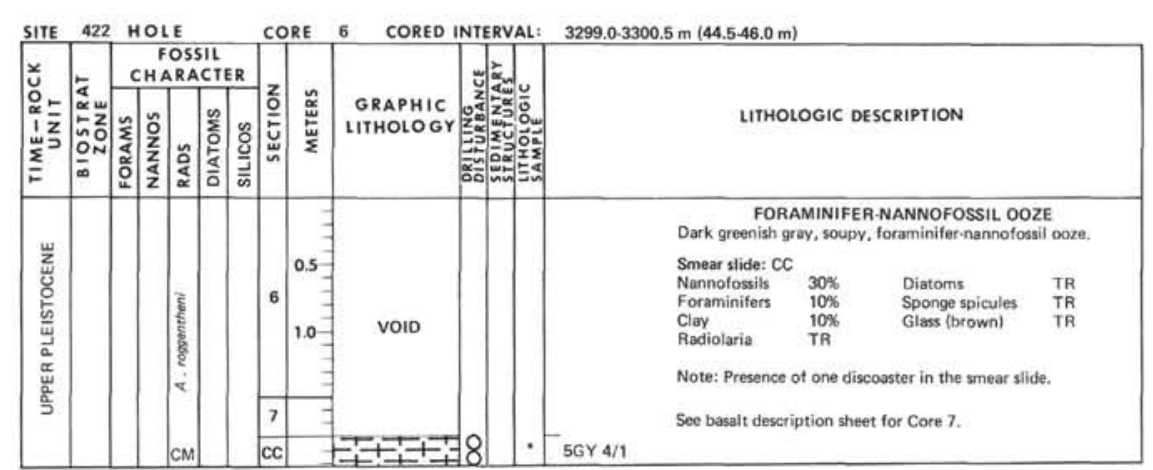

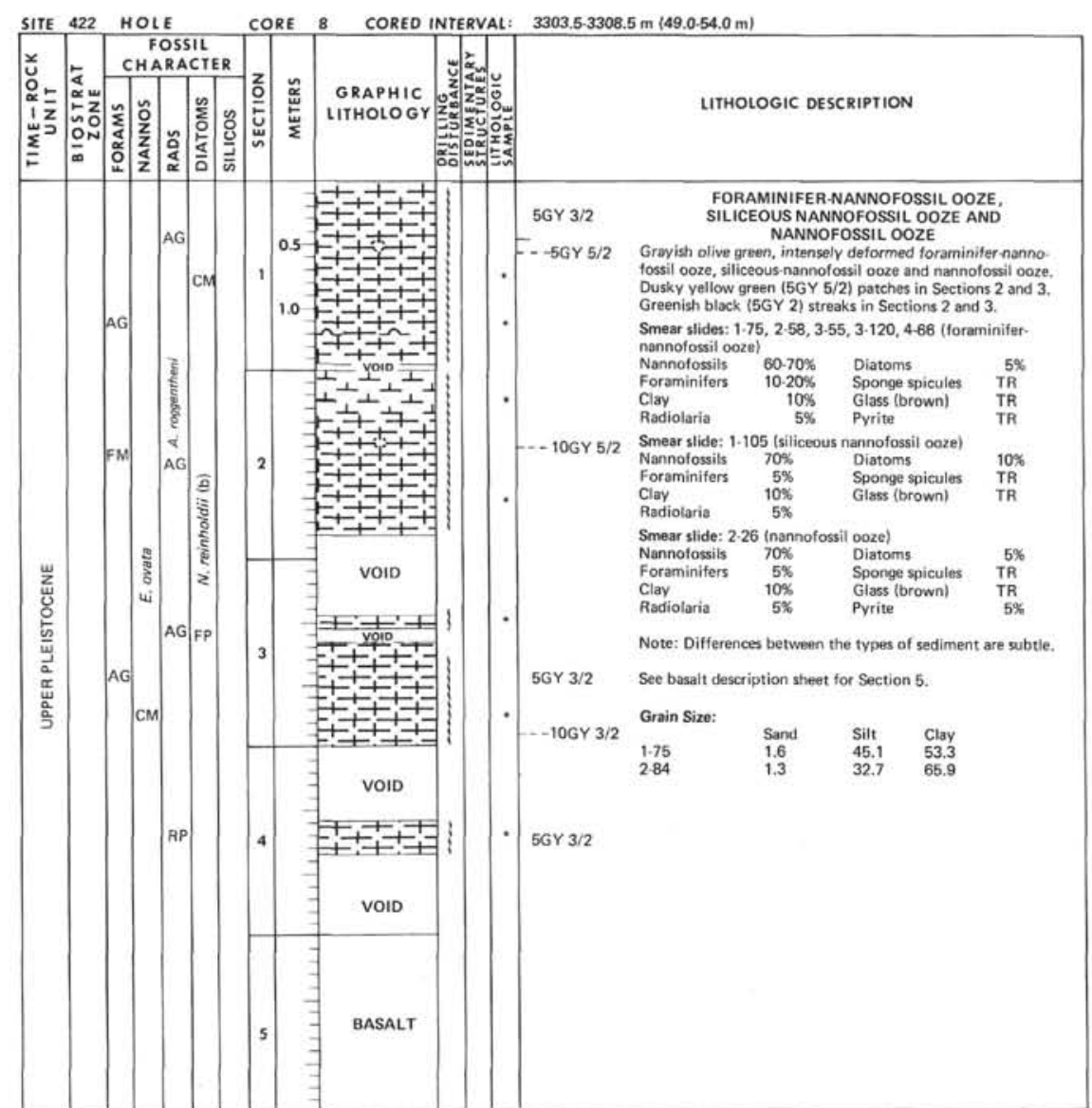




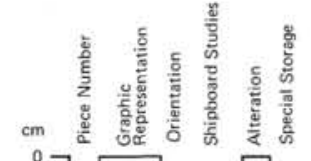

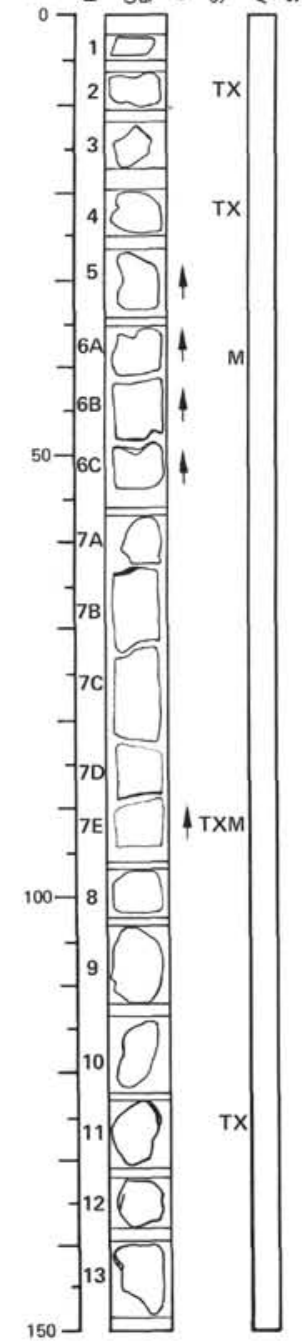
VISUAL CORE DESCRIPTION
FOR IGNEOUS ROCKS

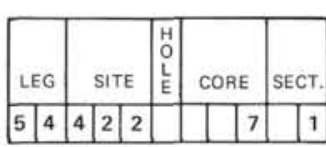

Depth: $3300.5 \mathrm{~m}$ to $3303.0 \mathrm{~m}$

ROCK TYPE AND STRUCTURE Texture corsens through Ploce 9 , is tiner in Piese 10.

TEXTURE

Aphanitic 2.3\% vesicles in most pieces, more abundant in Pieces 10 and 12. Tube vesicles in 13 .

MinERALOGY

Blue clays in vesicles, zeolite (?) in 6B,

THIN SECTION DATA (1000 counts)

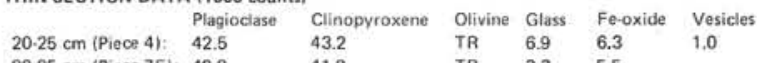
$90.95 \mathrm{~cm}$ (Piece 7E): 48 \begin{tabular}{lllll}
43.2 & TR & 6.9 & 6.3 & 1.0 \\
41.8 & TR & 3.3 & 5.5 & $=$ \\
54.1 & TR & \multicolumn{1}{ll}{} & 5.9
\end{tabular} 122.131 cm (Piece 11): 34.0

Also $1.2 \%$ plagioclase phenocrysts.

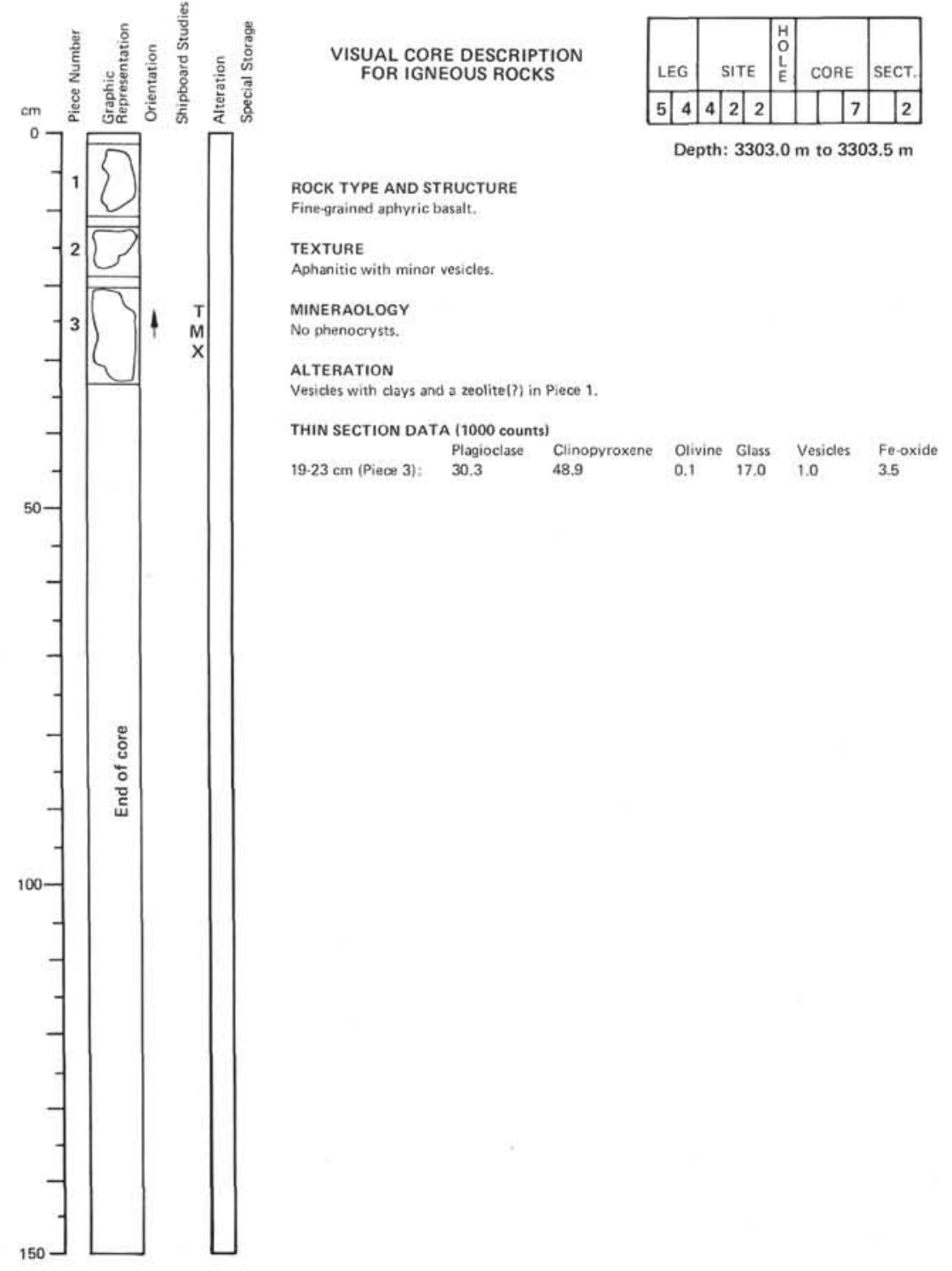



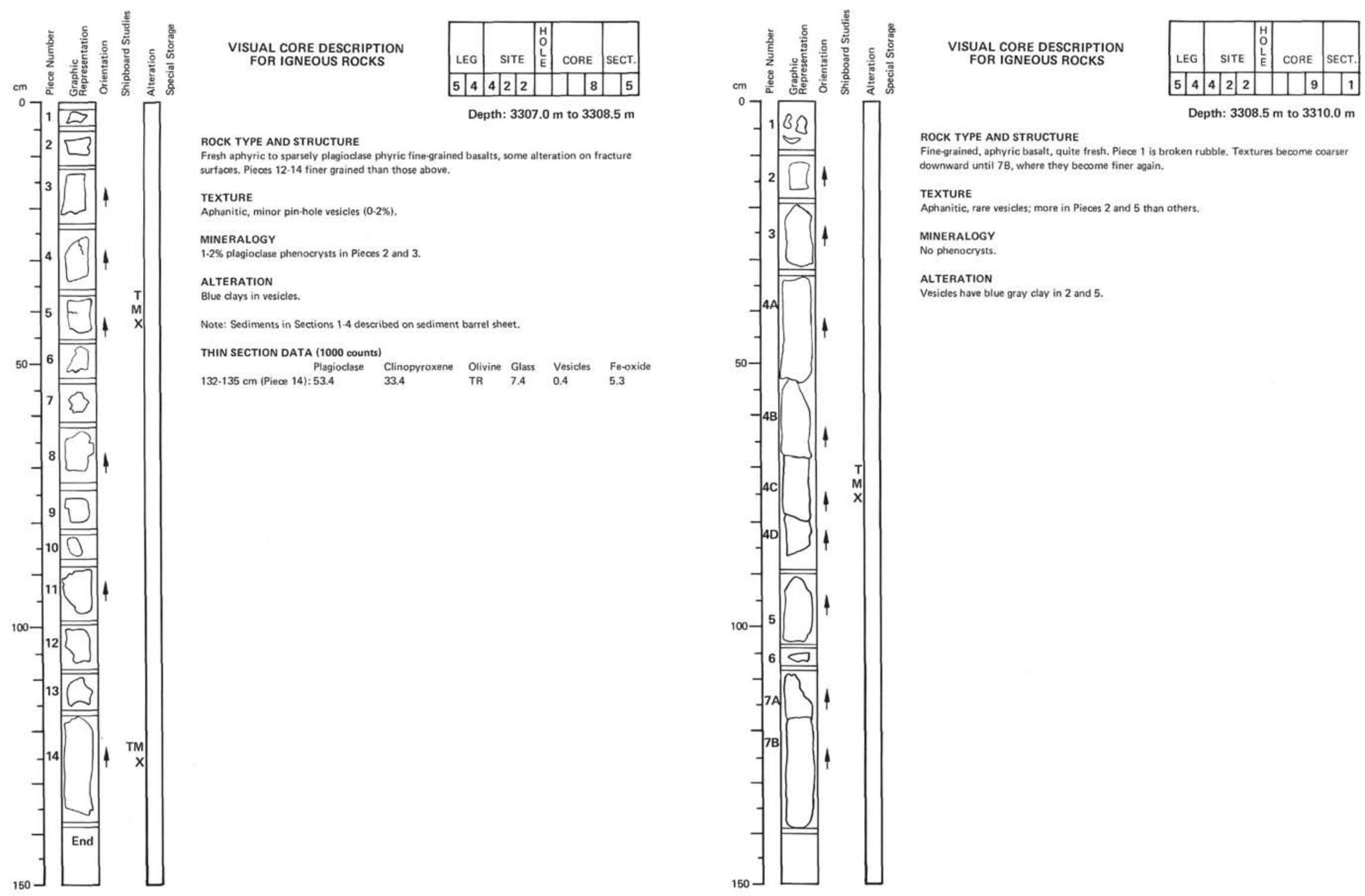

ROCK TYPE AND STRUCTURE

Dept $3308.5 \mathrm{~m} 103310.0 \mathrm{~m}$

downward until 7B, basalt, quite fresh., piece 1 is

TEXTURE

s. more in Pleces 2 and 5 than others.

MINERALOGY

ALTERATION

Vesicles have blue gray clay in 2 and 5 . 


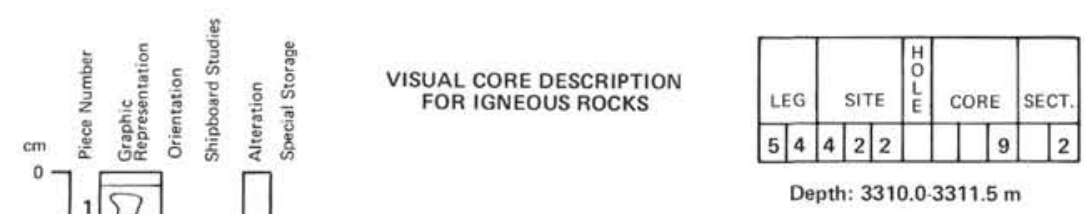

ROCK TYPE AND STRUCTURE

Fine grained aphy sict

TEXTURE

Aphanitic to microlitic. Minor small vesicles, more abundant in $4 \mathrm{C}$ downward.

MiNERALS

Plagioclase microlites visible in hand sample

ALteration

Blue clays in vesicles, thin cracks with clays in $4 A, D$, and E. $1.2 \mathrm{~mm}$ alteration rind, Pieces

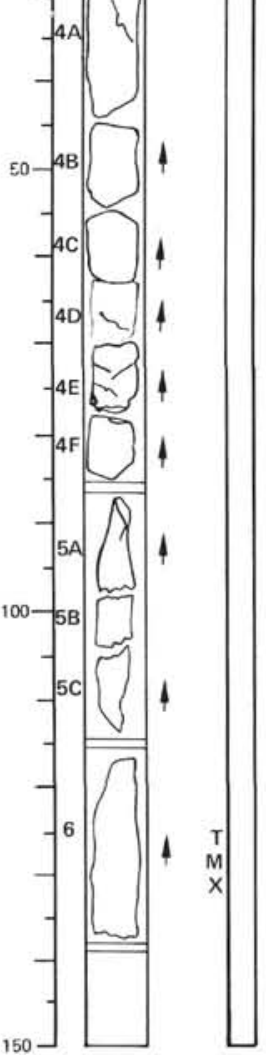

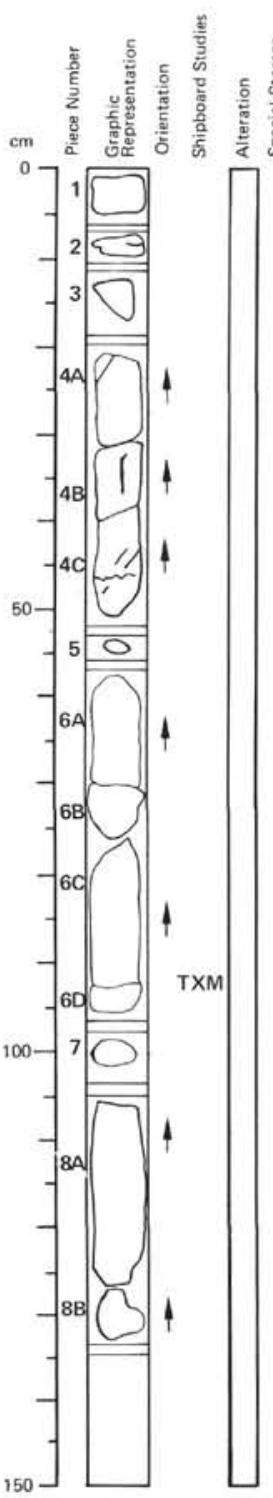
VISUAL CORE DESCRIPTION
FOR IGNEOUS ROCKS

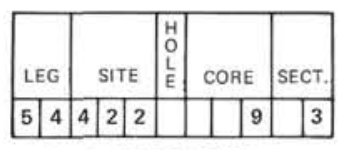

Depth: $3313.0-3314.5 \mathrm{~m}$

ROCK TYPE AND STRUCTURE

Fine-grained aphyric to very sparsely plagioclase-phyric fresh basalt. Glassy segregations in Fes $6 A$ and $6 \mathrm{D}$. Deep tube vesicles in $8 \mathrm{~B}$

TEXTURE

re plagioclase phenocrysts

MINERALOGY

ALteration

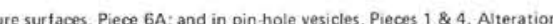
minerals in racks in Pieces $2,4 \mathrm{~B}$ and $4 \mathrm{C}$

THIN SECTION DATA (1000 counts)

\begin{tabular}{lllllll} 
& & Plagioclase & Clinopyroxene & Olivine Glass Fe-oxide & Vesicles \\
\hline $\mathrm{cm}$ (Piece 6C): & 52.6 & 34.2 & 9.4 & 1.3
\end{tabular} 


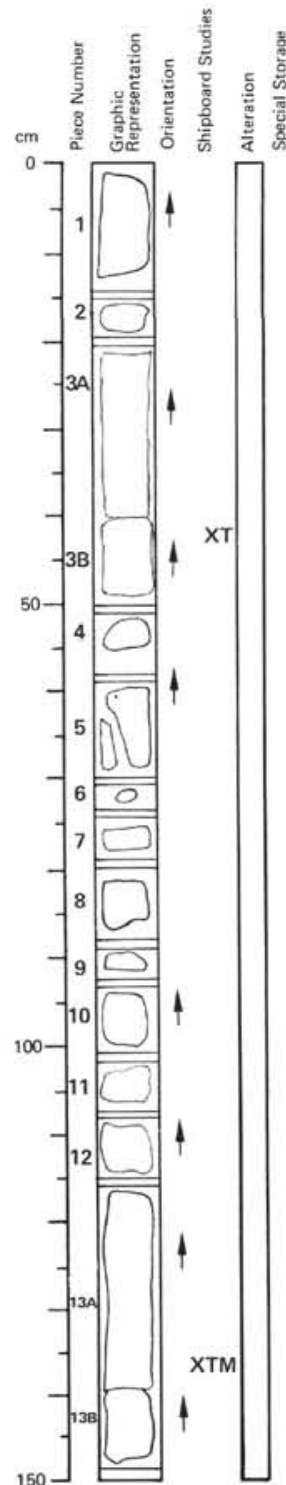

VISUAL CORE DESCRIPTION FOR IGNEOUS ROCKS

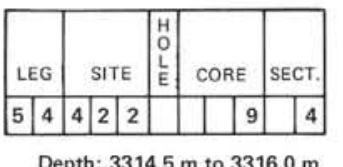

ROCK TYPE AND STRUCTURE

Fine-grained aphyric to verv sparsely plagioclase phyric bassit. Glassy segregations in Pieces 4 in

TEXTURE
Microlitic.

MiNERALOGY

.

ALTERATION

Blue clays in vesictes in Pieces 8 and 10. Small alteration veinlets in 10.

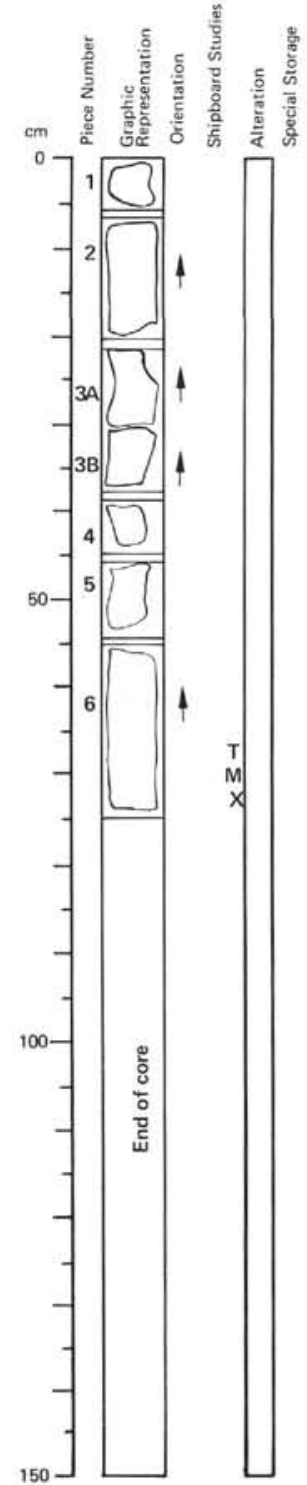

VISUAL CORE DESCRIPTION FOR IGNEOUS ROCKS

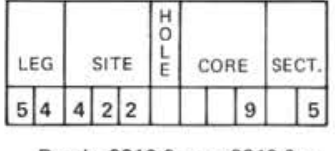

Depth: $3316.0 \mathrm{~m}$ to $3318.0 \mathrm{~m}$

ROCK TYPE AND STRUCTURE

14. A tew tubular vesilces on Piecoss 1,2 and 5. Vesicles more rare and smaller elsewhere.

TEXTURE

MINERALOGY

aLteration

Minor; blue clay in vesicles in Pieces 1 and 6 . Greenish clay on top outer surface of 6 .

THIN SECTION DATA (1000 counts)

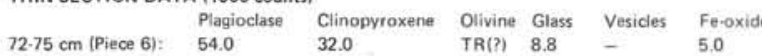




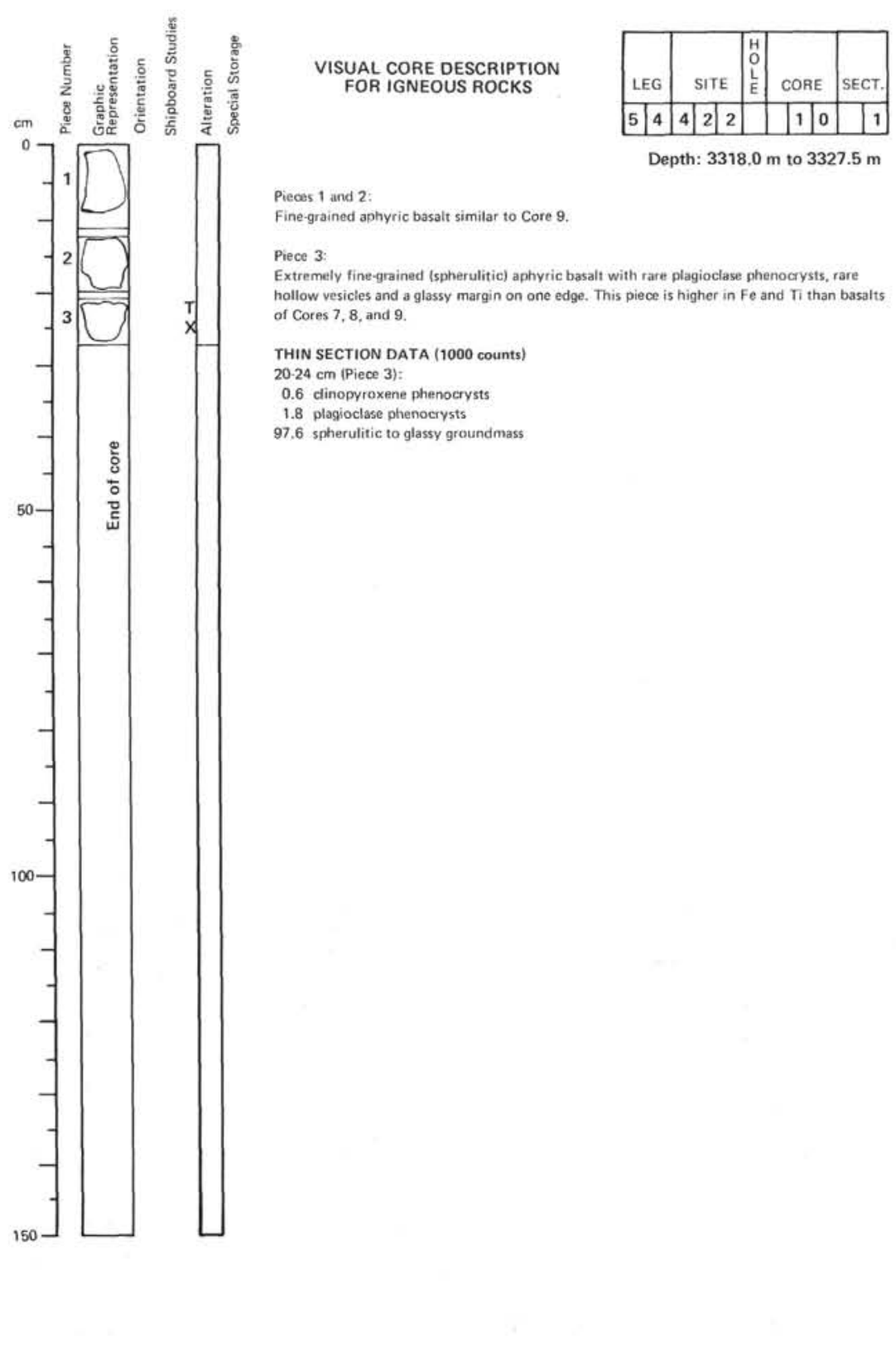



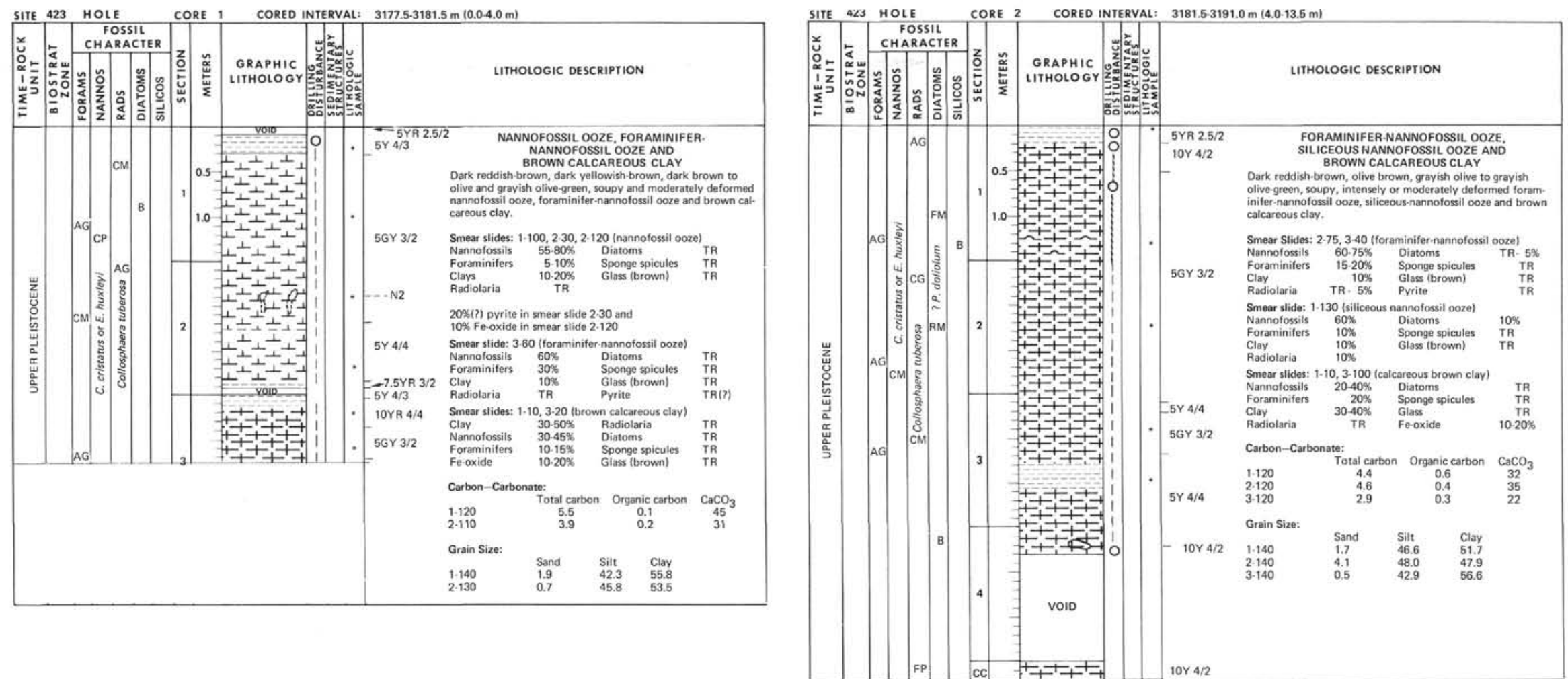


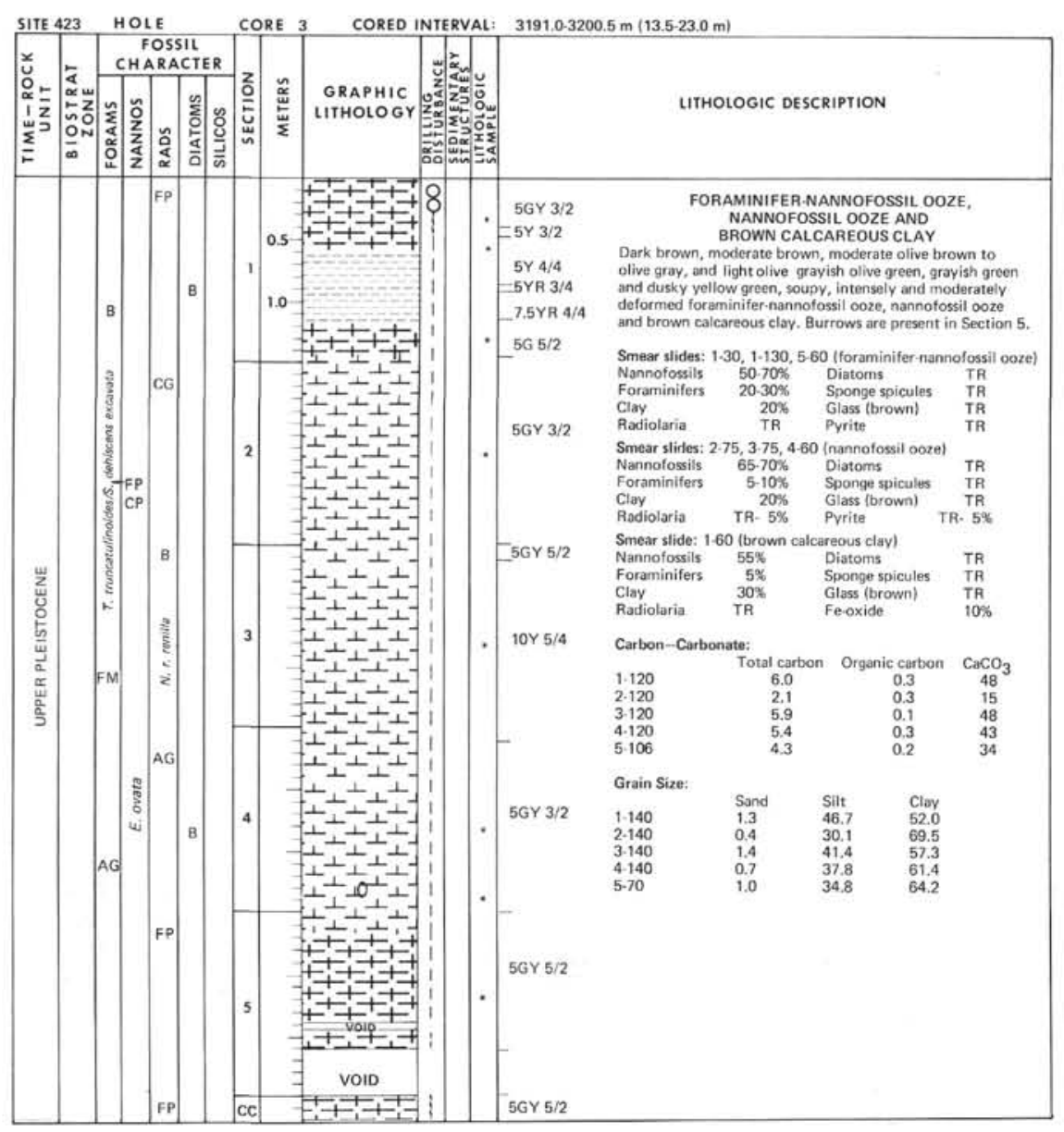

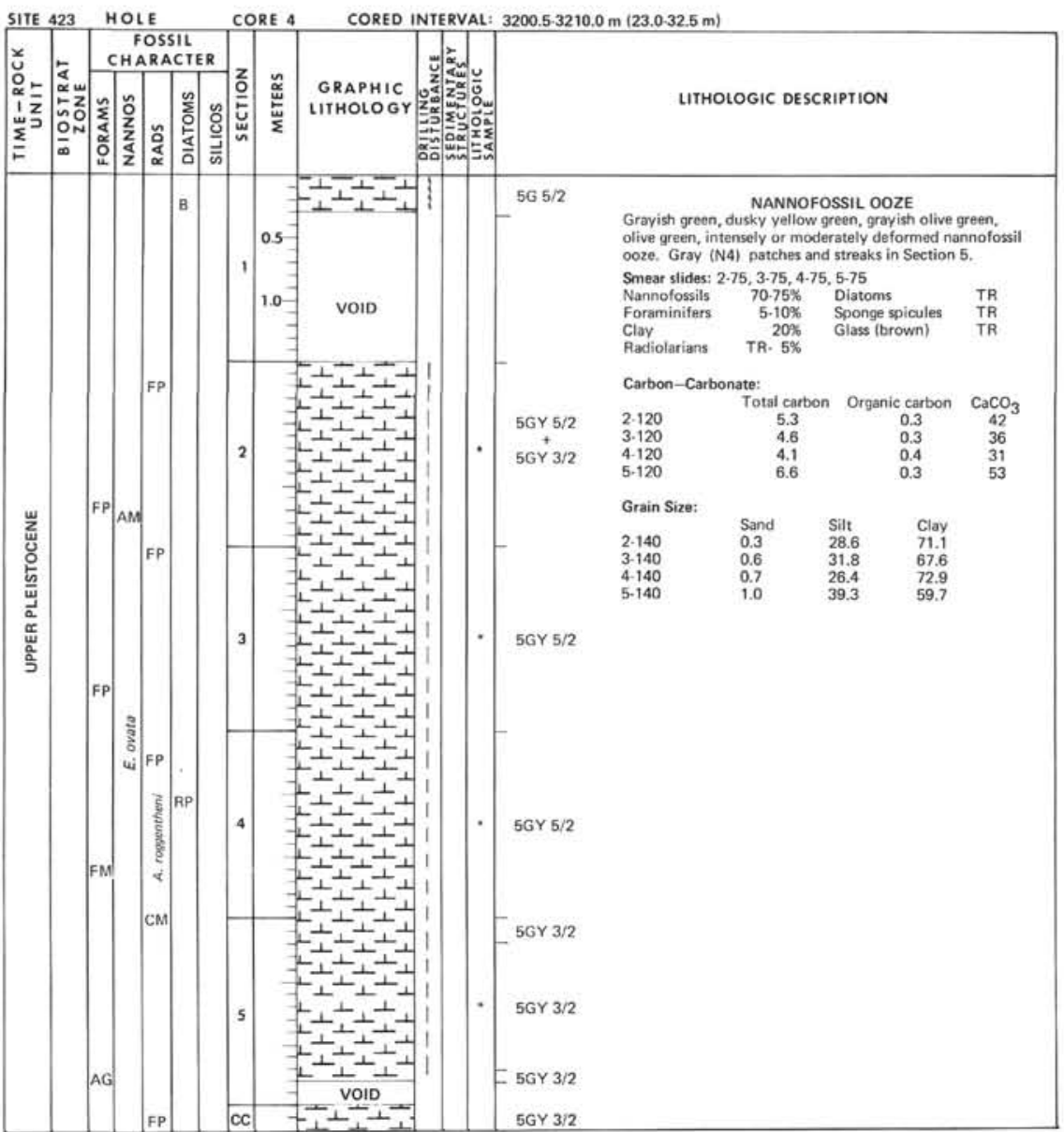




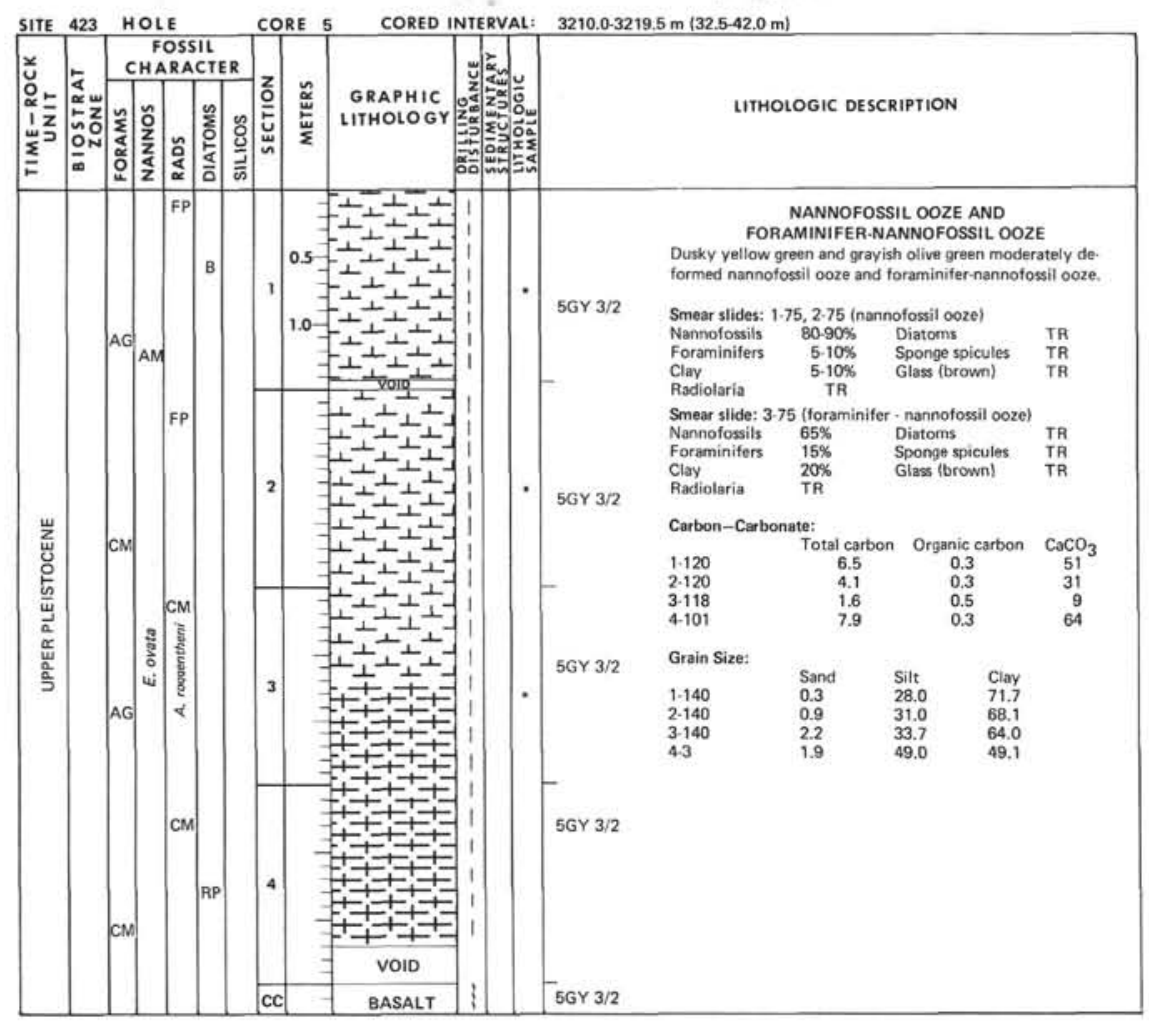




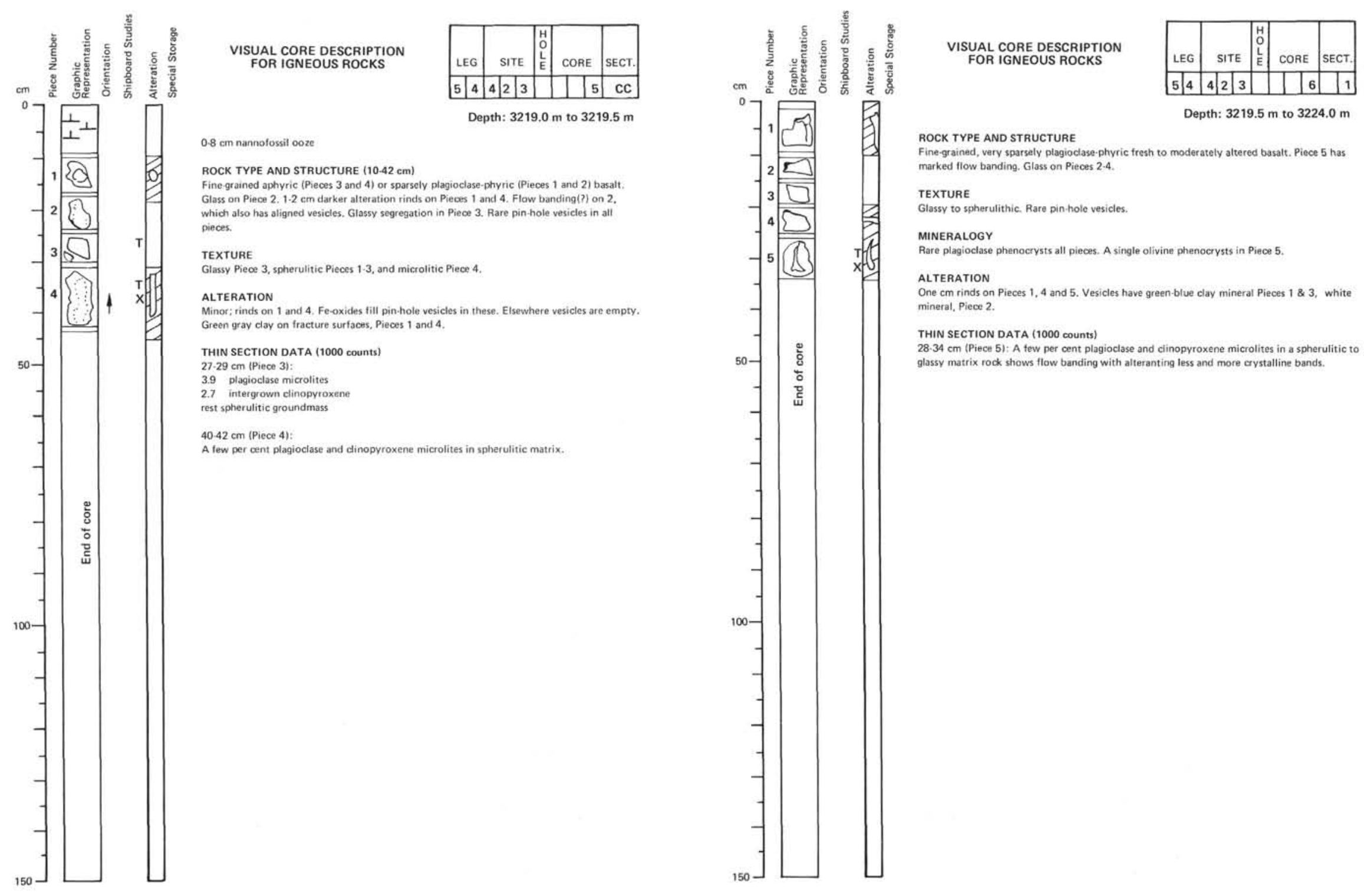



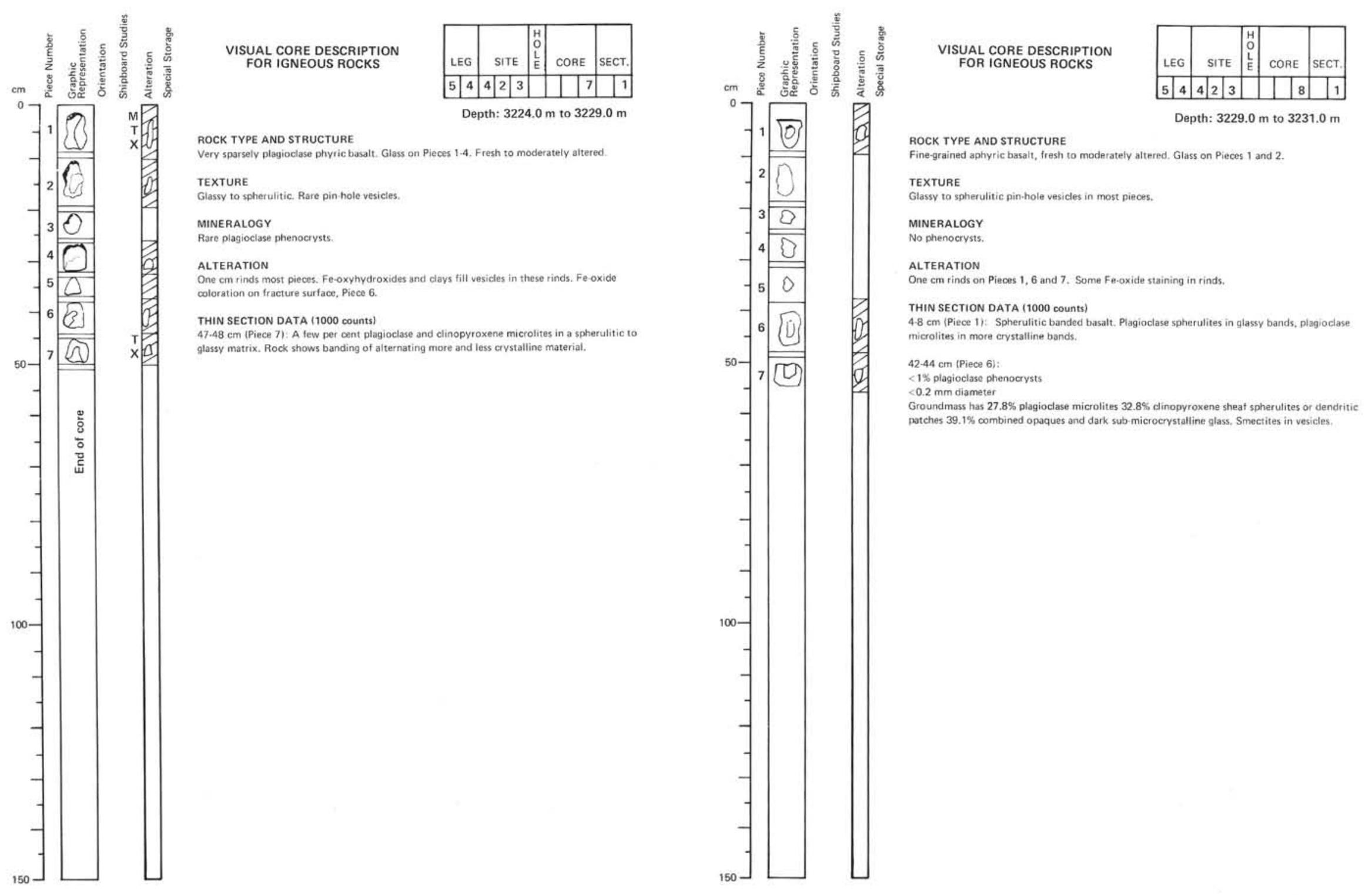


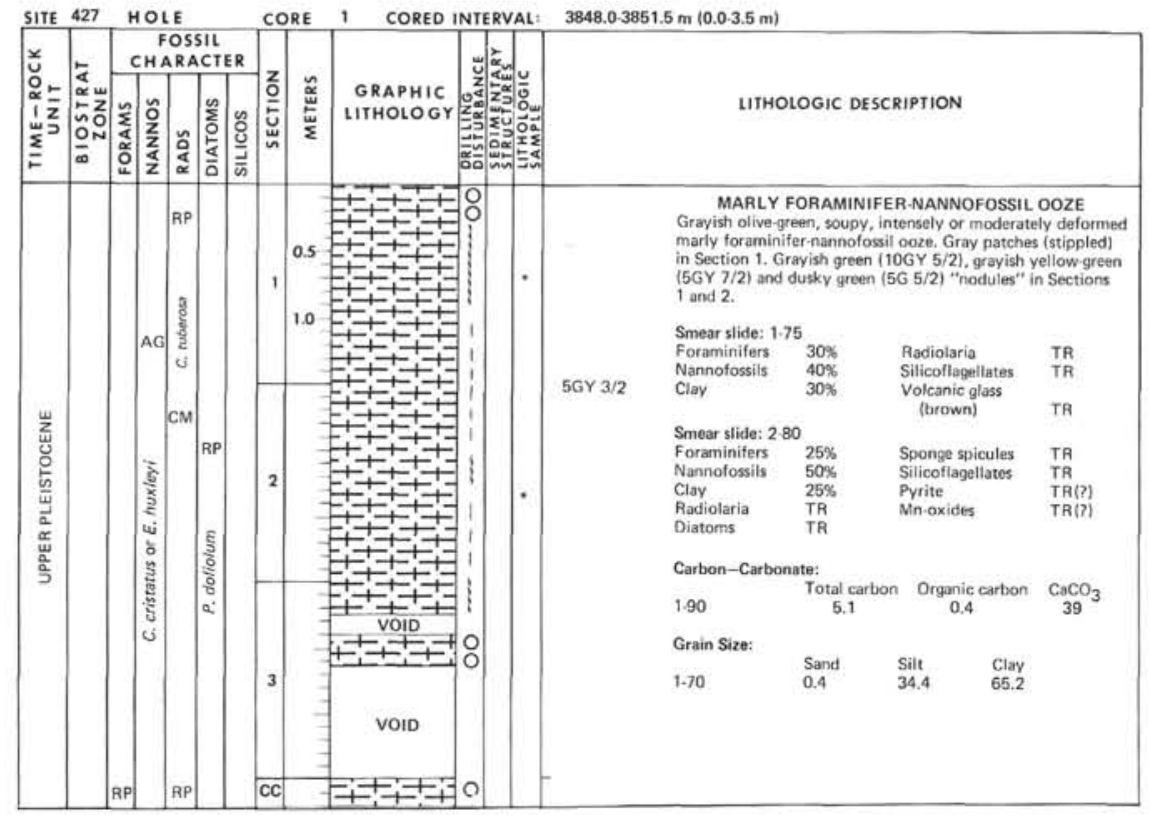

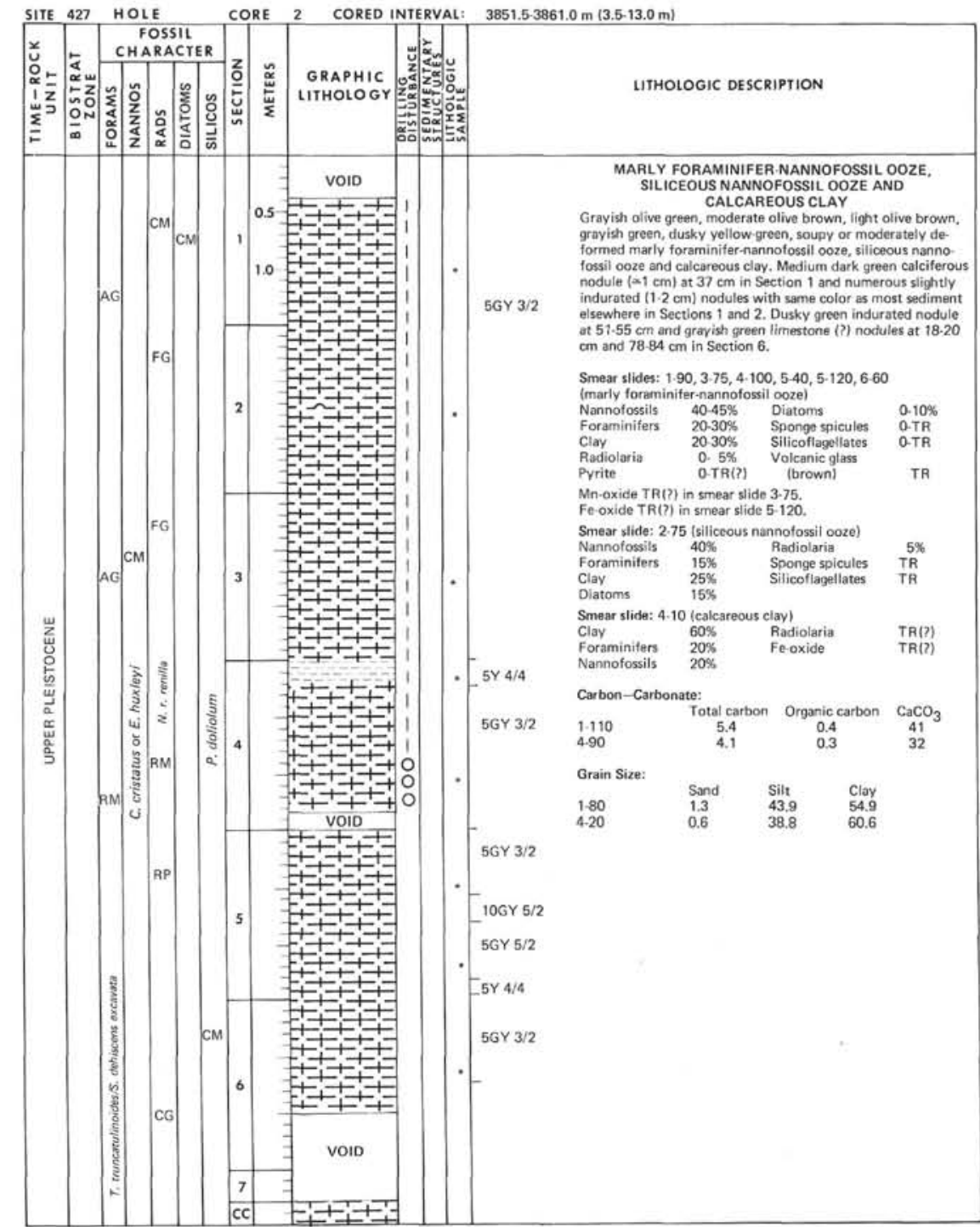




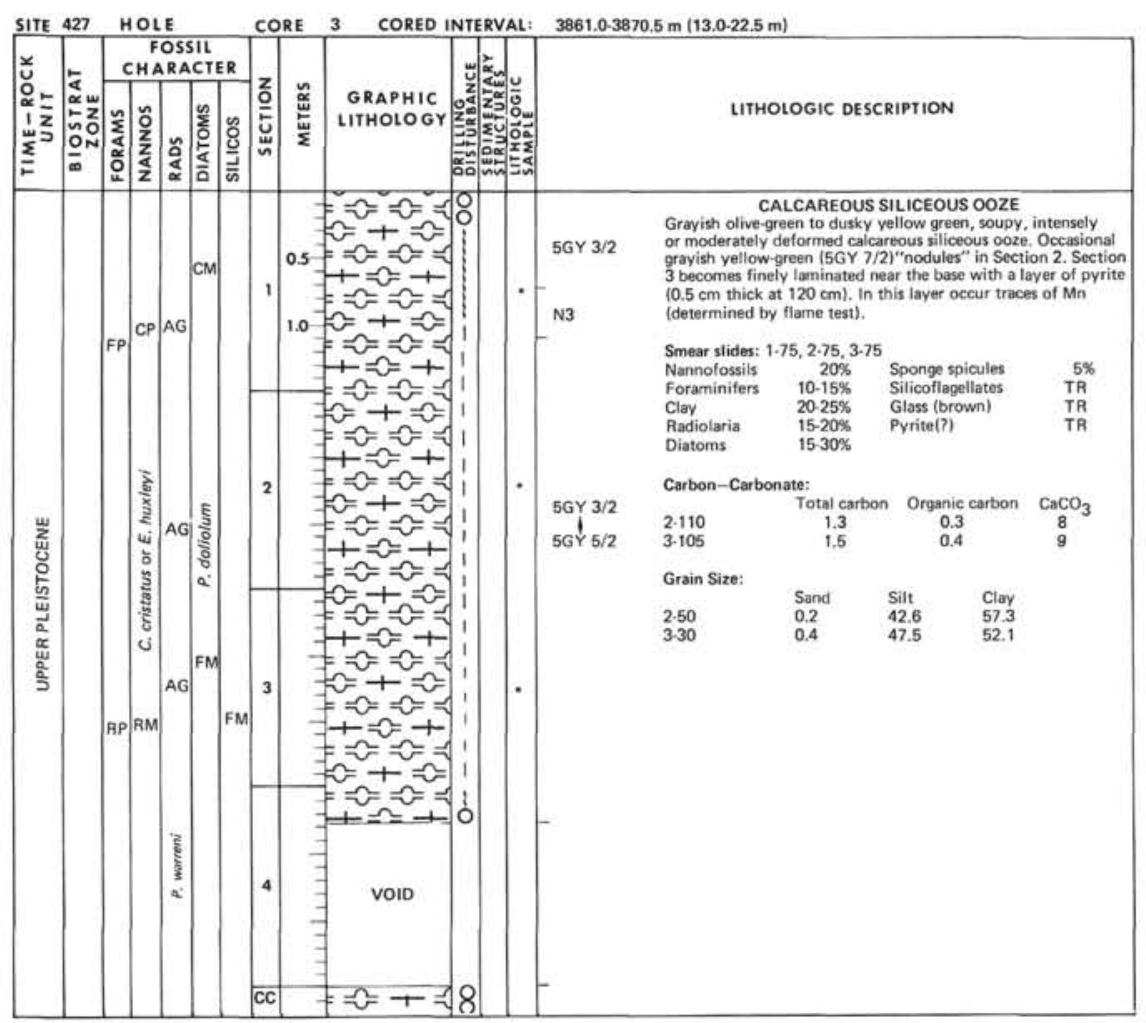

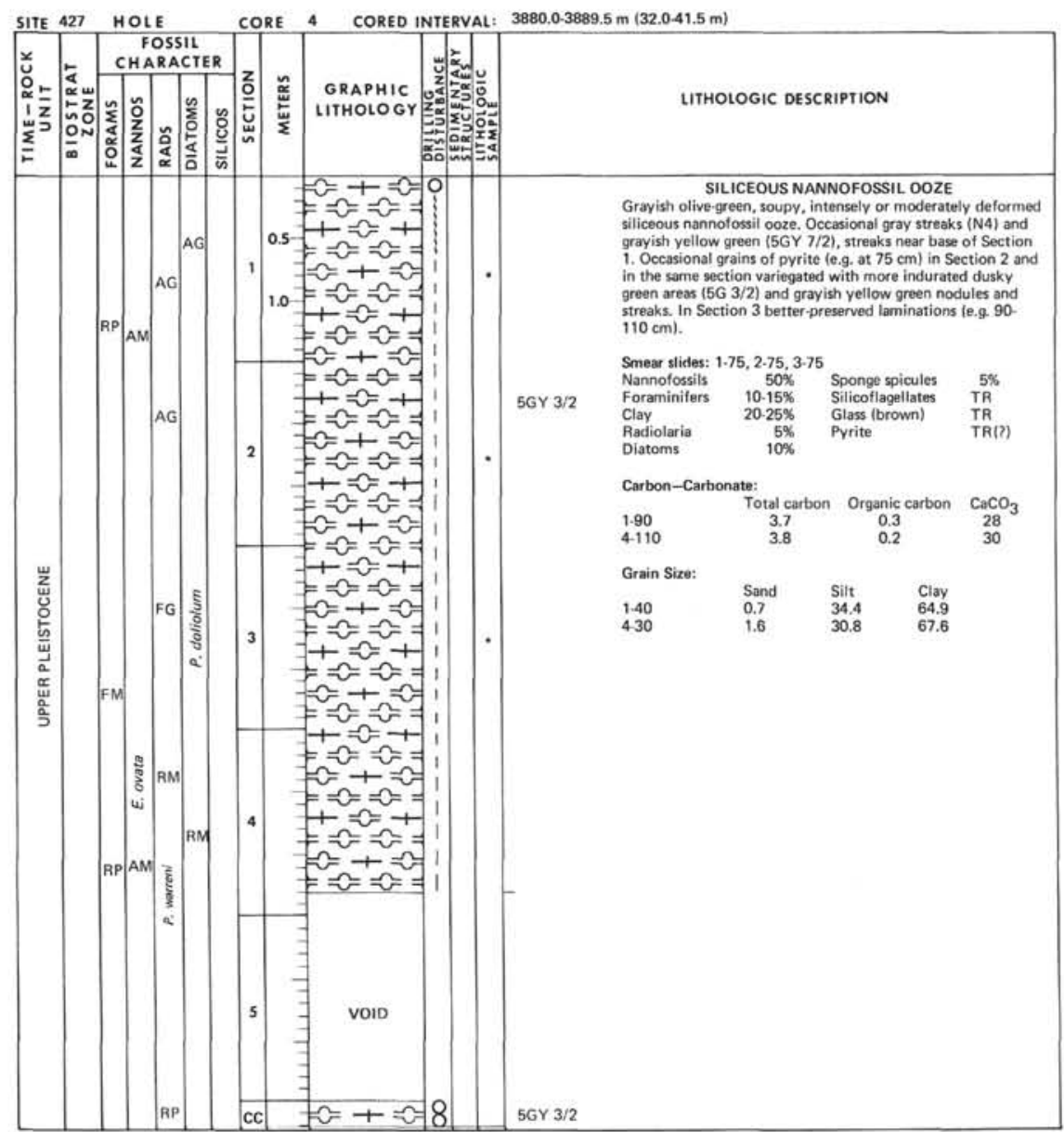



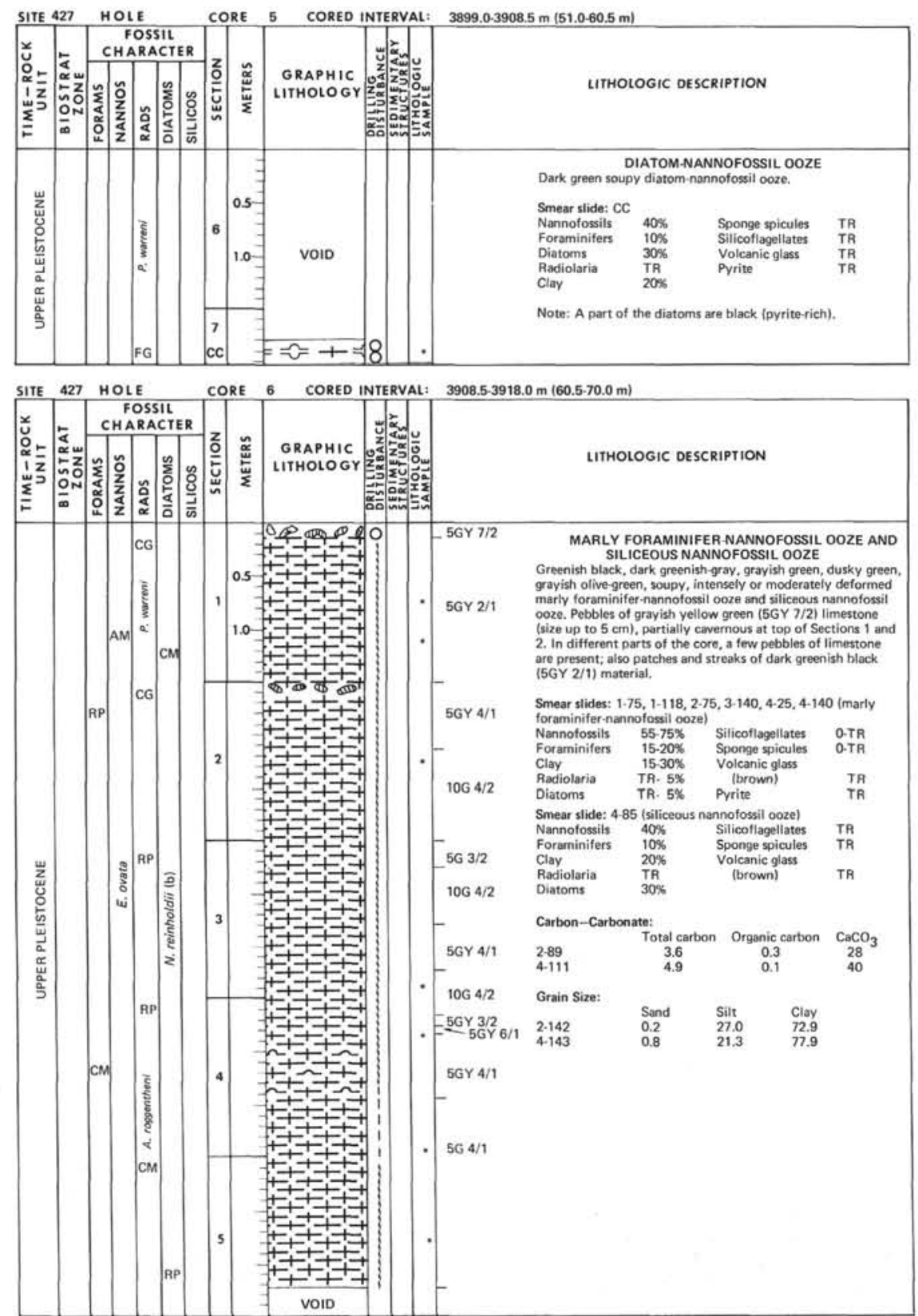

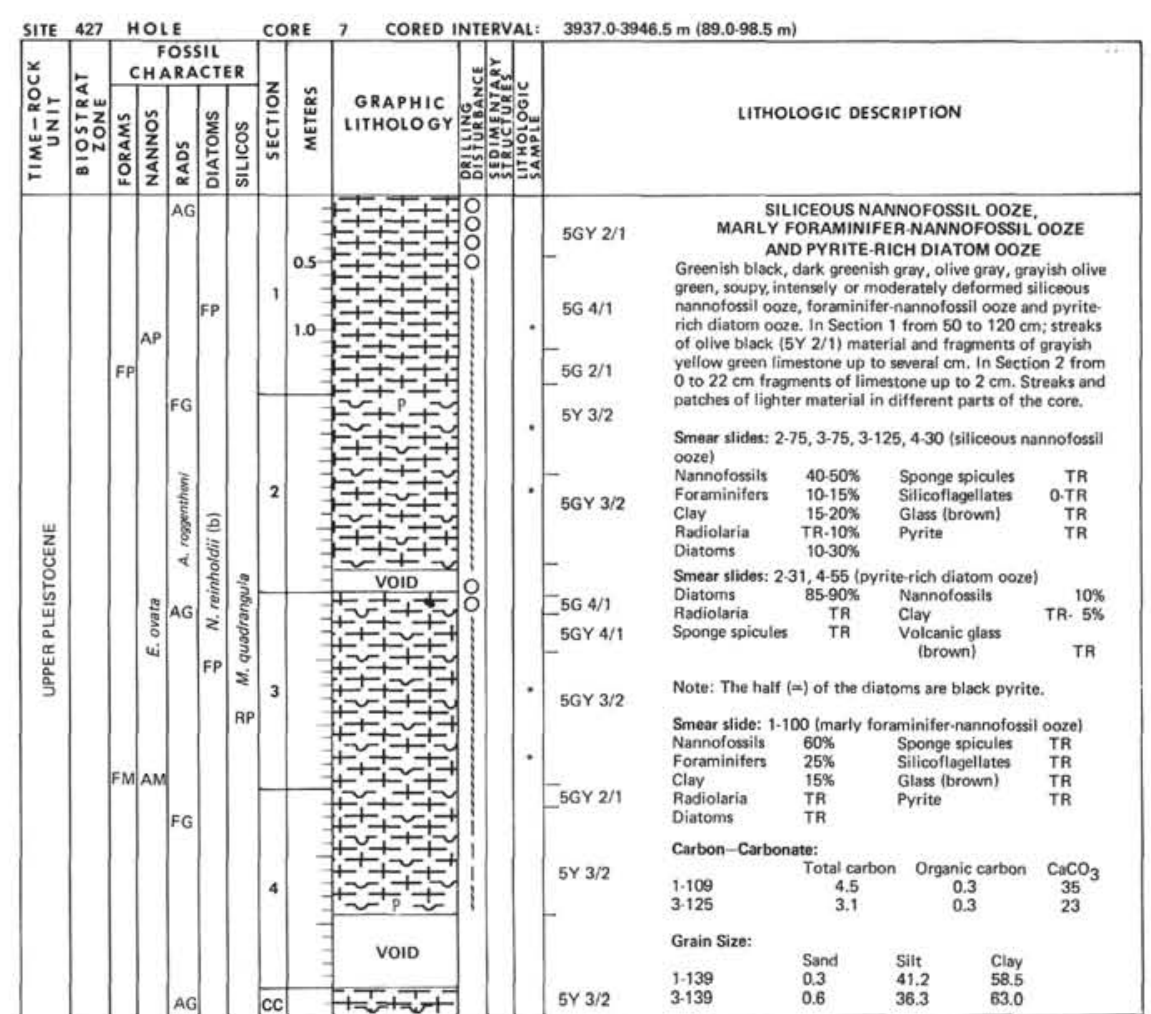




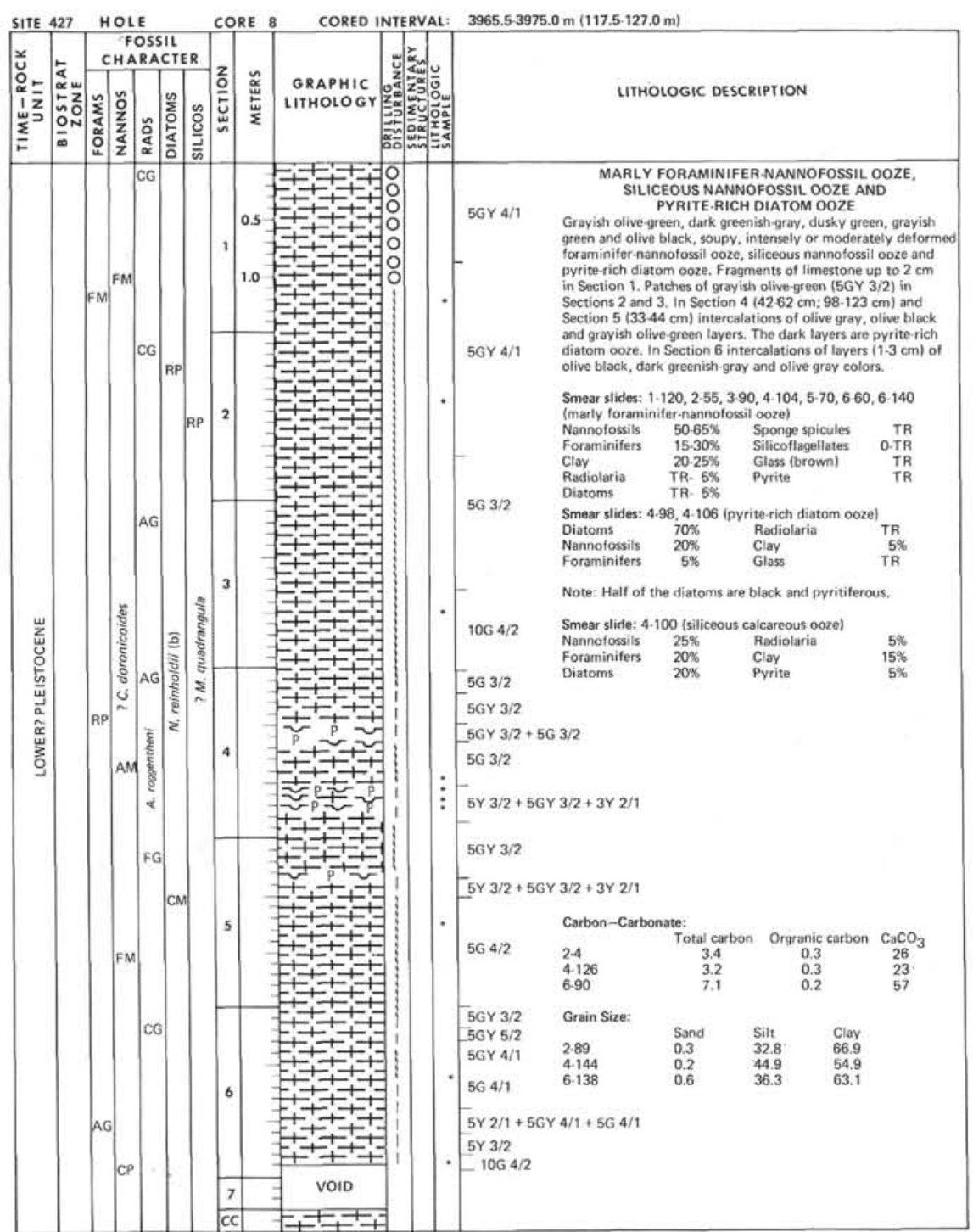




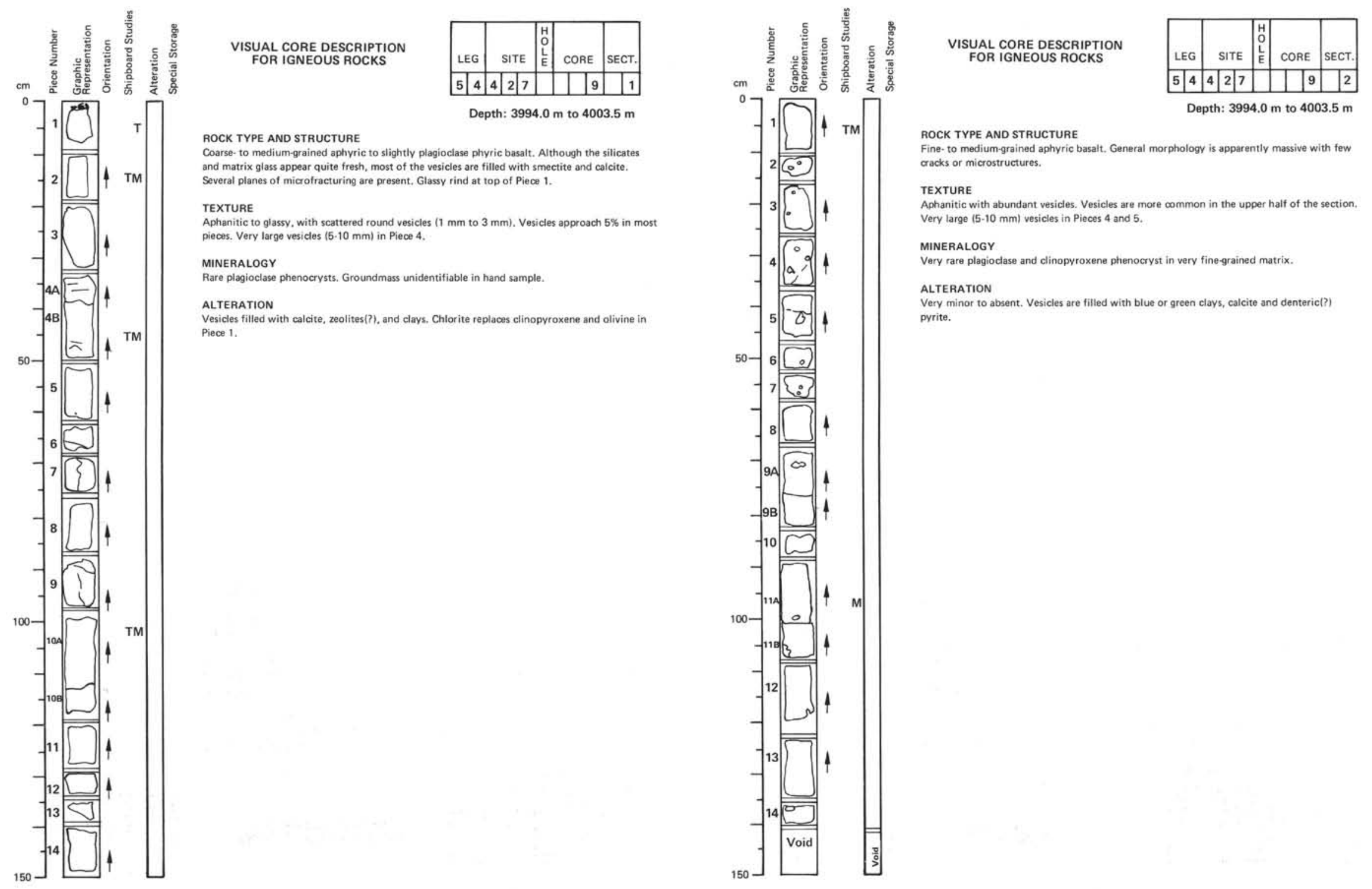




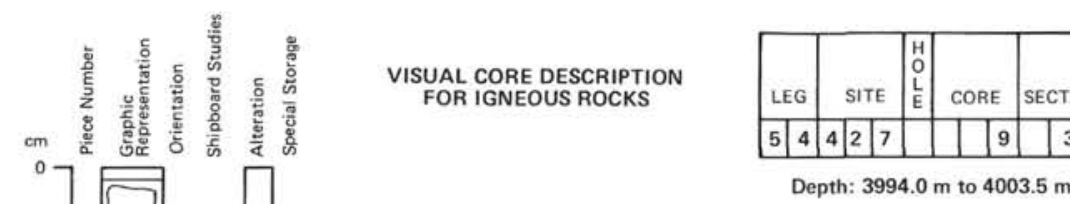

ROCK TYPE AND STRUCTURE Fine-grained aphyric bralt in upper $10 \mathrm{~cm}$ of section. Medium-grained buselt in remainder of section. Medium-grained basalt is sparsely plagioclase phyric

TEXTURE

scaitered throughout.

MINERALOGY

ALteration

green clay and zeolites (?)

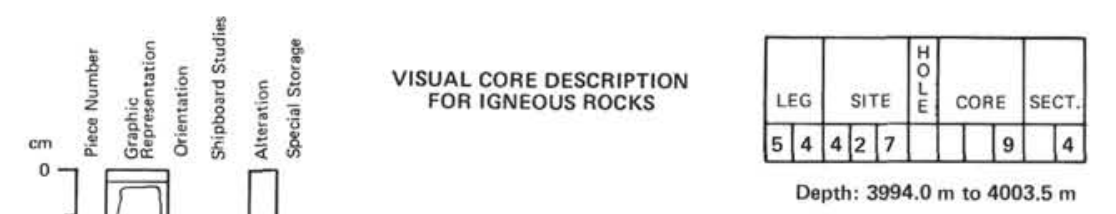

ROCK TYPE AND STRUCTURE

Depth: $3994.0 \mathrm{~m}$ to $4003.5 \mathrm{~m}$

TEXTURE

Aphanitic to glassy. Non-vesiculas.

MINERALOGY

Rare $1.2 \mathrm{~mm}$ plagioclase laths and subhedral dinopyroxenes. Large $(-1 \mathrm{~cm})$ plagioclase pheno-

arst in Piece 3.

ALTERATION

Fresh.

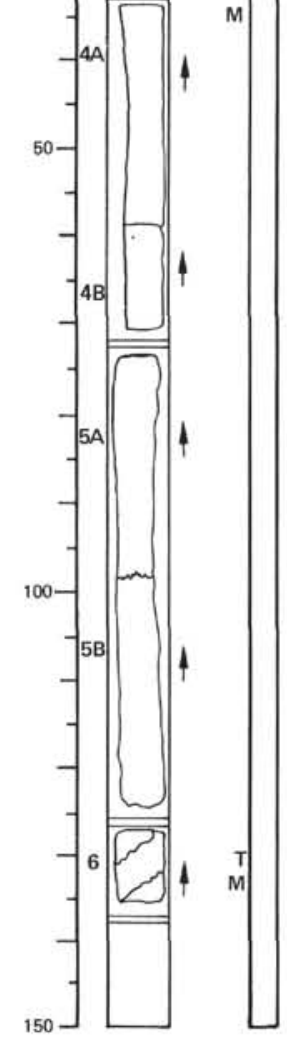



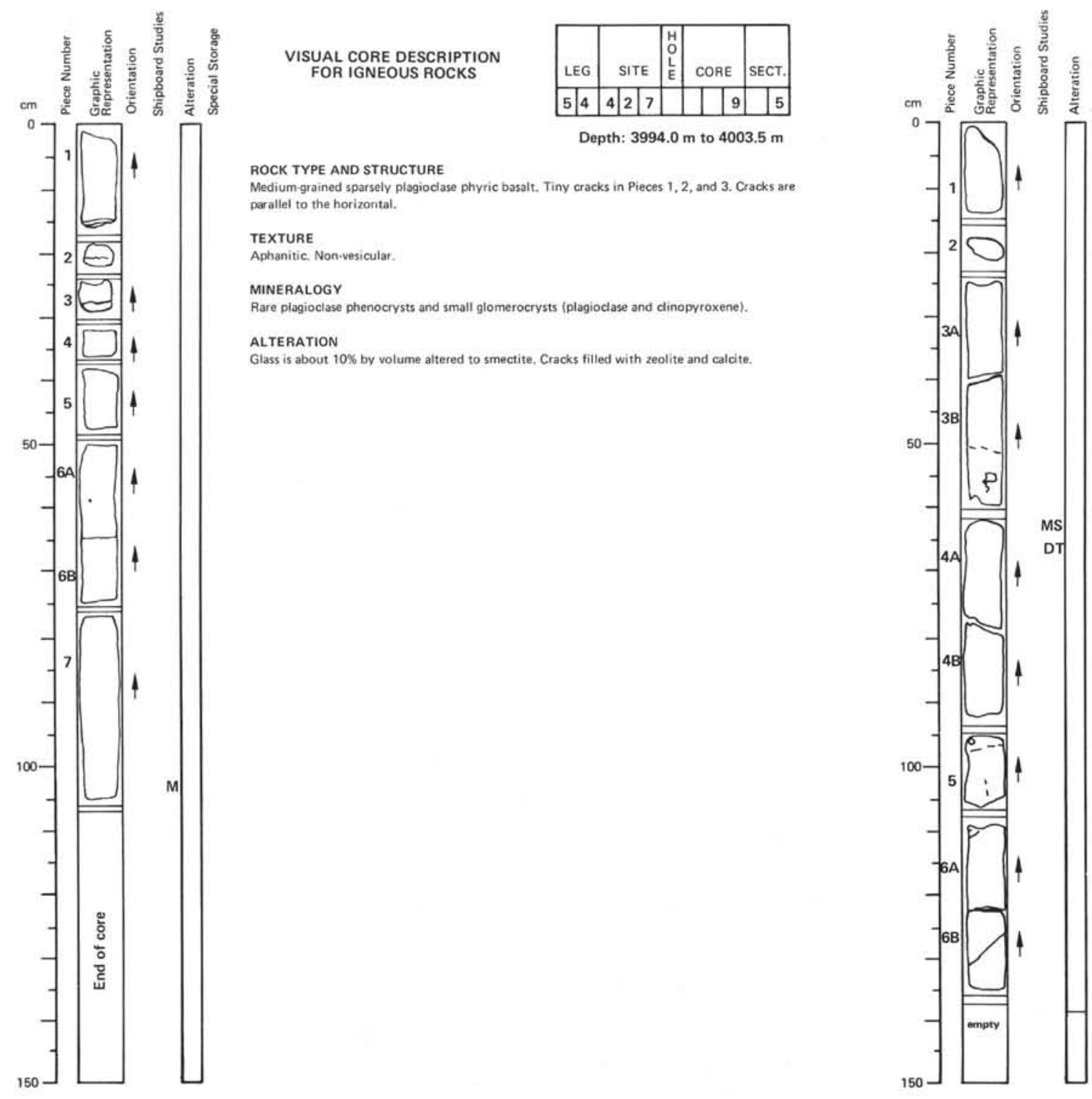
VISUAL CORE DESCRIPTION FOR IGNEOUS ROCKS

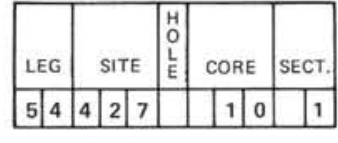
Depth: $4003.5 \mathrm{~m}$ to $4013.0 \mathrm{~m}$

ROCK TYPE AND STRUCTURE

The

TEXTURE

Very few tiny scattered vesicles. One large $13 \mathrm{~mm}$ ) vesicles in Piece 5 .

MINERALOGY

The

ALTERATION

Megascopically fresh appearance. In thin section, $5 \%$ of glass altered to clay and iron oxide. 


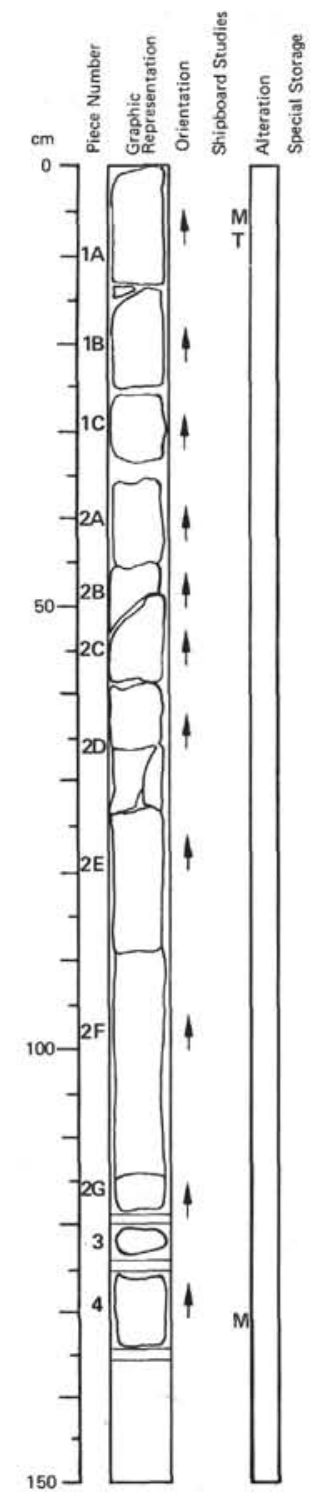

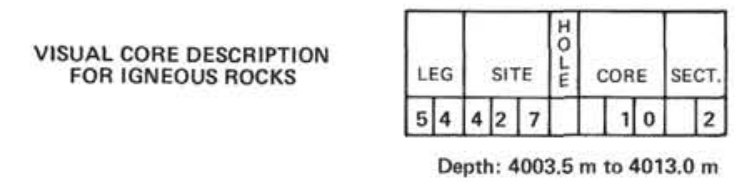

ROCK TYPE AND STRUCTURE

Entire section comprises medium-grained aphyric basalt. No noticeable joints, fractures, or other structural elements.

TEXTURE

Aphanitic to glassy, non-vesicular.

MinERALOGY

Very rare plagiodase phenocrysts in fine-grained to medium-grained matrix.

ALTERATION

Less than $1 \%$ of glass altered to clay. Calcite and brown clay coat and fill very rare vesicles.

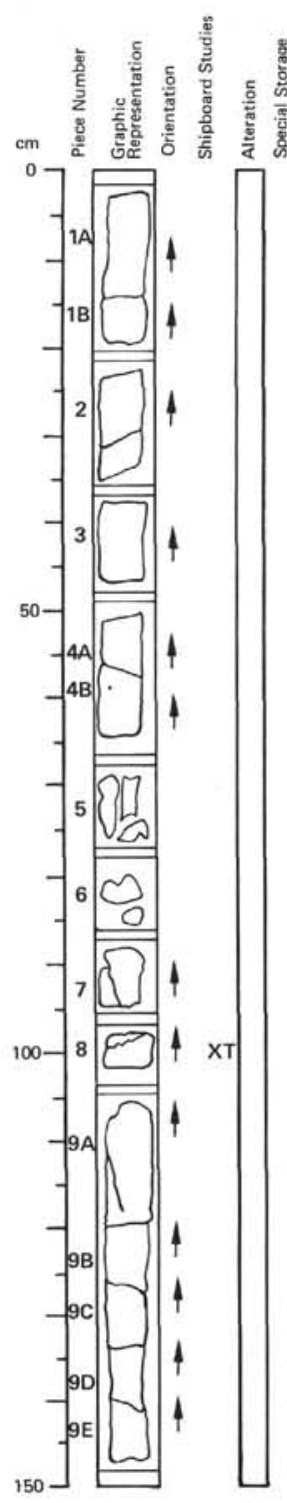

VISUAL CORE DESCRIPTION

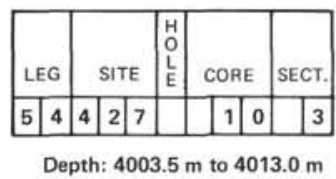

ROCK TYPE AND STRUCTURE

St. Fractures occur neariy (o) therizontal and steeply inclined $\left(\sim 80^{\circ}\right)$ to the horizontal:

TEXTURE

MINERALOGY

ALteration

ther coat fractures. 

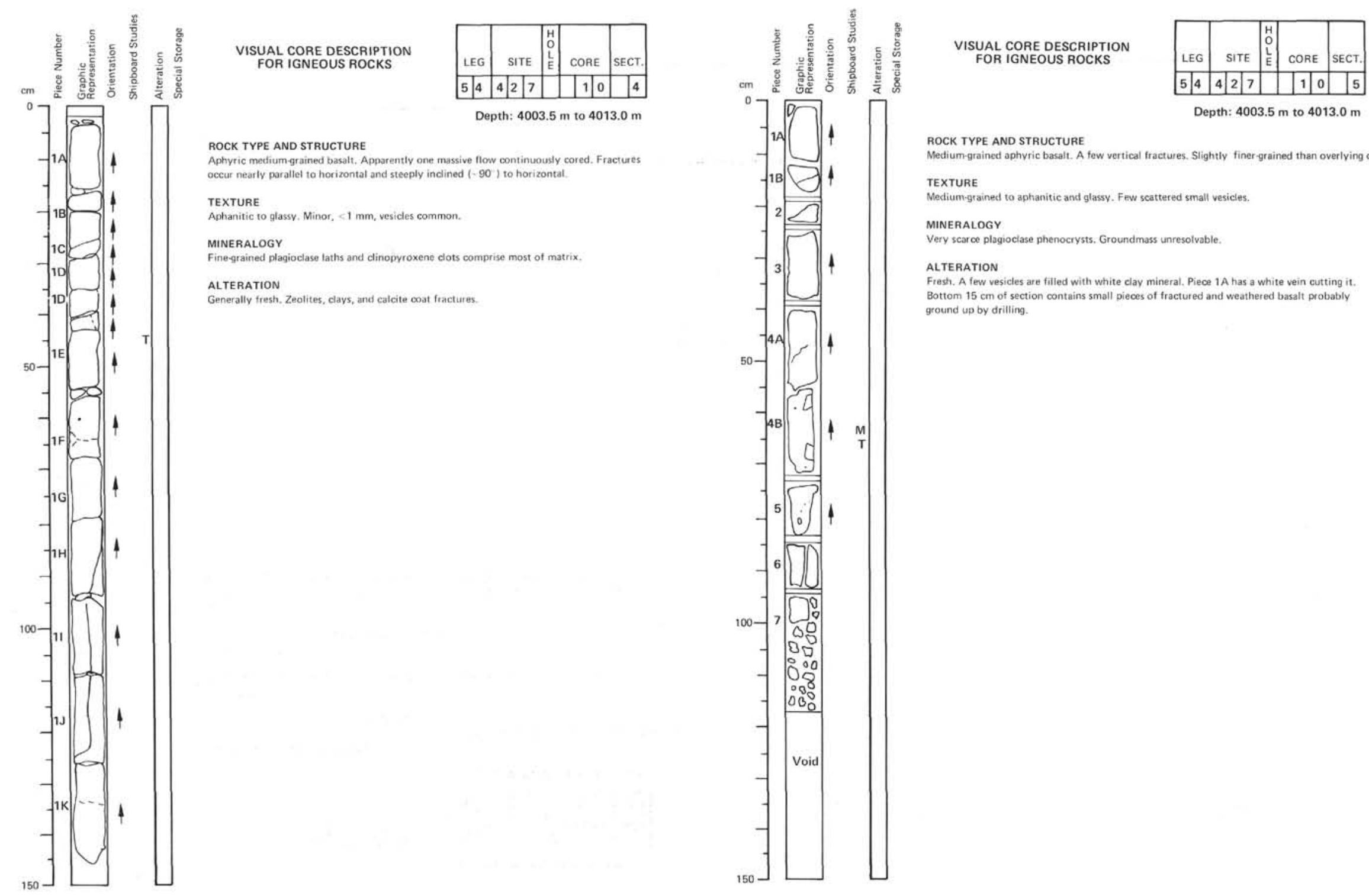

ROCK TYPE AND STRUCTURE

Medium-grained aphyric basalt. A few vertical fractures. Slightly finer-grained than overlying core.

TEXTURE

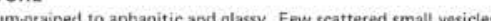

MineralogY

Very scarce plagioclase phenocrysts. Groundmass unresolvable.

ALTERATION

Piece 1 A has a white vein cutting it. Borim 


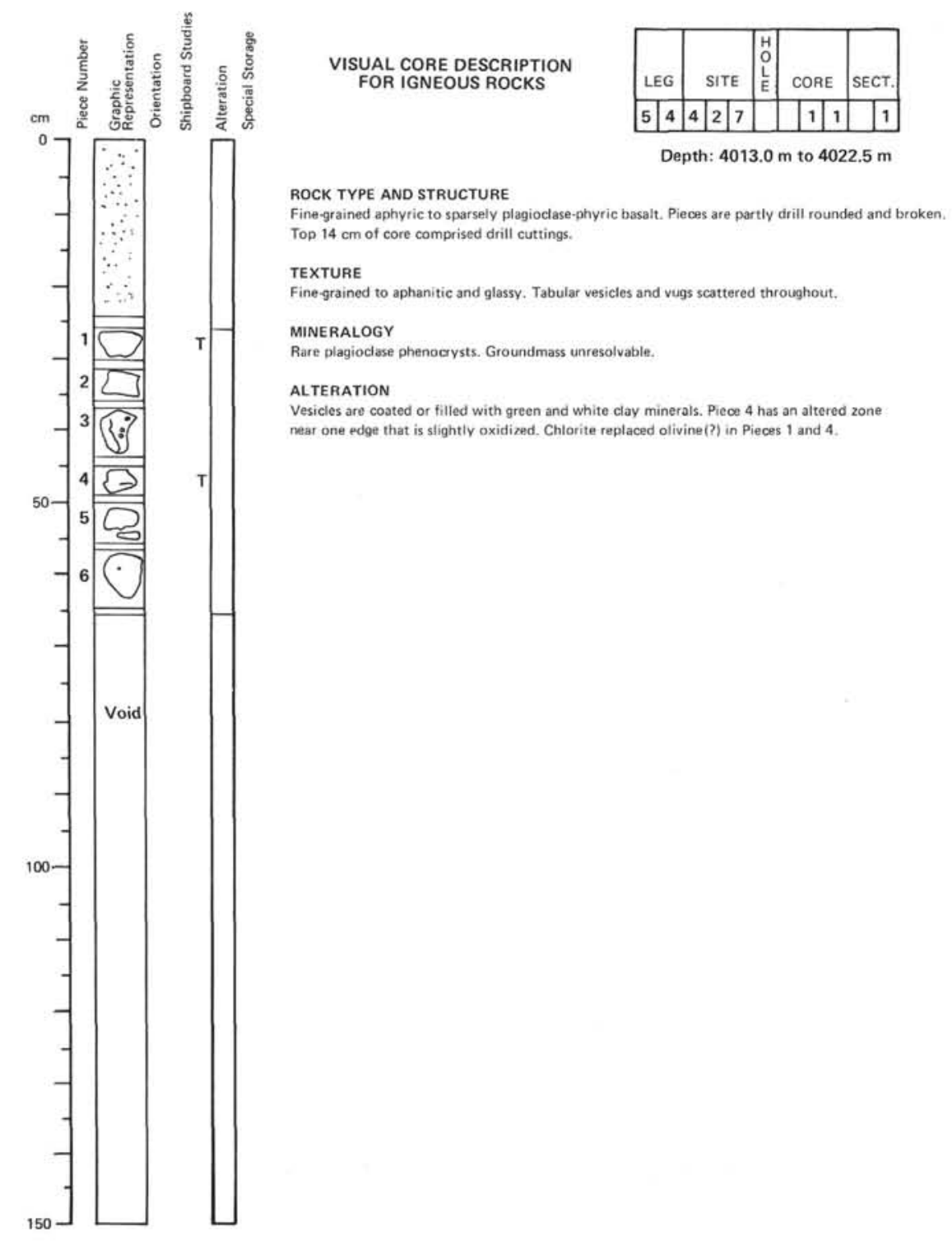

MINERALOGY

ALTERATION 


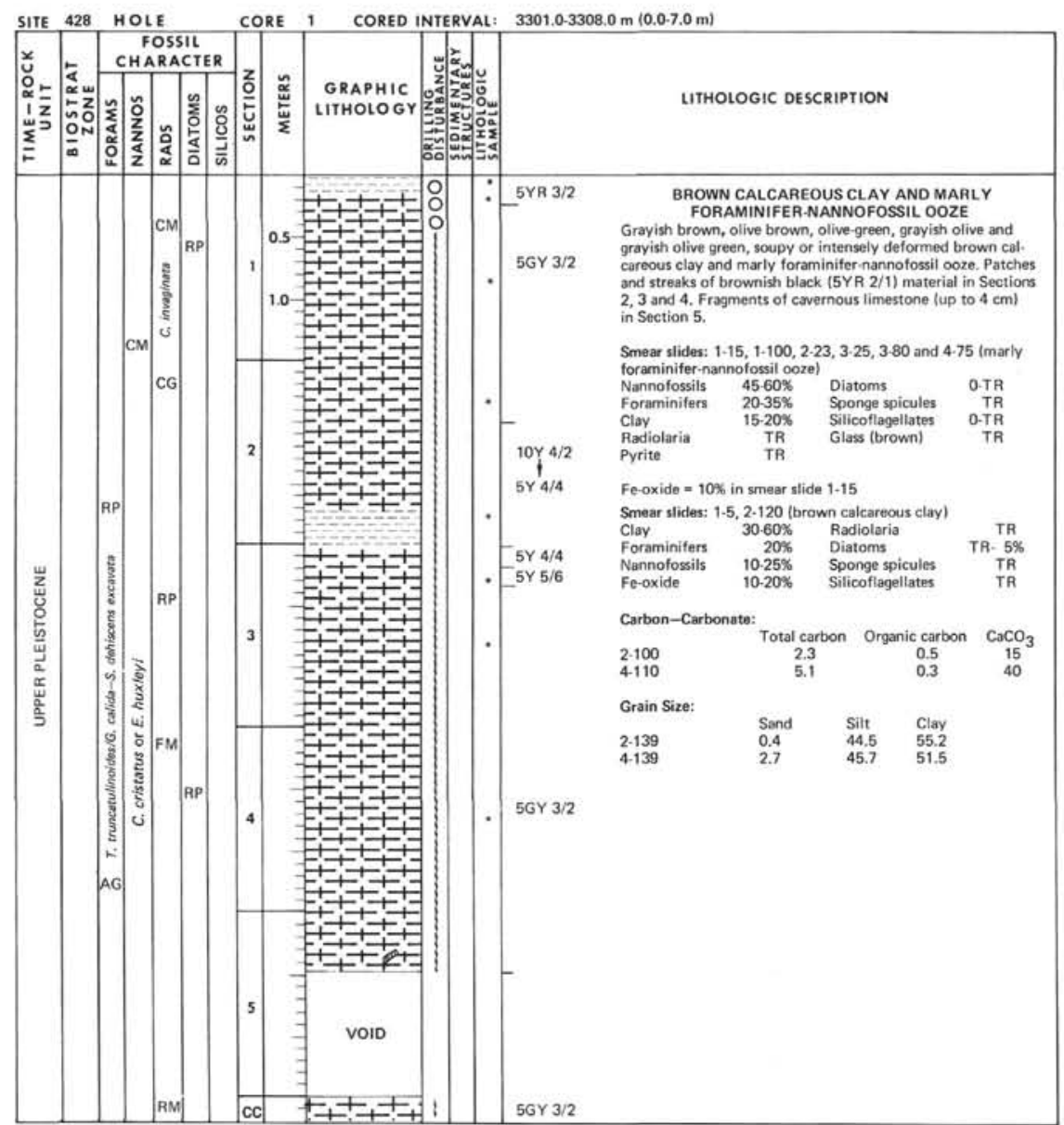

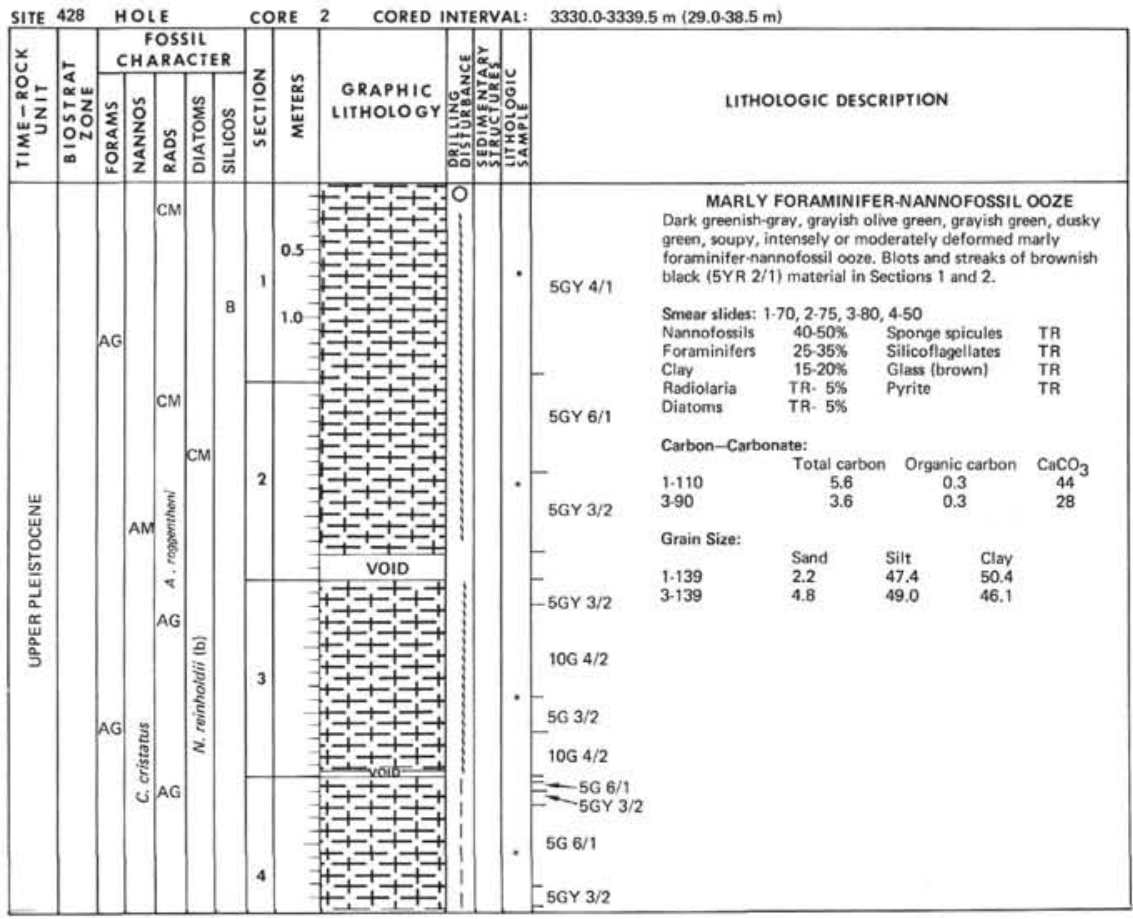




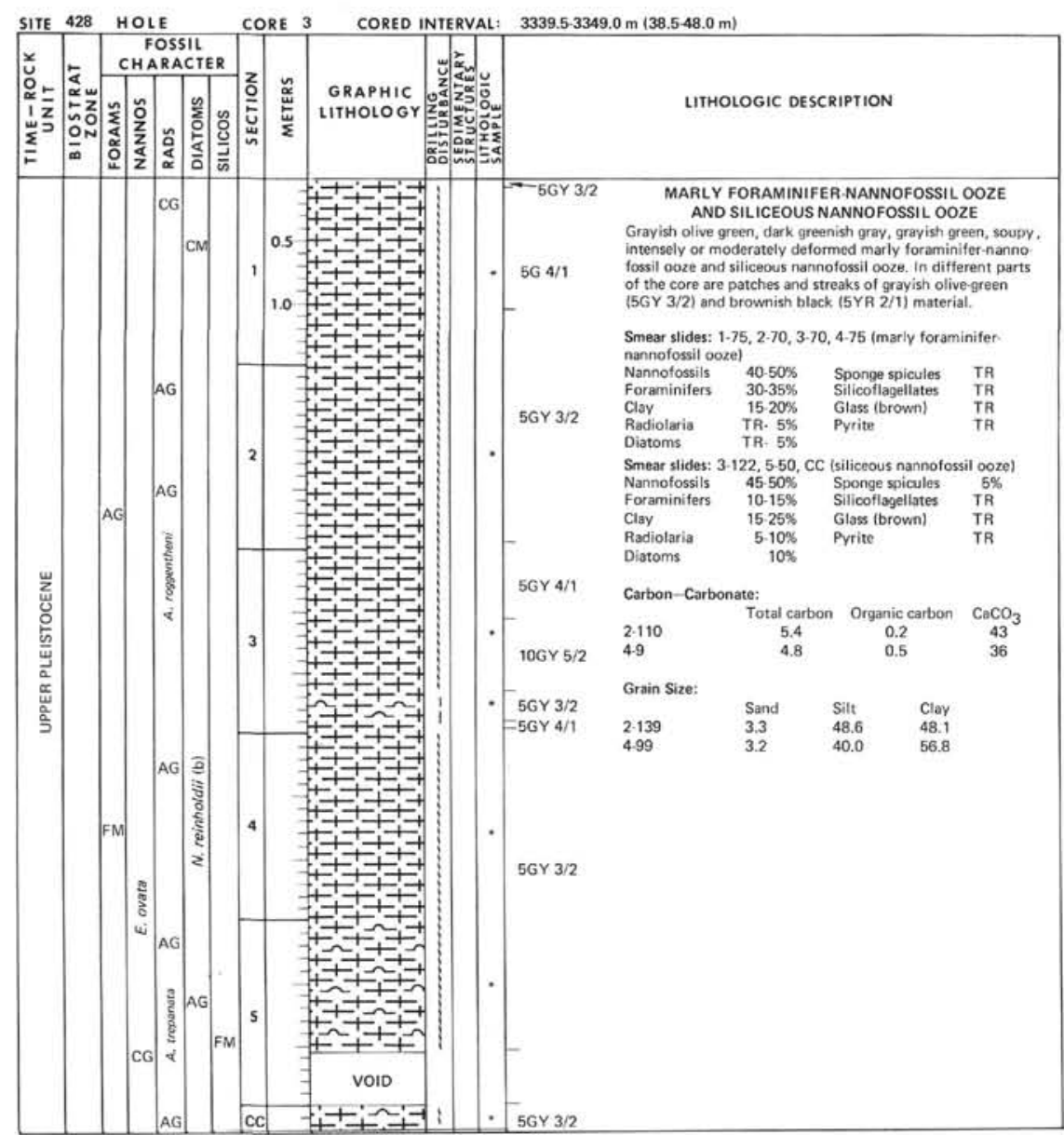

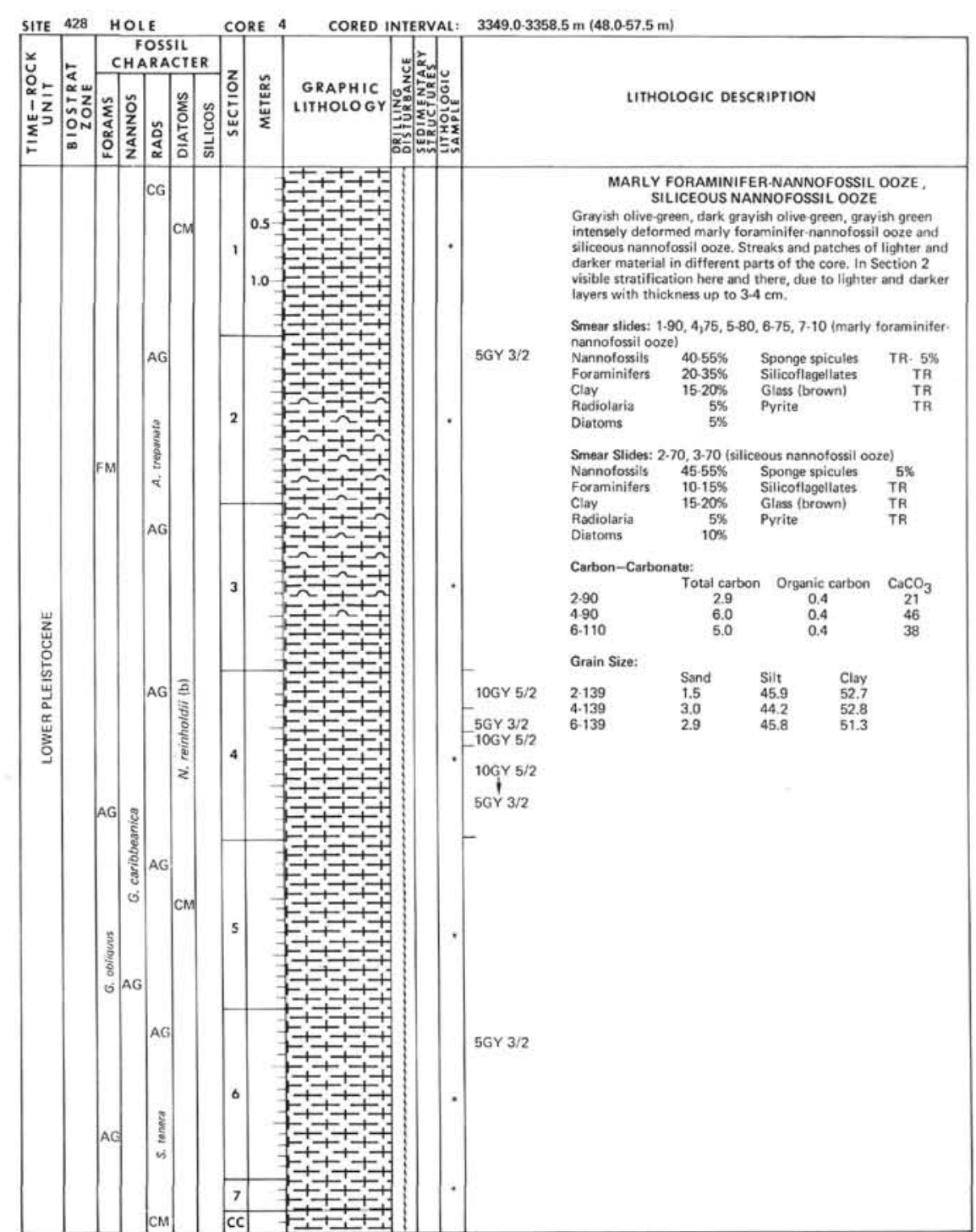




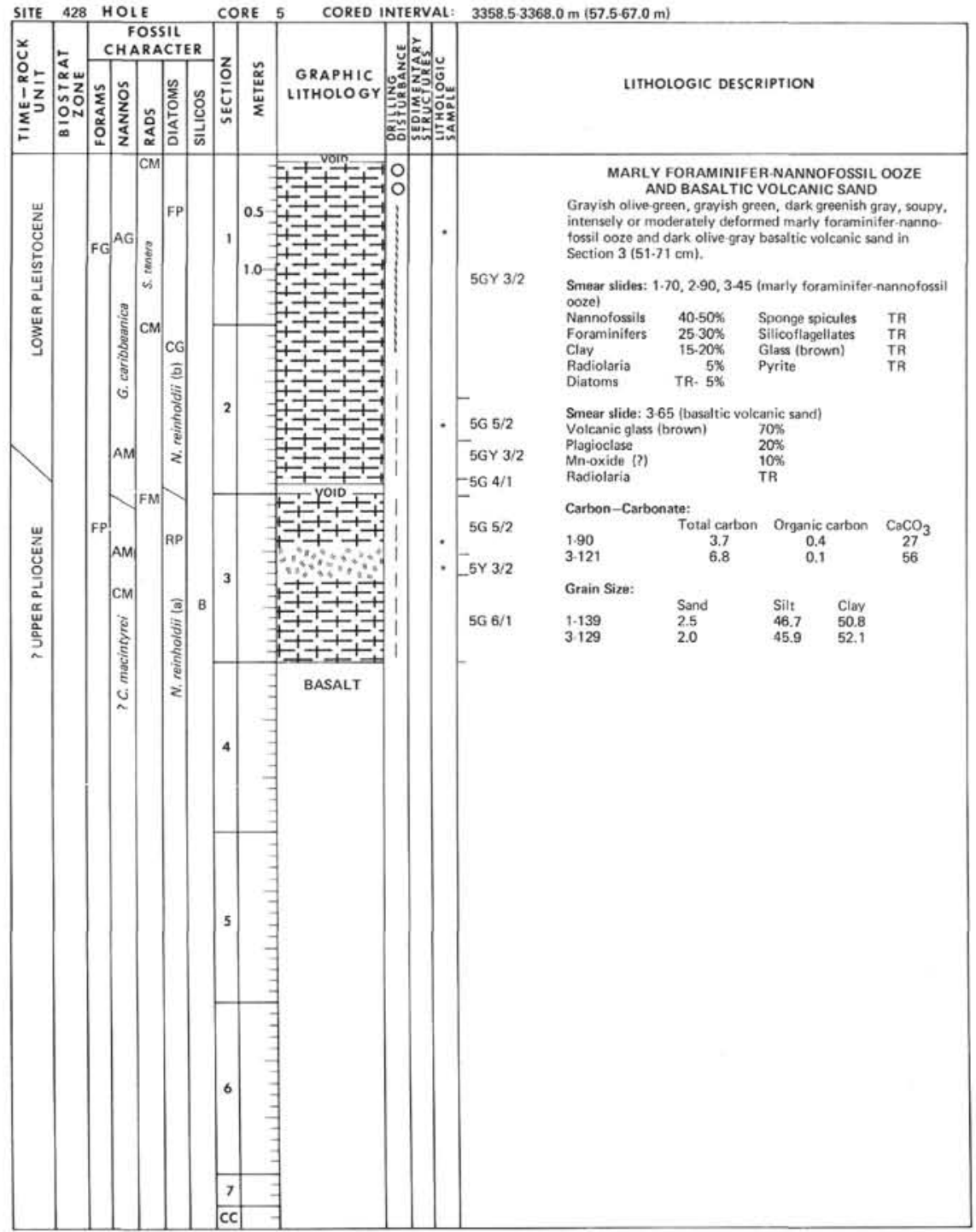




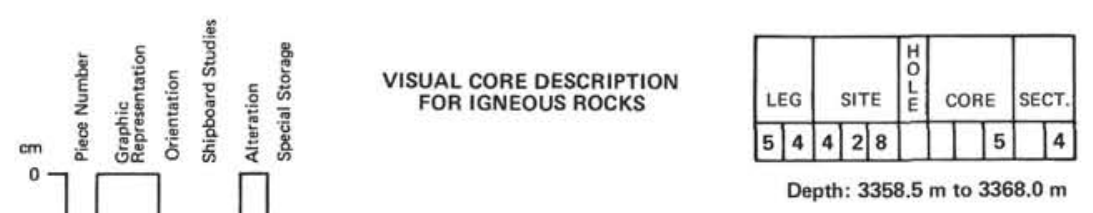

ROCK TYPE AND STAUCTURE is parallel to vertical joints in Pieces 8 and 10 .

TEXTURE

Aphanitic to glassy with scattered, $<1 \mathrm{~mm}$, vesicles.

MineraLogY

Olivine detectable in thin section as well as plagioclase and devitrified glass.

ALTERATion

Oxidation rinds in Piecos 8 and 10. Clay and/or calcite vesicle fillings common throughout. Glass

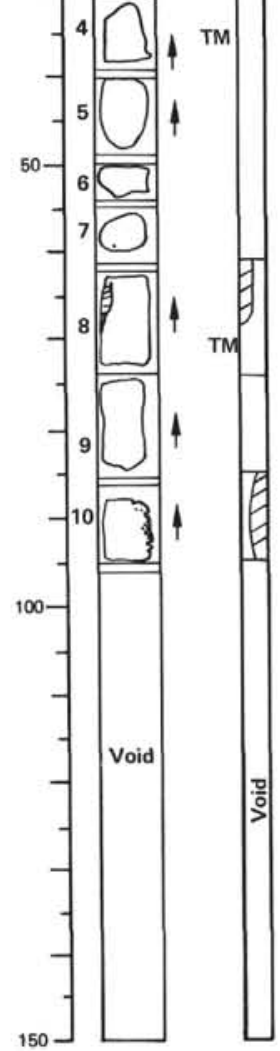

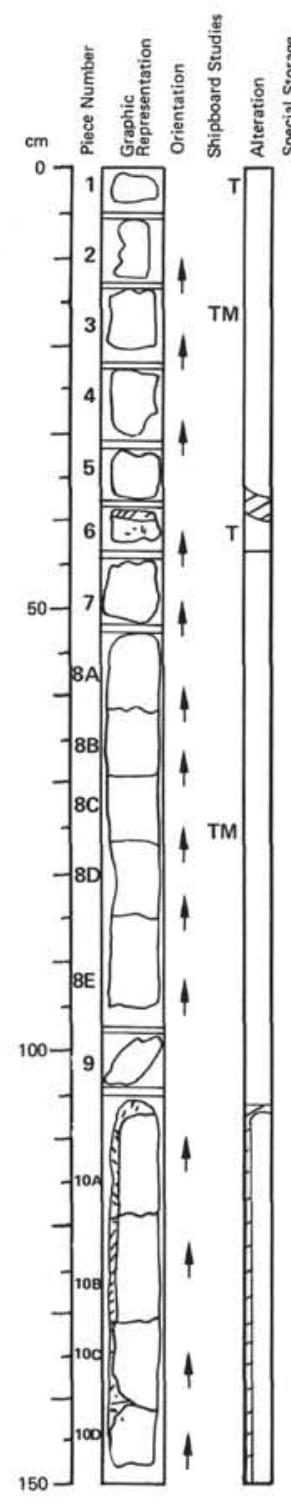

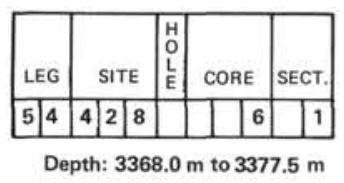

ROCK TYPE AND STRUCTURE

VISUAL CORE DESCRIPTION

Fine- to medium-grai $10 \mathrm{C}$, and 10D: horizontal fracture controls weathering in Piece 6. Vertical joints bound the left

TEXTURE

Aphanine and glassy to medium erained Scorialike structures in altered rind of Piece 6. Large Asides confined to Piece 6, small vesicles scattered throughout.

MineRALOGY

Olivine, plagioclase, and clinopyroxene identifiable in thin section. Groundmass in glass

ALTERATION

Weathered, oxidized rind parallels joints in Piecess $6,10 \mathrm{~A}, 10 \mathrm{~B}, 10 \mathrm{C}$, and 10D. Vesicles partly filled with calcite in Sample 6. 


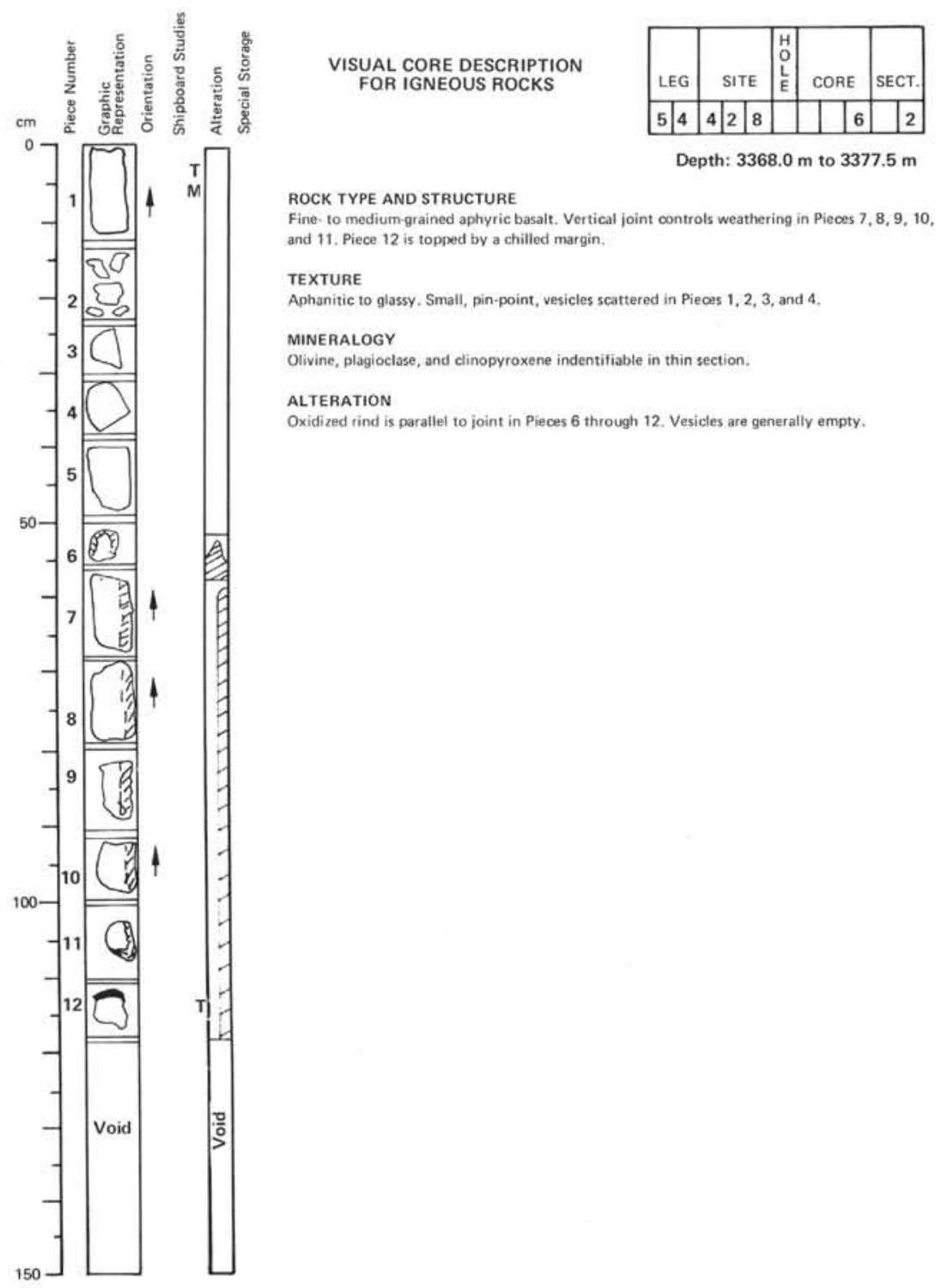




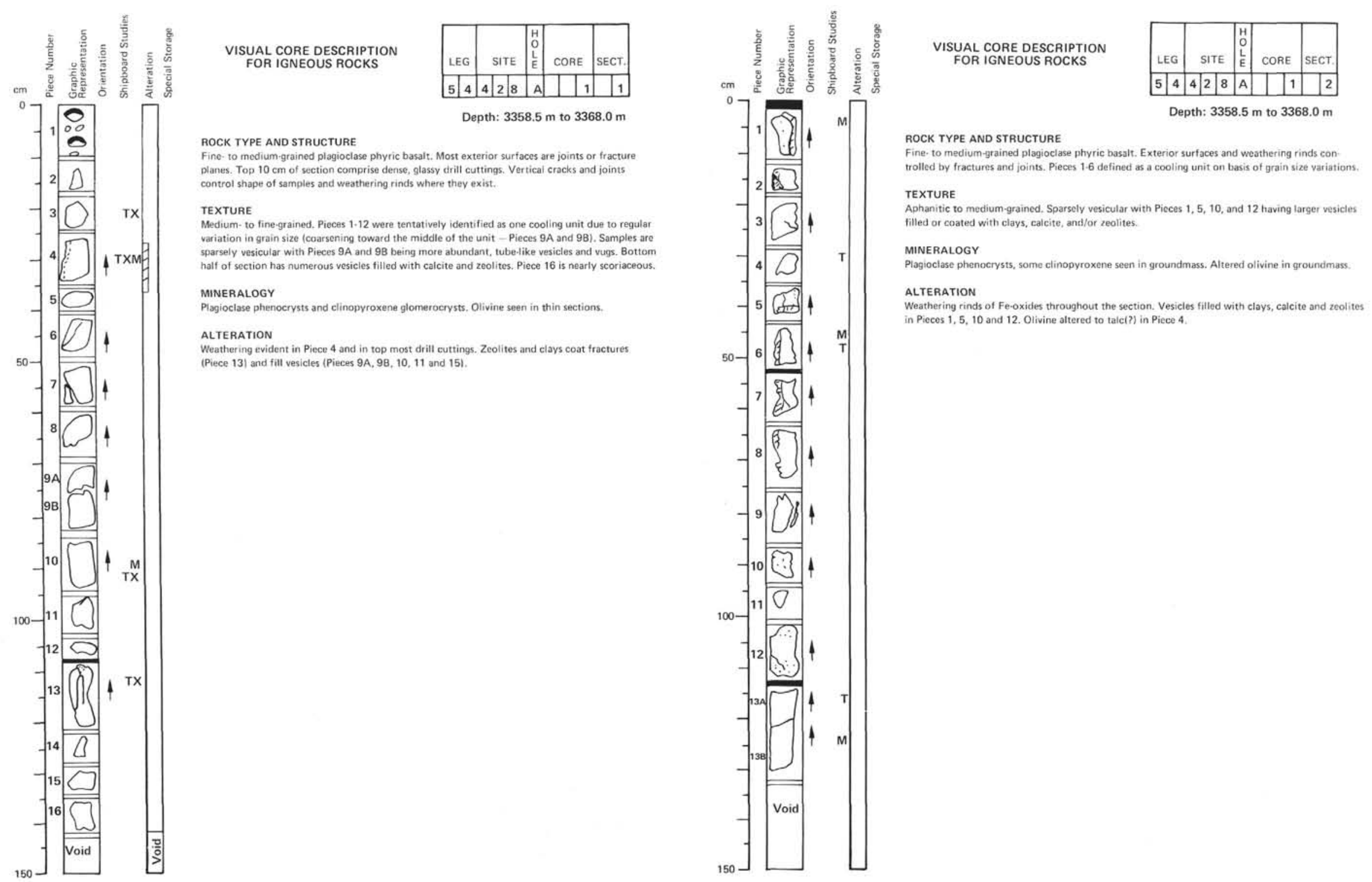
.

Medium. to fine-grained. Pieces 1.12 were tentatively identified as one cooling unit due to regular MINERALOG

ALTERATION (Piece 13) and fill vesicles (Pieces 9A, 98, 10, 11 and 15). 

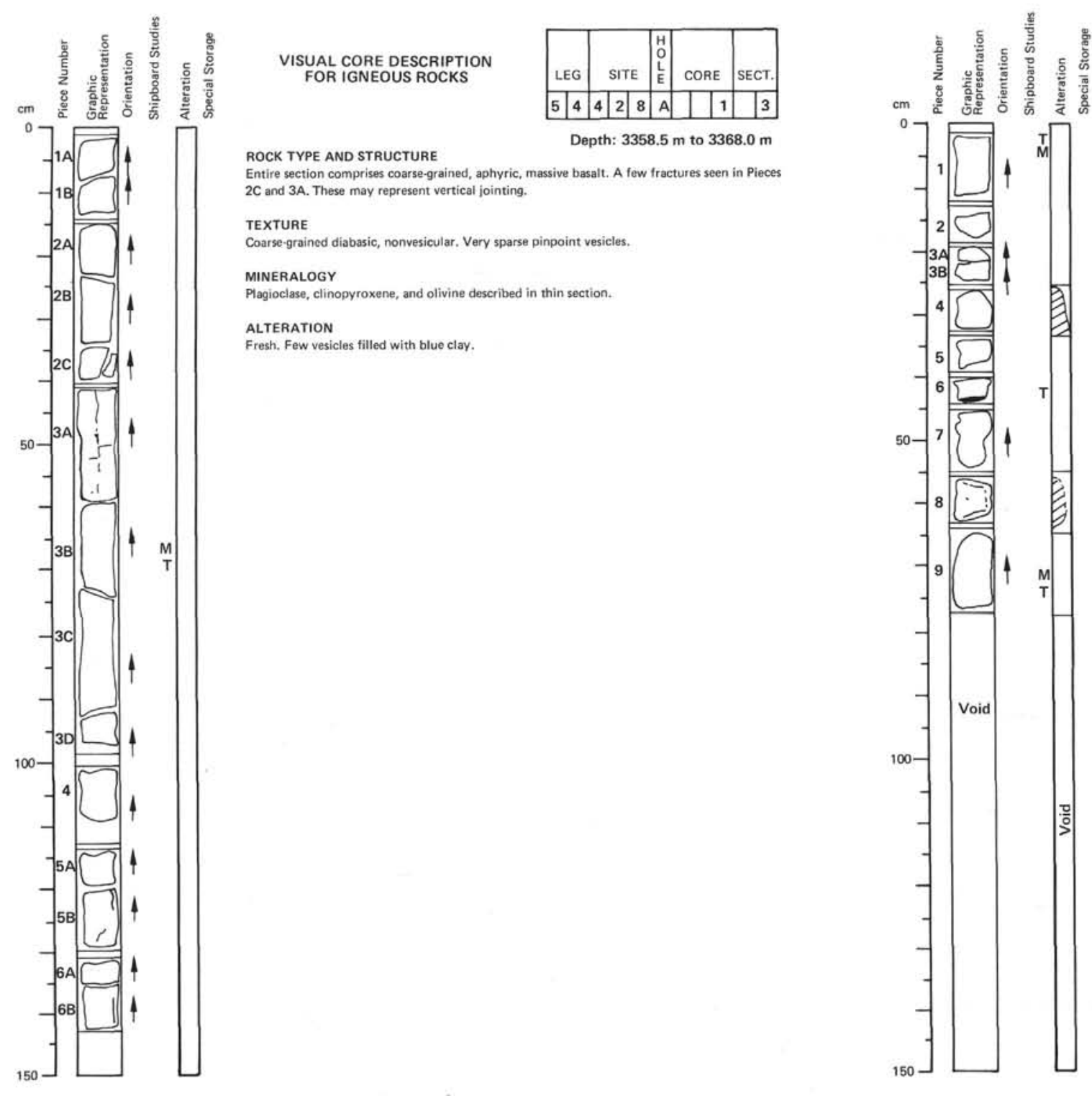

VISUAL CORE DESCRIPTION FOR IGNEOUS ROCKS

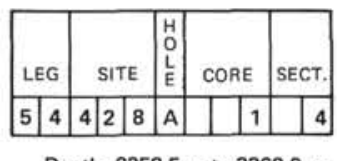

ROCK TYPE AND STRUCTURE

horizontal and does not control weathering. Glassy margin on unoriented Piecas

TEXTURE

Aphanitic with glassy segregations (Pieces 6 and 7) to medium-grained. Pinpoint vesicles scattered

throughout.

MINERALOGY

, clingection.

ALTERATION

almost completely weathered. Clay filled vesicles occur in Pieces 1, 3A, 3B, and 6. Piece 6 has a thin cooting of blue clay. 

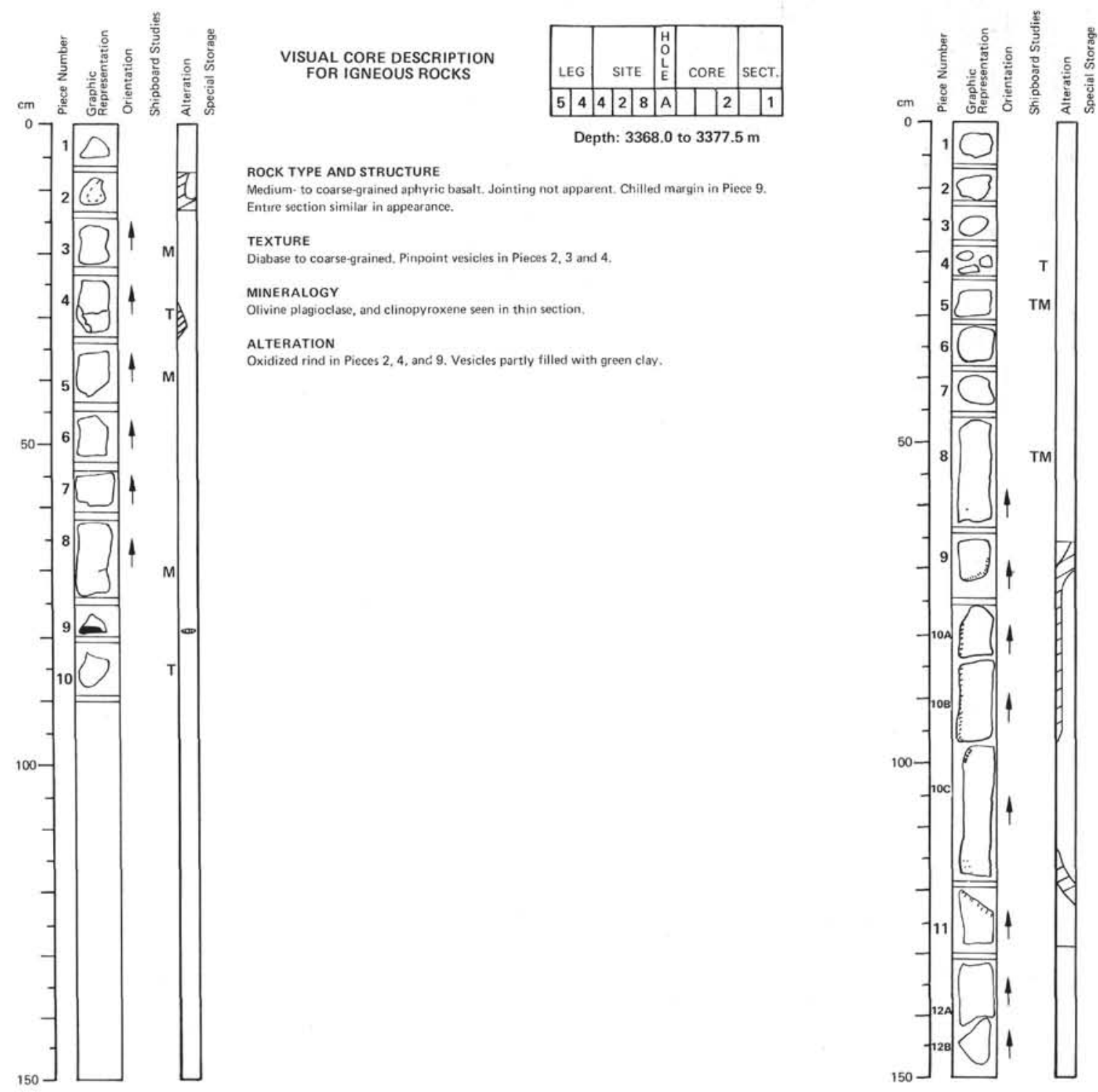

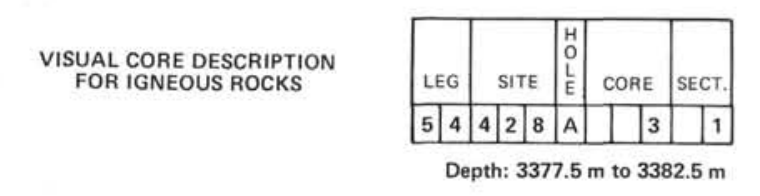

ROCK TYPE AND STRUCTURE

Entire section comprises very fine-grained, vertically jointed aphyric basalt.

TEXTURE

Aphanitic; rare, pinpoint vesicles.

MINERALOGY

Olivine, plogioclase, and clinopyroxene observed in thin section.

ALteration

Scattered vesicles filled with green/blue clay. Pieces 9 through 11 have weathered surfaces

parallel to fractures. 


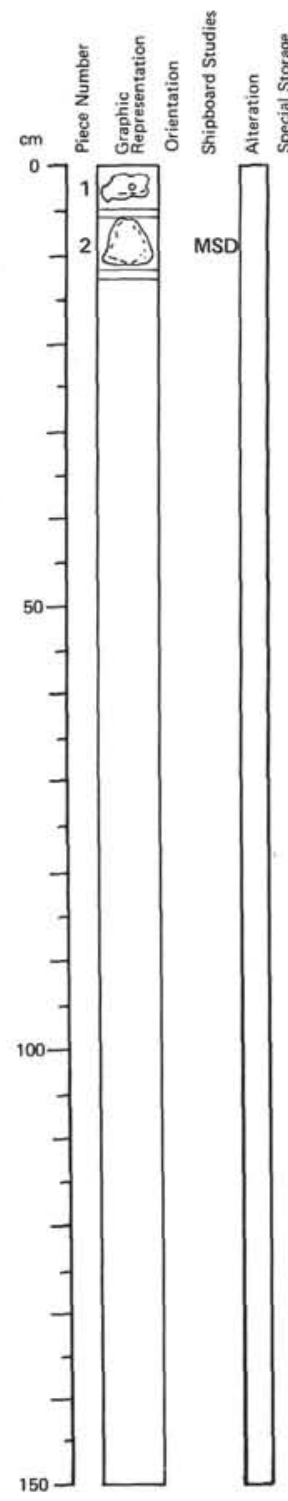

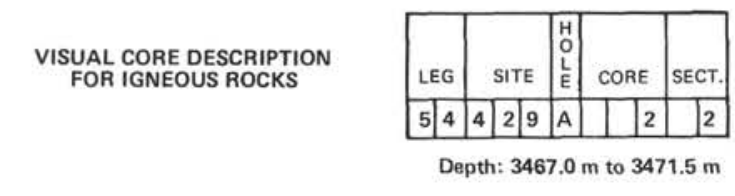

Fine-grained aphyric sparsely vesicular basalts. Both piecos have $0.5 \mathrm{~cm}$ alteration rinds, Fracture surfaces on these show a greenish yellow coating.

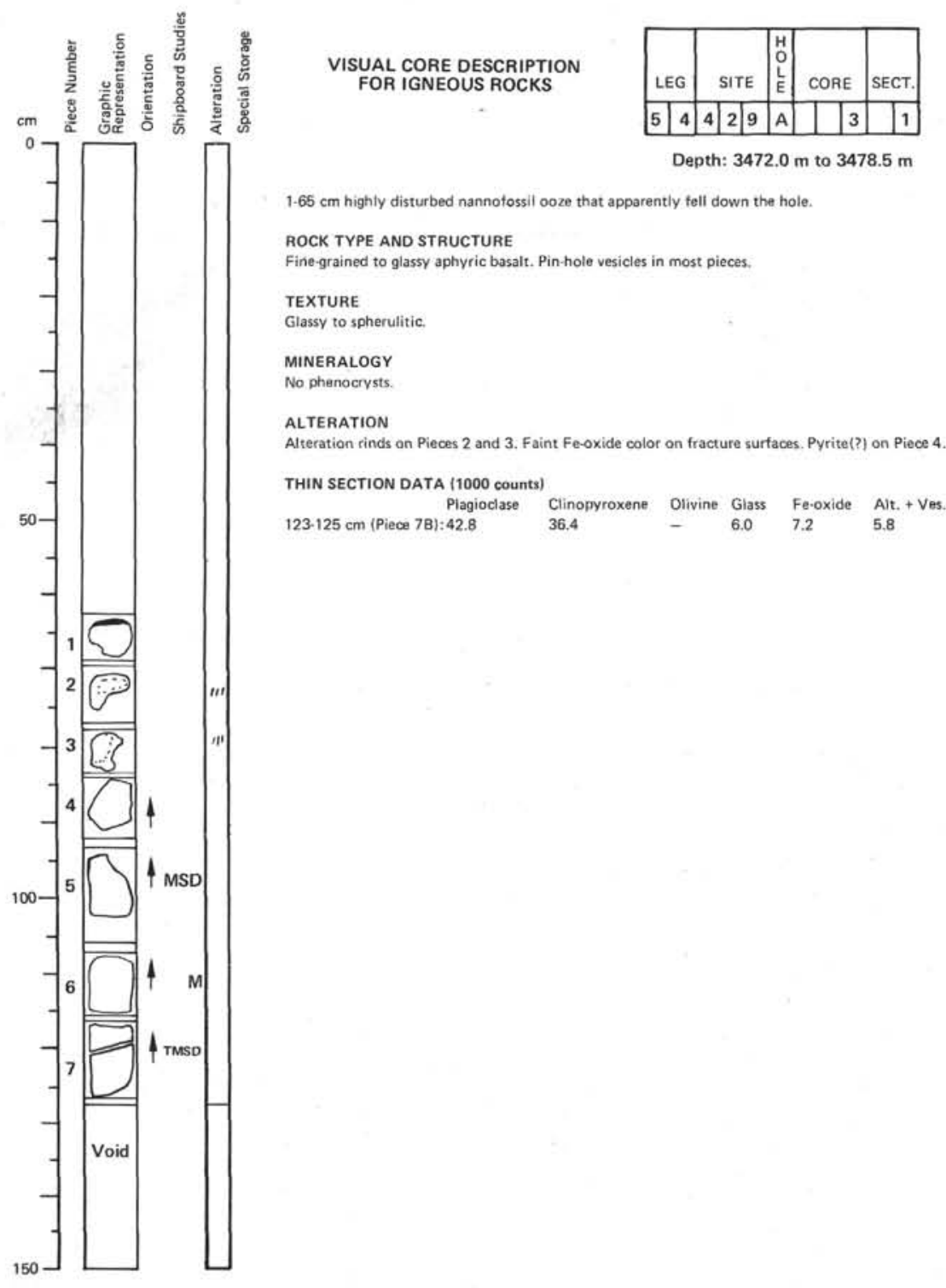



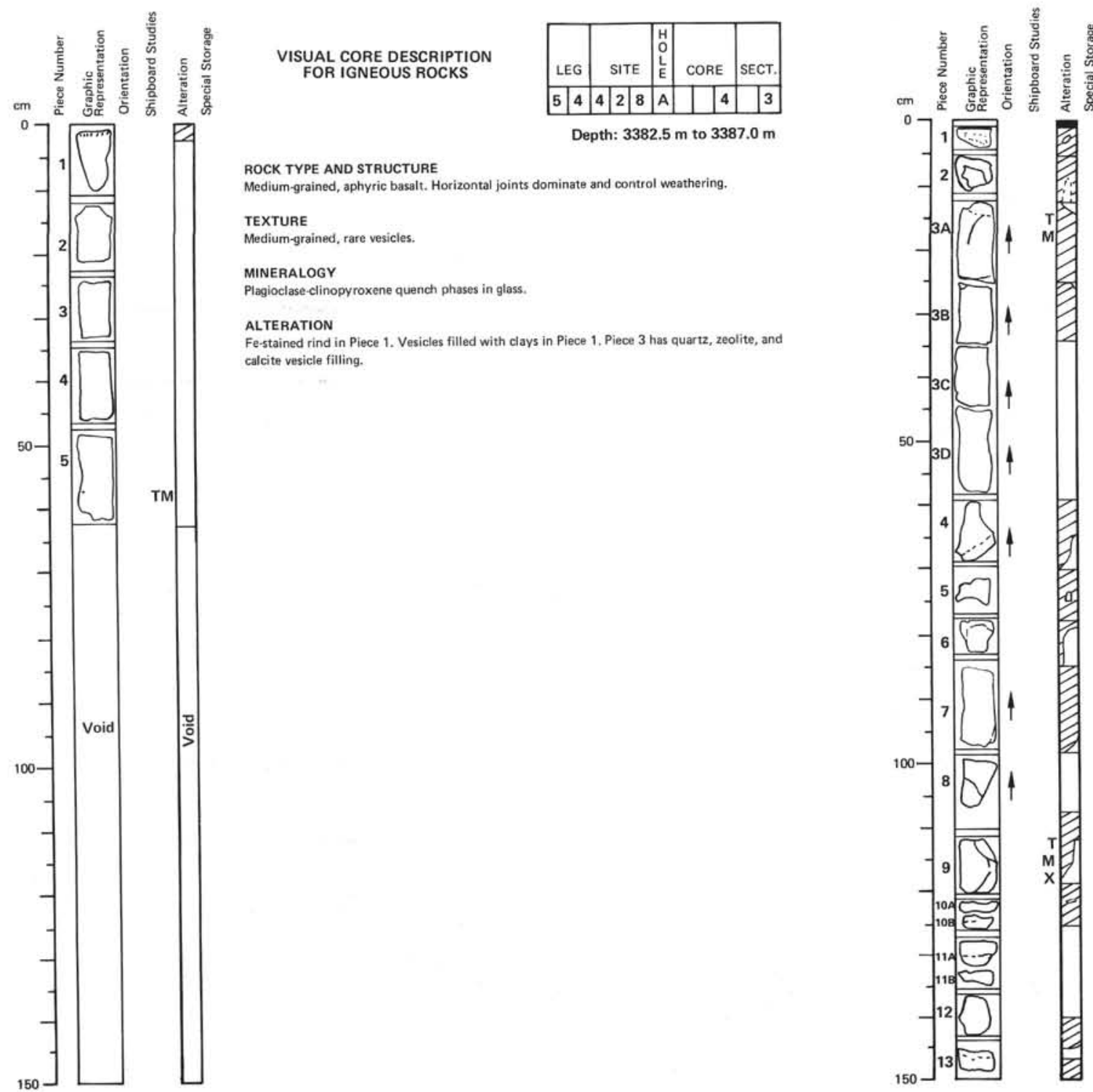

VISUAL CORE DESCRIPTION FOR IGNEOUS ROCKS

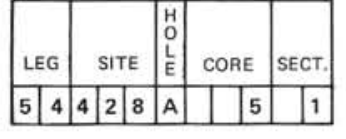

Depth: $3387.0 \mathrm{~m}$ to $3396.5 \mathrm{~m}$

\section{ROCK TYPE AND STRUCTURE}

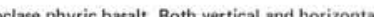
pints control weathering rinds, Chilled margin at top of Piece 1.

TEXTURE

A through 13 .

MINERALOGY

Plagioclase and clinopyroxene as phenocrysts and also as quench phases.

ALTERATION Weathering rinds of Fe-staining throughout. Zeolites fill vesicles in Pieces 7 and 8 . Oxide vein cuts
Piece 9 . 


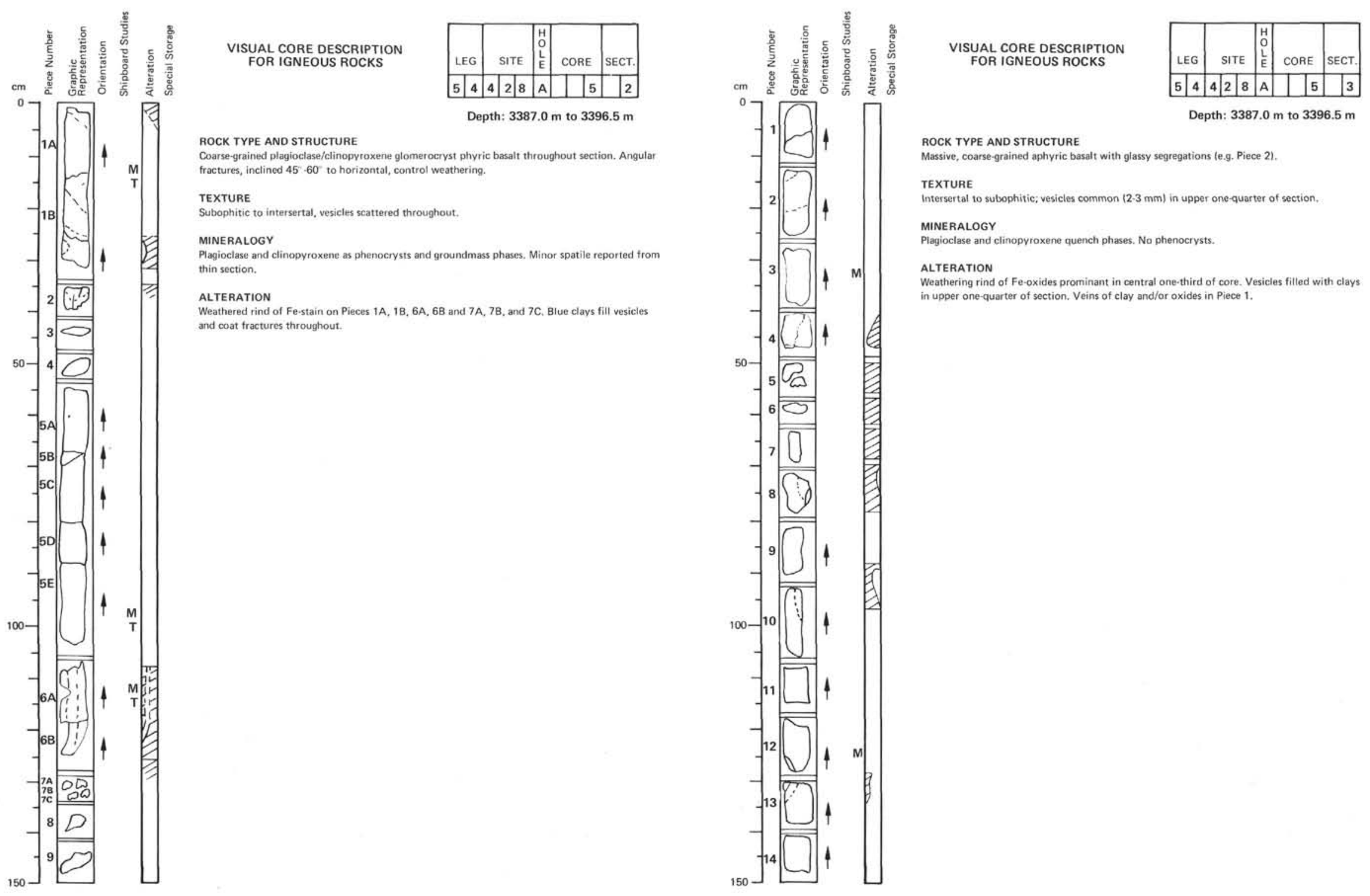



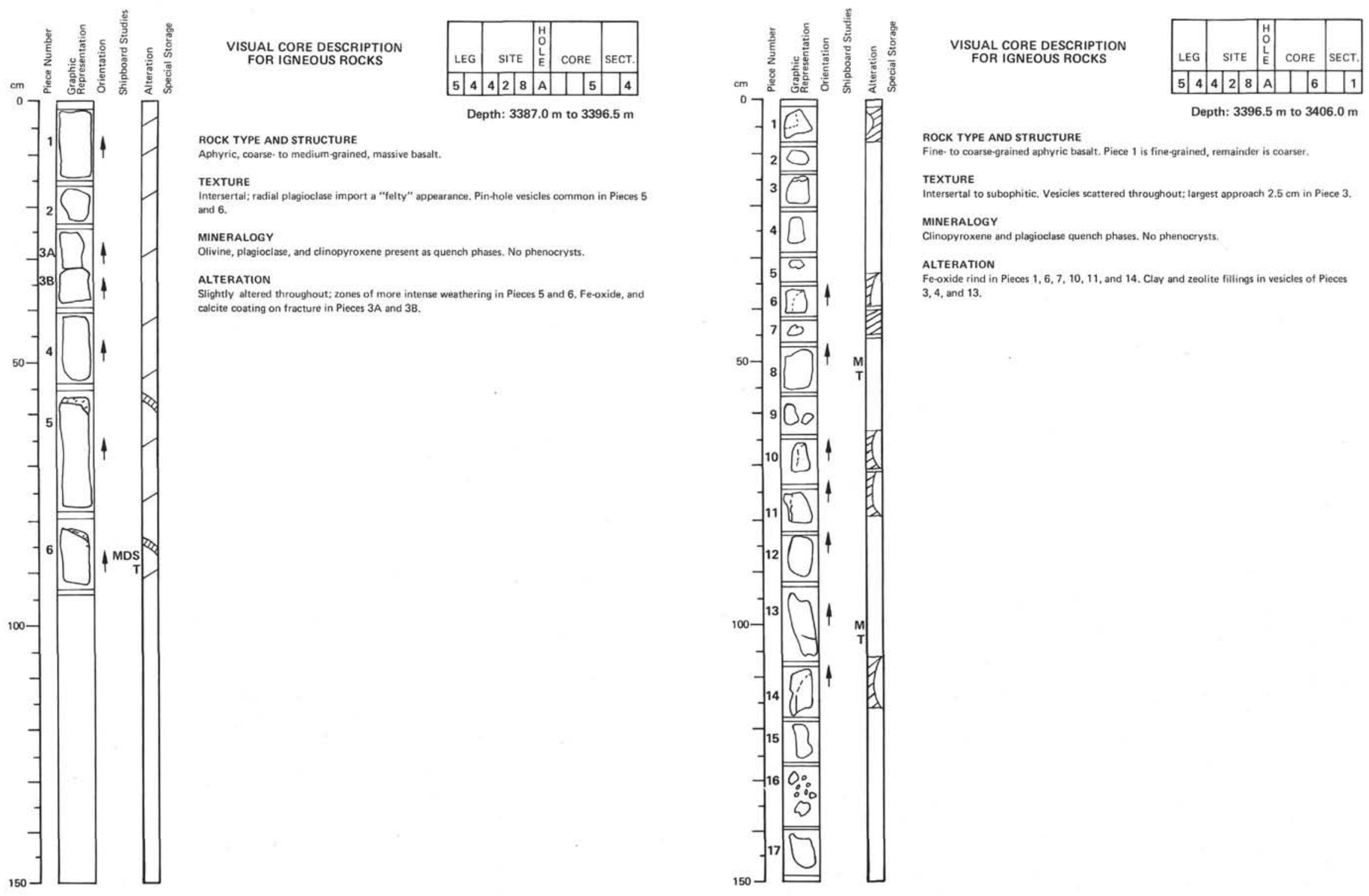

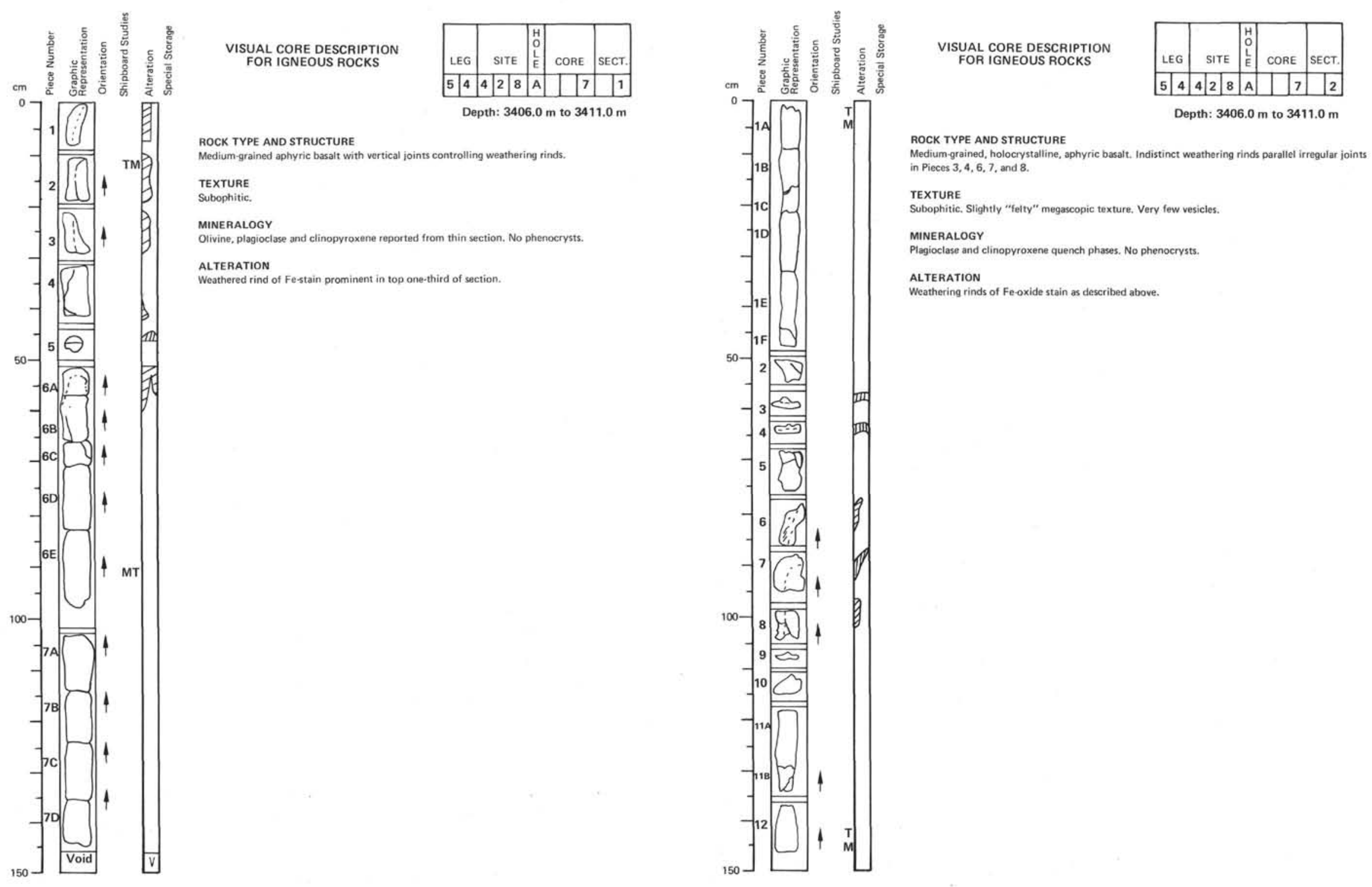


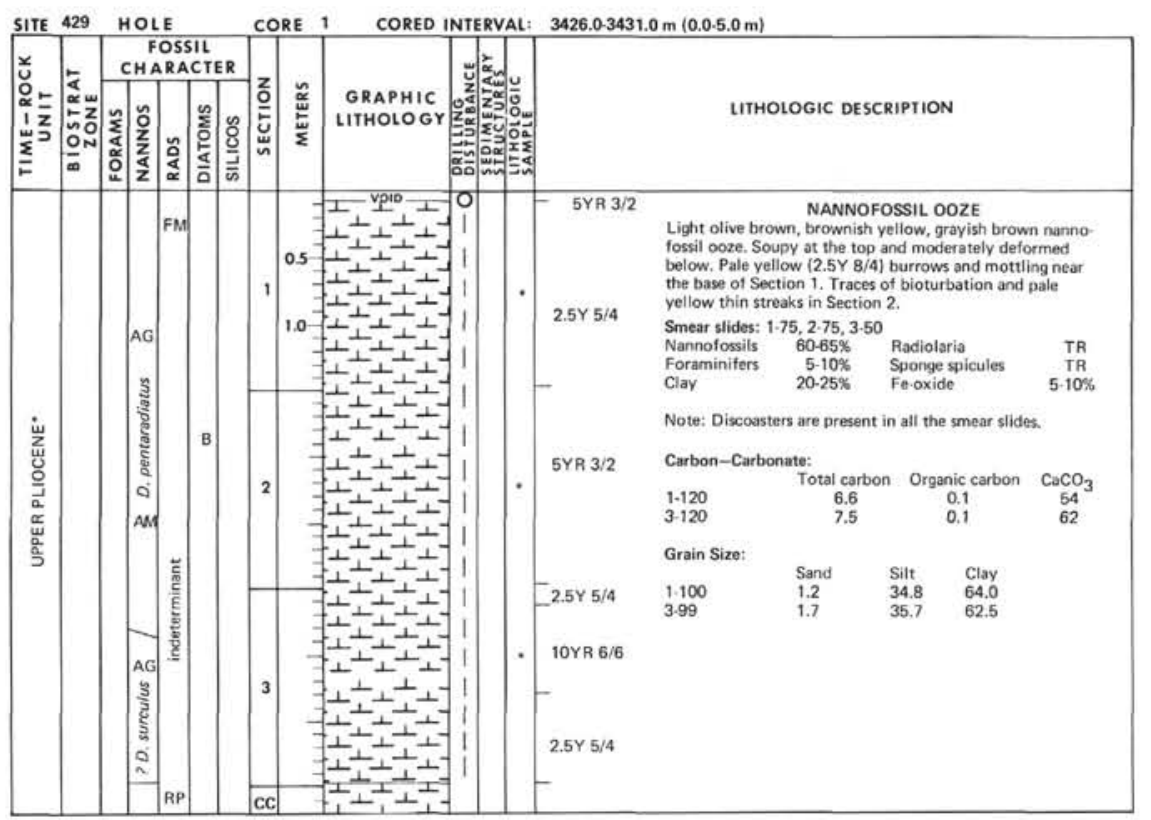



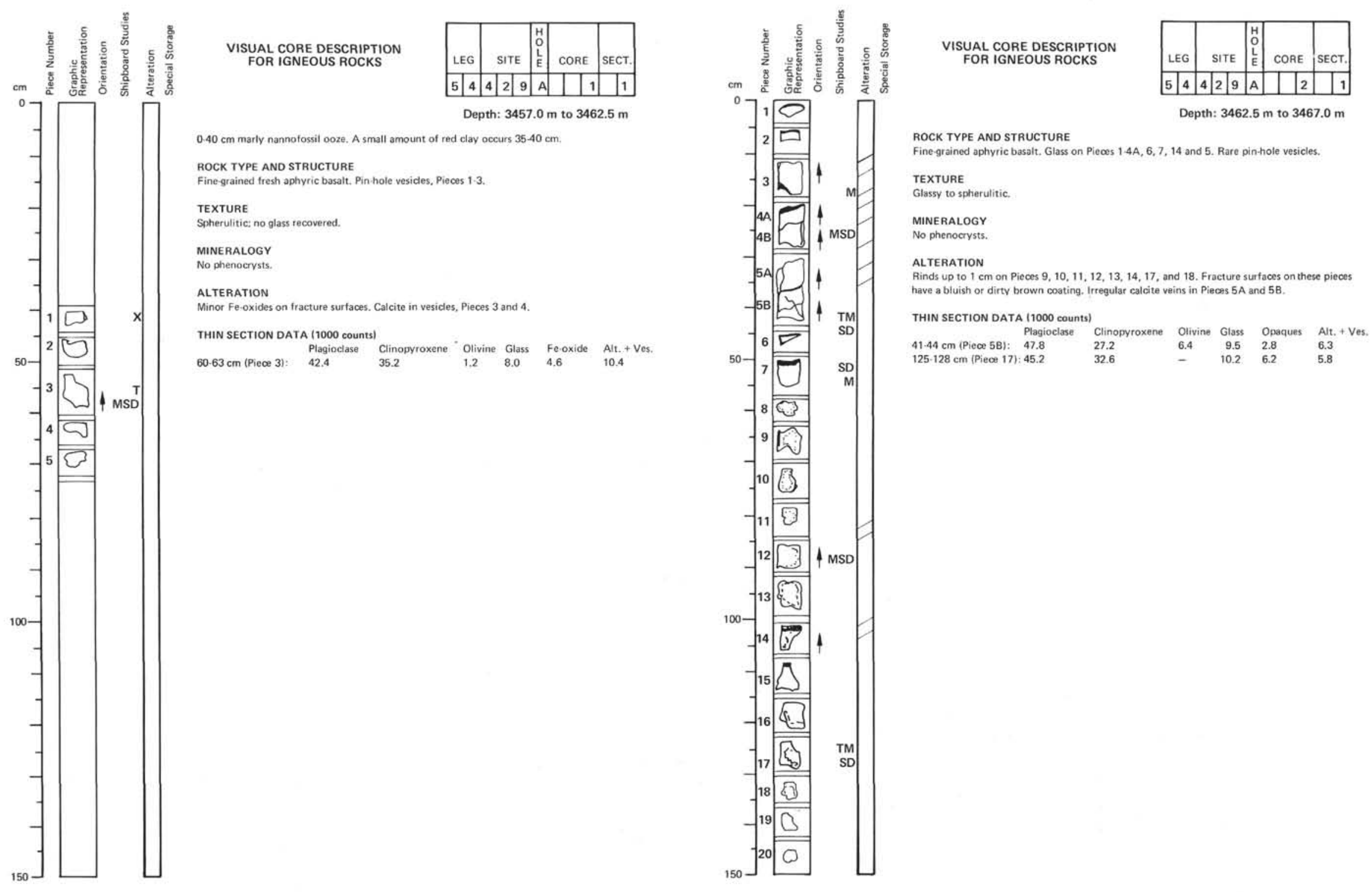


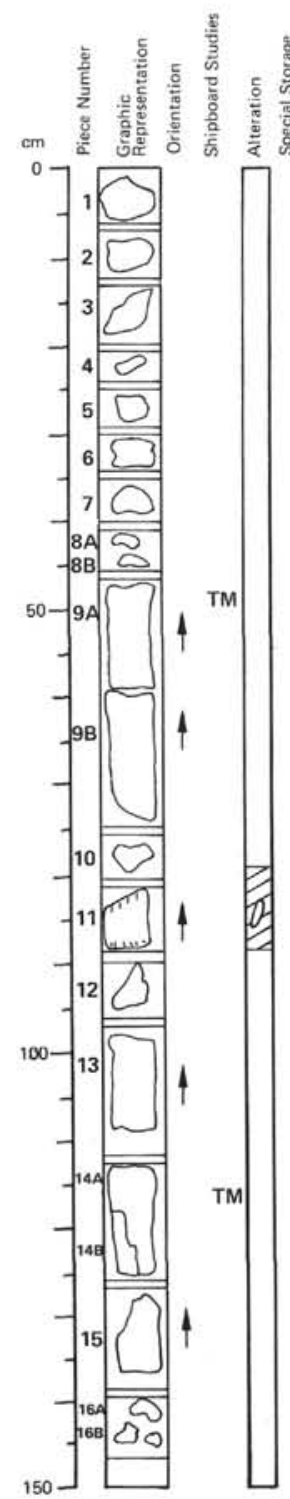

VISUAL CORE DESCRIPTION FOR IGNEOUS ROCKS

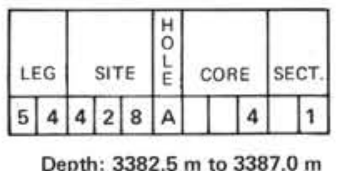

ROCK TYPE AND STRUCTURE

(1)

Aphanitic to glassy. Dark, glassy segregations comman throughout. Pinpoint vesicles common. MineraLoGY

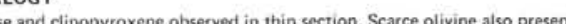

ALteration Olivine altered to talc or chlorite. Vesicles (especially in 9 A and 98 ) and fracture surtace
(11 and 15 ) coated with white secondary minerals. Vesicles contain calcite fillings throughour.

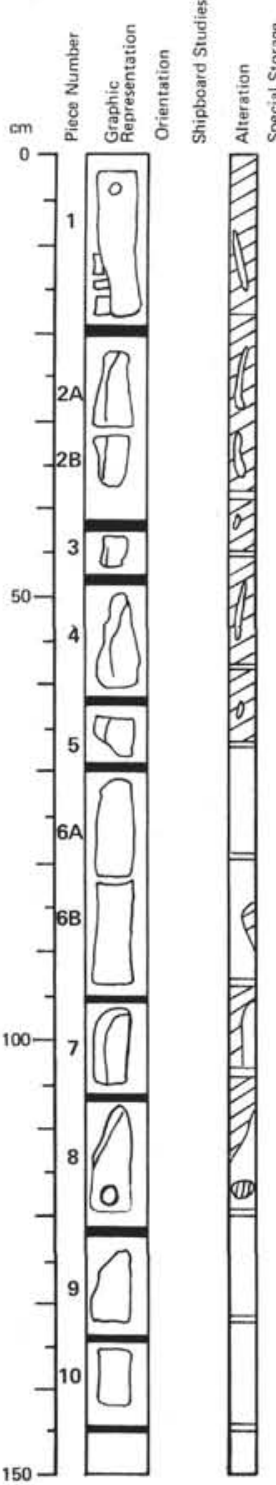
VISUAL CORE DESCRIPTION
FOR IGNEOUS ROCKS

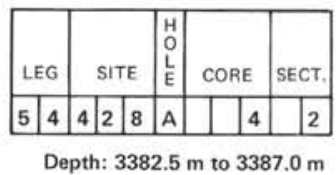

ROCK TYPE AND STRUCTURE

Xige-grained, aphyric, vertical

TEXTURE

Aphanitic, with scattered pinpoint vesicles.

MINERALOGY

quench phases in glass.

ALTERATION

al joints. Veinlet of carbonate in Piece 2. Vesicles commonly filled with calcite or zeolites and green clays. 
Site 419

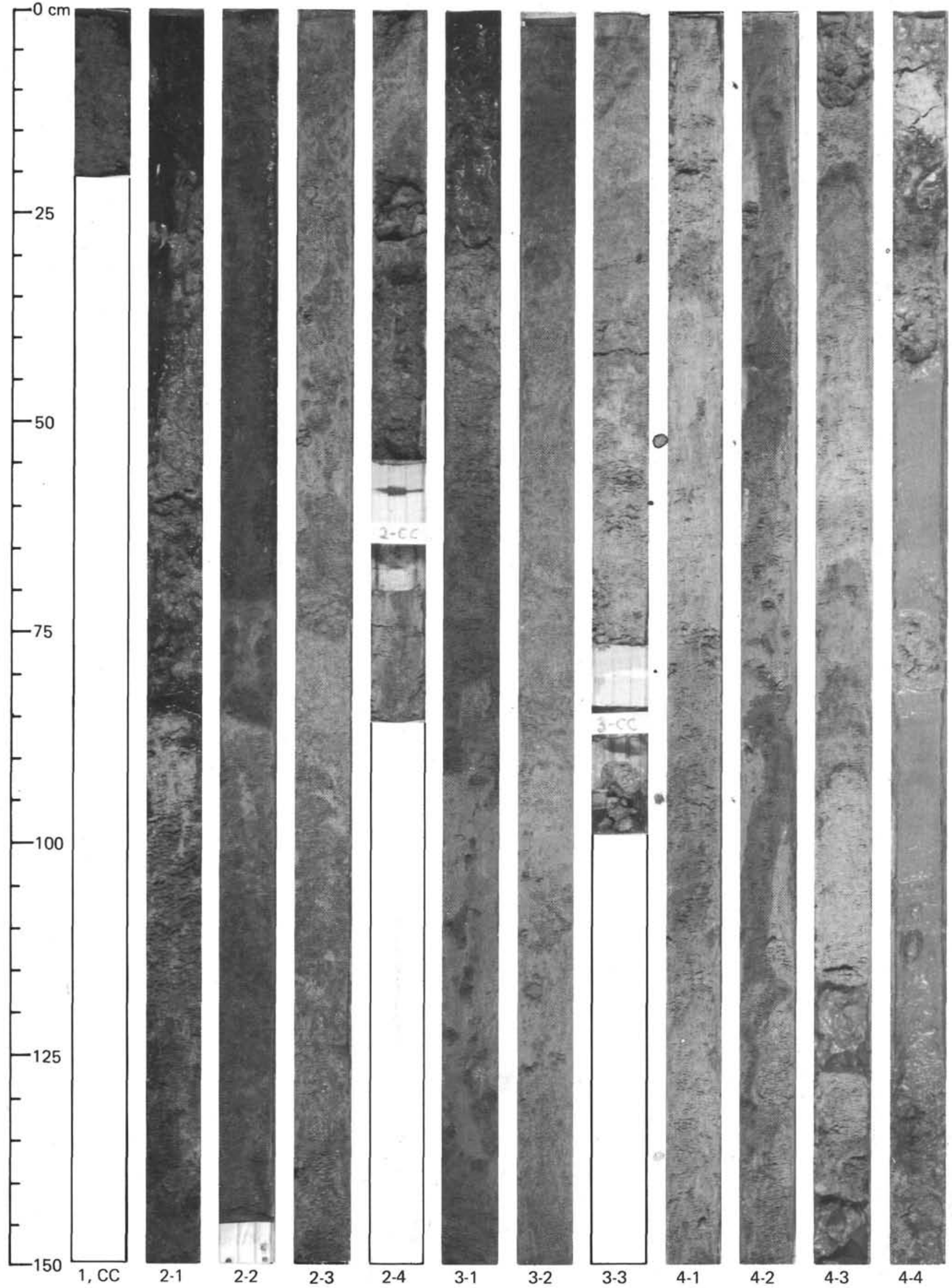


Site 419

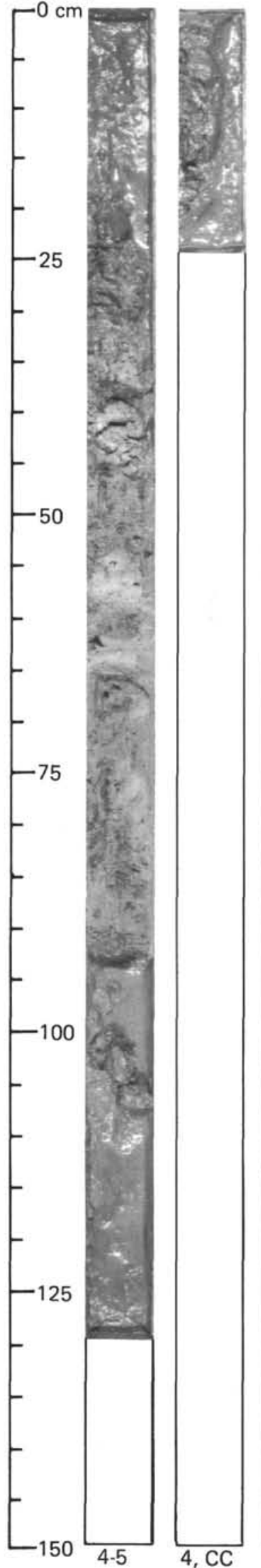

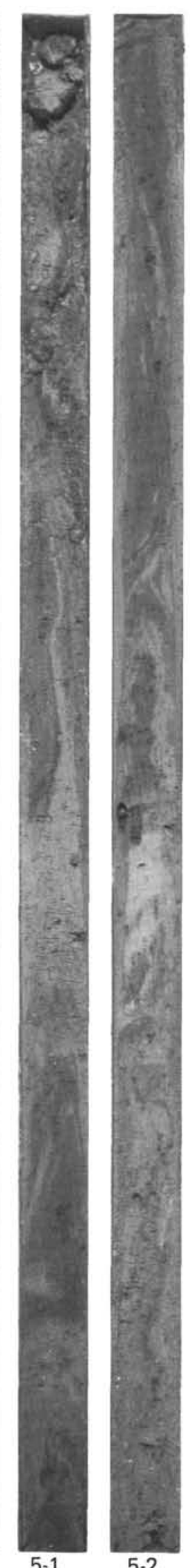

5-1

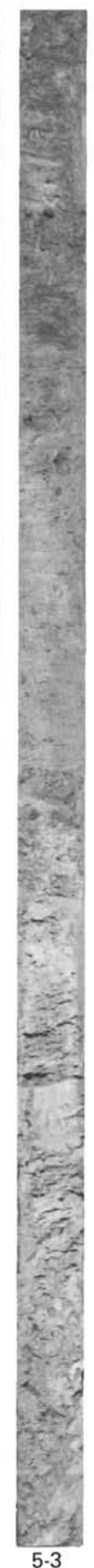

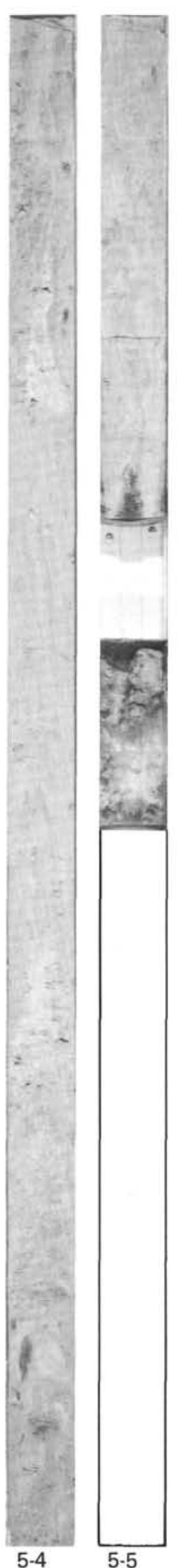

Hole 419A

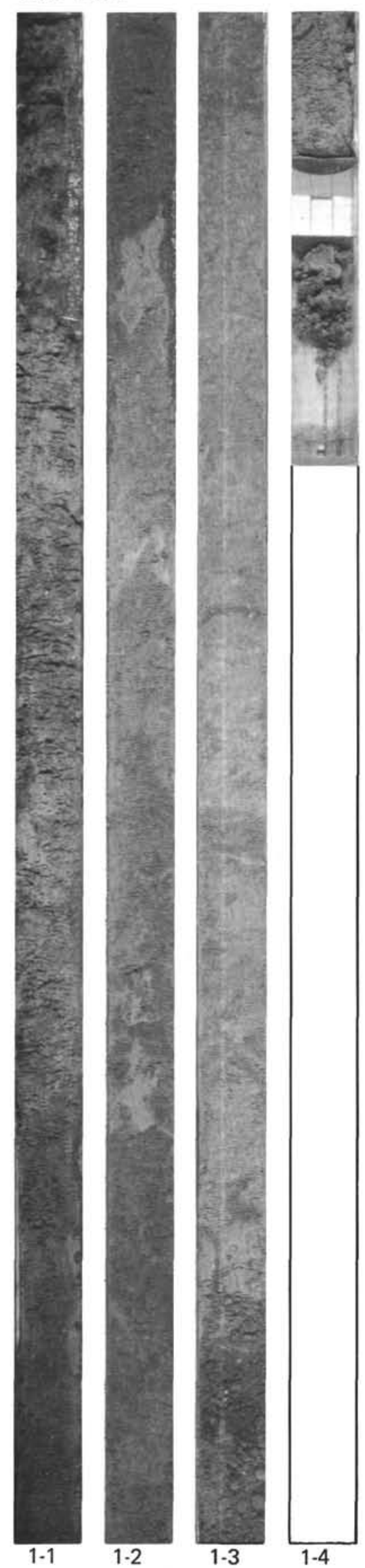



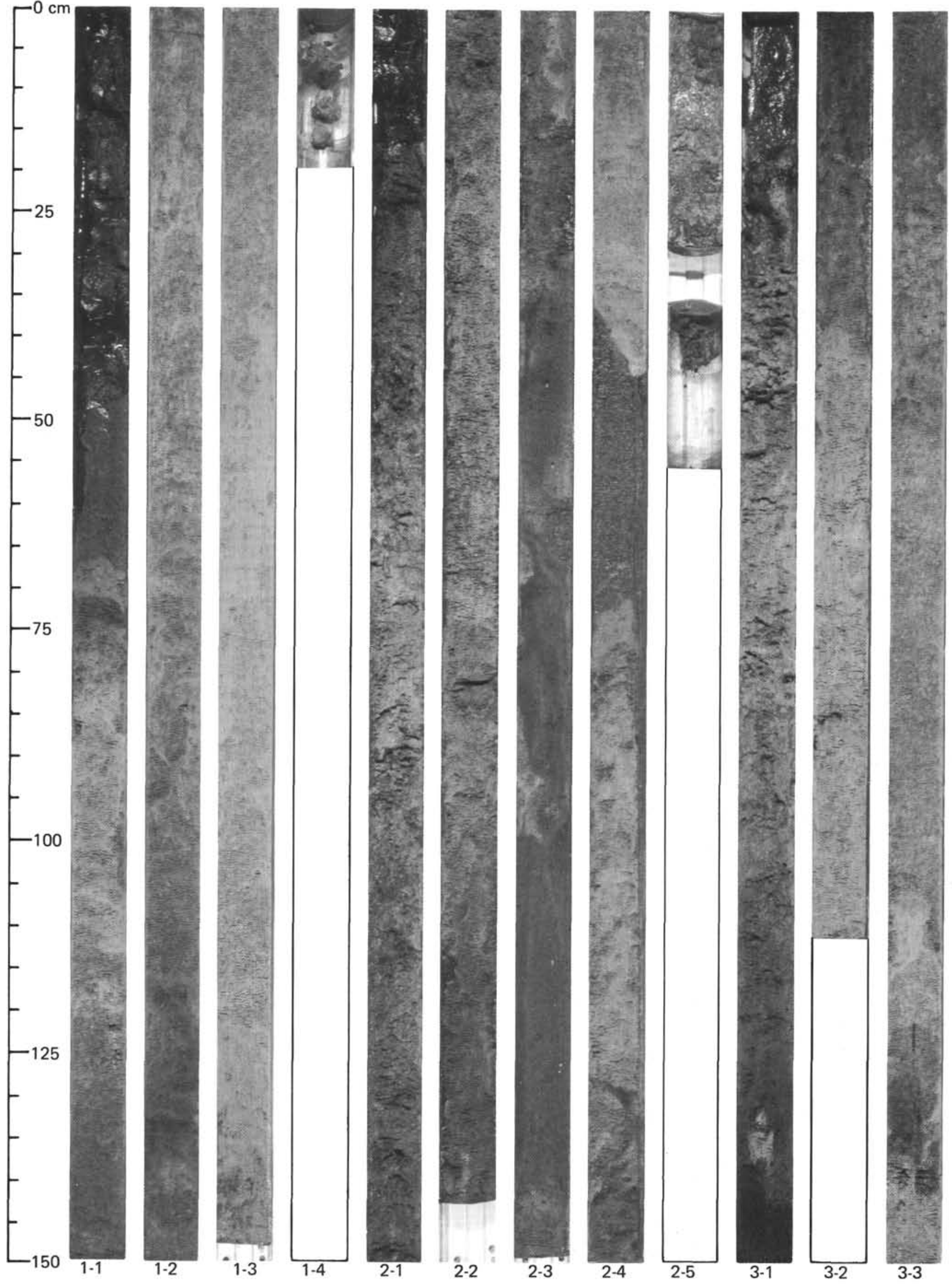
Site 420

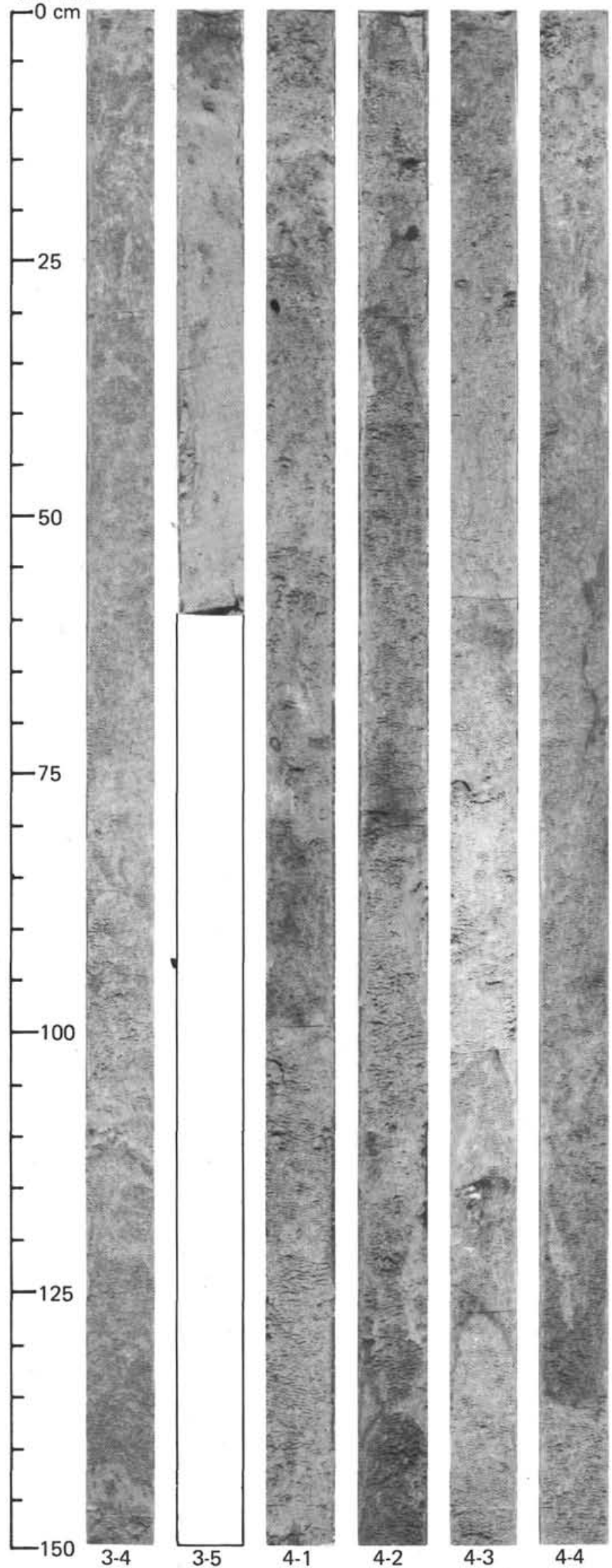

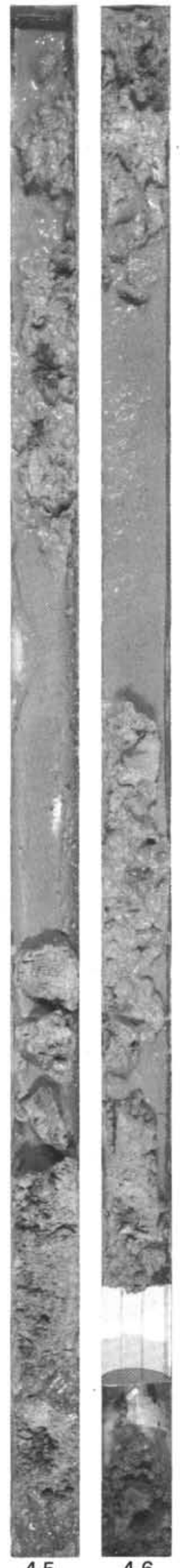

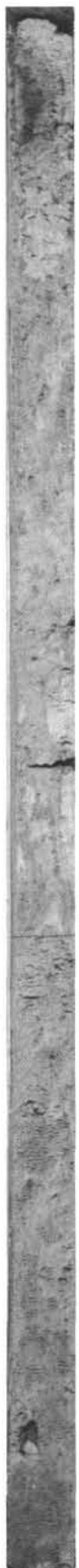

5-1

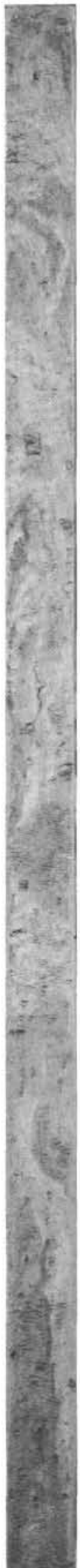

$5-2$

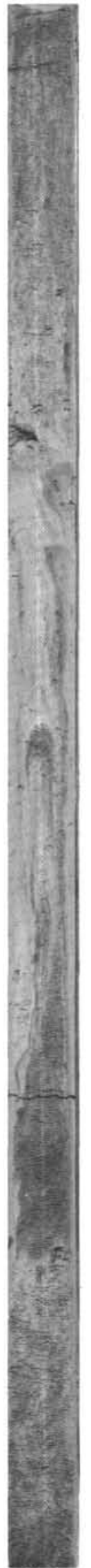

$5-3$

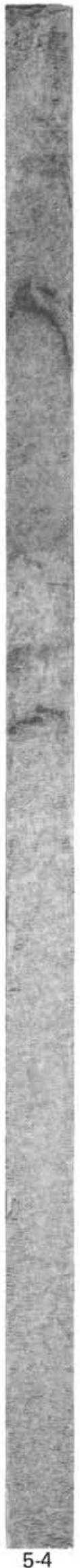


Site 420

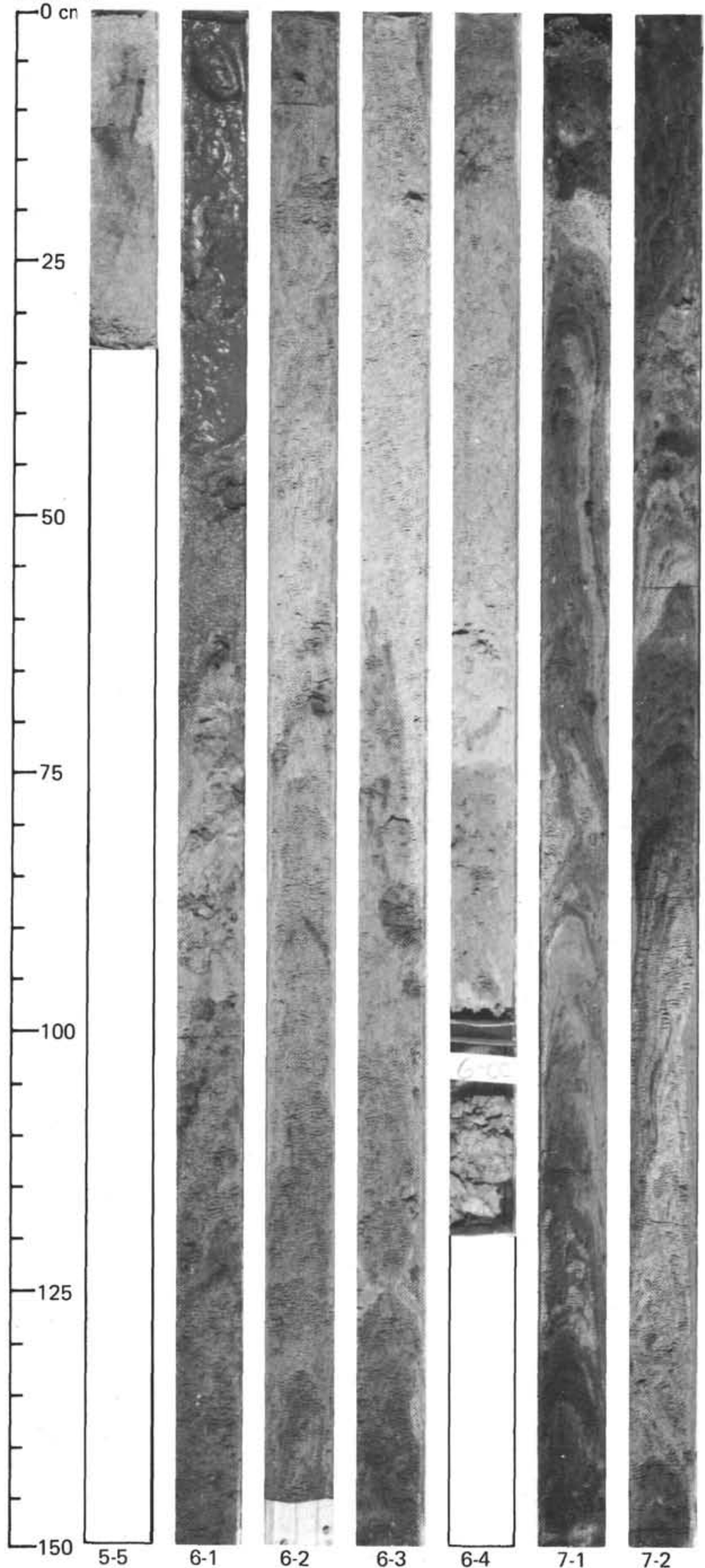

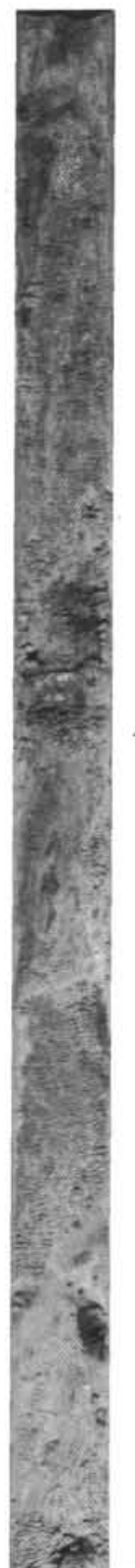

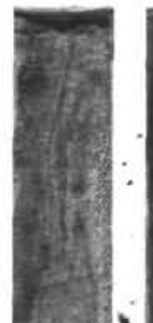

的

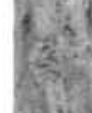

in.
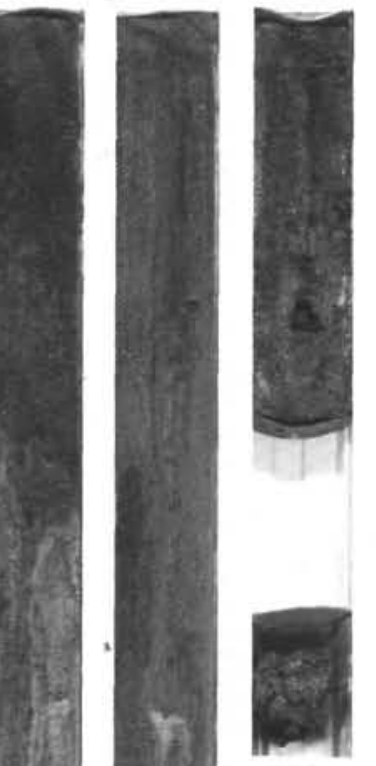

$5^{5}$
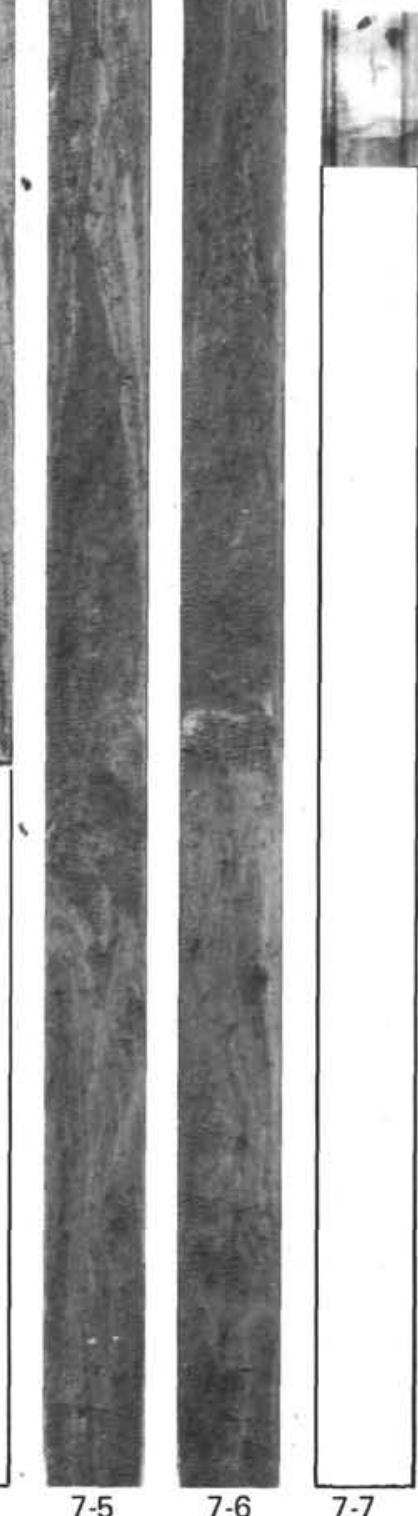
Site 420

\section{$0 \mathrm{~cm}$}
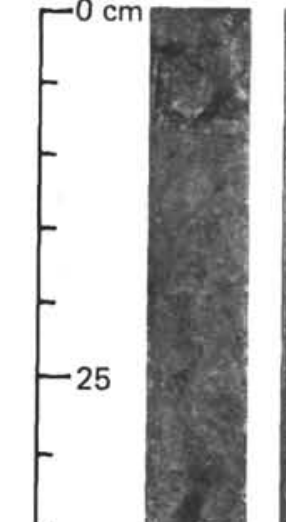

$-50$

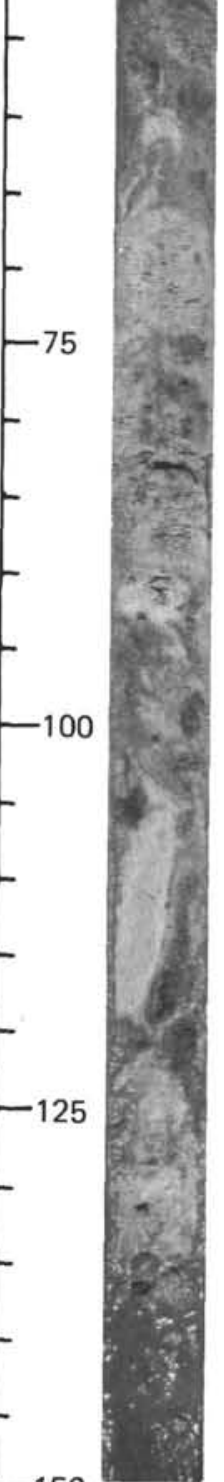

$-150 \quad 8-1$
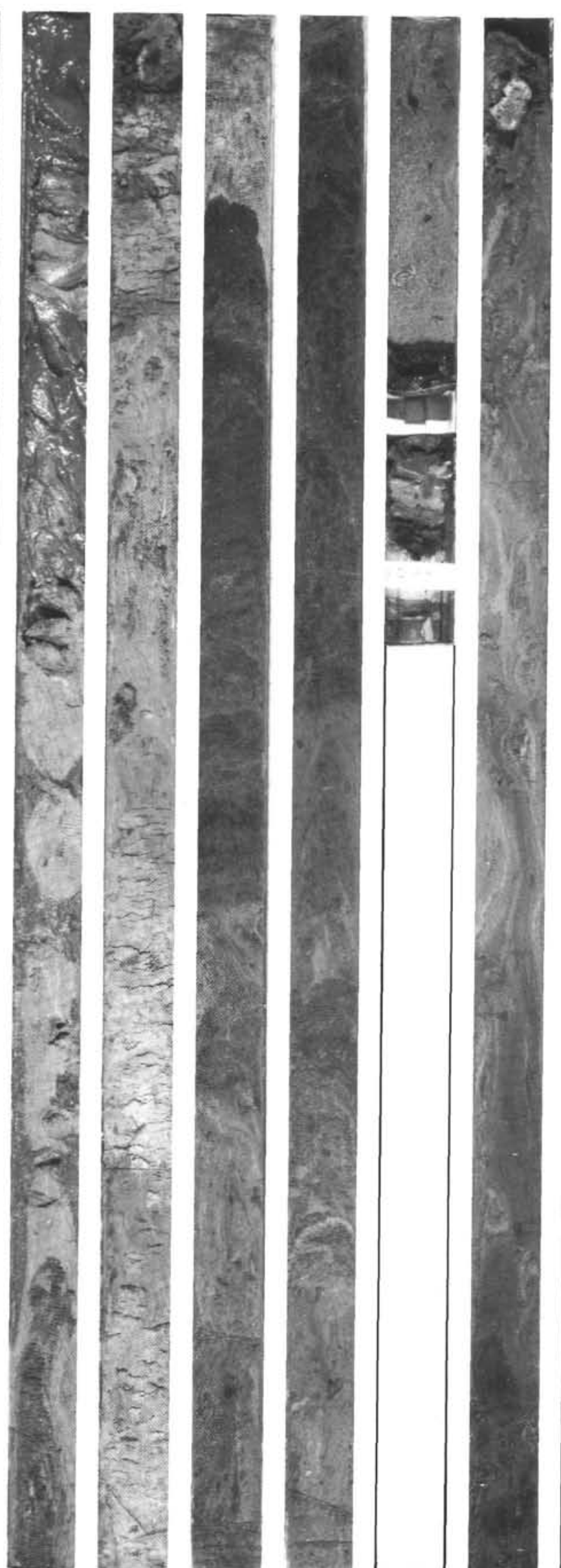

8-2

8-3

8-4
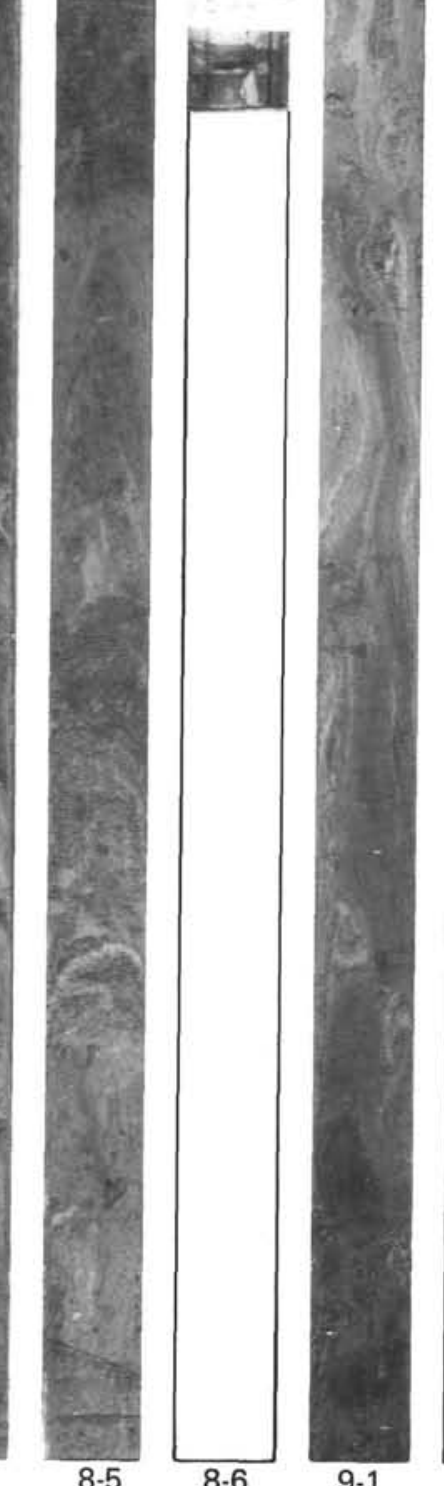
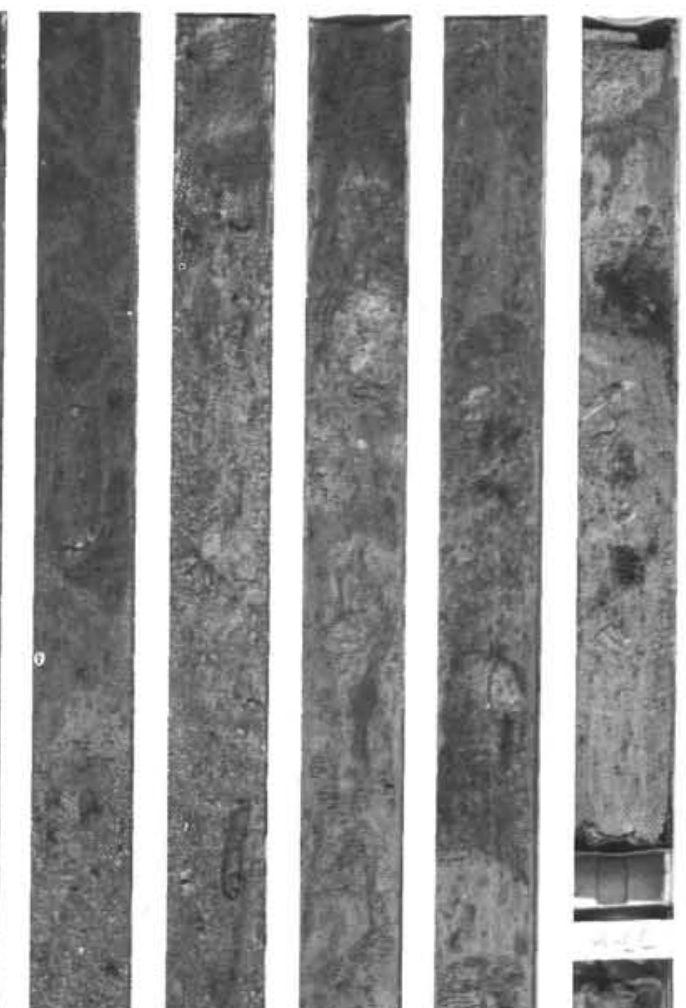

$$
\frac{1}{2}
$$
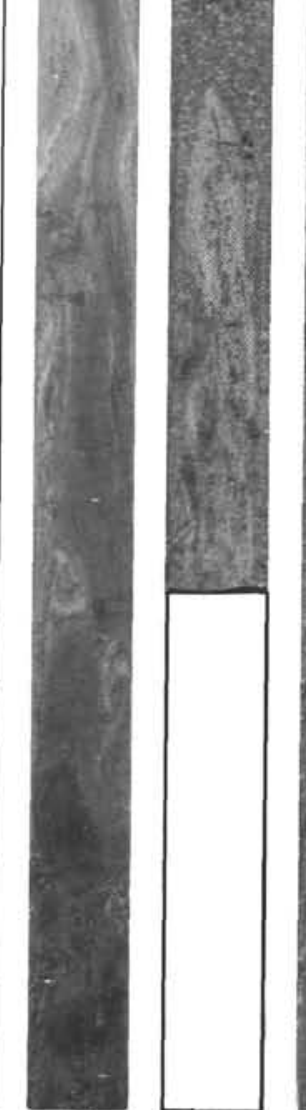

$9-1 \quad 9-2$

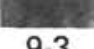

9-3

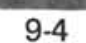

9-5

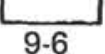




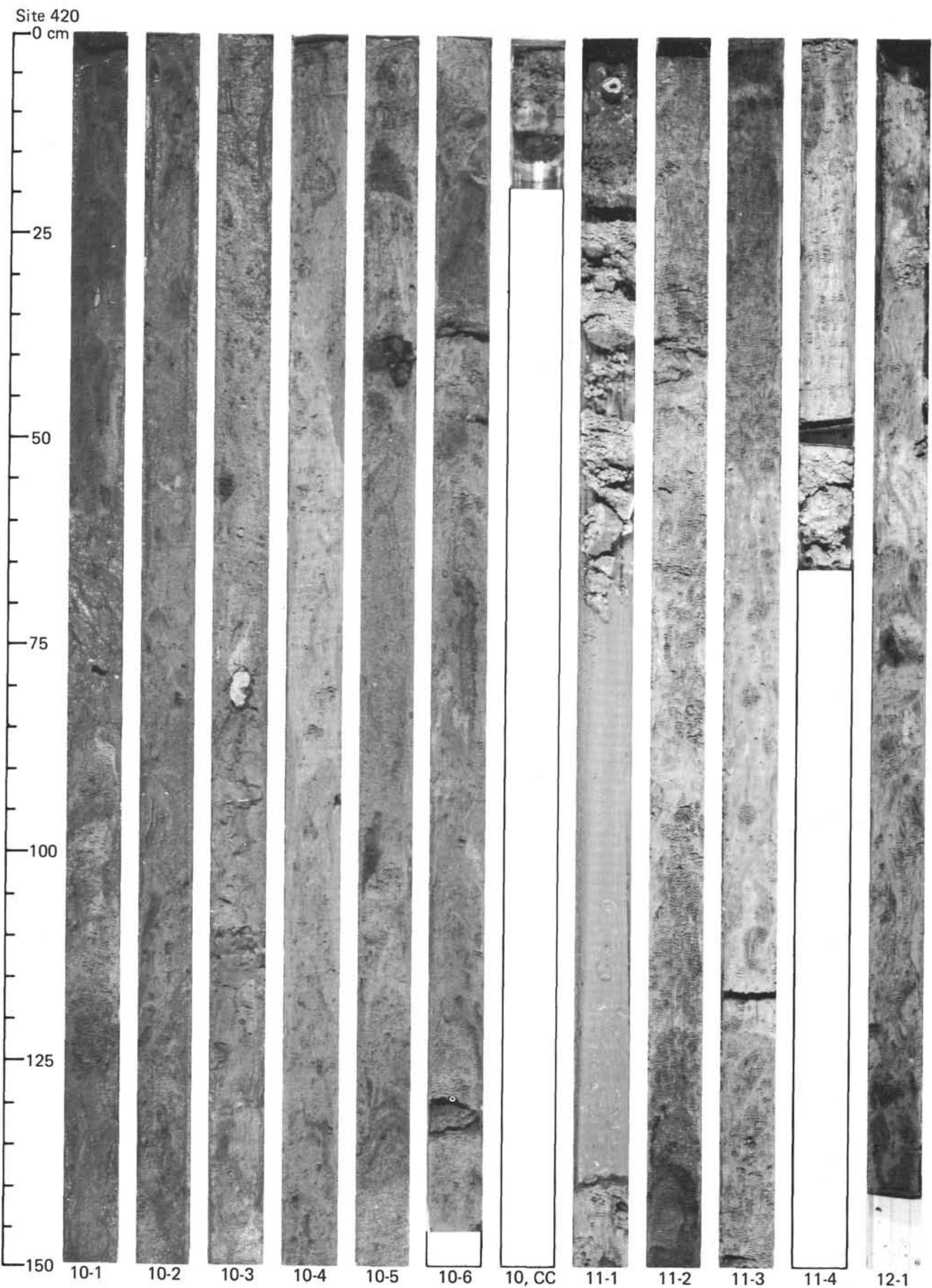




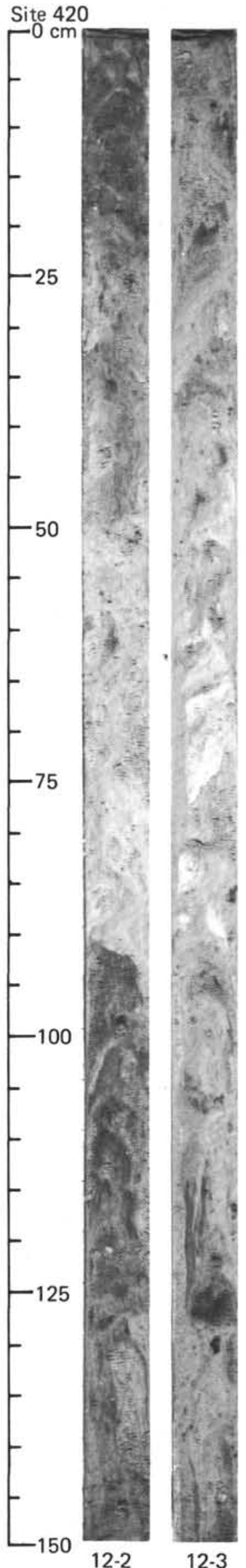

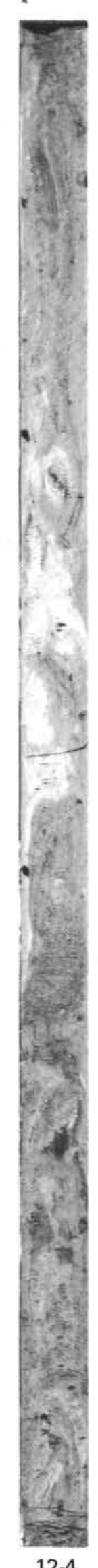
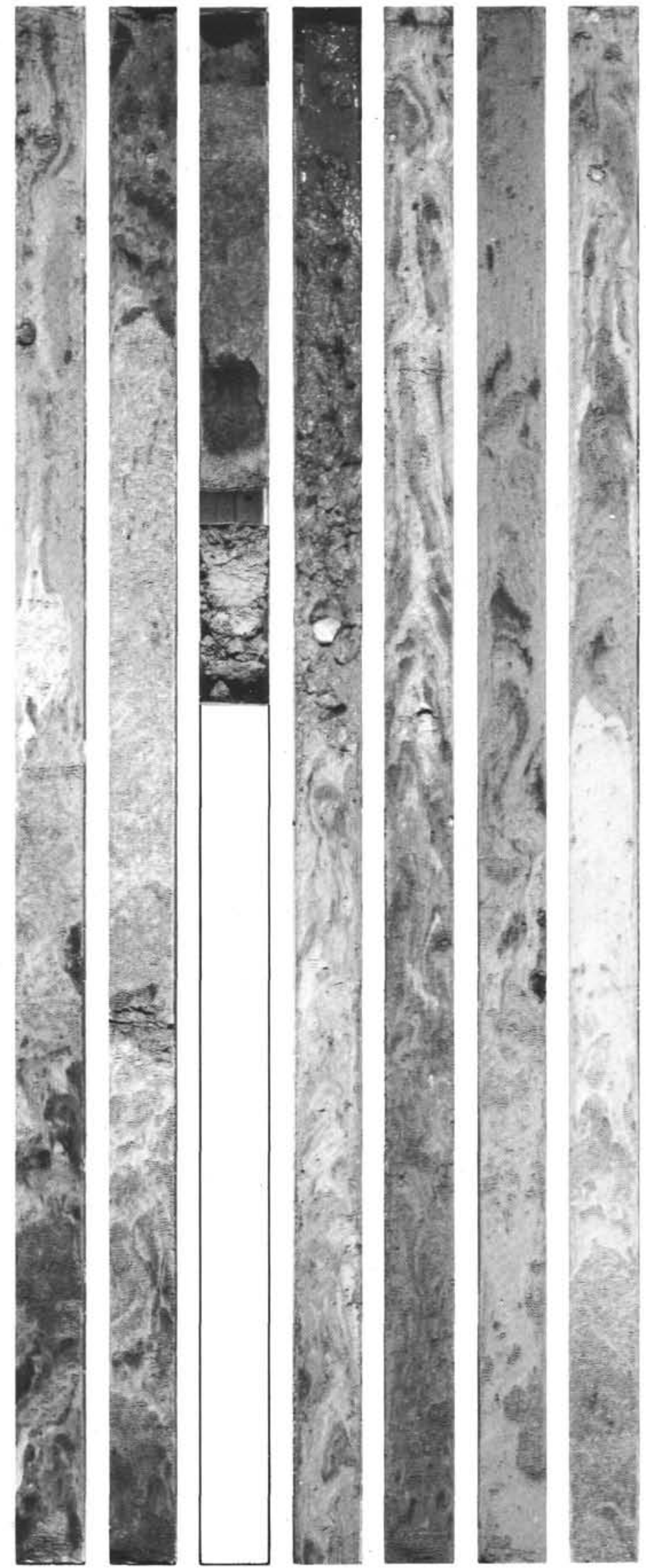

12-5
$12-6$

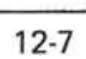

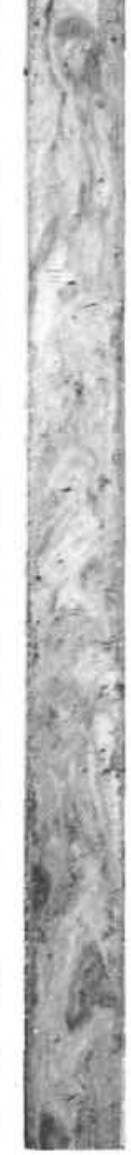

13-1

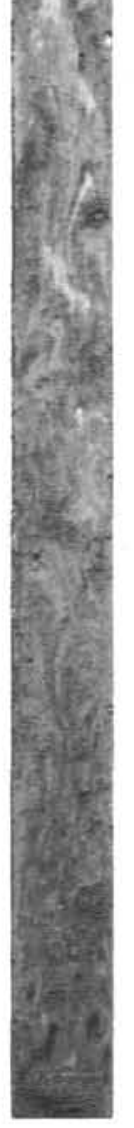

13-2

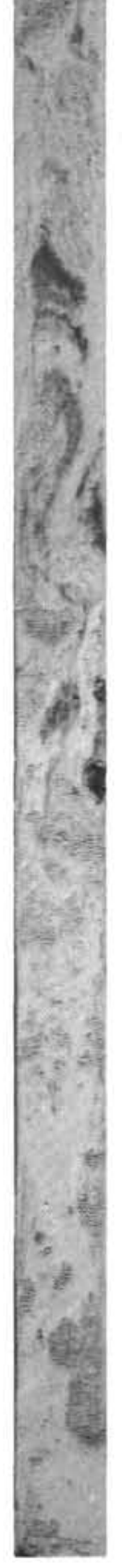

13-3

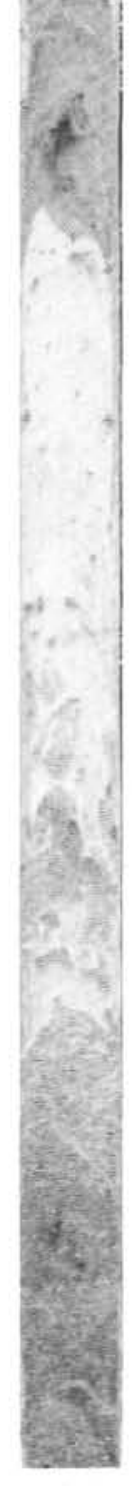

13-4
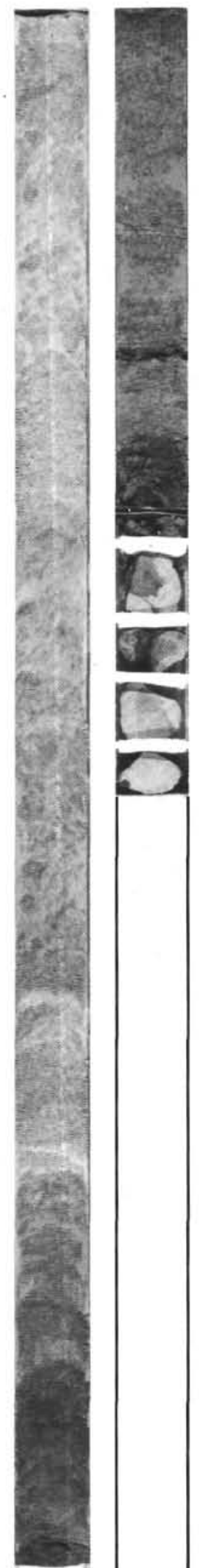

13-5 


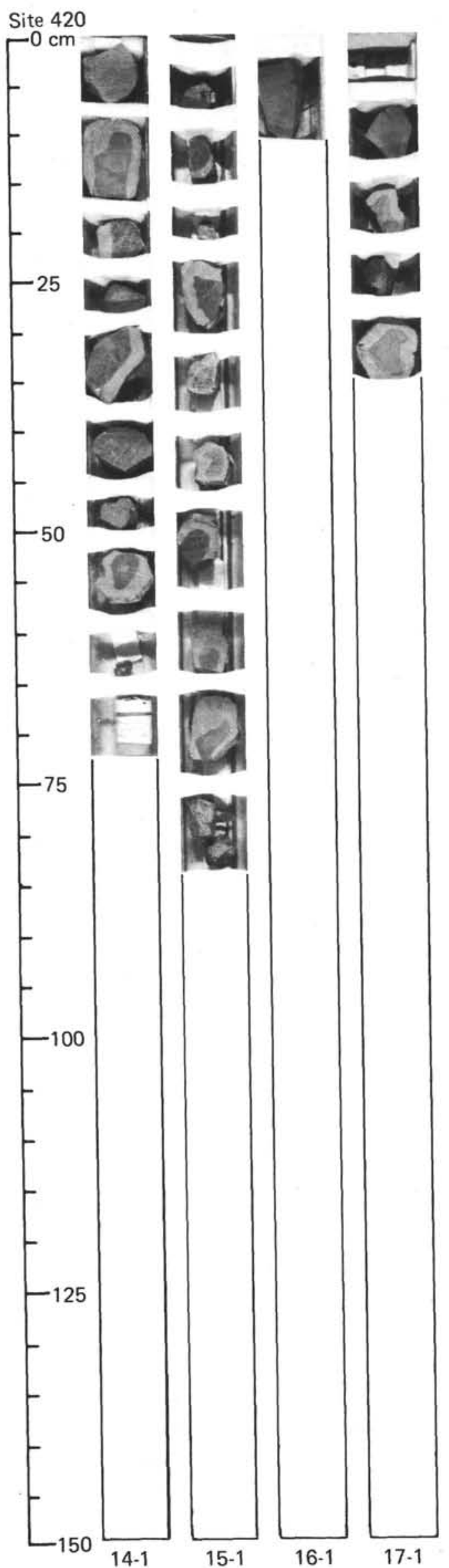

Hole 420A

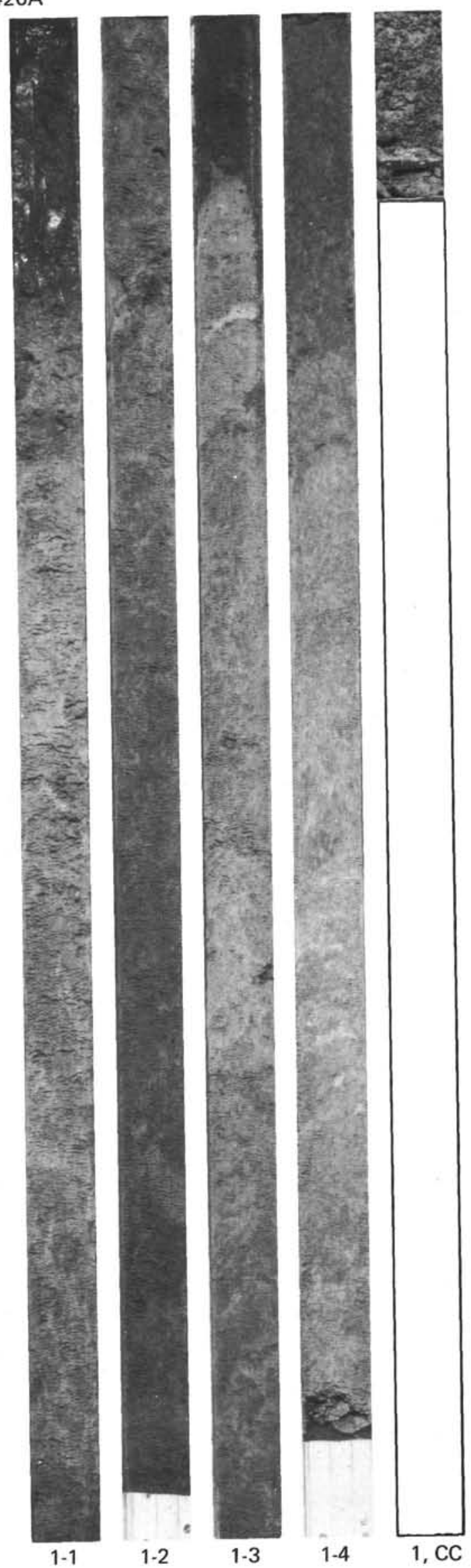




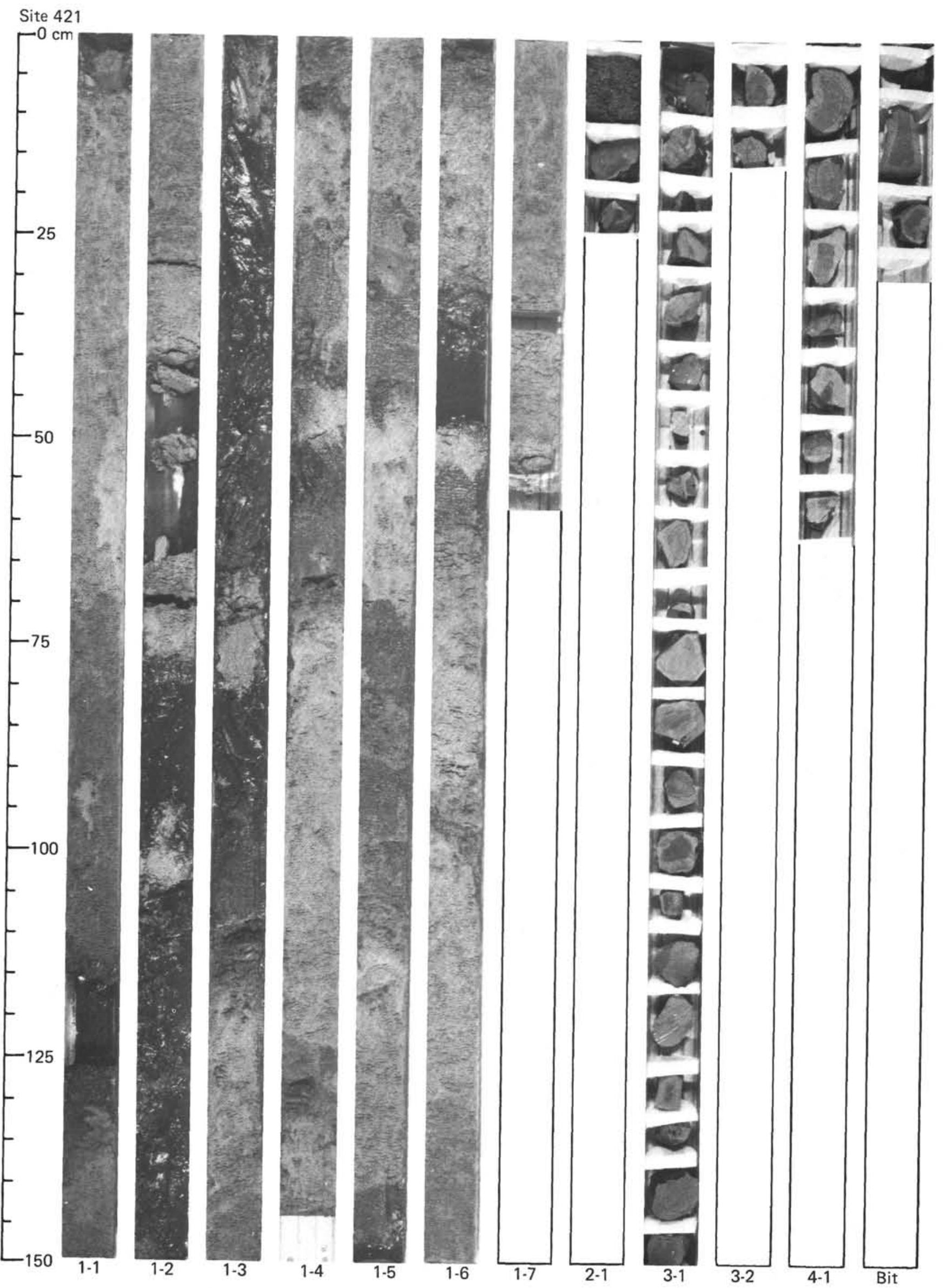


Site 422

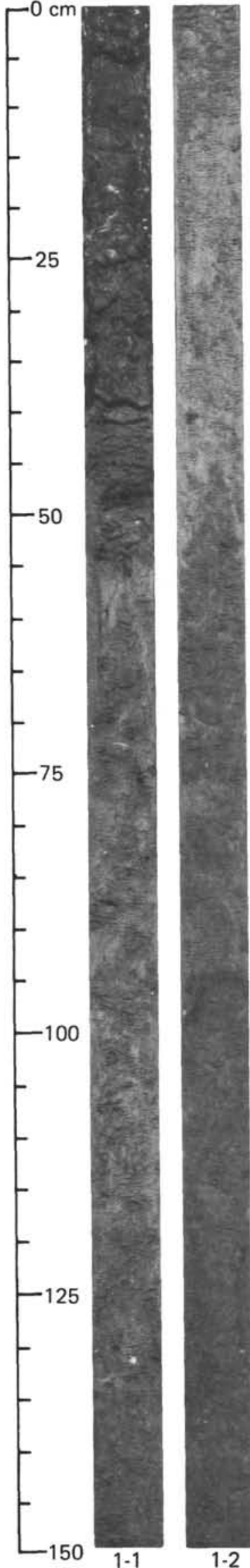

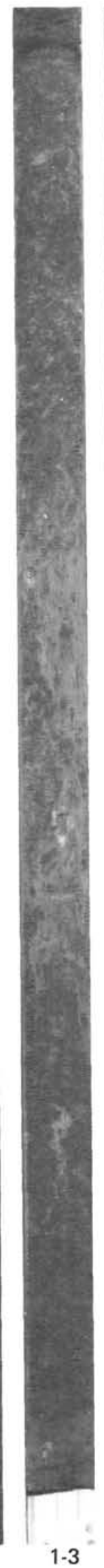

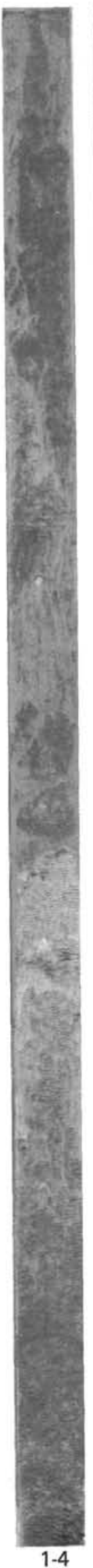

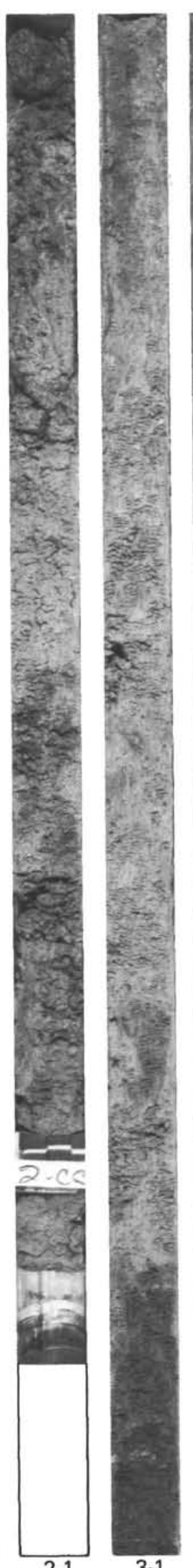

3-1
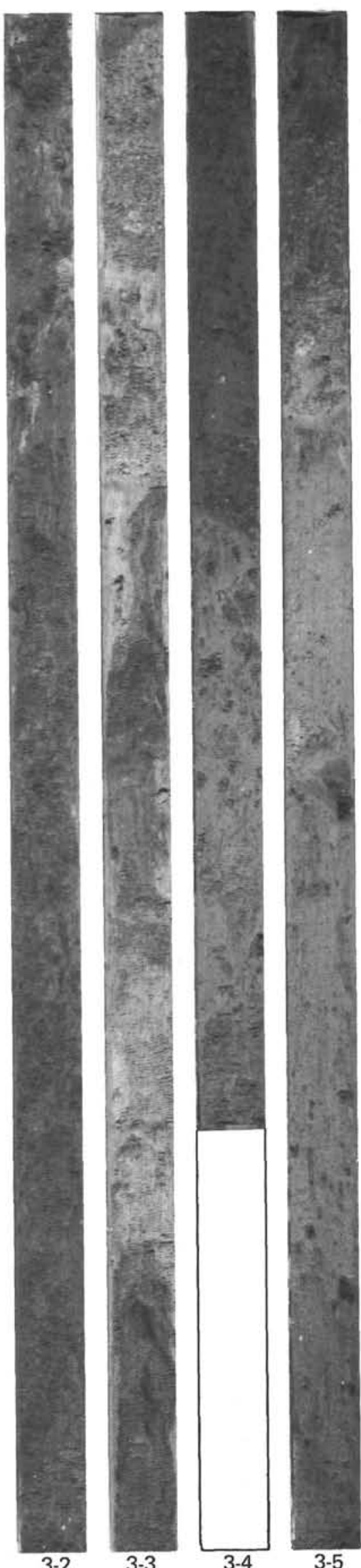

3-5
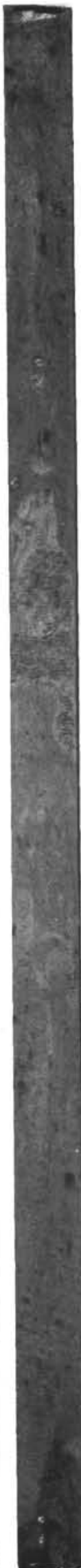

3-6 
Site 422

- $0 \mathrm{~cm}$

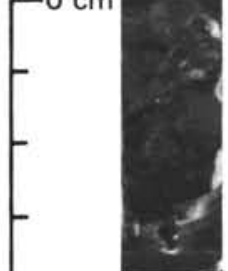

$-75$
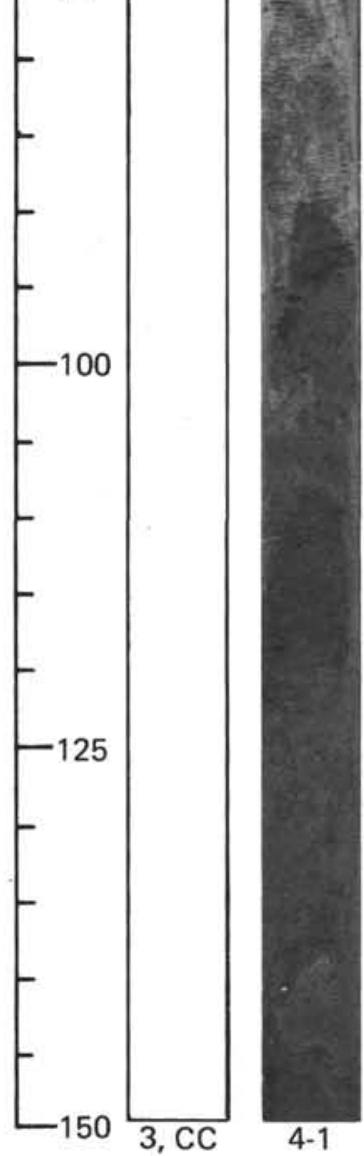

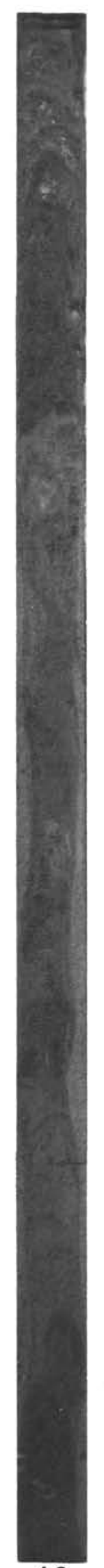

4-2

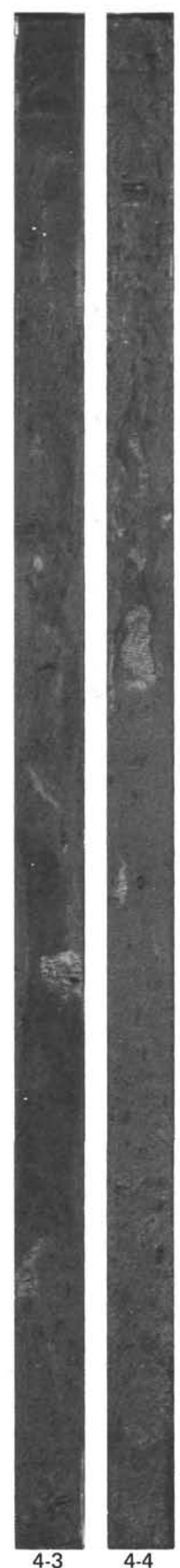

4-3

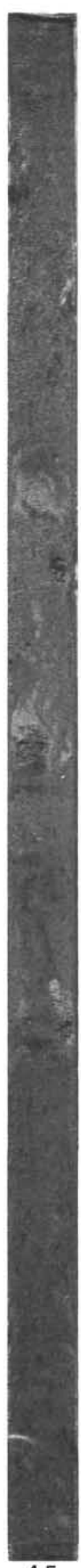

4-5

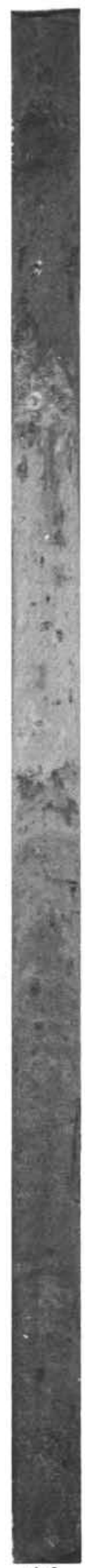

4-6
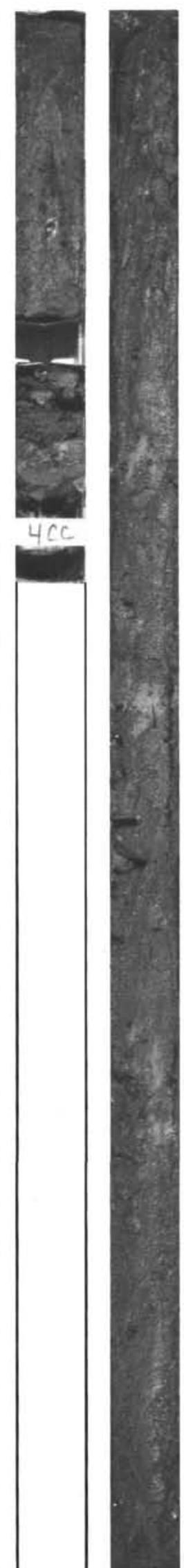

4.7

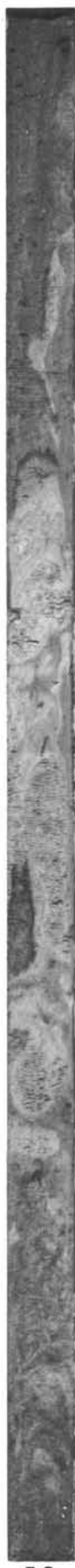

5-2
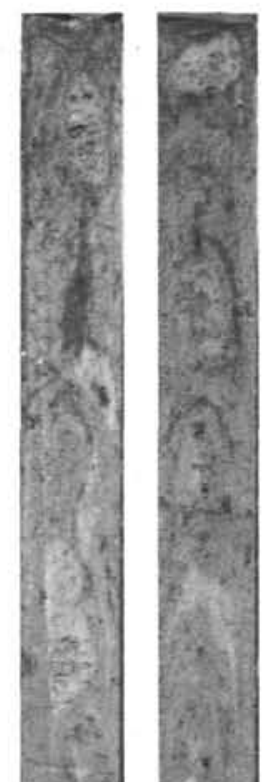

(x)

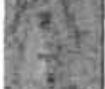

as
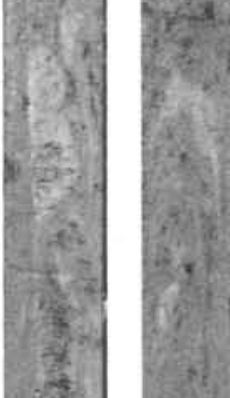

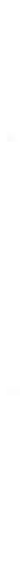
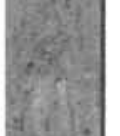

हो)

1)

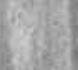

$\int^{3}=$

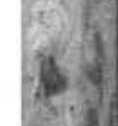


Site 422

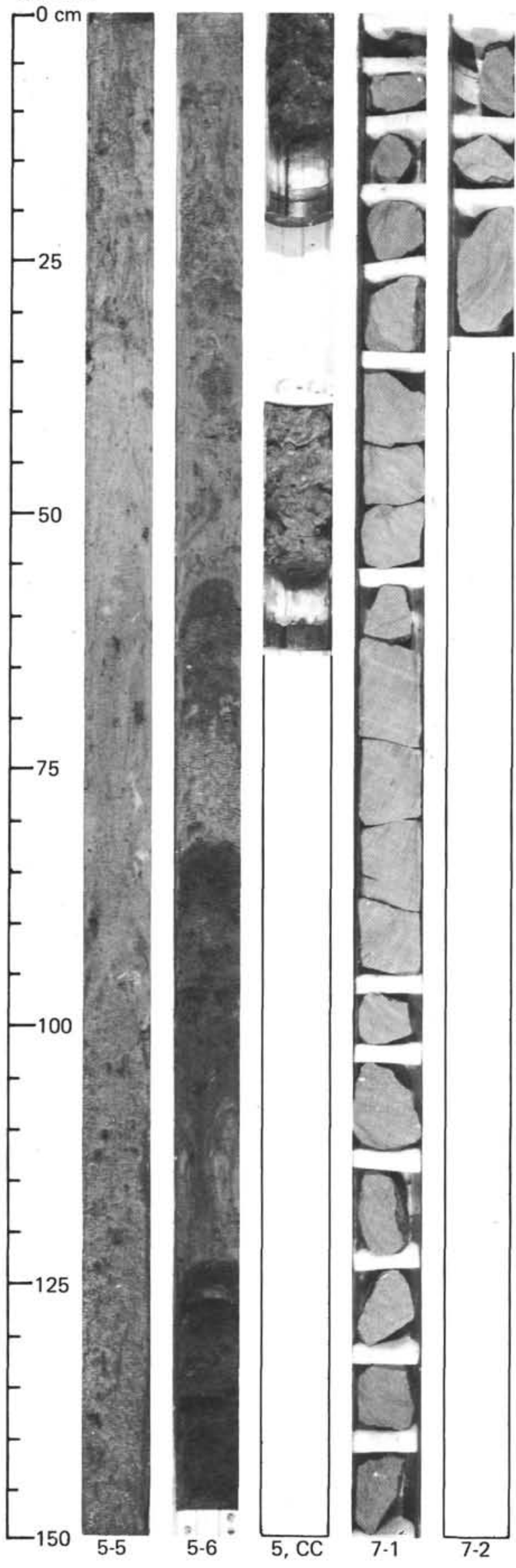

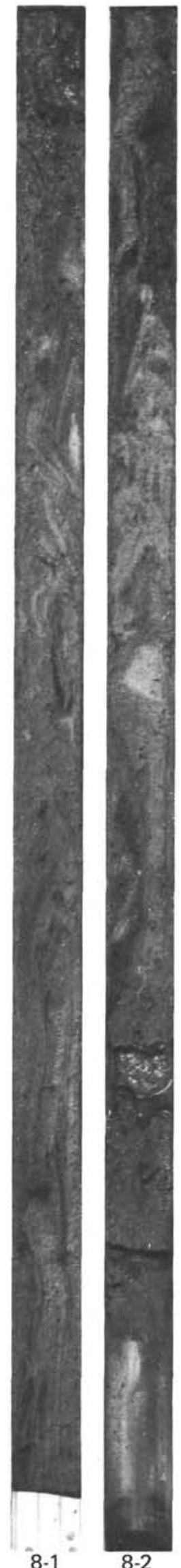

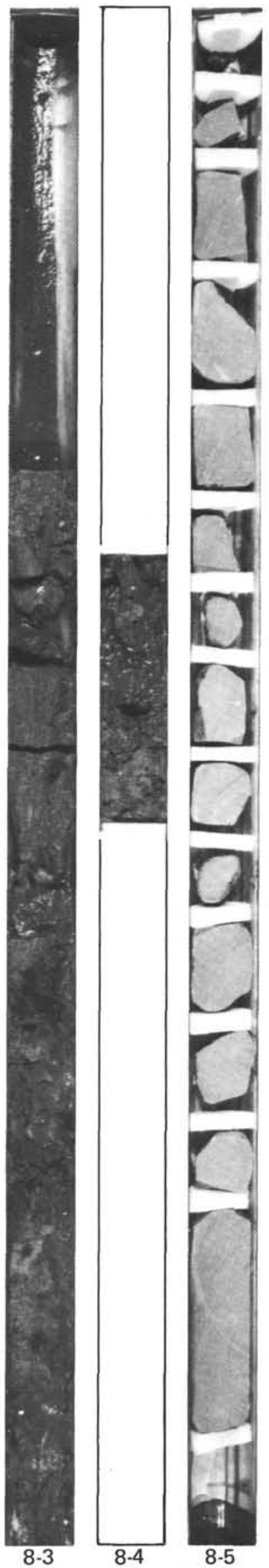


Site 423
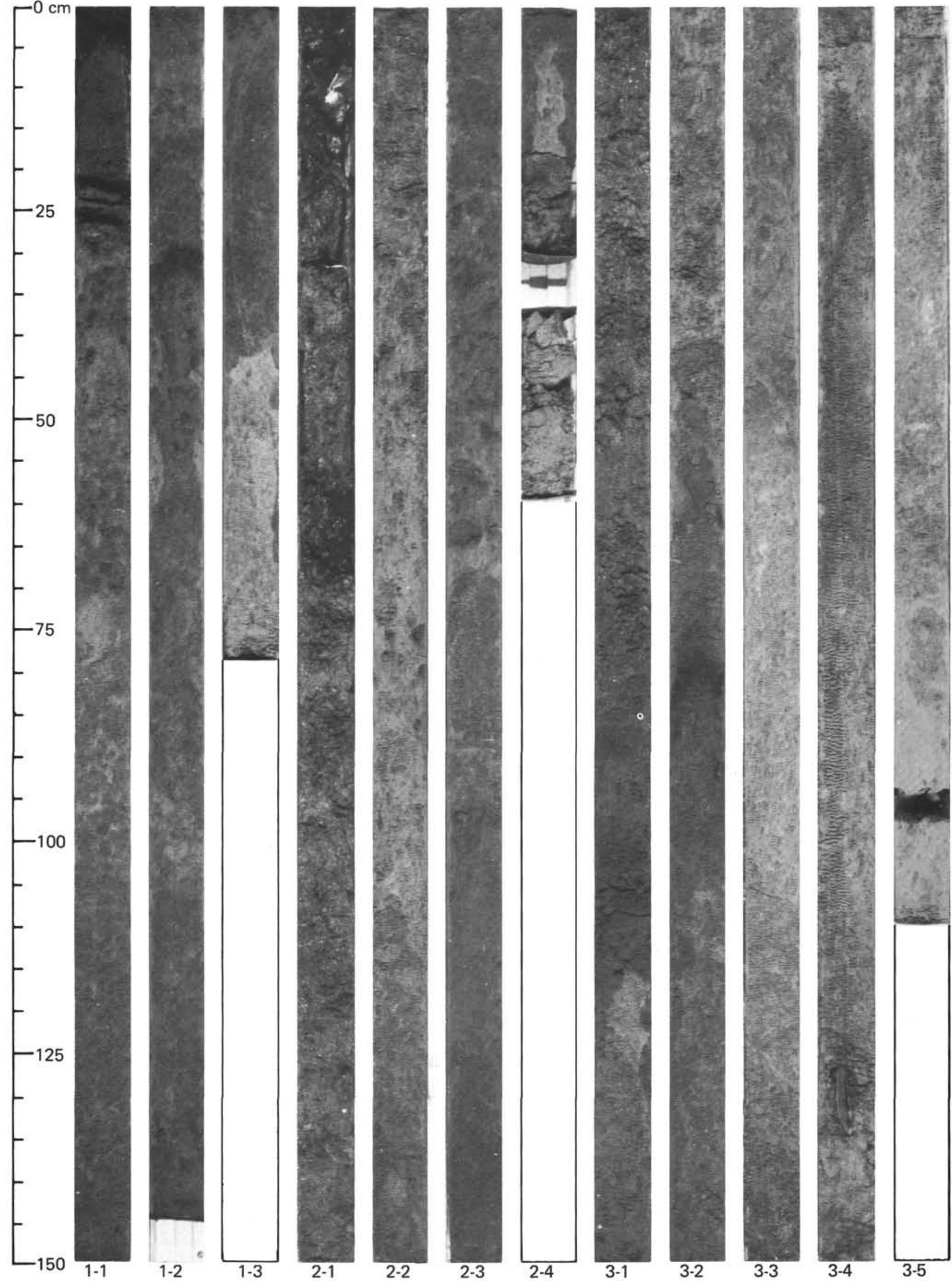


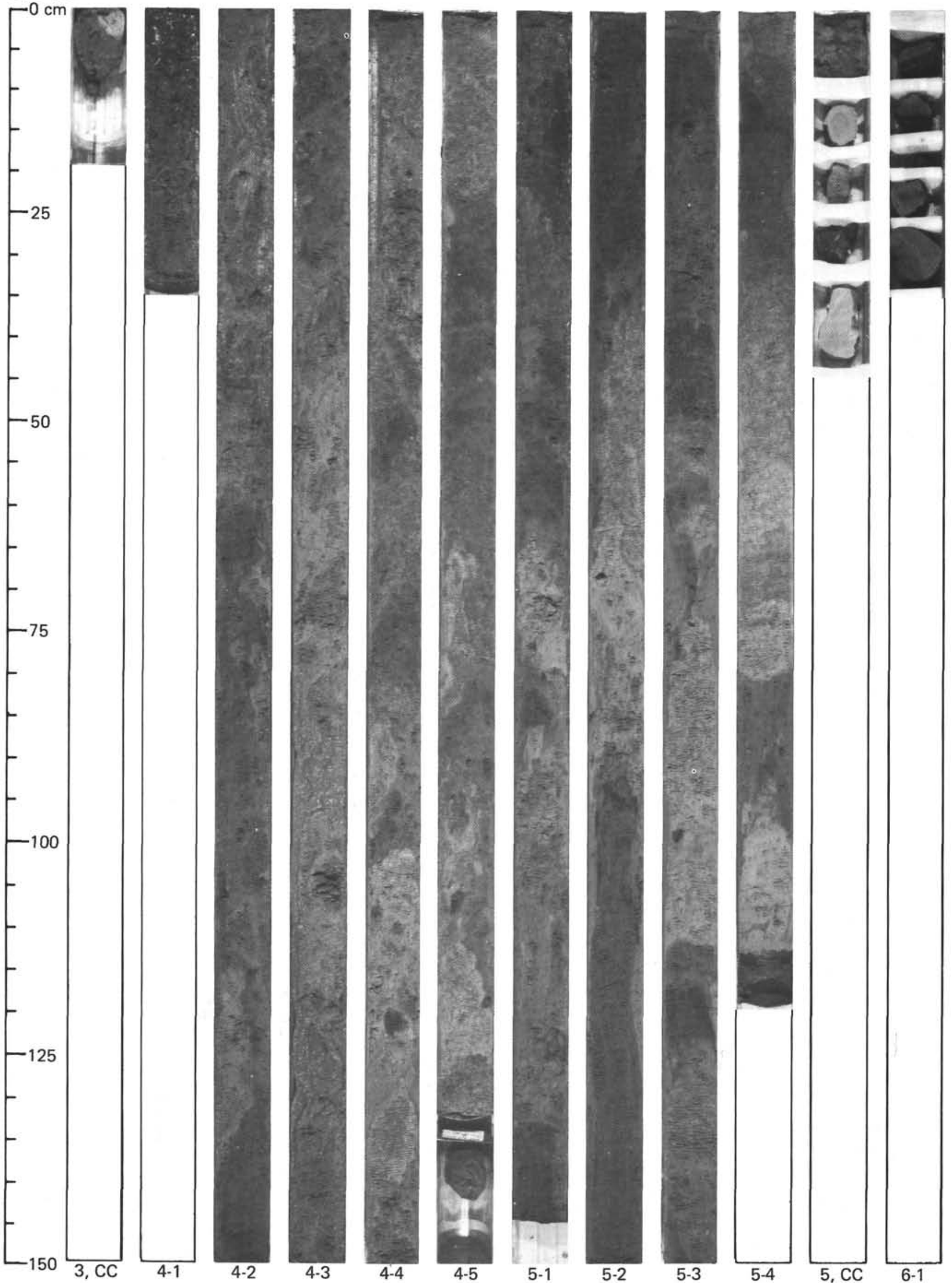



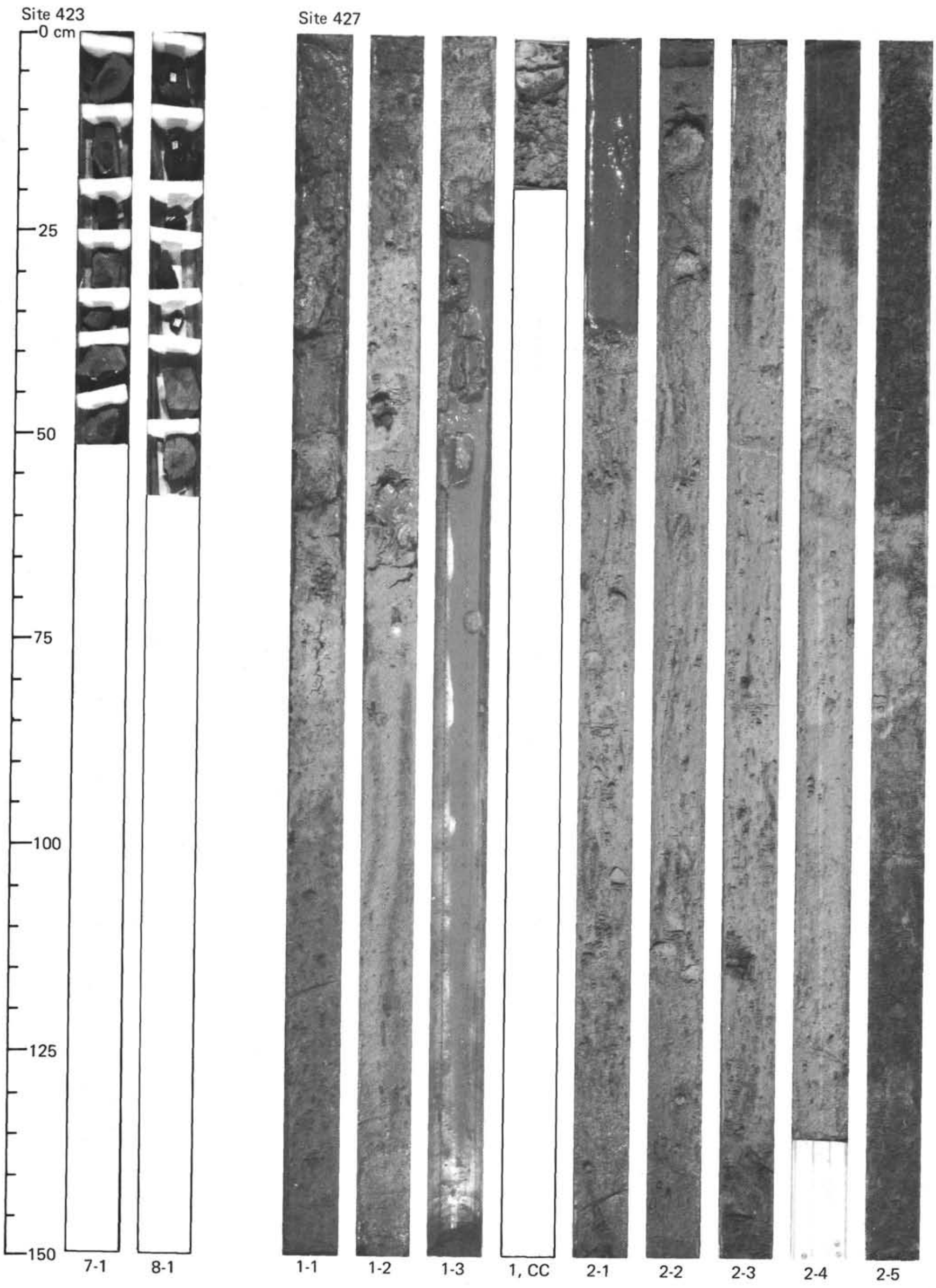
Site 427
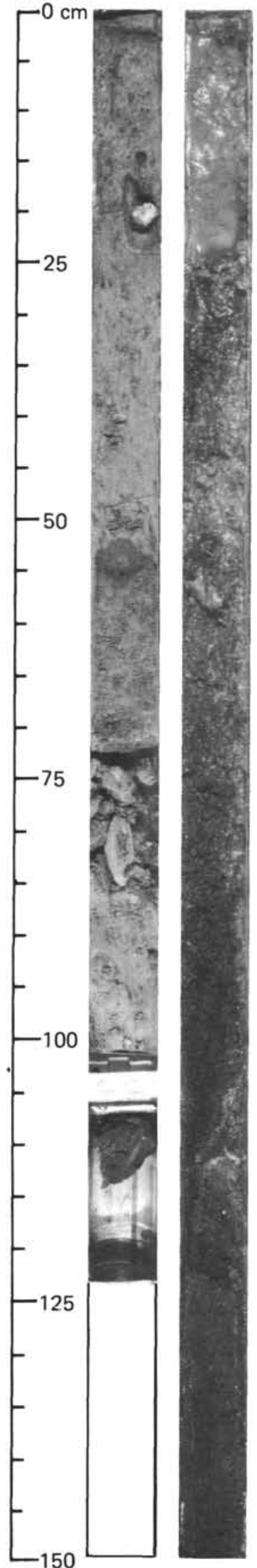

$-150$
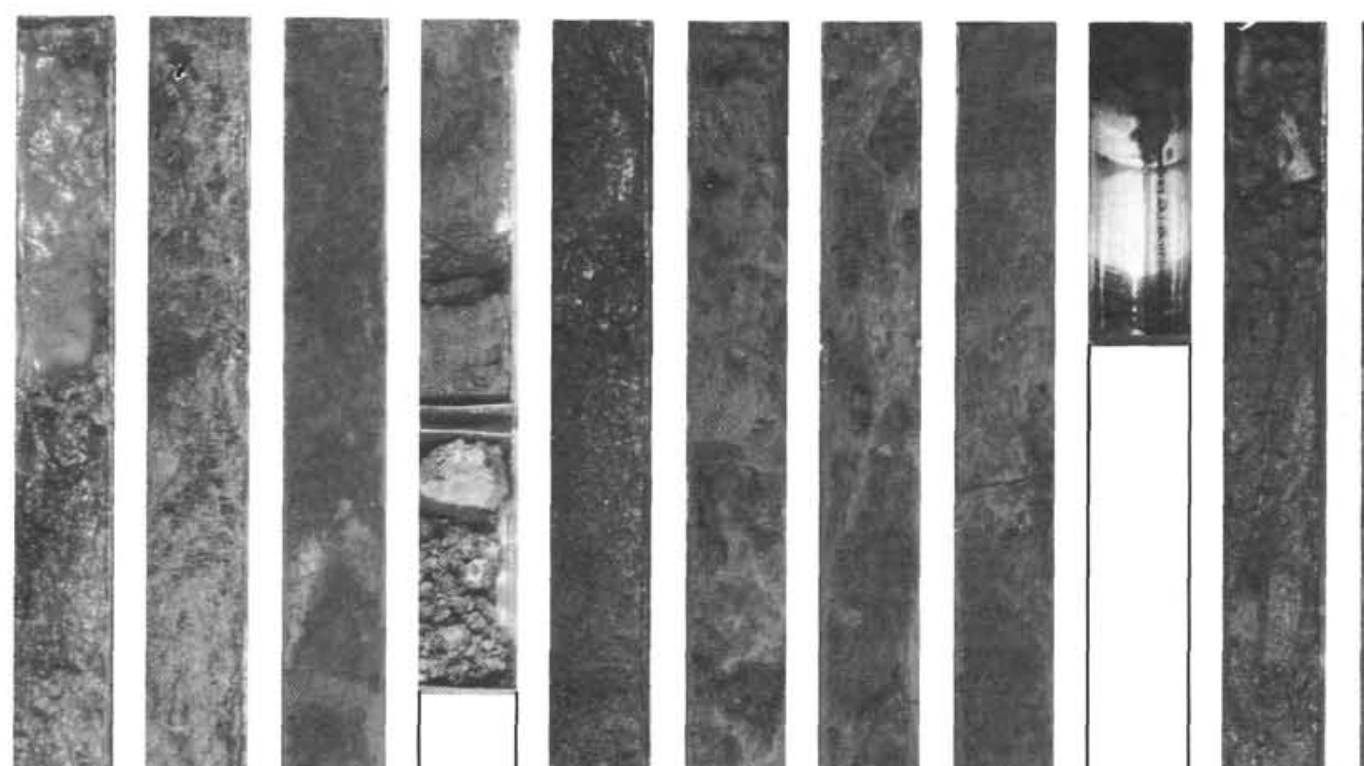

4
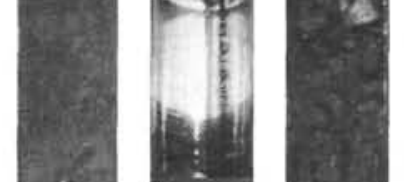

race
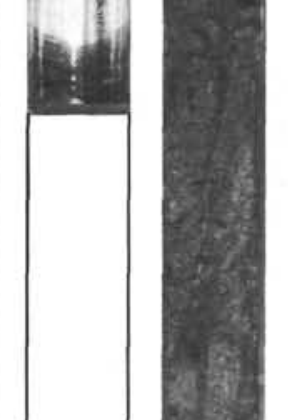

atis

6)

4

50

40

ast

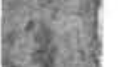

2)

He
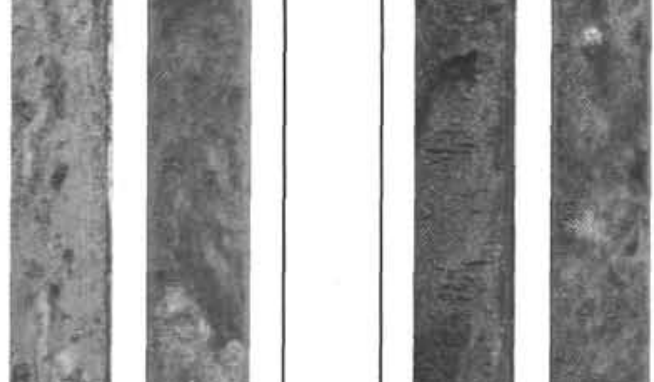

$$
\text { (1) }
$$$$
\text { 18tas }
$$

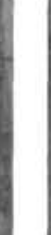
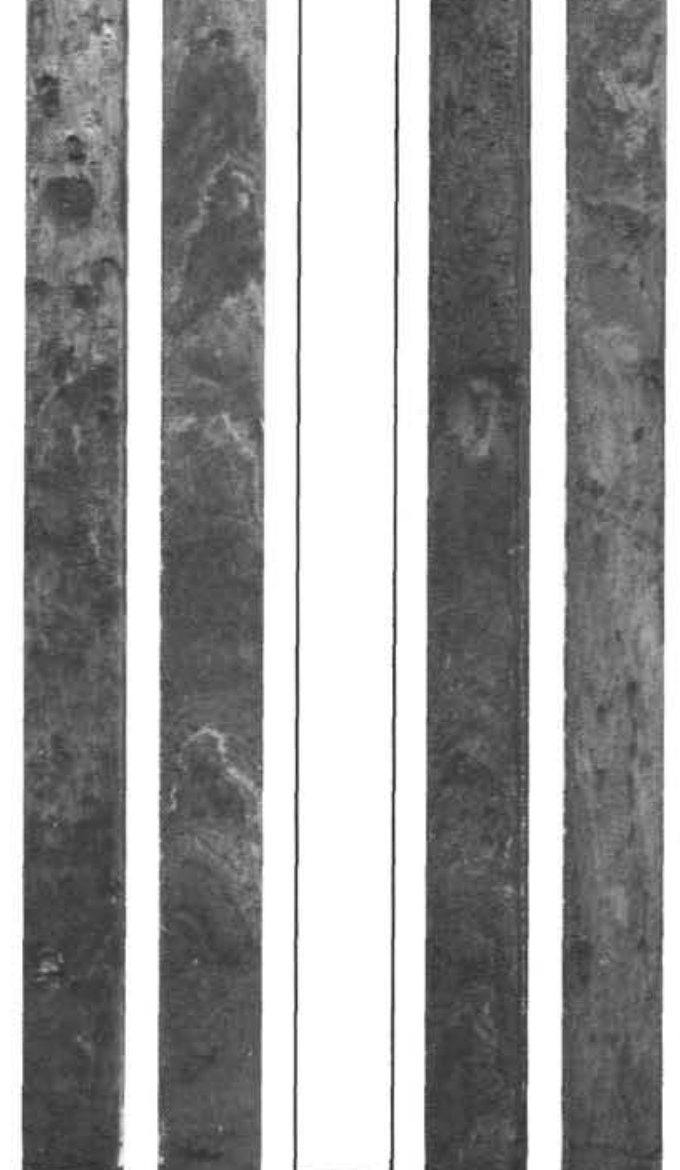

$3-2$
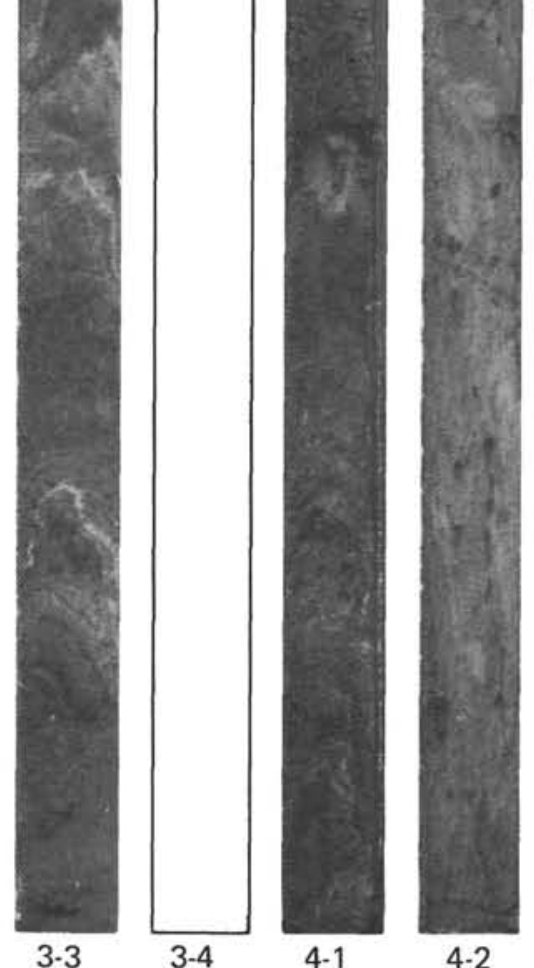

4-1

4-2

$4-3$
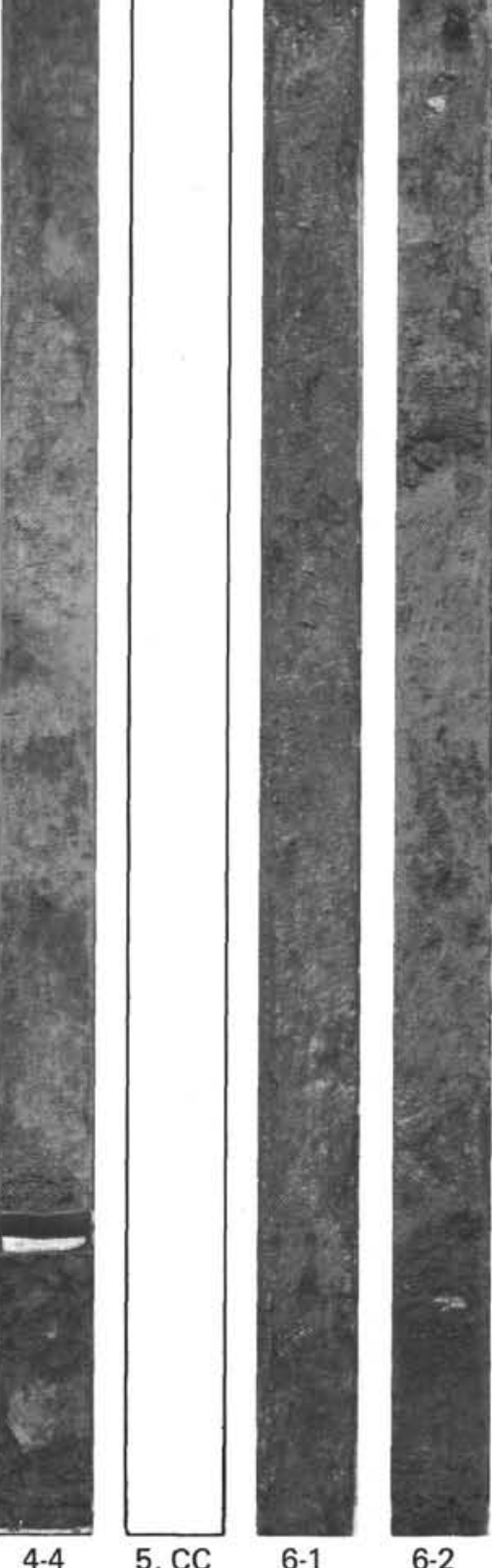


\section{Site 427}
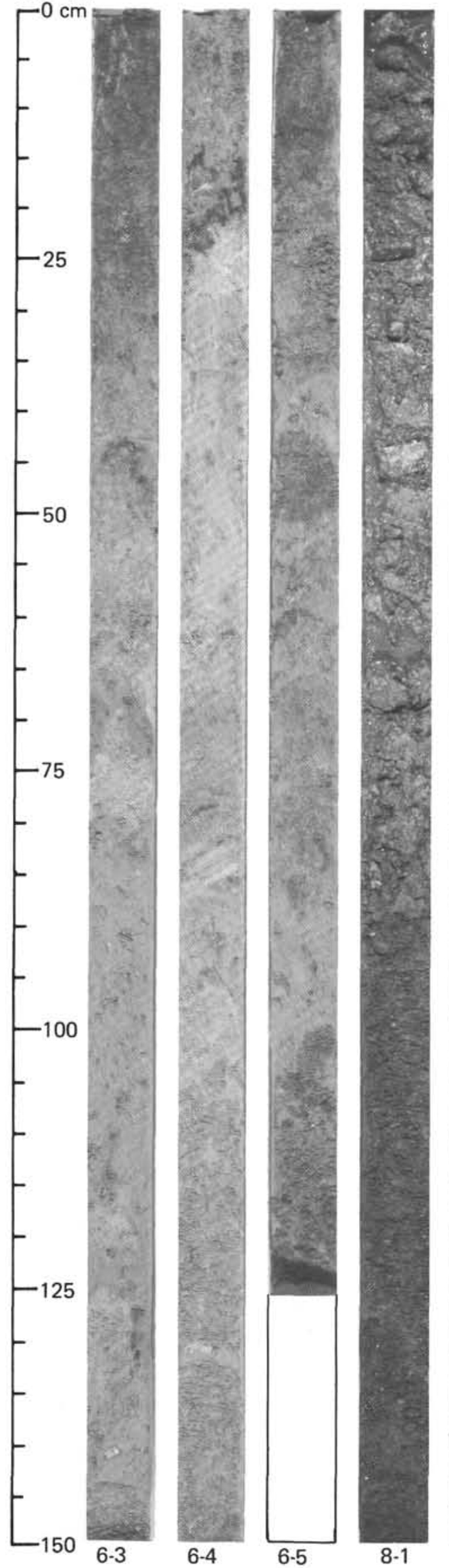
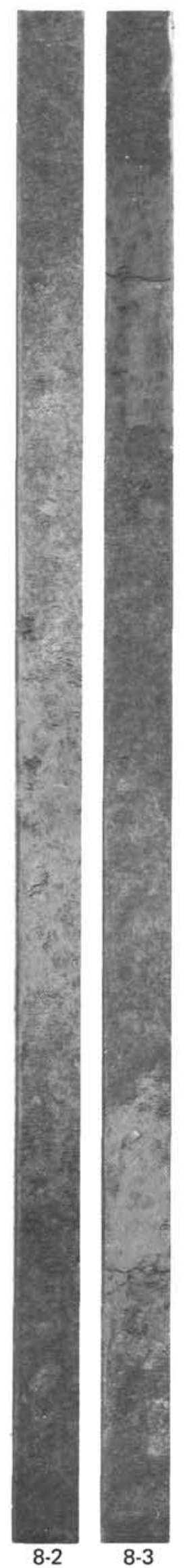
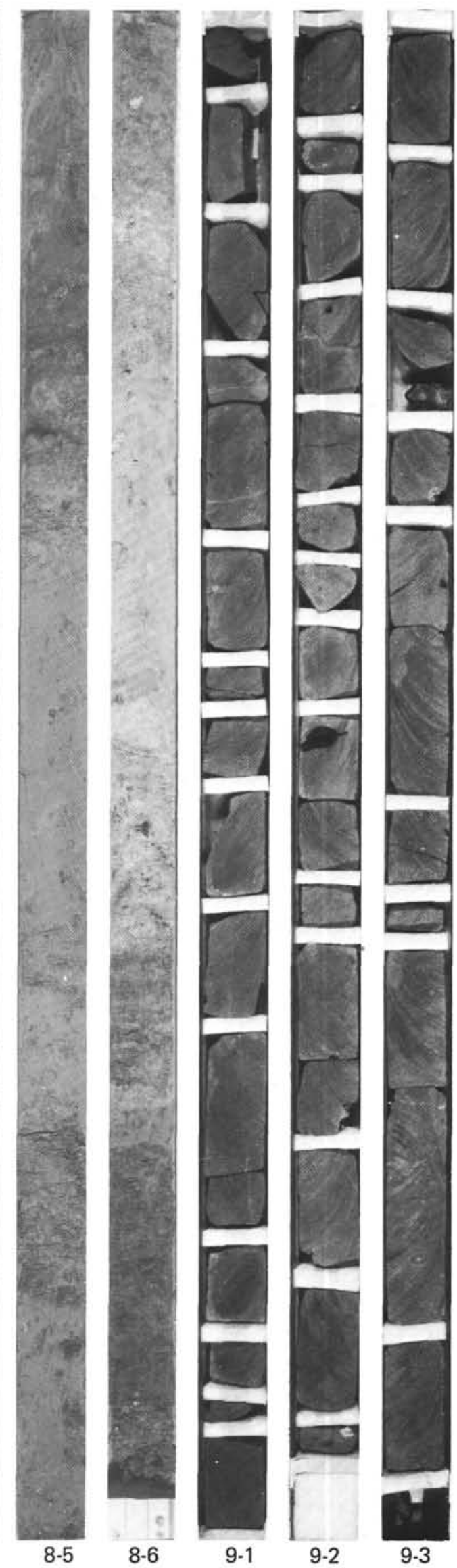
Site 427

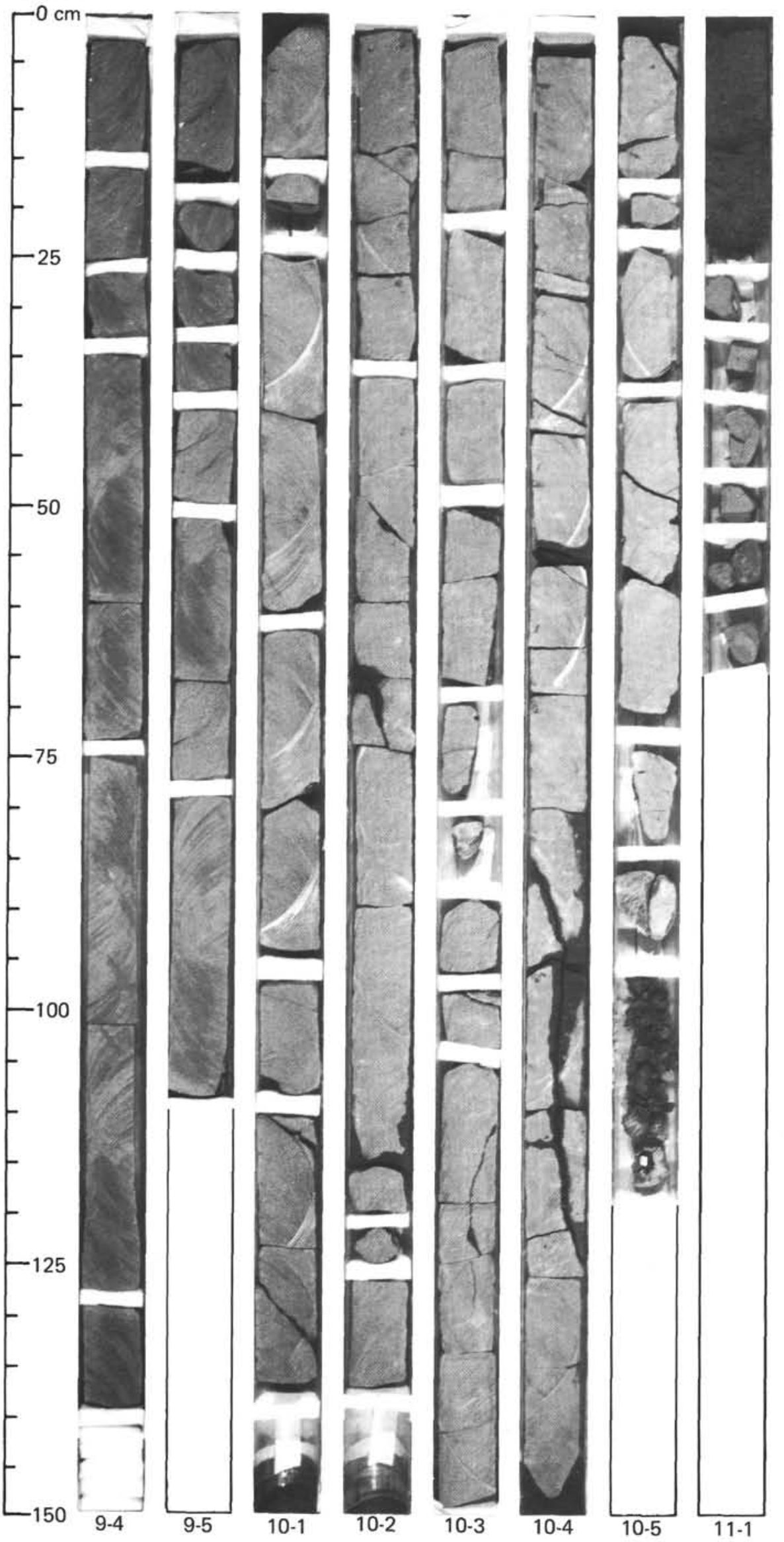


Site 428

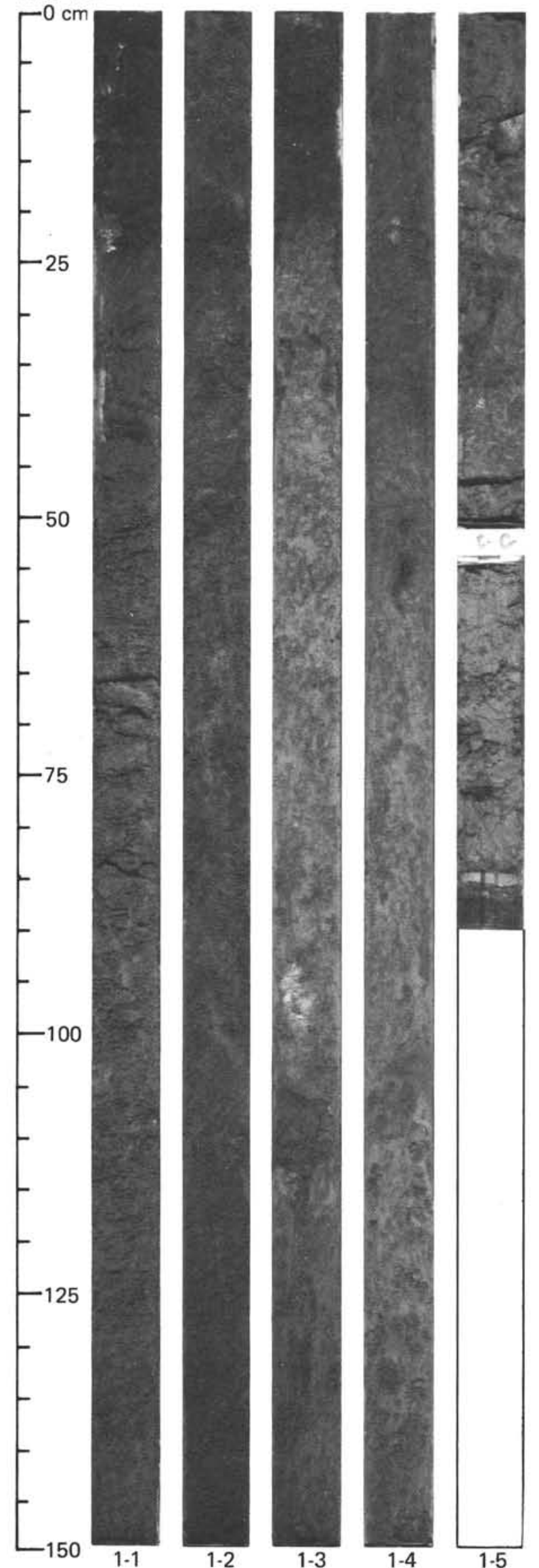

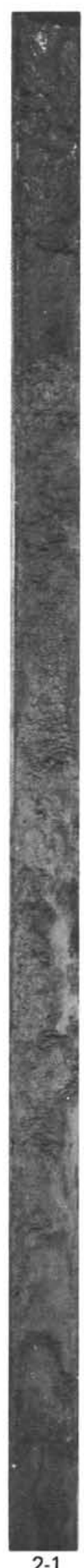

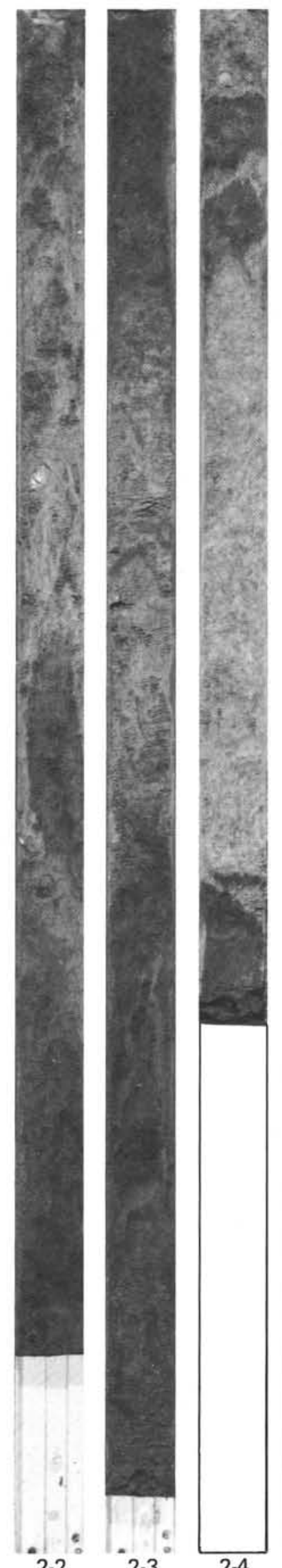

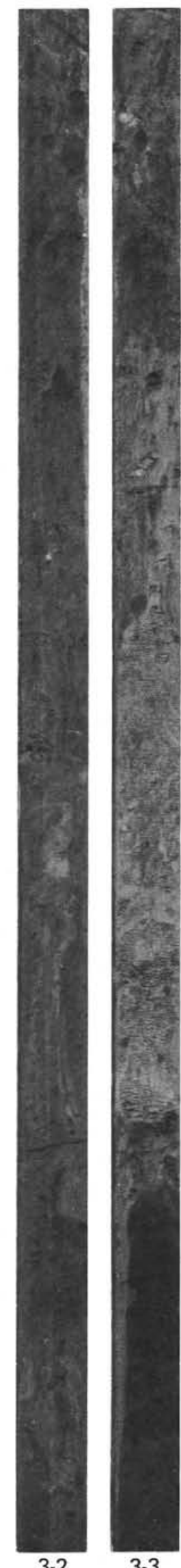

3-1 
Site 428

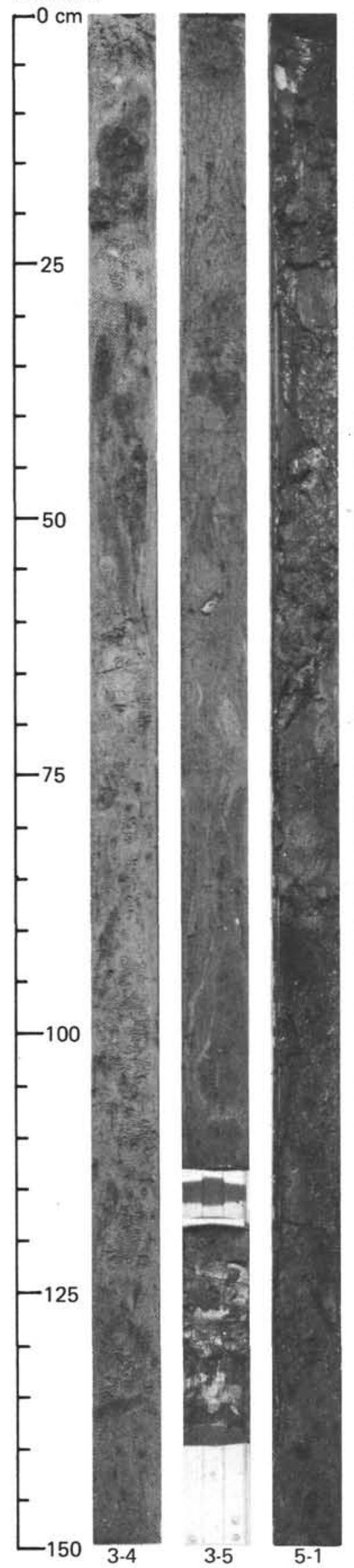

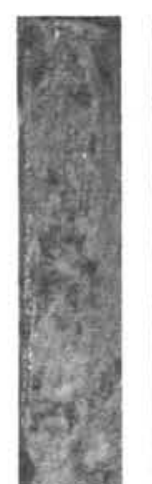

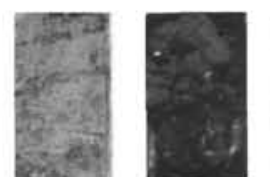

Fas

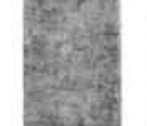

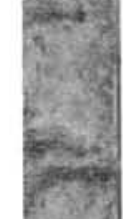

in $=3$
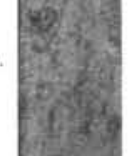

2
5
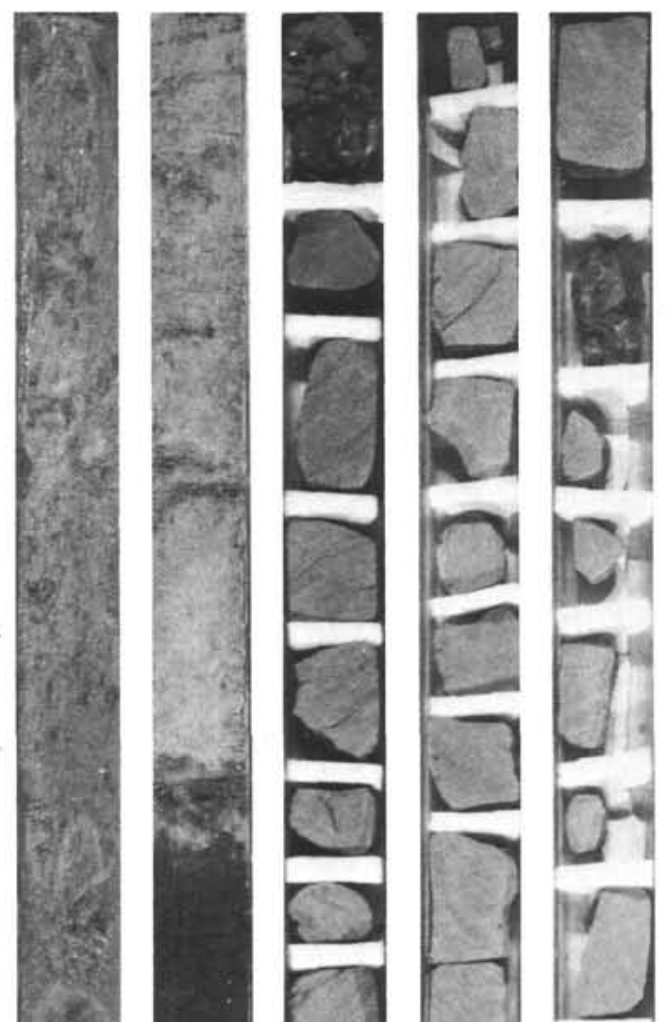

ind

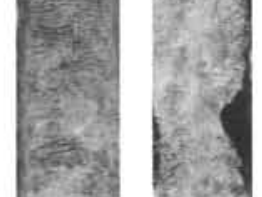

ix. $\quad$ :
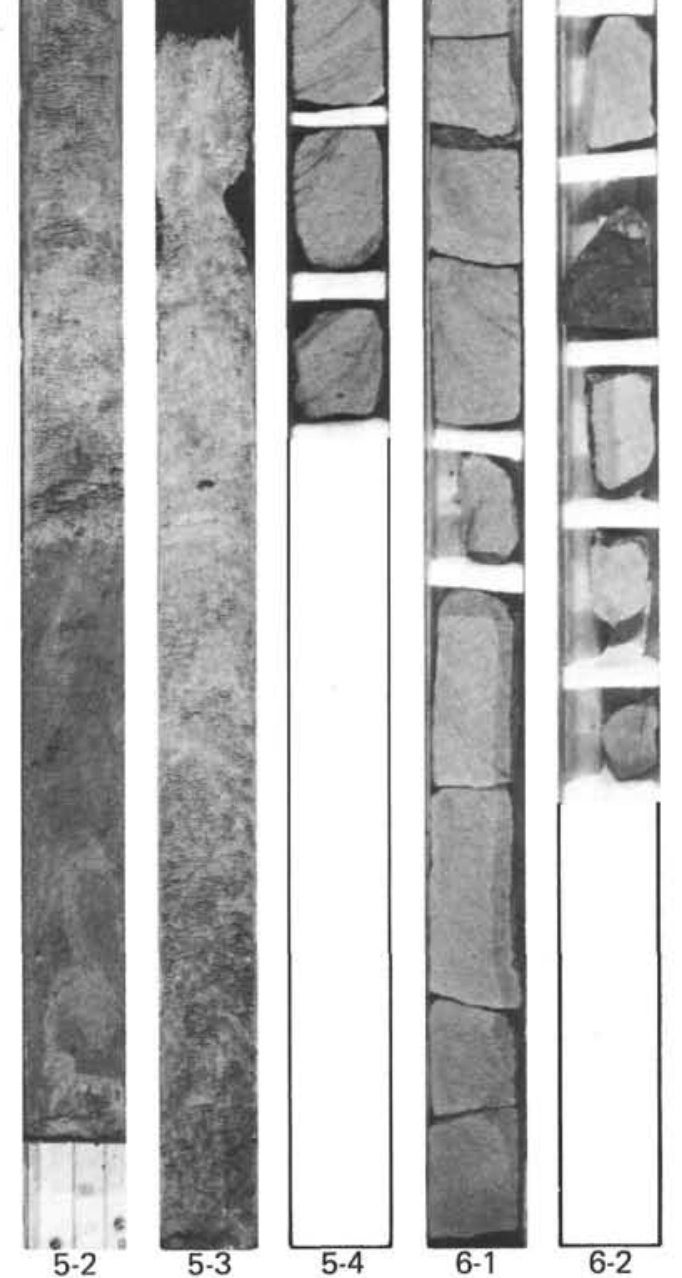
Hole 428A

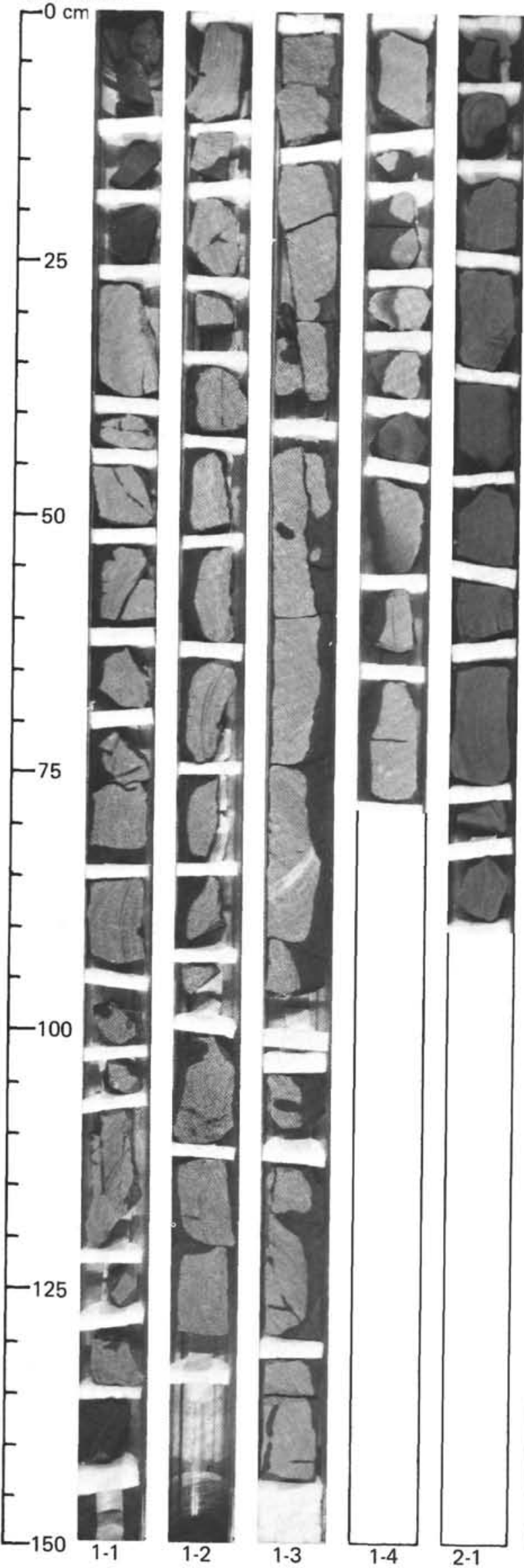

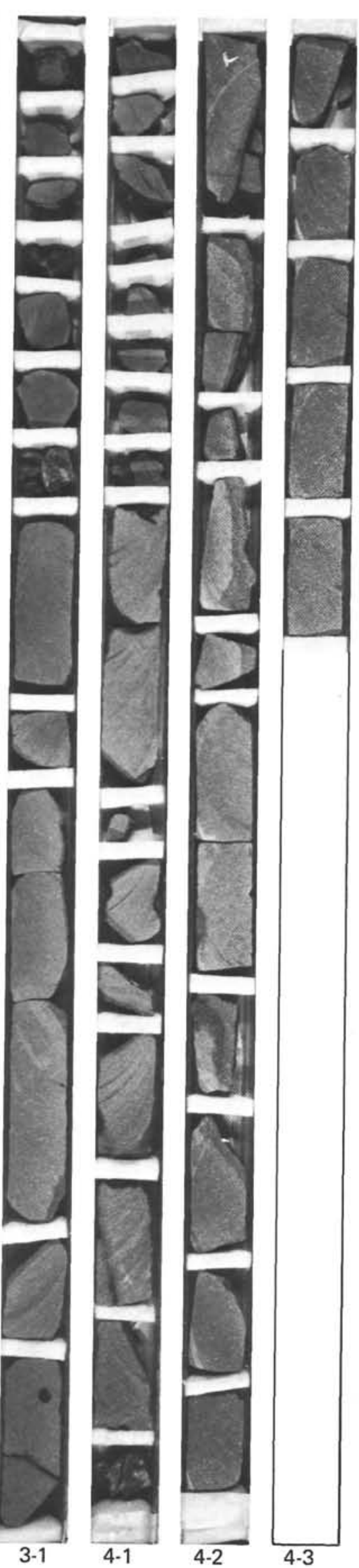


Site 429

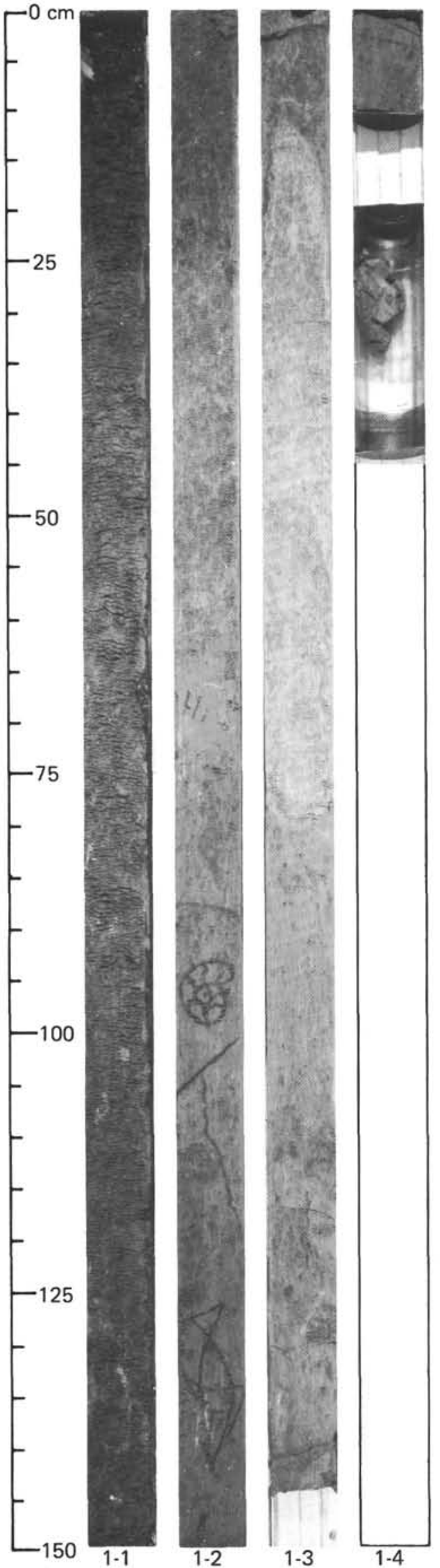


SITES 419-423 AND 426-429

Hole 429A

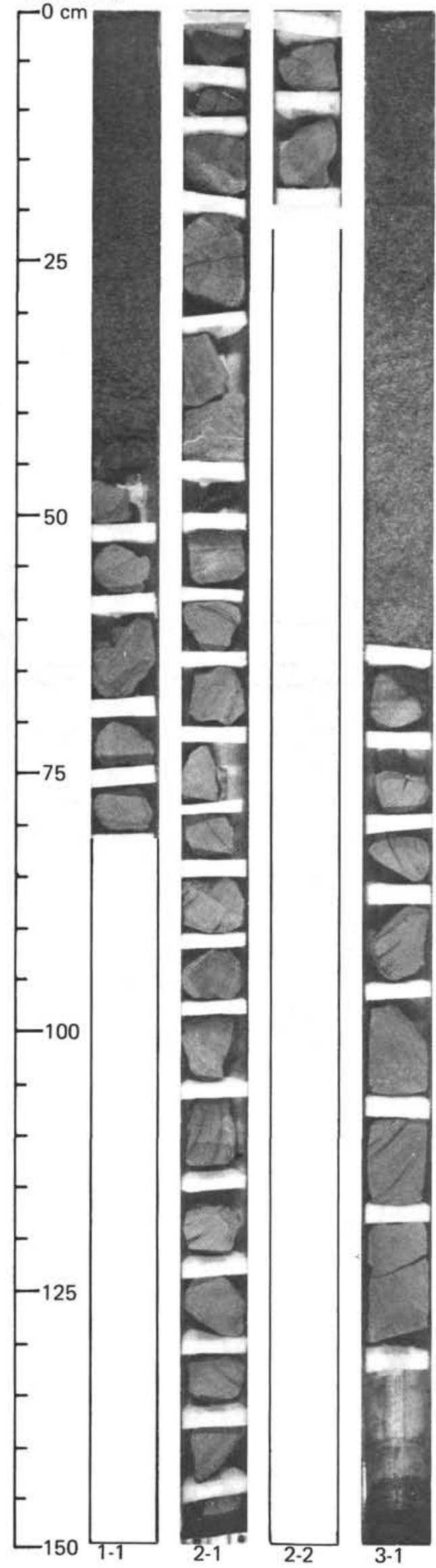

